\title{
PERSONALIA AND WOMEN'S SPATIAL PRACTICES IN THE ROUTINE OFFICE
}

\author{
By \\ Lynn Chalmers \\ Diploma of Interior Design (Royal Melbourne Institute of Technology) 1981 \\ Master of Design (University of South Australia) 1996
}

\author{
A dissertation \\ presented to Ryerson and York Universities. \\ in partial fulfillment of the \\ requirements for the degree of \\ Doctor of Philosophy \\ in the Joint Graduate Program of \\ Communication and Culture
}

Toronto, Ontario, Canada, 2015

CLynn Chalmers 2015 
AUTHOR'S DECLARATION FOR ELECTRONIC SUBMISSION OF A DISSERTATION

I hereby declare that I am the sole author of this dissertation. This is a true copy of the dissertation, including any required final revisions, as accepted by my examiners.

I authorize Ryerson University to lend this dissertation to other institutions or individuals for the purpose of scholarly research

I further authorize Ryerson University to reproduce this dissertation by photocopying or by other means, in total or in part, at the request of other institutions or individuals for the purpose of scholarly research.

I understand that my dissertation may be made electronically available to the public 
Personalia And Women's Spatial Practices In the Routine Office

Doctor of Philosophy , 2015.

Lynn Chalmers.

Joint Graduate Program of Communication and Culture, Ryerson and York Universities.

\begin{abstract}
Office design is a contemporary cultural discourse, where space is conceived in abstract terms. Organizations mission and purpose are translated into the spatial design of workplaces. In the most dominant sectors such as finance and banking neoliberal organizations operate around the space of flows, generated by globalization, technology and postmodernity (Castells, 2000). The space of flows is also manifest in the spatial design of the workplace shaping employees' working identities and behaviours. The dissertation asserts that there are two classes of office workers evolving in the workplace: the professional knowledge workers who are increasingly mobile and autonomous; and the routine clerical workers who are captive in a hegemonic system that keeps them doing clerical work with little prospect of promotion. It is significant that the clerical class is composed mostly of women. Personalia and Women's Spatial Practices In The Routine Office examines the head offices of Investors Group in Winnipeg, Canada, in terms of how the company's offices both reflect and generate spaces of flows. Women's participation rates have grown from being a small minority in the 1900 s to approximately $70 \%$ of the clerical workforce in the 2000 s. Through microanalysis of previously unexamined personalia, or personal objects at the desk, the dissertation finds work spaces are expressive of women's lived experiences of work. By conducting interviews and photographic studies of the workspaces of 11 women at Investors Group the research uncovers the ways women use the personalia at their
\end{abstract}


desks to reappropriate the everyday spaces of the office. The identification of the term personalia becomes a key concept in the work and a contribution to the study of the close environment of the office desk. Social networks with co-workers, past and present are honored in the personalia at the desk; and tactics such as repurposing office supplies as gifts, along with numerous individual and heterogeneous behaviours demonstrate that routine work spaces are not neutral spaces, but are open to the expressive practices which de Certeau calls operations. The ways that women make space for themselves and push against the hegemony of the neoliberal organization are specific and instructive. They reflect women's values and the identities crafted for public and private consumption. The research closely examines the practices of women in the financial services industry through the filter of Lefebvre's trialectic for the analysis of space (1991), de Certeau's ways of operating and tactics (1998), and Franck's interpretation of Women's Ways of Knowing (1989; 2000). The research demonstrates how personalia in the contemporary workplace reflects women's values, and how women's values have influenced the design of the workplace. 


\section{ACKNOWLEDGEMENTS}

I have been extraordinarily lucky to have Dr. Janine Marchessault as my advisor. Her positive support and unusual openness was critical to completing this journey. She is a believer and kept that alive in me. I also really appreciated Dr. Michael Prokopow's willingness to stay connected to the work, and his comments have always been generous and thoughtful. Professor George Kapelos graciously stepped in to be my Ryerson University committee member. I have had amazing support from Ryerson, from Jo Anne Mackie, the graduate student advisor who helped me navigate the bureaucracy and from Dr. Paul Moore and Dr. Jennifer Mactavish, who put a kind face on the bureaucracy and gave me the opportunity to complete what had become an extended trip. My external readers Professor Lois Weinthal and Dr Jacqueline Vischer brought a different perspective to the work that allowed for a stimulating and very productive discussion, along with a number of revisions that I believe have improved and distilled its contribution. I am very grateful for your insights.

The journey included a number of moves, two weddings, the birth of a grandbaby, a term as Acting Head of the Department of Interior Design, lots of teaching and my partner's surgeries including hip replacements. I have enjoyed almost every part of it and learned enough to know now how much I don't know.

My partner, my children and their partners have been continuously supportive and generous throughout. They have been there to encourage, to listen and to help whenever and however they could. Jo and Darcy moved their lives to Toronto so I could start the Ph.D. Victor stayed in Winnipeg and looked after our dog and cat. I guess they all knew how much this has meant to me.

Investors Group should also feature on this list of those to whom I am grateful. Without their co-operation and preparedness to give me access to their information, the work would not exist. I thank Dr. Richard Irish, now retired, Allan Heibert, Roberta Verdonck-Milne, Shannon Boulanger, Lisa Tottle and Lori-Ann Thibodeau. Most 
especially I would like to thank the women I interviewed, as their participation allowed me to explore an area that has fascinated me since becoming a designer. I should also thank Art Mauro who generously gave his time, as did Dick Archer, Jim August and Neil McMillan.

My sincere thanks to Christopher Budd at Studio Architects, Washington. Always the engaged practitioner, his appreciation and knowledge of research and its ability to inform practice is an inspiration. There were so many people who answered my questions and dug out information for me, including Canadian designers Leonie Glenat, Anita Jones, Eleanor Brydone and Gail Tyshynski.

Miriam Unruh, Director of the Academic Learning Centre at the University of Manitoba also deserves a special vote of thanks for seeing me through the last and most challenging stages of the writing and ensuring at least some of it made sense. Her friendship is a lasting product of this work. Friends and colleagues Mary Anne Beecher, Debra Scott, Ian Skelton, Iara Lessa and Susan Close, cheered me through the dark days.

Rose Kuzina shepherded me through editorial minefields but the mistakes in the work are all mine. Jo Chalmers, your talent and patience in helping with the visual composites is very much appreciated.

This journey is nearly done. I am grateful and very pleased to be completing it. I have grown and I am look forward to the next adventure.

Thank you all! 


\title{
DEDICATION
}

\author{
Dedicated with appreciation and love \\ to \\ my father \\ Frederick John Chalmers \\ \& \\ my grandson \\ Fred Chalmers Perro
}

And to all of the strong women in my life. 


\section{CONTENTS}

ABSTRACT

ACKNOWLEDGMENTS

V

DEDICATION

vii

CONTENTS

ix

LIST OF FIGURES

xiii

INTRODUCTION

Personalia - Methods for spatial research

Structure of the dissertation

Chapter One LITERATURE REVIEW AND METHODOLOGY

Spaces of Flows and Spaces of Constraint

Designers' Role

Research Questions: Space of Identity

Standpoint Theory and "Women's Ways of Knowing"

Methodologies For The Everyday

Phenomenological Research Approach

Eliciting Ethnography Through Images

Material Culture Of The Everyday 


\section{CONTENTS}

Chapter Two WOMEN, OFFICE WORK AND INTERIOR DESIGN 31

History of the Modern Office

Professional Managers

The Office Building 1930 - 1960

Organizing Systems: Departments

The Human Relations Movement

Johnson Administration Building, Racine

The Influence of European Modernism

Office Planning

The Speculative Skyscraper

Planning Principles

The Decline of Organizational Hierarchy

Conclusion

Chapter Three WINNIPEG AND INVESTORS GROUP

Introduction

Winnipeg

Development of the Downtown

Investors Group Limited

Globalization

Mauro's "Act of Faith"

Technology

Conclusion 


\title{
CONTENTS
}

Chapter Four INSIDE THE OFFICE

\author{
Introduction \\ Interior Design Services \\ Feminist Standpoint Theory \\ Broadway Avenue Head Office \\ Organizational Culture \\ New Strategic Plan \\ Clerical Workstations \\ Criticism of the Interiors \\ The Executive Floors \\ Typical Floors \\ State of Art for the Investment Industry, \\ Organizational change
}

Chapter Five NARRATIVES \& VISUAL COMPOSITES

Introduction

Personalia -the context of the Research

Gloria, Sharon, Perl, Molly, Amanda, Camila,

Laura, Reyna, Felicity, Leigh, Rose.

Chapter Six CASE STUDY ANALYSIS

Introduction

The Subjects Of The Research

The Locus Of Personal Space

Identities And Values

Social networks

Material Culture 
Time and Space

Tidiness and Control

Oneiric Spaces: dreams and angels

Habitus

Co-Worker, Team Player

Family Space And Private Space

Conclusion

CONCLUSION

Space for social networks

Choice and Control

Personalia

Social Networks, Friends and Co-workers

Family

Identity

Home places and heterotopias

Research Methods

REFERENCES

Appendix One

Appendix Two 


\section{LIST OF FIGURES}

\section{Chapter Three}

Figure 1. Sod Turning Ceremony for One Canada Centre

(Investors Group Archives)

\section{Chapter Four}

Figure 2. Investors Group head offices in 1963 after the addition of three floors

(Investors Group Archives)

Figure 3. Executive office area in 280 Broadway Avenue

(Investors Group Archives)

Figure 4. Investors Group first computer in 1959 was an IBM 1401

(Investors Group Archives)

Figure 5. Typical Floor Plan, 1988 Brochure to celebrate the opening of One Canada Centre (Investors Group Archives)

Figure 6. Main Floor Plan, 1988 Brochure to celebrate the opening of One Canada Centre

(Investors Group Archives)

\section{Chapter Five}

Figure 6 A Sixth Floor Plan showing desk locations (IG)

Figure 6 B Second Floor Plan showing desk locations (IG)

Figure 6 C Zones of significance (L. Chalmers)

Figures 7-16 Gloria's Desk (authors research photographs)

Figures 17-24 Sharon's Desk (authors research photographs)

Figures 25 - 30 Perl's Desk (authors research photographs)

Figures 31 - 38 Molly's Desk (authors research photographs) 


\section{LIST OF FIGURES}

Figures 39 - 48 Amanda's Desk (authors research photographs)

Figures 49 - 56 Camila's Desk (authors research photographs)

Chapter Five continued.

Figures 57-63 Laura's Desk (authors research photographs)

Figures 64 - 70 Reyna's Desk (authors research photographs)

Figures 71 - 77 Felicity's Desk (authors research photographs)

Figures 78-83 Leigh's Desk (authors research photographs)

Figures 84-90 Rose's Desk (authors research photographs)

\section{Appendix Two}

Figures 91 - 95 Floor 18 Boardroom Anteroom (authors research photographs)

Figures 96 - 98 Floor 18 Boardroom (authors research photographs)

Figures 99 - 100 Floor 18 Chairman's Assistant's Desk (authors research photographs)

Figures 101 -103 Floor 18 Dining Room (authors research photographs)

Figures 104 -106 Floor 19 Reception Area (authors research photographs)

Figures 107 -110 Floor 18 Historical Display \& Directors Lounge (authors research photographs)

Figures 111 - 113 Floor 18 Executive Assistants Desk and Storage (authors research

photographs)

Figures 114-118 Floor 18 New Meeting Room, Telephone Room, Lift Lobby and New Cloak

Room (authors research photographs)

Figures 119 - 121 Floor 18 Reception Area (authors research photographs)

Figures $122-125$ VP's Office and Meeting Room (authors research photographs 


\section{INTRODUCTION}

My curiosity about the office began as a new graduate from an interior design program in Australia. Office design was a primary source of work for interior design practices at the time and one of my tasks as a young designer was to evaluate space and furniture requirements for individual workers. This involved surveying how people worked at their desks and recording the existing conditions of workers, such as how much desk surface and storage they needed to perform their jobs, and on which side they located their phone.

In the 1980 s computerized spreadsheets were not commonplace and the work involved extended periods of time spent in back offices and fairly dreary environments talking to the users of the space. By the time I had finished those existing condition surveys I had a well-developed sense of what it was like to spend time in the spaces of routine office work. As an idealistic young designer I was excited about how design might bring change and improve the lot of office workers. I had developed an empathy for the necessary but unexciting roles that routine office workers play in organizations and an interest in how these workers claimed their space.

The definition of routine office work used in the dissertation is repetitious office administrative functions performed by white collar workers, the work may be routine but it is not unskilled. Routine clerical workers are those workers whose tasks require them to be located at a desk and in an office for their working week. They perform

skilled clerical tasks that require peer support and consultation making them difficult to perform remotely, they also can be confidential in nature.

Thirty or so years later the change that has affected ways of working has been profound. The radical shifts that technology and globalization have wrought have unleashed and mobilized a new class of knowledge workers, allowing them to work from home or on the move. However routine office workers are still tethered to their desks in Winnipeg and in cities around the globe where labour costs are relatively cheap. 
Clerical work became normalized for married women in the 1950s and 60s, just as our expanding need to consume increased the pressure for dual family incomes, rendering the role of stay-at home mother untenable for most. My research seeks to understand the ways in which women are embodied through the personalia at their desks, in the physical environments of routine office work.

Personalia is defined in the Chambers Twentieth Century Dictionary as "notes, anecdotes, or particulars relating to persons." Webster New World Dictionary defines the term as "personal details concerning, or personal items associated with, a persons life." I have co-opted this term in the dissertation to mean the personal objects on the desk that are associated with the persons life; their work life and their life beyond the office. For the women interviewed in this study the coloured sticky notes and staplers were as much a reflection of their values and preferences as other objects gifted or brought from home. The identification of the term becomes a key concept in the work and a contribution to the study of the close environment of the office desk.

When I was searching for examples of phenomenological case study research I was directed to Women in Trouble by social worker and academic Elizabeth McCormack. The book is framed by the researchers interviews with women in prison to look at the systemic problems of incarceration. The profound issues that were evident in every interview shocked me. Not surprisingly, the women came from backgrounds of abuse and neglect and were caught in cycles of destructive behaviours. The research in which I was engaged in seemed irrelevant and introspective by comparison, I questioned why I would make something so mundane as the personalization of the desk as the focus for a dissertation.

However, my interest in the everyday of the office has been with me for a long time. I addressed workplace change in my Masters of Design thesis in the 90s and after discovering the theories of the everyday in Lefebvre and DeCerteau I found a place to uncover and expose the subtle and often gendered practices of resistance that I had been made aware of by my early experiences in design. I was generously given insights into the personal spaces and personalia of the women who participated in the photo- 
elicitation research and felt a responsibility to value their everyday lives. Investors Group opened their archives to me and the retired designers who were responsible for Investors Group headquarters interiors gave me access to their records and information.

The dissertation is informed by De Certeau's sociological studies of the everyday in Paris. His research methods involved observations and narratives of his subjects going about their everyday lives. The research situates the 11 women and their occupation of the borrowed space of the office uncovering the culture of the organization from the perspective of the women. The research is essentially speculative and observational in nature.

Much of the research into the design of the office has been carried out or funded by office furniture manufacturers and is directed toward increasing productivity, carrying an intrinsic bias towards generating new product design and increasing consumption (O'Neill 2008, 2009, 2010). Most other spatially oriented researchers addressing workplace are working in the area of environment and behaviour (Hedge 1987, Brill et al 1985), or organizational psychology (Vischer 1996, 2005, Steele and Jenks 1977). In contrast, my concern in this research was to apply cultural and critical theories to the workplace to create a richer understanding of the micro details of how the everyday space of the office is occupied. What might the occupation of routine workspace tell us about women's roles, values and ways of operating? Second wave Feminist Standpoint theory (Franck 1989) and Women's Ways of Knowing (Belenky et. al. 1986) provide an important framework for this dissertation as explained further in Chapter One. I use it as Lucinda Havenhand (2004) suggests, to understand women's values and ways of operating, and as a vehicle for examining what might represent women's space and how it might differ from spaces occupied and understood as men's space.

\section{Personalia - new methods for spatial research.}

This dissertation develops a new method for analysing office environments for the discipline of interior design by studying the personalia and close space of the desk and the embodied behaviours of those that occupy it. I question existing assumptions 
about the meaning of personalia on the office desk, and develop a base line associated with personal occupation to encourage further research in this area.

Lefebvre's theory of the everyday provides the optimistic view that everyday life that cannot be contained by bureaucratic regimentation, harbouring the desire that generates transformation through celebrations and domestic pleasures. The dissertation study uses phenomenological methods to understand how this transformation occurs. The work does not address a hypothesis but researches with the intention of reflecting on the creation of women's complex identities as co-workers, friends, mothers, and aunties, and to understand women's values as reflected in their personalization of the desk.

Lefebvre's understanding of transformation occurs through small celebratory gestures, memorials and remainders. This dissertation with its microscopic study of personalia at the desk facilitates the flow of social discourse as a means to understand and interpret artefacts and individuals that are usually overlooked in the neoliberal organization.

The framework used for analysis emerges from the women's voices, containing themes that are consistent across a number of the interviews and observations. The observations don't fall into tidy categories and many of the issues overlap and represent multiple and conflicting constructions. The conclusions are not fixed in place and are open to reassessment and re- evaluation bringing attention to the office as the site of gendered spatial relations.

The work reinforces the notion of personalia at the desk as representations of Lefebvre's lived space. Sketching out a moment in time and space for the ephemeral activity of individualization of the desk.

Susan Halford, sociologist and researcher, determines that the spatial is an important adjunct to traditional organizational research carried out in sociology. She depicts office design as a contemporary cultural discourse, where space is conceived in abstract terms, suggesting "spatial discourse shapes the production of working selves who we are at work and how we understand our working identities" (Halford 2008:932). 
Halford advocates for research that "pays greater attention to the agency of individuals and groups in responding to organisational space"(2008:932).

The subject of women office workers and how they craft their own identities in the office environment is important because it addresses a population and a phenomenon that often goes unnoticed. Studies of workplaces are most often focused on productivity and satisfaction. They consider environmental conditions but do not look closely at the occupied environment for individual ways of subverting and taking ownership of space. Much has been written about the emergence of a new class of knowledge workers who have quickly become the privileged class of office workers. By comparison routine office workers are often contracted employees whose work is located at a dedicated workstation, their work is stressful and constant. Routine workers are organized into highly supervised teams that offer each other support to solve more complex problems.

The work capitalizes on women's ways of working that are more collaborative and social, and the work force in this area is largely female. The ways that women make space for themselves and push back are multifaceted and fascinating. This study brings attention to them. The contribution of the thesis is to study the personalia that embodies the workplaces of women routine office workers in the financial industry as subjects of a hegemonic system that contains and restricts them by enforcing a class structure. The research method I employed allowed for the research subjects to be engaged in the study, photo elicitation allowed for subjective and emotional content to be offered up and valued. Balenky et al's Ways of Knowing is applied by Havenhand (2004) to a consideration of women interior designers. Havenhand provides a language to discuss values that frame feminist identities and is reflected in the case study analysis and the conclusion

The dissertation reflects on issues that have been of interest to me for many years as an interior design practitioner, then as a studio professor teaching interior design. My problem was always how to research the topic of the workplace from the perspective of personal worlds. As I was developing the dissertation topic I carried out a 
small study in an interior design office in Toronto, looking at the individual tactics of employees in adapting the workplace to meet their needs. I was delighted to have my hunches confirmed, noting all sorts of borrowed furniture and office paraphernalia were being employed to create personal spaces for these creative workers. I was unable to interview the employees whose desks I had studied and realized the problems when the subjects are not engaged. The research conclusions were limited to my own assumptions about participant motivations and I resolved to ensure the PhD research would actively engage my subjects' perspectives.

In 2008 was invited to observe a design project in the programming phases with Christopher Budd at Studios Architects. The project was for a new building for Olmstead County, bringing together disparate social services organizations under one roof. The challenge was to understand the different organizational cultures and practices that were being brought into close proximity for the first time. The part of Budd's process that I observed involved using image cards to generate a focus group discussion about the values of each unit and their hopes and dreams in moving to a new way of operating. The process involved individuals selecting images in response to prompts such as "choose an image that reflects how your work group feels now", the rationalizations for individual choices generated subjective emotional content and discussion that would not have occurred as part of the usual programming phases of a large project. It was a form of photo-elicitation that brought the employees perspectives into focus and generated information that allowed the designers to respond to emotional knowledge rather than the more usual mapping of the organizations needs and vision.

I employed the method with students in a project redesigning the offices of a Winnpeg film production company Buffalo Gals. The management of the firm participated in a process where image cards were used in response to questions such as "choose an image to sum up the management philosophy for the new offices". One participant selected an image of a group of nuns, singing in a field. She explained the new offices should be egalitarian and empowering, encouraging open communication 
between all who worked there. The image proved very powerful in helping design students understand what was important to the group of women who worked in an atypical non-hierarchical organizational structure. The student's design solutions were very responsive to the client's requests for a flat management structure where open communication was a significant aspect of how work gets done.

Interior design is a profession that builds on the designer's capacity to elicit invisible ways of operating. It is empathetic at its best and visual research methods help to connect designers to clients experience and emotional knowledge, unlocking very human responses to space that help us to get beneath the surface of an organization in ways that surveys and standardized methods struggle to achieve.

\section{Structure of the Dissertation}

In this study, I examine the years prior to 1960 to establish the character of offices leading up to World War II and then the five decades up until 1990. Using the case study of the Investors Group head offices in the period between 1956 and 2000, the research illustrates the seismic shift in factors affecting the design of office space at this time. The Investors Group (IG) organization proved to be a good subject for the project reflecting the astonishing growth of the financial sector in this period - having commissioned and built new head offices on Broadway in 1956, expanded by three floors in 1963; and embracing a completely new concept of head offices for the One Canada Centre, completed in 1987. The history of the organization as a Canadian leader in the financial services industry bridges between high modernist design, influenced by Taylorism, and post modernism, with its greater focus on the Human Relations Movement. These were the most significant influences on the design of office in the last half of the $20^{\text {th }}$ century and coincided with the professionalization of interior design. The projects at IG demonstrate the changes in the environmental design professions. The first head office building in 1956 was designed by architects and furnished by furniture retailers and decorators in the modernist tradition, but by 1987 a professional interior design company was commissioned at the same time as the architects to 
develop the new building concept and orchestrate the fitting out of the building and the staging of the move. One Canada Centre proved to be an unusual and early example of integrated design where the interior designers served as significant players in the design and construction process. Although the University of Manitoba (where I work) has partnerships with IG that allowed me to connect with their senior management getting permission to photograph workstations and interview routine clerical workers was not easy. IG offered me management desks as an alternative but I was interested in routine clerical workers and they finally agreed to connect me with 12 volunteer subjects. It was important to me that my research address routine clerical workers, as the group of office workers who had received the least attention and recognition in studies of the design of office environments. It was only as the work progressed that I became aware of the large predomination of women who perform routine clerical functions in the finance sector and I shifted the focus of the dissertation to address this rarely acknowledged phenomena.

The first chapter reviews the literature and methodologies that provide the background for the dissertation. Chapter Two addresses women, work and spatial environments that support work. It will analyze the management theory that has determined the nature of the physical space for office work looking at the shift from hierarchical disciplined organizations inspired by Taylorism to flatter management structures that support teams, collaborative working and different forms of supervision and production resulting from neoliberalism and globalization.

The third chapter considers Manuel Castells "space of flows" in relation to the finance sector and patterns of employment. It introduces Winnipeg as the home of the Investors Group headquarters. The chapter provides a context for the idea of a building designed for the financial services industry in the 1980s with its largely female clerical workforce and looks at the rapid evolution of technology as the generator of new ways of working.

Chapter Four discusses the commodification of office buildings and the evolution of interior design services as new ways of thinking about the design of offices. The 
chapter expands on Feminist Standpoint theory and Women's Ways of Knowing as structures for the analysis of office environments from the perspective of the women who work there. The interior design of One Canada Place is analyzed through this filter, and is compared to Broadgate in London.

Chapter Five introduces the photo-elicitation research bringing the women's voices and artefacts into the dissertation through the narratives and visual composites of the photographs of the women's desks. This evidence allows for the analysis that follows in Chapter Six.

Chapter Six brings focus to the desks and personalia of the routine clerical workers at Investors Group. A model for the analysis is developed and employed to uncover complex values and social networks that are represented by the personalia and spatial practices and tactics of the women.

The conclusion draws the disparate elements of the dissertation together to argue for the benefits of a phenomenological inquiry that attends to the spatial. It demonstrates the need for greater consultation in the design process with the routine clerical workers of organizations, in ways that give them greater control and more socially-oriented spaces that respond to women's practices and ways of knowing. Desk spaces should be provided with adequate space around the screen and ancillary pinup space that encourages employees to curate collections of personalia and in so doing participate in growing the social networks of organizations in unstructured and organic ways that enable them to have greater freedom and control. 



\section{CHAPTER ONE}

\section{LITERATURE REVIEW AND METHODOLOGY}

\section{Spaces of Flows and Spaces of Constraint}

Edward Said, academic and post-colonial theorist, has commented that mobility and migration are the markers of our time (Said 1994). The cities of the $21^{\text {st }}$ century are responding to the impact of telematics, computer networks, telecommunications, global economic dispersal and centralization. Spatial dispersal of economic activity has been made possible by telematics and contributes to an expansion of central functions. Cities are the preferred sites for the production of services particularly for the most innovative and internationalized service sectors. Cities have always served as the sites for the production of finance and advanced corporate services. Saskia Sassen asserts that today's global cities are in part the "spaces of post-colonialism" with the transmigration of rich and poor. Both groups lay claim to space, creating conflict. Sassen suggests the rich, the new transnational professional knowledge workers, can change the social morphology of cities with very little resistance, "reconstituting strategic spaces in the city in their own images" (1997:131). According to Manuel Castells, sociologist and philosopher, the "most dominant functions in our society are organized around the space of flows “(2000:14), referring to financial markets, transnational production works and media systems. The space of flows relates directly to the increasing globalization associated with neoliberalism and post-modernity.

In this dissertation I assert in that global flows of information and capital are visible in the offices of financial institutions. But these flows have created a tide that leaves many routine office workers in its wake. Those with limited access to new technologies of empowerment are locked into nine-to-five jobs that are at the ugly edge of the knowledge economy. These routine jobs are essential but unheralded in the new economy. Jobs such as data processing and routine clerical work involve managing 
quantities of information in highly supervised environments rather than employing knowledge creatively. Such jobs have little likelihood of promotion and long shifts that entail close work at the computer or on phones. Many of these jobs are filled by women $^{1}$, and working class immigrant women are well represented in these numbers. In the case of this study, half of the women are immigrants from south-east Asia, specifically the Philippines and Indonesia.

Much has been written about the emergence of the new class of knowledge workers who have quickly become the privileged class in the office. They are seen as the primary asset of businesses and are wooed with benefits and cutting edge communications technology. This compensates for the shrinking desk space they are assigned in office environments, as offices now represent a microcosm of the space of flows. Professional knowledge workers are increasingly mobile and unfettered by routine. They are encouraged to work on the move and are available to their employers 24 hours a day, seven days a week. They parallel the mobility of professions that can transmigrate between centres of finance. Office space designed for the knowledge worker allows for a variety of informal places for meetings and gathering. Knowledge work is supported by in-house cafes and the latest technologies, space is provided for the development of creative ideas or quiet work on projects that require focus. The knowledge worker may have a dedicated desk but often will independently determine their preferred location for productive work. They can shift their place of work to suit the task at hand and take full advantage of opportunities that arise. They are the rich of the office.

The poor of the office are the routine clerical workers, mostly women and often immigrants. The spaces of their work are most often dedicated cubicles where they spend their shifts. They are held captive in a hegemonic system that keeps them performing routine work with little prospect of promotion. At Investors Group the routine clerical workers have little independence of operation. Their work is centred on

\footnotetext{
${ }^{1}$ Nearly $60 \%$ of clerical jobs in the finance industry are occupied by women including financial institutions and insurance companies.(World Economic Forum, "The Corporate Gender Gap Report 2010.")
} 
the hard-wired screens, on their desks, hours are logged, and the lunchroom and meeting rooms are too small to provide alternative places for work. Most desks are without a telephone if their work does not require one, and the policy of the organization discourages personal calls during working hours, effectively closing off the outside world. The offices were constructed and occupied in 1987 and the women's ways of working in the space has not changed significantly since then. The close space of the desk becomes the primary location for routine workers to express their values, priorities and individuality. Personalia collected at the desk provides a source of control for the women occupying dedicated clerical desks. It allows for the constant stream of work to be limited by desk cleaning rituals and time spent in social networking.

The nature of an organization is demonstrated in the construction of space, but space also reveals underlying priorities and the values of the users and designers of the space. The spatial turn which is evident in recent theoretical work from anthropology and sociology focuses mainly on cities, economies and globalization in the work of Soja (1996), Harvey $(2000,2001)$, and Castells (2000) who build on the early spatial writing of Lefebvre (1991), Foucault (1977), and Benjamin (1968,1999).

Working as a genealogist of power, Michel Foucault (1977) positions the organization of space as the diagram or signifier of systems of power inherent in institutions such as hospitals, schools and prisons. An example he develops is the spatial serialization of the classroom that has evolved from the relationship of the Master and his pupil. Students were ranked and categorized by knowledge, behaviour and social status and accordingly allocated a position in the spatial order

by assigning individual places it made possible the supervision of each individual and the simultaneous work of all. It organized a new economy of the time of apprenticeship. It made the educational space function like a learning machine, but also as a machine for supervising, hierarchizing, rewarding. (Foucault 1995: 147).

Foucault's project in Discipline and Punish brought attention to the shaping of human subjects from without to create compliant and docile minds and bodies. Hierarchy and rank have provided the hegemonic structure of the organization in the $20^{\text {th }}$ century. The design and allocation of space in the office has been carefully 
orchestrated to provide rewards in the form of individual spatial assignments such as, levels of privacy, location with relation to access to windows and natural light, and amount and quality of furniture provided, aligned with ranking and status.

Walter Benjamin was aligned with the Frankfurt School but drew references variously from Marxism, Surrealism and Zionism. ${ }^{2}$ His unfinished work The Arcades Project (1999) has posthumously established him as a contemporary philosopher of the spatial. He understood the significance of the introduction of iron into the framing of social space, writing about the phenomena of the arcades of Paris. These vaulted iron and glass structures connected department stores and shops retailing textiles, creating palaces of consumption. They provided entertainment for the masses and were popular with tourists. Entertainment became intrinsically connected to the idea of consumption, and was made more accessible and acceptable for the working classes. Through The Arcades Project Benjamin brings attention to the intrinsic connection of the social existence of human beings and their spatial condition. His method is original and instructive, using a bricolage of commentary, citations, images, poetry and newspaper reportage, variegated traces of daily life (1968) as the vehicle of a new spatial medium to consider the historical period politically, socially and aesthetically.

Henri Lefebvre, French sociologist and philosopher, is arguably the most influential of the contemporary spatial theorists. His work has been widely sourced for the development of the discipline of human geography ${ }^{3}$. It is interdisciplinary in nature and has currency in design theory in planning, environmental, and architecture. Lefebvre's writing begins from Marxist understandings of the structure of society but expands beyond to look at the formation of urban space as the reproduction of the social relations of capitalist production. Aronowitz (1991) asserts that "for Lefebvre everyday life is the site of and the crucial condition for the 'reproduction of the relations of production'..[his] central argument is that state and economy are outcomes of the everyday" (135).

\footnotetext{
${ }^{2}$ Hannah Arendt's Introduction in Illuminations Walter Benjamin: Essays and Reflections (1968)

${ }^{3}$ Hubbard, Kitchin, and Valentine 'Editors Introduction' in Key Thinkers on Space and Place pg. 5.
} 
As such Lefebvre rejected the constraints of the classical Marxist position of the base/ superstructure model. He argues the significance of the everyday is the outcome of a century of conflict where capitalism has survived revolution.

Lefebvre's The Production of Space (translated in 1991) was the first philosophical work to closely examine the significance of spatial and social practices as central to understanding the production and reproduction of everyday space. "Space is social morphology: it is to lived experience what form itself is to the living organism, and just as intimately bound up with function and structure" (Lefebvre 1991:94). Lefebvre developed a trialectic approach to thought that valued not only history and sociality but also emphasized spatiality as a way of understanding lived experience. He elaborated a method for analysing space that considers the perceived space of everyday life, the conceived space of architects, planners and developers and the lived space of dreams and possibility, accessed through art and culture. Lefebvre's theory of the social production of space provides a starting point for understanding the dialectical relationship between the office workers and the space that both constrains and enables them. In The Production of Space (1991 [1974]) Lefebvre brings spatial considerations to the forefront of the philosophical realm and develops a framework for the study of spatial practices where "the reproduction of social relations is predominant" (1991:50). Lefebvre theorizes about the three distinct and yet interrelated elements as the causal components of space.

He understands the conceived as the result of formalized design processes determined by planners, architects and technocratic agencies. The perceived is the space that is produced and reproduced through everyday social interaction and experience. The meanings we give to space and the reordering of that space to reflect and reinforce those meanings is the lived. This third space of clandestine and alternative practices has informed the work of geographer and cultural theorist, Edward Soja.

For Soja third space implies a decentering, disruption and disordering of all forms of binary thinking. Lefebvre's approach opens a third space of political choice, a meeting place for others. Soja develops Lefebvre's argument for difference, complexity and 
diversity, against the specific geography of capitalism defined through the increasing forces of homogenization, fragmentation and hierarchy. "At its best such critical spatial thinking seeks to undermine it's own authority by a form of textual and political practice that privileges uncertainties, rejects authoritative and paradigmatic structures that suggest permanence or inviolability, invites contestation, and thereby keeps open the spatial debate to new and different possibilities" Soja (1996: 107).

Soja situates race and gender in the third space perspective through the work of bell hooks and Dolores Hayden among others. "Urban spatiality was seen as oppressively gendered in much the same way that the cityscape was shown to be structured by the exploitative class relations of capitalism and the discriminatory geographical effects of racism, the two other major channels of radical modernist urban critique developing over the same period in the spatial disciplines"(Hayden 1984, 110). This is useful to consider because it assumes there is space for the other, allowing for the insertion of a gendered and racially aware discourse.

Part of the project of Lefebvre's The Production of Space (1991), was the Marxist analysis of the rational cartesian space of modernism. Lefebvre questioned the erasure of diversity and difference demonstrated in architecturally conceived environments confiscated from nature and typified by space as a set of things/signs and their formal relationships. He describes abstract space as the dominant form of contemporary space, housing amongst other things, the institutions of knowledge, power and wealth, and exercising a negating and repressive force on those who occupy it. History is reduced to memory or weak symbolism in abstract space. Abstract space positively enforces the technological, scientific and knowledge bound to power. David Harvey $(2000,2001)$, a Marxist geographer and theorist, also took up Lefebvre's urban spatial theories. He elaborated their economic and symbolic dimensions to address social injustice and challenge capitalist space. The tactics of workers in the office represent an example of the complexity and contradiction Lefebvre associates with abstract space. Office workers do militate but in largely subversive and ad-hoc ways, to produce the space they need for the work they are responsible for doing. By studying the personalia at 
women's desks the dissertation demonstrates the subtle ways that workers can militate against the totalizing aspects of abstract space.

Susan Halford, co-director of the Work Futures Research Centre at the University of Sussex, argues that spatiality has been omitted from the sociology of work research. In her essay Sociology of Space, Work and Organization (2008), she sets out to demonstrate the need for a greater focus on spatiality to create a new sociology of work. She neglects to notice the designers of workspaces have something to contribute to this discourse asserting that geographers are the rightful and recognized experts when it comes to spatial theorizing. There is no doubt that the human geographers were early advocates to challenge the neutrality of space and time in the construction of social theory and research methods. Doreen Massey's work Spatial Divisions of Labour (1984) generated a new and productive cross-disciplinary dialogue between urban/economic/social geographers and sociologists. She demonstrated that the complexity of spatial divisions historically imposed on different forms of labour would affect regional inequities and economic potential. Massey also wrote on the gendering of spatial divisions, a topic developed further in Daphne Spain's writing particularly Gendered Spaces (1992), and Hanson and Pratt's Gender, Work and Space (1995). Although their work rarely steps inside the spaces to understand more than the spatial plan, their work is more quantitative in nature and they look to draw conclusions rather than focus on the embodied and messy everyday understandings of spatial occupation. "These "ways of operating" constitute the innumerable practices by means of which users reappropriate the space organized by techniques of sociocultural production" (de Certeau 1984: xiv-xv).

We can see a more embedded and embodied understanding in the phenomenological sociology of de Certeau, Giard and Mayol's The Practice of Everyday Life Volume $2\left(1998^{4}\right)$ where the rituals of living and cooking are uncovered and examined. It is this approach that provides a model for the case studies in this dissertation. They form a window into the complex and messy lives lived in office

\footnotetext{
${ }^{4}$ The Practice of Everyday Life: Volume 2 Living and Cooking was first published in French in 1994.
} 
environments, the place where the designers plan (conceived space) and the workers experience (perceived space) meet in the space of dreams and possibilities (lived space). "Enter any work organisation and we are, necessarily, engaged in complex spatialities: engaged with the meanings, materialities and bodily performances embedded in and produced by these organisations of space and spatialities of work"(Halford 2008: 927). The study of personalia using ethnographic methods uncovers complex spatialities that span personal, inter and intrarelationships. They represent personal and group identities, histories and dreams.

\section{Designers' role}

Design is a developmental process which John Zeisel, sociologist, architect and author, in his seminal text Inquiry by Design $(1981,1984,2006)$ depicts as comprising three complex and interwoven activities - imaging, presenting and testing. The design process is iterative and cyclical with information and critical input feeding into the design outcome. The design process for interior design is grounded in detailed information collected from the client and case studies, with presentations to clients and consultants feeding back and requiring iterative adjustments.

The process for the design of an office involves extensive consultation with the client before the design process can begin. This takes many different forms but usually engages with a high percentage of the office constituency to understand the operations and needs of the organization at the detail level. In 1985 Investors Group engaged the workplace furniture manufacturer Steelcase, to carry out a rigorous and large survey of the equipment required for all those employees likely to move into their new headquarters. Typical office configurations for each level of the organization were developed as a result. This information assisted the organization to move from a very hierarchical departmental structure to one based on flatter hierarchies and standardized office sizes. The typical office layouts, along with the management philosophy and vision, informed the planning of the floors. Workstations for work groups in the open office areas were planned in greater detail by the office furniture supplier. 
In the 1980 s the executive floors and public areas of the building received much greater attention from the designers with the open planned areas often being developed by furniture suppliers or office juniors, as was the situation at Investors Group ${ }^{5}$. Design budgets focussed on the development of the executive areas, public areas and management offices as this represented the identity of the corporation to clients and employees. The design process in the 1980's prioritized the front of house space, rendering the back of house spaces where the clerical workers were located as less visible and less valued.

\section{Research Questions : Space of Identity.}

The desk provides the space of identity for those workers who are denied the technologies of mobility that facilitate different opportunities for the expression of identity. This study addresses the desks of routine clerical workers who are women and often immigrants. For these women, work is a necessity, not always a pleasure, and can be seen as part of the eddy of workers who do not enjoy the privileges of mobility or the relative freedom of knowledge workers. The question this dissertation seeks to understand is how does the physical environment of the workplace, the desk, and its personalia reflect the creation of women's identities and values in response to the hegemony of the financial services industry?

The office workplace evolved rapidly in the second half of the $20^{\text {th }}$ century with the impact of technology, globalization and the increasing democratization of work. Women's participation rates (Kanter 1977:26) have grown from being a small minority in the 1900 s to approximately 75.5 per cent of the administrative and clerical workforce in the $2009^{6}$. How does the workplace reflect women's values, and how have women's values influenced the design of the workplace?

Research methods include narratives of the women as phenomenological case studies based on semistructured interviews using photo-elicitation. These methods

\footnotetext{
5 Leonie Glenat personal communication.

${ }^{6}$ Statistics Canada - women as a percentage of Clerical and administrative employees www.statcan.gc.ca/pub/89-503-x/2010001/article/11387/tbl/tbl012-eng.htm
} 
align with the valuing of ordinary voices and personalia that might provide richer and more complex instruments for understanding the office environment than is usually employed. The thesis does not seek to produce a normative behavioural study or extrapolate generalizations but rather to propose a series of individual case studies that build on theories from feminism and material culture by reflecting the voices and practices of the women routine workers. The material of the research is illuminating and diverse and the methods seek to reflect that.

\section{Standpoint Theory and "Women's Ways of Knowing"}

To be able to discuss and analyze the research findings it is important to have a theoretical frame through which to view the women's narratives. "Women's ways of knowing" allowed me to understand what might be a representation of women's values and modes of operation. Based on feminist research carried out on a very diverse group of research subjects Belenky et al. provides me with a language to discuss women's identity and concerns.

The women's suffrage movements of the late $19^{\text {th }}$ century are generally regarded as the first wave of feminism. They focused on legal obstacles to women's rights such as the right to vote, own property, employment rights, equality in marriage, and the right to hold positions of political power and authority. Second wave feminism grew out of the women's liberation movements in 1960s and 1970s and built on the achievements of the suffrage movement. Feminism in this period addressed sexuality, reproductive rights, women's roles, labour in the home and patriarchy. It was critical, as Women's Studies departments were established in universities, that women had authoritative texts written by women addressing issues of importance to women.

One such text was written by a group of sociologists - Mary Field Belenky, Blythe Mcvicker Clinchy, Nancy Rule Goldberger and Jill Mattuck Tarule (1986) who researched the epistemology or "ways of knowing" of 135 rural and urban women, aged 16 to 60, from diverse racial, economic and educational backgrounds with a focus on identity and intellectual development. Their work was grounded in the research of William Perry 
(1970) whose conclusions were based on all male students from Harvard University. Belenky et al.'s findings were significantly more far-reaching and gender-related. They developed five "ways of knowing" or knowledge perspectives, dependant on conceptions of self, relationships with others, and understanding the origins and identity of authority, truth and knowledge. (Belenky et al.1986) "Women's ways of knowing" as interpreted by Karen Franck (1989) provides a framework for the analysis of identity and how it might be reproduced in the spaces of office workers, as discussed in the case studies in Chapter Six. Chapter Four will expand on feminist standpoint theory and “women's ways of knowing" (see pages 76 - 78).

\section{Methodologies for the Everyday}

This dissertation draws on a number of research methods in an attempt to intuit subtle and divergent meaning from the ephemeral traces of occupation in the spaces of routine work. It uses methodologies of the everyday inspired by Michel de Certeau's (1998) sociological studies of French working-class culture, such as ways of living and cooking. De Certeau, a theologian and historian, was interested in theorizing everyday operations that make use of the cultural products of modern society. Cultural products have trajectories that are determinable but often unsuspected,"sketching a theory of everyday practices in order to bring out their murmuring the 'ways of operating' that, as a majority in social life, often only figure as 'resistances' or as apathies in relation to the development of sociocultural production" (de Certeau, Giard and Mayol 1998:xx).

Giard (1998) explains in her introduction to The Practice of Everyday Life: Volume 2 Living and Cooking that de Certeau saw the insinuation of tactics of resistance where others only saw obedience and standardization. He believed in the intelligence and inventiveness of powerless people who use tactical nimbleness in the face of the strategies of power. His desire was to refute the thesis of passive consumers and mass behaviour. Interviews were used as a way of giving the floor to ordinary people but required a particular quality of empathy from the interviewer. Giard's significant contribution to de Certeau's work is seen in The Practice of Everyday Life: Volume 2 
where her feminist influence led to research on cooking, a place where women's practices could be considered (1998: xxviii).

When I first came across The Practice of Everyday Life the work resonated with my own observations about the ways in which office workers operated in spaces owned by the organization and assigned to them. The personalia at the desks always seemed to be more than the creation of a "sense of oneself" (Csikszentmihalyi and RochbergHalton 1981) or a way of symbolically representing identities to others (Sundstrom and Sundstrom 1986). The seeming randomness of the objects and the subversion of everyday office supplies suggested something else was at work.

\section{Phenomenological Research Approach}

Phenomenological inquiry is often categorized as "qualitative inquiry" or "grounded theory" or "theory grounded in the empirical world". Phenomenology examines the kinds of symbols and understandings within a group that give meaning to a way of living and experiencing, and as such is well suited to unpacking the micro culture of the office environment.

Heidegger asserted that our relationship to the world is neither "idealist" (acts on the world) nor "realist" (world acts on her) but rather we are caught up in the world and immersed in an "undissolvable unity" (Stewart \& Mickunas, 1990). Heidegger called this "dasein" or "being-in-the-world". Because of this indivisibility the major challenge is to avoid subject/object dichotomies. Phenomenology's response is towards "intentionality" where human experience and consciousness necessarily involve some aspect of the world as their object, which reciprocally provides the context for the meaning of experience and consciousness (Seamon, 1980: 4).

Phenomenology became central to Continental philosophy throughout the $20^{\text {th }}$ century, launched by Edmund Husserl, Martin Heidegger, Maurice Merleau-Ponty, and Jean-Paul Sartre in the first half of the century. Beginning with Edmund Husserl's concept of transcendental philosophy, invariant structures of consciousness underlying human experience are able to be identified through phenomenology. Husserl specifies 
that "logical concepts ... must have their origin in intuition: they must arise out of ideational intuition founded on certain experiences, and must admit of indefinite reconfirmation" (1970b, pp. 251-252). His emphasis on imagination, ideas, and essences give the human sciences their distinctive character.

Merleau-Ponty and Heidegger reacted to the notion of structures of consciousness. Heidegger reinterpreted the structures to be categories of human experience rather than pure cerebral consciousness, establishing an existential correction (1962 [1927]). Merleau-Ponty sought to question the mind-body convention common in western philosophy at this time. He moved from cerebral structures to lived experience, embodying phenomenology (1962 [1945]). The goal is "a rigorous description of human life as it is lived and reflected upon in all of its first-person concreteness, urgency, and ambiguity" (Pollio et al.1997:5). It is the move to value lived experience that places the dissertation case study research into a phenomenological framework. In phenomenological studies the investigator refrains from making suppositions, focusing on a topic with fresh eyes, constructing questions to guide the study, and deriving findings that will provide the basis for further research and reflection.

De Certeau's sociological method was influenced by Henri Lefebvre's writing on the social construction of space and shares the language of spatial practices. In the context of the office we could understand the trialectic as the conceived representing the formal organizing plans and drawings that instruct the creation of the office and is constructed by the interior designer or space planner. The office workers who occupy and experience the spatial configuration and its environmental ramifications are represented by the perceived; and the lived is the location of individual identities and dreams in the spaces of work, resisting the constant movement of people and their locations within the corporation. Lefebvre's trialectic makes room for the average person to exercise personal resistance to enable transformation, countering the oppressions of everyday life. "Lefebvre's emphasis on the oppressions of everyday life are countered by a transcendent belief that everyday life cannot be contained by 
bureaucratic regimentation, that it harbours the desire that generates transformation. Nature, love, simple domestic pleasures, celebrations, and holidays all erode any prospect" (McLeod in Harris \& Berke 1997:15).

Phenomenological approaches to research inquiry have significance for this topic because they allow for the "bodily, visceral, intuitive, emotional and transpersonal dimensions" (Seamon n.d.:4) of the women office workers to be acknowledged and legitimized. Everyday life challenges reductive categories such as public and private, work and leisure, routine and escape allowing the analysis to move beyond these dichotomies. We get another kind of knowledge from intuitively 'becoming one with' the subject and therefore participative kinds of methodologies are relevant to this inquiry. Harmon (1994) suggests "we learn about reality by identifying with the observed"

Following the reflective process, the researcher constructs a full description of his or her conscious experience. This is called a textural description and includes thoughts, feelings, examples, ideas, situations that portray what comprises an experience. In the dissertation the narratives and visual composites were a way of constructing a depiction of the everyday of each woman, a distillation of the essence of our interview. The perception and interpretation of the women's narratives together with the images allowed me to reflect upon and develop essences and meaning from the everyday of the women clerical workers.

\section{Eliciting Ethnography Through Images}

Visual research methods are various and diverse. Some researchers have used visual material to make theoretical arguments which are only available through imagebased methodologies, while others have used visual material in ways that are essentially illustrative. The photograph can be a faithful record of a space or an interior, or it can be an artefact to be interpreted and read much like a painting. Photography was first used at the turn of the $20^{\text {th }}$ century, and was linked to sociology as both practices explored and documented society. Images were discarded in 1916, as North American 
sociology, concerned with appearing more scientific, moved away from "manipulated prints, iconographic poses, inconsistent before-and-after photographs, portraits out of context, and images based on clumsy techniques" (Statz, 1979: 128). However interest in visual research was revived in the 1960s.

"Photographs are forms of data which the researcher has obtained with their camera, as opposed to administering a survey or conducting an interview" (Emmison and Smith, 2000: 24). The photographic record allows for research data that is too fleeting or complicated to be captured and described in writing. The reflexive mode of the use of photography as described by Douglas Harper involves the subject in the definition of meaning. "In the reflexive mode the sociologist actively involves the research subjects in the interpretation of images .... p process referred to as "photo-elicitation'" (Emmison and Smith, 2000: 29). Jenkings, Woodward and Winter (2015) assert that "with respect to photo elicitation, we need to recognize that the photograph is not simply a source of information, of details that can be read by the informant. Rather, it is part of a collaborative interaction between the interviewer and interviewee in the production of analysis and data."

Photo elicitation has been acknowledged to be especially useful when interviewing children where traditional verbal interviewing techniques are seen as potentially limiting, even exclusionary (Epstein, Stevens, Mckeever \& Baruchel, 2006). Collier (1979) suggests the use of photographs makes the research subject into a co-researcher and can bridge between strangers, facilitating communication that may lead to "unfamiliar, unforeseen environments and subjects"

In developing the research method I intuitively and imaginatively developed a research area that responds to my own experiences and observations as a workplace designer and student of office environments. The area of personalization of the workspace is generally understudied although it more recently has become an area of academic interest eg Brandes and Erlhoff (2011), Byron and Laurence (2014), Wells and Thelan (2002) and Elsbach (2004). 
I searched for research methods that would allow me to "become one with the subject", to study the micro- environment of women in the office. The method I employed was photo elicitation. The benefits of the photographs were such that at the interview stage they allowed the women to reflect on the contents of their spaces as valued and authentic. They also allowed for visceral responses with expressions of the emotional history and content of the desktop personalia.

Emmison and Smith describe photographs as secondary to the in-depth interviews; however my own experience with photo-elicitation suggested that the photographs provide invaluable spatial information such as the location and visibility of personalia at the desk that reflects unconscious choices made by the subjects. This type of information would not have been uncovered by the interviews. The main component of my research involved making photographic images of the close working environment of routine clerical workers in the financial services industry, associated with 60-minute interviews with the 11 women workers who were located in two departments. Chapter Five combines the narratives and visual composites of each woman's workspace. The interviews, the photographs and my field notes were used to reflexively interpret the artefacts of personal occupation found on the workers desks. The result of my analysis are in Chapter Six. The framework for the analysis was developed from the content of the photo-elicitation research and its theoretical underpinnings. The benefits of the photographs were such that at the interview stage they allowed the women to reflect on the contents of their spaces as valued and authentic. They also allowed for visceral responses with expressions of the emotional history and content of the desk top personalia. The photographs allowed for my continued reflection on the subjects values and the nature of the small objects and spatial practices at the desk. They allowed for a richer reading and interpretation of the interviews and the images.

In his text Inquiry by Design John Zeisel (2006) discusses the benefits of observing and photographing physical traces to determine how the physical environment meets the needs of its users. He suggests observing physical traces requires systemic looking for traces of previous activity that was produced 
"unselfconsciously" or consciously as a response to the physical environment. This method of reading the physical environment is used frequently by designers to intuit patterns of use; however, when the reading is performed systematically the meanings that might be extrapolated are more complex and interesting from the perspective of the researcher. Zeisel talks about these as "rich impressions" that may be "highly Illustrative", but they do need to be balanced by questions about what is missing from the picture.

Zeisel (2007:161) advises that the benefits of this research method are a source of provocative images that deal with long-lasting phenomena; however, he warns against drawing superficial hypotheses without further investigation. In response to this concern I chose to used photo-elicitation, as discussed previously, to actively involve the research subjects in the interpretation of my photographs of their close work environments. The images enabled interview subjects to discuss more directly the values implicit in personalia at their desks.

The value of the ethnographic research to this project is that it facilitates the interpretation of artefacts through the flow of social discourse that often reveals more about context and cultural environment. According to anthropologist Clifford Geertz (1973),) ethnographic research attempts to fix the [artefact] ephemera of the work environment, to allow deeper analysis and enable and legitimize the study of the "homely and microscopic".

\section{Material Culture of the Everyday}

The study of material culture has expanded from anthropology to embrace the physical object as a site for historical study that does not rely on the written word; its use is particularly evident in American studies. Material culture eschews any single methodology seeking instead to "develop the explanatory power of artefact knowledge in order that such knowledge might ultimately expand human understanding" (Schlereth 1985:7). 
The study of material culture is interdisciplinary drawing on and contributing to studies in art, architecture, decorative arts, cultural geography, history of technology, cultural anthropology, culture and social history. It is able to address three-dimensional spatial understanding that is often salient to the objects themselves. Schereth (1985:12) lays claim to a special sensory knowledge that is derivable from the study of material culture; it is a non rational effective knowledge that works with our tactile senses to ground our experiences beyond the abstract symbolic uses of language.

The relevance of material culture research to the project of studying the everyday is significant, as demonstrated in the work of Daniel Miller (2008), British anthropologist and author. He has studied clothing, the home, media and the car amongst other things, to understand our relationship to objects in contemporary society and the complex role that consumption plays in human emotions. The attributes of spatial inclusion, interdisciplinarity, sensory knowledge and relevance to the everyday make material culture research an obvious choice for understanding the tactics of the everyday in the office. The objects that are the focus of the dissertation project are the personalia that accumulates on the desks and pin boards of women workers in conjunction with their spatial practices. We cannot study these close spaces of habitation in a historical context as the building was first occupied in 1987. Because personalia is ephemeral and previously disregarded as insignificant, it remains unrecorded. The dissertation uses current employees' workstations to understand women's spaces produced in the open office areas of Investors Group. As discussed previously the workstations were photographed by the author to capture a moment in time, and provide a place from which the "unseen" can be observed as if for the first time. The images were used as data and an "aide de memoire" as I interviewed the women regarding the value and meaning of their experiences at their desks. In this research each subject becomes an individual case study or portrait ${ }^{7}$ of phenomenological ethnography, focusing the research on the individual and the embodied experience of that individual in the close environment of the office.

\footnotetext{
7 Daniel Miller uses this term in his 2008 book "The Comfort of Things."
} 
In her essay "Intimacy and Objects", Beverly Gordon (1997) makes the argument that women are more comfortable than men in proximate, personal situations where involvement, texture and detail are relevant. She suggests this is due to divergent socialization, working from Hall's "Hidden Dimension"(1966). She relates this thesis to women's traditional forms of art making that she describes as "small delicate and typically representational, and either made of soft materials or built up with soft forms and colours" (Gordon 1997:239). Gordon's thesis, while controversial, provides interesting validation for the significance of women's use of personalia as a representation of their values and identity. These gestures are small, detailed and textured, such as Molly's focus on her proximate pinup space. The detail of the tiny christening ornament, and the colourful patchwork ceramic plate extolling her to "live well, laugh often, love much" and her professional mantra, the 5S's, provide comfort and connection to Molly's personal world from her location at the desk. The personalia at the desk often has no value other than its social context, inviting us to see these expressions as Lefebvre's lived space embodied.

Additional research involved surveying the internal publications of Investors Group from 1960 onwards and obtaining plans of One Canada Place. I spent time in the archives of Investors Group where I found historical photographs and publicity material that helped to reconstruct the character and culture of the organization (see Chapter Three). I photographed Investors Groups' head offices extensively (discussed in Chapter Four and images in Appendix Two). I interviewed the senior management of the organization from 1987 including CEO Dick Archer; Chairman Art Mauro; Facilities Manager Neil McMillan; Winnipeg Core Initiative board member Jim August; principal of Rice Brydone Interior Design Group Eleanor Brydone; and the designer who lead the project for Rice Brydone Anita Jones. I also had a number of interviews with local interior designers Leone Glenat and Gail Tyshynski who worked for Insite, the furniture contractor on the project.

The following chapter addresses the history of the workplace from the perspective of women and spatial environments that supported office work. It analyzes 
the management theory that has determined the nature of the physical space for office work, looking at the shift from hierarchical disciplined organizations inspired by Taylorism to flatter management structures that support teams, collaborative working and different forms of supervision and production resulting from neoliberalism and globalization. 


\section{CHAPTER TWO}

\section{WOMEN, OFFICE WORK AND INTERIOR DESIGN}

The radical shift in the gender of office workers over the 20th century has generally been ignored by mainstream organizational theorists (Mills 1953; Handy 1989; Drucker 1993) and workplace design critics (Becker \& Steele 1995; Duffy 1982,1992; Myerson \& Turner 1998). This dissertation addresses the growing numbers of women entering the white-collar workforce in the period between 1960 and 1990; and the simultaneous growth of the female-dominated interior design profession that was substantially responsible for designing workplaces during this time.

Additionally, the academic writing addressing gendered space generally focuses on domestic interiors (Attfield and Kirkham 1989, Sparke 1995), public space (Wilson 2000, Sparke 2008) and spaces of consumption (Chaney 1983, Friedberg 1993) with the examination of workplaces limited to gender segregated workplaces, such as the garment industry (Hanson and Pratt 1995). The dissertation brings attention to office work as gendered space.

I am interested in the influence of women on the essentially masculine nature of the office and its design. I argue that the outcome of the shift in gender and management philosophies supported by the emerging influence of the newlyprofessionalized interior designer resulted in an office environment that became more closely aligned with women's preferred ways of working, but that the routine office workers have yet to benefit substantially from new working environments.

I look at the years prior to 1960 to establish the character of offices leading up to World War II and then the five decades up until 1990. My dissertation draws on Lefebvre's (1991) thesis of the socio-spatial dialect that creates and recreates the spaces we occupy. The women workers can be seen as operating in Lefebvre's differential 
space where surreptitious change occurs as the result of workers' accumulated actions; and the architects and interior designers working at the level of conceived space.

\section{HISTORY OF THE MODERN OFFICE}

The physical form of the modern office of the $20^{\text {th }}$ century is the product of shifting management theories. Placing the plan of the physical layout of the office under closer scrutiny, we can observe the priorities and values of the organization and the image of the organization being established or reinforced by the furniture and office locations (Sundstrom 1986: 9-10). The modern office was first conceived of in the early 1920 s in response to the management theory that revolutionized the manufacturing industry, and a rapidly growing class of white-collar workers. Fredrick Winslow Taylor's 1911 Principles of Scientific Management, proposed the careful study and definition of work tasks leading to the restructuring of work practices. Granath asserts that the key principle of Taylorism was "that each task in a given production process should be defined and performed according to empirically founded knowledge and methods, not simply rules of thumb" (1991: 111).

Taylors' Principles became widely accepted globally as industrialization spread. They advocated for shorter working hours, breaks in work, paid holidays and an improved physical environment; in return, the workers carried out strictly defined tasks according to instructions, without the ability to improvise or refine the process. The intellectual component of the work was externalized and administered by supervisors and managers. The management principles required that the plan of the office also needed to change to provide for greater supervision and managerial oversight. The modern office was to be a demonstration of Taylorist principles, with clearly defined tasks supervised and managed in a hierarchical structure, with the knowledge and power residing at the top of the organization. Taylorism was evident in office planning from the '20s on, with businesses prior to that typically modelled on a large house with a series of rectangular rooms strung along corridors. 
New administrative practices and systems were created, first in banks and then were spread to other organizations; "issues such as labour recruitment, disciplined work schedules, cost reckoning, and the seeking of customers were addressed, and the solutions built into systems" (Kanter 1977: 19). The aggregation of previously externalized functions under the control of management characterized this period. Also, independent contractors inside the company with the power to hire and fire were replaced with central personnel departments and centralized administration.

\section{Professional Managers}

Feminist sociologist Rosabeth Moss Kanter reviews the history of corporations, noting there were many mergers of small enterprises that occurred in the period between 1889 and 1929. The mergers created a need for a new category of professional managers "to take charge of the ongoing function of corporations" (Kanter 1977: 19). Business schools were slowly established at American universities, with the Wharton School of Finance and Commerce being the first in 1884. Management as a professional field for men was established with the Harvard Business School in 1908, with a doctoral program introduced in 1922. In an effort to establish authority for this new profession, an ideology of rational efficiency was promoted that justified "the unilateral exercise of power by management" (Moore 1962: 237). Power was to be exercised by those who were not business owners, and were not therefore legitimized by money or class but by education.

Kanter asserts the origins of management theory were infused with masculinized and paternalistic values that established the centralization of management control in a hierarchical structure built upon titles and status levels and were implicitly male (Kanter 1977: 22).

The growth of the insurance industry and establishment of mail order businesses in North America at the turn of the $20^{\text {th }}$ century were bolstered by the adoption of communication technologies developed in the previous century, such as the telephone, typewriter and telegraph. The adoption of the typewriter led to an explosion of the 
clerical sector and many of these jobs were filled by women, who earned less than half the wages paid to men (Spain 1992: 192). "Between 1900 and 1920, the percentage of women in the labour force who were clerical workers zoomed from 2-12 percent " (Kessler-Harris 1982: 148).

"Typewriter" was the term used for the machine and the women who operated it. The early adoption of the typewriter created "an entirely new attitude to the written and printed word" because it "fuses composition and publication" (McLuhan cited in Kittler 1999: 202). Kittler argues that phallocentric pens wielded by male clerks and writers in the $19^{\text {th }}$ century gave way to the fine finger skills of young female typewriters and irretrievably feminized work with words at the turn of the $20^{\text {th }}$ century (1999: 206). What women lacked in education in math and writing skills, they more than made up for with dexterity; a note from two German economists in 1895 attributes to this to piano lessons (Kittler 1999: 194).

The new role of the typewriter in the office led to the establishment of standards for office paper, envelopes and files that stored correspondence. Desk drawers were developed for the filing of paper, replacing the traditional scrolled letters held by red tape.

Systematic approaches to organizational management and office planning became popular, bringing rational scientific notions of efficiency and highly defined skilled and unskilled areas of work. Supervision became a priority in the planning of office space, with large workrooms familiar from industrial production laid out with rows of desks aligned to regularize output and optimize supervision by male managers. Furniture also evolved in this period to suit the new efficiencies of management processes. "The modern efficiency desk developed in 1915 for Equitable Assurance Company's new Manhattan headquarters was pivotal in the emergence of modern office culture. Little more than a table with shallow drawers, this new desk banished the privacy previously afforded by roll top desks and the cabinet-like Wooton desk" (Albrecht and Broikos 2000: 22). 
The efficiency desk allowed easier supervision and forced workers to keep office correspondence moving rather than hidden in pigeonholes. "Aligned in orderly rows the Modern Efficiency Desk symbolized the era's obsession with factory-like standardization and rational science" (Albrecht and Broikos 2000: 22).

\section{The Office Building, 1930-1960}

The architecture of office buildings of the period was reminiscent of institutional architecture with uniform spaces and very little embellishment. As the size of the population of office workers increased, the need for a new building form became apparent. New materials technology was developed to efficiently construct multi-storey buildings, along with the means to transport people efficiently through vertical space via elevators. In the 1930s electric light came into common use along with central ventilation systems, allowing for a larger floor plate size and more regular hours of operation.

A visionary prototype for the modern office, illustrated in American management handbooks from the period, was the Larkin Building (1904) in Buffalo, designed by Frank Lloyd Wright for the Larkin Mail Order Company's business. The building was designed for 1,800 secretaries, clerks and executives, and it had to be clean and comfortable to attract women employees to the industrial sector of the city. It presented a stern red brick façade to the external world, but opened up to a vast atrium at the core of the architectural plan to celebrate Wright's concern for "the new industrial ideals" and was lit by natural light filtered through a glass ceiling. The lintels spanning the perimeter of the interior void bore inspirational words in groups of three: GENEROSITY ALTRUISM SACRIFICE; INTEGRITY LOYALTY FIDELITY; IMAGINATION JUDGEMENT INITIATIVE; INTELLIGENCE ENTHUSIASM CONTROL; CO-OPERATION ECONOMY INDUSTRY. It personified the "masculinized and paternalistic values" that Kanter refers to, but nevertheless provided new and careful consideration of the employees' well-being and health.

The planning of the departments was configured as follows: the mail centre and entrance lobby were located on the first floor, overlooked by the typewriting 
department on the second floor and the mail order department on the third floor. The fourth floor housed a kitchen, bakery and dining rooms, classrooms, a branch of the Buffalo Public Lending Library and a conservatory. A rooftop garden served as a recreation area for employees and their families.

Wright wrote in his autobiography, "The dignified top-lighted interior created the effect of one great official family at work in day-lit, clean and airy quarters" (Wright 1943: 150-51).

A predominantly female workforce informed Frank Lloyd Wright's designs for the unprecedented Larkin Administration Building in Buffalo, New York (1906).

Conceived as the headquarters for the soap company's mail-order business, Larkin was the first office building to integrate innovations in architecture with progressive management philosophy, mechanical systems, spatial distribution and furniture. Partly to attract the best workers (mostly women) and partly for public relations. Wright designed a clean, light-filled world completely separate from the gritty industrial environment around it. This monument to the progressive-era ideal of uplifting work, designed with the most advanced communications and distribution systems, also provided opportunities for employees' selfimprovement: a YWCA, library and music lounge. (Albrecht and Broikos 2000: 21)

Although the Larkin Building was hailed by business texts as the model office, Wright didn't design another office building until much later in his career when he was commissioned to design the headquarters for Johnson Wax in Racine. His approach to office design came from a concern to improve the working conditions of the average man and woman, and he introduced innovations such as the wall hung toilet pan to maintain cleaner washrooms, stained glass windows to inspire employees, and glass doors to allow as much light as possible to penetrate the building. The design process started from an understanding of the flow of work through the company, and as such Wright designed buildings that fit the organizational systems that were evolving at this time. 


\section{Organizing Systems: Departments}

The new business office developed a structure of departments with specific functions determined by classic managerial principles and informed by notions of efficiency. Punctuality and synchronicity were paramount and led to the creation of "bullpens" or large open halls occupied by clerical workers performing repetitive and routine tasks in the same place at the same time. Departments were laid out with offices for the managers. Personal secretaries were located outside the offices, serving as the day-to-day interface with the new technology required in managerial work, such as typing confidential letters, answering the telephone and placing calls, and organizing the boss's appointment schedule.

The first secretarial school in Providence, Rhode Island - the Katherine Gibbs School (established in 1911) - prepared "well bred" young women for "elite secretarial jobs". Women were not only taught typing, shorthand and personal grooming but accounting and grammar, allowing Gibbs girls to secure better jobs (Kanter 1977: 27). Their education responded to the needs of the male executives they would work for.

Secretarial work was divided into two kinds: The elite corps of private secretaries were directly attached to one or more bosses for whom they did a variety of tasks and from whom they derived status. Other secretarial work was done in steno and typing pools whose occupants were little more than extensions of their machines - and highly replaceable at that. The contrast in privileges, rewards and status of these two types of work enhanced the desirability of the private secretarial position making it seem the culmination of a clerical worker's aspirations. (Kanter 1977: 27)

Standards of dress and behaviour in the office were implied and supervised. Male clerks expected to be employed for life; young women typewriter operators were expected to leave employment when they became engaged to be married. Workspace was assigned based on status, and greater personal space and privacy was acquired as one moved up the hierarchy. The title "manager" provided a private office.

Spain asserts that women's jobs can be classified as "open floor", but men's jobs are more likely to be "closed door" - that is, women's work in offices was being carried out in more public spaces with much less control over the environment than men's 
work. "This lack of spatial control both reflects and contributes to women's lower occupational status by limiting opportunities for the transfer of knowledge from men to women" (Spain 1992: 206). She explains women were segregated in secretarial pools that separated them from the decision-making that went on in the managerial offices, denying them the opportunity to work without repeated interruptions. This impacted their capacity to make valuable contributions that could have given them greater status and better pay. The physical environment of the office conspired to keep women in clerical roles with very little capacity for taking on managerial roles.

\section{The Human Relations Movement}

New managerial approaches led by Elton Mayo were being explored in the 1930s at Harvard Business School. He established what later became the discipline of Human Resources Management. Its curriculum and research was based on applied and empirical studies drawing on multi-disciplinary approaches that incorporated biology, biochemistry, psychology, sociology and anthropology. The human relations movement attempted to shift the focus of research into organizations to include social relations, workers' motivation and satisfaction, and move away from masculinized and paternalistic values inherent with the centralization of management control.

The movement worked from the premise that people are motivated by social as well as economic rewards. Mayo demonstrated the importance of emotional, nonrational social relations that shaped behaviour and influenced productivity. "In Mayo's view workers were controlled by sentiment, emotion, and social instincts, and this phenomenon needed to be understood and taken into account in organizational functioning" (Kanter 1977: 23).

The longest running Hawthorne experiment involved the relocation of a group of six young immigrant women to a separate room to build relay assemblies. The women responded to the intimate atmosphere of the assembly room by developing friendships over time, as they were able to talk while they worked. Over the years of the experiment, the women's productivity rose significantly. The individuals were observed 
to have become a team. "Mental attitudes, proper supervision and informal social relationships experienced in the group were key to productivity and job satisfaction" (Anteby and Khurana n.d.). Mayo's team also carried out well-known research that accidentally uncovered the Hawthorne Effect, a term used to identify any type of shortlived increase in productivity caused by attention from researchers. The Hawthorne study focussed on the effect of the physical environment on productivity, including increases in illumination levels, maintaining clean workstations, clearing floors of obstacles and relocating workstations. This may have been the first research that linked the importance of the physical environment to productivity in the workplace.

Mary Parker Follett was a social worker, management consultant and pioneer in the Human Relations Movement. She graduated from Radcliffe College in 1898. Her writing over the first three decades of the $20^{\text {th }}$ century informed the evolution of more progressive and effective management strategies that reflected the creation of collective goals for management and workers. She wrote a number of seminal texts advocating integration, the non-coercive sharing of power based on the use of her concept of power with, rather than power over. She is credited with having first used the expression "transformational leadership". Kanter suggests Parker Follett's expertise and interest grew from her experience in the administration of social welfare organizations as local networks, where many women were able to develop collaborative managerial skills (1977: 23). In 1926 Parker Follett moved to England to live and work, consulting with the League of Nations and the International Labor Organization in 1928. She was largely forgotten in the United States, but her work on adult learning in organizations (1924) continues to have relevance in current discourses around learning organizations. Parker Follett is hailed by Peter Drucker as the prophet of management, and the book published after her death in 1933, Dynamic Administration (1941), was rediscovered in Japan in the 1960s and was highly influential in the restructuring of Japanese businesses to incorporate teamwork.

Kanter suggests the human relations movement brought a feminization to the masculine ethic and encouraged new forms of organization to emerge, such as team- 
oriented project management systems. However, the masculine ethic of the rational manager "told men how to be successful as men in the new organizational worlds of the twentieth century" (1977: 25). "If the human relations school's metaphor was the 'family' rather than the 'machine' of classic models, the organization was still thought to require a rational controller at its head. Writers on management practice and organizational theory distinguished between the manager's logic of efficiency and the worker's logic of sentiment “(1977: 24). While men were being groomed for success in the corporate world, women were employed in greater numbers to play the supporting roles in routine office work and secretarial functions.

We can see the influence of the human relations movement on the built form of the office in a subsequent project designed by Frank Lloyd Wright for his client Herbert Johnson. Constructed from 1936-39 the Johnson Wax Building demonstrated the ideals shared by Wright and Johnson who believed in a new industrial democracy; "inspired by Puritan idealism, social conscience and moral sentimentality" (Frampton in Lipman 1986: xi). Frampton depicts this as a belief "that Taylorized production, reduced working hours, increased welfare and benefits (S.C. Johnson \& Son was an early American firm to introduce profit sharing) together with improved environmental conditions could...overcome the contradictions of capitalism and inaugurate a new golden age" (Frampton in Lipman 1986: xii).

\section{Johnson Administrative Building, Racine}

Wright's innovation in the design of the administrative building (1939) for the Johnson Wax Company was the creation of a community of workers, isolated from the urban setting in which they were located, but with all of the components of a cultural and social community; the project housed a cinema and performance space that seating 250 , and squash courts. The building develops many of Wright's earlier themes, including a vast central workroom lit by an innovative glass tube roof.

The Great Workroom that represented the central hall of the workplace was designed to create a greater sense of co-operation and efficiency, with employees 
having direct access to one another (Lipman 1986: 94) "Wright laid out the departments to promote efficient flow of information", departments were co-located for improved communications with a central filing department accessible to all, located under the south mezzanine. The Great Workroom, "a top-lit hypostyle hall" supported on 64 lily pad columns, established an aesthetic that combined the feeling of being in a forest of trees and within an ecclesiastic space. It was designed as the workspace for the female clerical workers of the Johnson Wax Company, while the floors above housed the men in managerial positions. The offices of the middle managers were located on the mezzanine, and the penthouse housed the senior executives and boardroom.

True to Wright's democratic ideals, the furniture developed for the Great Workroom established the design language that was common throughout the administration building, including the desk and chairs in Chief Executive Herbert Johnson's office. A system of furniture designed to integrate with the streamline styling of the building derived its form from the curvilinear gestures of the building plan and the strong horizontal lines that characterized the elevations.

Wright's chair design for Johnson Wax originally had only three legs, supposedly to encourage better posture (because one would have to keep both feet on the ground at all times to sit in it). The chairs had foam rubber padding and were colour coded based on the department; red for the credit department, green for the billing department, beige for sales and blue for the branch house records department. The chairs were adjustable and the back of the seat pivoted vertically to allow a greater range of movement. Chairs for the Great Workroom were scaled down for the women using them.

Tubular steel was an economic choice and Wright developed a number of desk types as a response to the nature of the work being performed. The desks for the accounts department were designed so heavy ledger trays could be moved from the master filing cabinet in a small rolling stand and placed in hanging bins incorporated into the desks for temporary use. The desk system developed was simple and elegant; the images represented them as uncluttered with maple work surfaces and rounded ends. 
They were light and quite feminine in design. The desk system incorporated nine variations according to task.

The work surfaces were much larger than standard desks of the time at approximately 82 " $\times 32$ ". They were two feet longer than a standard desk, more generous and much more in line with the scale of desk Frank Lloyd Wright would have used in his own office for laying out drawings. The work surfaces of the desk cantilever over the frame gave maximum workspace clear of supports. There were three work surfaces provided; the lowest for a typewriter, the middle surface was the writing and layout surface, and the top provided a small shelf that was handy storage for trays and files and gave the user a modicum of privacy. The dimensions for the height of the work surfaces most likely have would have been derived from the Gilbreth's work (1921) in establishing universal human dimensions in the 1920s. The walnut timber selected for the work surface distinguished executive desks.

The original drawing for the office desk and chair provided to Johnson shows the desk engaged with the mushroom column stem. This feature was not included in the final desk design but spoke to Wright's singular vision that encompassed building and furniture in one gesture. The desk in its original form included pivoting trays for storage, a file drawer, task lighting and a wastepaper bin. All of the necessities of everyday office work thoughtfully integrated into a complete system to support individual workers, but no consideration was given to personalia at the desk at this time. Personal items such as family portraits were appearing on executive desks but were not thought appropriate for other employees and might serve as a distraction from the work in hand. The women clerical workers who occupied the Great Workroom are said to have "enthusiastically accepted being together in the large room" (Lipman 1986: 94).

The floor plans for the office spaces in the Larkin Company and S.C. Johnson Wax Company demonstrate the typical division of labour between the "workers" (mostly women) and the executives (all men). However, prototype furniture systems that were developed for both projects brought detailed attention to desks, chairs, light fittings, 
office landscaping, and the upholstery textiles and colours that considered women as the occupants and users in a community of workers.

Frank Lloyd Wright's design philosophy fits best into a movement emanating from Europe at the beginning of the century that saw the interior as part of a Gesamtkunstwerk, a "total work of art", in which the interior formed an integral part of the total project. The movement's goals, as described by Sparke, "aimed to bring together architecture and the decorative arts into a new synthesis that would not only facilitate modern life, but that through the use of non-historicist forms inspired by the contemporary worlds of nature and the machine, would actually embody it" (Sparke 2008: 38). Sparke asserts that the "new interior" that developed as a result of the Gesamtkunstwerk philosophy merged previously separate, public and private spheres, creating a new spatial vocabulary with women as its growing audience in the developing consumer society of the period. Women were, however, not just passive consumers. They formed a major component of the evolving class of "white-collar" workers. ${ }^{8}$ Women were paid less than the men and filled the assistant roles, but they found the work offered better pay and more freedom than domestic service or factory jobs (Mills 1951).

Women performed routine office work in the new jobs created when men left to enlist and fight in World War I. "Finger dexterity is often more important than creative thinking. Promotions consequently become relatively rare" was the prevailing attitude expressed by The War Manpower Commission (cited in Mills 1951:205).

Wright's Larkin and Johnson Wax buildings are exceptional in their prescience. They exhibit a belief in the potential of the designed environment on the productivity and satisfaction of clerical workers who were mainly women. They represent unique North American examples of the possibilities of the physical environment when the designer and corporation work towards a utopian ideal. We can criticize them today for

\footnotetext{
8 Social historian, Thomas J. Schlereth (Victorian America: Transformations In Everyday Life 1876- 1915 Harper Perennial: New York 1992 P. 29) noted, members of this new urban managerial class were "active participants in the era's revolutionary changes in politics, leisure, education, and consumer culture."
} 
their paternalistic and often naïve understanding of status and gendered relations; however, the Larkin and Johnson administration buildings remain examples of uniquely humane office environments, where the workers and employers' needs were considered significantly in the design process. Wright is often hailed as the most significant architect of the $20^{\text {th }}$ century. However, architectural historians when discussing his influence often overlook the design of his office buildings. This may be due to the sheer volume of innovative projects Wright designed, or because corporate architecture in North America subsequently followed a very different path influenced by the European Modernist architects.

\section{The Influence Of European Modernism}

European interest in the work of Frank Lloyd Wright led to the German publication in 1911 of two portfolios titled Studies and Executed Buildings of Frank Lloyd Wright. According to Mauro F. Guillen, the European architects were the first to understand the significance of the industrial era and the possibilities of new materials such as steel and concrete. Architects in Continental Europe in the early 1900s "actively advocated and planned for a transformation of society. The emerging modernist architecture (movement) in Europe stood out in strong contrast to American architecture, in that it was avant-garde ...it was revolutionary, that is, moving at the forefront of social and economic change rather than following it " (Guillen 2006: 9). Beginning with Peter Behrens in the 1900s and culminating at the Bauhaus in Germany the 1920s, the European architects of the period embraced Taylorism and its call for order through the systematic application of method, standardization and planning, embracing the idea of "technology as a social arbiter" (Maier 1970). New technology was to create social change and the projects that were the focus of Bauhaus architects tended to be affordable social housing. Hitler closed the Bauhaus School in 1933 and its teachers dispersed. As a result the Modernist movement didn't have a great impact on office design in Europe. It did, however, influence the development of the North American office tower. As former Bauhauslers, such as Mies Van der Rohe and Walter 
Gropius, immigrated to America to escape persecution they established themselves in the American architectural scene. The tenants of the Bauhaus School and its preoccupation with a rational machine aesthetic were soon evident in the post-war building boom of the 1950s and 1960s in the cities of America.

Modernist buildings from the post-war period were designed on a structural grid to frame large open interior spaces with access to views and natural light, afforded by areas of glass curtain wall. Acoustic ceiling tiles recreated the modular building grid in the interior with lighting and air conditioning integrated into them. The interior was laid out with the executive offices against the perimeter window walls, often framed in timber panelling that excluded light from the central secretarial and clerical pools, and reinforcing the hierarchical and gendered structure of the corporation.

\section{Office Planning}

"In the beginning, office buildings were desperately in need of interior design. For the most part, purchasing agents just ordered desks and chairs with little thought of planning. My background as an architect directed my efforts towards space planning, a little known profession not yet practised in the 40's"(Bassett cited in lorio 1994).

Knoll Associates Incorporated, established in 1946, was the product of the marriage of Hans Knoll, a furniture manufacturer, and Florence Schust (Knoll Bassett). Florence Knoll Bassett was educated as an architect, beginning at the Cranbrook Academy, then studying at the Architectural Association in London, and then the Illinois Institute of Technology where she studied with former Bauhausler Mies Van Der Rohe. She credits Van Der Rohe with having "a profound effect on my design approach and the clarification of design." "As the director of the Knoll Planning Unit, Bassett established herself as one of the most important and influential interior planners and designers of the second half of the twentieth century. Believing that intelligent design "strikes at the root of living requirements and changing habits," she established the practice of 
working closely with the corporate sector to determine the needs of the people who would actually use the spaces that her company designed "(Iorio 1994).

Florence Knoll Bassett embodied Sparke's thesis of "the new interior" drawing on technological innovation, mass-produced product, and the synthesis of art, architecture and decoration to facilitate and celebrate modern life.

The office building of this period is parodied in the office set for the television series Mad Men (2007-15). The story is located in an advertising agency on Madison Avenue in New York, and the exterior of the building is a composite of existing office towers. The series has been a critical success due in large part to a generous budget that has allowed for high production values and an evolving office set that has captured the detail of the period from the early to late 1960s. Richard Williams suggests:"... it is the interior that stays in the memory, describing with marvellous clarity the complexities, subtleties, and sexual politics of the modern open plan office" (2013: 101).

The office is the location of much of the action, the primary zone being the open office area. The open plan is a public zone occupied exclusively by female secretaries and reception staff. The typing pool is uniform and beige, framed by a continuous dropped ceiling with gridded fluorescent lighting; the women provide the only colour here. The private zone is comprised of individual offices occupied exclusively by male senior executives. Their offices face the street and the public world but are separated from the open plan by solid walls of timber panelling, interspersed with opaque glazed panels. Female secretaries protect the zone in between; "whose principle task is to limit as far as possible contact between the two zones" (Williams 2013: 101). The executive offices exude masculinity, symbolized by large and dominant desks, the drinks cabinet and constant smoking. The colour palette is rich, with timber and drapes providing texture, and accent furniture in strong solid colours. Windows onto the downtown emphasize the importance of these men as players in New York's sophisticated urban scene. There are softer furnishings, such as chairs that allow for the sitter to be comfortable and relaxed. But at the same time authoritative, abstract works of art decorate the walls, offices are softly lit with lighting to accentuate the individual, and 
framed by the backdrop of the city (Williams 2013: 103). The contrast between the women's workspace and the men's emphasizes the value of the men, as individuals set apart from the organizational space occupied by the women. Personalization of the work area was limited to the executive offices, with a now mandatory photograph of the wife and family, and a trophy recognizing sporting achievements. The women's desks in linear rows with the typewriter in the same place on each desk suggest the women are powerless and replaceable. The script unfolds another story with strong female lead characters, but we witness their constant struggle with the need to accommodate the entitled and sexist behaviour of the men.

The modern open office plan in the 1950s and '60s delineated gender boundaries by providing men with symbols of status and careers to aspire to, while women were seen to be marking time on their way to a good marriage and children.

The Schnelle brothers developed the earliest example of open office planning in West Germany, post-World War II. They were office furniture manufacturers in Quickborner, Hamburg with an interest in developing greater communication between supervisors and workers with less emphasis on status and authority (Sundstrom 1986: 36). Known as the Quickborner Team, they developed the radical status-free style of planning referred to as burolandschaft (office landscaping) that was adopted by large German corporations such as Osram, Krupp, Boehringer, Ninoflex and Mercedes Benz in response to European socialism and the growth of the influence of workers' unions (Brooker 2013: 59).

Burolandschaft was characterized by layouts with few offices, free-flowing circulation paths and the organic placement of light moveable desks and chairs; screens defined work and relaxation areas. Wall-to-wall carpet created visual continuity and the use of mobile screens provided acoustic remediation. The only spaces defined by walls were the offices for the executives and conference room. The movement reflected the desire to democratize management and placed value on the individual worker. It represented a break away from planning based on the linear organization of tasks, to a layout based upon studies of the interrelationships of individuals and teams. The 
intrinsic problems of acoustic and visual exposure were dealt with by generous personal space allocations that were eroded away by later enthusiasts of this approach to planning. The open landscape concept required a commitment from management to a non-hierarchical organizational structure that was a radical departure for the North American corporation. In North America, despite attempts to develop this approach to planning, most organizations were too inherently hierarchical in their management structure to be able to employ the new office landscaping principles to great advantage. The approach, however, offered a challenge to conventional planning principles and inspired the language of the open office plan. A number of panel-based office furniture systems emerged in response to the idea of greater flexibility, which led to the design of the cubical workstation satirized in the Dilbert cartoons. With the upholstered panel came the first opportunity for those in the open office to claim personal space.

\section{The Speculative Skyscraper}

The development of the corporate office building took a different form in Europe from the type of development that became the norm in North America. In Europe office buildings continued to be designed by architects for the specific needs of particular organizations. In North America the model of the speculative skyscraper became an efficient and cost-effective model for corporations. Office space constructed by developers was leased rather than owned, and as a result the buildings and interior spaces were more generic in character and generally architecturally conservative.

The fit-out of offices was commissioned separately from the architecture of the building. This was most often handled by an interior designer or interior design team in

an architects' practice to tailor the office to meet the specific needs of the organization. As the typology of "office tenancy fit-out" emerged, a greater number of professional interior design teams and practices sprang up to meet the need. By 1982 Graf Klein is advocating employing a design professional to those organizations considering new office space. She suggests they can offer a range of services in the planning phases that make their advice invaluable such as: comparing rented spaces "to determine suitability 
and relative cost including construction or renovation", analyzing existing operations and establishing space standards, and analyzing different strategies for "buying, building, or leasing space" (1982: 238).

\section{Planning Principles}

In the 1970s furniture companies embraced the language of the open plan office and promoted it as the answer to the problems of rapid change in the nature of business. Based on furniture systems rather than solid partition walls, individuals and groups could be relocated or expanded as required. The principles being promoted by

firms such as Steelcase used multiple planning concepts (all furniture-based solutions) such as the open office landscape and panel-based workspaces: a concept where desks and storage elements could be attached to privacy panels to divide up spaces.

The individual worker was now seen more frequently as a business asset and became the subject of research and literature on productivity and effectiveness in the office. Workstations designed for specific tasks and specific users were advocated, and required user need evaluations and the establishment of space standards for roles and tasks. The furniture companies promoted the specification of furniture and equipment that was conducive to change. New panel-based systems made effective use of vertical space, creating the argument for higher panels to divide workspaces so overhead storage and lighting could be incorporated (here come the cubicles).

James E. Rappaport suggests, "that 'systems' will expand to include prefabricated components that will include all mechanical services. Ceiling tiles, complete with sprinkler lines and air handling ducts; moveable full height walls that include storage units; raised floor systems deliver air and power to workstations; as well as work stations themselves are the next step" with the expectation that organizations will take their systems with them when they move buildings (Graf Klein 1982: 43). This vision of a totally integrated customized system has not been realized, although aspects of the vision such as raised, serviced floors are in common usage today. 
In the 1970s the growth of businesses accelerated, generated by the shortened life cycle of products and the number of new products being introduced to the market. The exponential growth created the need for more agile and flexible organizations to accommodate changing technology and business methods.

Employees were also changing, as they were better educated. "The bulk of office workers of the future may no longer be young ladies marking time between high school and marriage. They may be instead, intelligent, aggressive male and female junior executives on their way up the corporate ladder," Steelcase suggested in their 1974 publication Planning Principles for Effective Office Interiors. Changing management attitudes were increasingly informed by psychology, and the development of fields such as environmental psychology and human relations. Second wave feminism had broadened the debate to include workplace inequality, reproductive rights and families.

Due to greater competition profit margins declined, and businesses responded by looking more closely at the cost of their operations. They wanted to make employees more efficient, and developed a greater awareness of the cost of physical space and the need for space to accommodate change. A style of planning developed in North America in the 1970s and 1980s using a hierarchy of cellular office sizes related to job titles. The offices were arranged around the perimeter window walls with a combination of bullpen and open plan workstations internally. The degree of privacy available for employees was directly related to rank and status, but if the organization did not object workers were now able to make space for their outside world to be represented by artefacts and images scaled down to suit the size of their cubicle.

\section{THE DECLINE OF ORGANIZATIONAL HIERARCHY}

The mass production of the typewriter and the introduction of the telegraph and telephone changed the nature of office work by the beginning of the 20th century, separating the more mechanical tasks from the intellectual processes. In the same way computers, the worldwide web, email, cell phones and integrated technology in the 
latter part of the 20th century have enabled the unrestricted flow of information, increasing the ability of organizations to work more fluidly and flexibly.

Peter Drucker, American management consultant, educator and author, wrote The Landmarks of Tomorrow (1957), identifying the emergence of "knowledge work" and "knowledge workers" resulting from the development of large modern organizations such as business enterprises, government instrumentalities, large universities, research laboratories and hospitals. He made a provocative assertion for the time, suggesting, "knowledge has become the 'primary' industry, the industry that supplies to the economy the essential and central resources of production" (Drucker 1968). Others have reflected on the evolution of western enterprise in this period from high-volume pyramidal structures to high-value organizational webs reaching across the globe (Reich 1992).

The resulting organizational structure required decentralized decision-making and power that was located closer to where the required knowledge skills predominated. Reich (1992) acknowledged this trend was a threat to the American economy as skilled jobs and profits from American corporations increasingly flowed out of the country. The global marketplace regarded jobs as commodities to be traded where the returns were most immediate and profitable. The globalization of organizations has created far-reaching social change, with traditional patterns of employment being radically altered and destroyed. In corporations whose were headquarter were based in North America, the outsourcing of components of the business and the ripples created by deregulation of international banking created organizational instability and massive job layoffs.

Middle management jobs were those that took the brunt of economic rationalism in the 1980 s with organizations moving to flatter and more efficient means of channelling information. "Many of mid-management's uncreative tasks can now be done better and faster by computers and telecommunications networks... IBM... estimates that just one part of its internal electronic network replaces... 40,000 additional middle managers and white collar workers" (Toffler 1990). 
The organizational structures that emerged saw management forced to take a more active leadership role, supported by general clerical staff that were expected to be more responsible and self-motivated. The space previously filled by the middle manager became a blurred line with increasing responsibility for those above and below it.

New approaches to managing the workplace were focused on breaking down communication silos and building teams using communication technologies that facilitated employee mobility (Duffy 2003). In many areas of knowledge work, workers were no longer tethered to the desk but were increasingly encouraged to work where they were most productive (Drucker 1993). Cell phones and laptop computers have increasingly allowed workers to work remotely from the office while remaining in constant communication. Knowledge workers work at clients' offices, in hotels and coffee shops, while commuting around the city and in remote locations. They have been liberated from their desks and are able to influence the environments they prefer to work from. These innovations in office design represent a significant shift away from the embedded grids and hierarchies of the workplace of the 1960s. However, they were not driven by improved technologies alone; the rising cost of real estate in urban centres and the need for organizations to be agile required lower overhead and the increased ability to respond quickly to shifting demand.

Work environments designed for the "creative elites" from the 2000s onwards have prioritized spaces for socializing and conversing with work colleagues, including cafes and impromptu meeting spaces, touchdown desks that allow workers to adjust the height of their work surface from standing to sitting, and a range of facilities from gyms and basketball courts to pinball machines and video games. Mobile technologies allow for personalization of the "desktop" in dynamic formats constantly accessible to the user making tchotchkes redundant.

\section{Conclusion}


The shift in gender and management philosophies supported by the emerging influence of the newly-professionalized interior designer has resulted in an office environment that became more closely aligned with women's preferred ways of working, where management practices emphasize collaboration and teambuilding. But it becomes clear that the innovation in office design has largely impacted knowledge workers and the working lives of routine office workers have received much less attention from designers, due to their position in the structure of organizations. As lower paid and often contracted positions, these women become less visible to management and may be seen as less critical to the company's bottom line.

My dissertation draws on Lefebvre's thesis of the socio-spatial dialect that creates and recreates the spaces we occupy. The women workers can be seen as operating in Lefebvre's differential space where surreptitious change occurs as the result of workers' accumulated actions. These actions will be the material of the case studies that follow in Chapters Four and Five. The prospect that routine clerical work would be taken over by computers has not yet been realized and the routine tasks that require human decision-making and critical oversight remain the work of mainly women clerical workers. This work is referred to as "on-boarding" (as opposed to "outsourcing"). The case studies address personalia in the close spaces that women, working in the financial services industry at Investors Group in Winnipeg, occupy and personalize. The project seeks to add to the critical literature on the workplace by studying the creation of identity and meaning at the desks of clerical workers left in the wake of a mobile society. 


\section{CHAPTER THREE}

\section{WINNIPEG AND INVESTORS GROUP}

\section{Introduction}

This chapter will be grounded in the theory of the space of flows first formulated by Manuel Castells (1996). Castells theorized the rapid increase in the movement of capital, information and people was a response to neoliberalism, technology and globalization in the late 1970s and 1980s. The deregulation of money markets allowed for unprecedented financial freedom for large organizations and wealthy individuals to play the money markets and diversify their investments. Corporations had access to global finances and were able to influence markets outside of their country of origin and establish bases internationally. Added to this was the movement of people across the globe following employment and education opportunities, with migrants seeking a more secure future for themselves and their families. The flows of information were related to both capital and people but were facilitated by new communication technologies that connected cities across the globe simultaneously.

Projects are worked on 24 hours, seven days a week, as information moves across international timelines. Global flows do not only affect large cities like Tokyo and New York. The ways of working that were facilitated by new telematic communications influenced all centres of commerce, as markets and methods of production morphed and changed. Immigration to urban centres, where lives were safer and opportunities for work were greater, grew disproportionately. Finding homes for newcomers put pressure on the real estate markets in the larger cities, driving up the cost of living.

Overpopulation, economic and political difficulties in the Philippines caused massive emigration starting in the 1970s. Cities like Winnipeg, Manitoba, offered a more affordable lifestyle that appealed to many new migrants to Canada. Thus the population of migrants, particularly those from the Philippines, grew steadily at this time. The migrants' "exodus from the Philippines in the second half of the twentieth century was influenced by increasingly intertwined global economic networks and domestic politics. Personal motivations to leave their country and 
families behind in search of better opportunities in foreign lands are based not just on practical reasons but also on a complex combination of compelling cultural, economic, and political factors, including gender roles" (Bonifacio 2013: 4).

Canada developed a policy to encourage skilled and well-trained Filipinos, ${ }^{9}$ who benefited from good quality public education in the Philippines, to fill positions in health care and the garment industry, as well as clerical and technical positions. ${ }^{10}$

"Women make up a particularly large proportion of the Filipino community (in Canada). This is especially true of women in their prime working years. In $2001,57 \%$ of the Filipino community, compared to $51 \%$ of all Canadians, were female" (Statistics Canada). The Philippines has become the third largest source of immigrants in Canada, after China and India. These immigration patterns reflect the space of flows, bringing Filipino women into global cities such as Toronto, from which they are diverted to smaller cities in the network such as Winnipeg.

The contemporary office is one of the principle spatial sites of the space of flows (Stalder 2001). The shift began in the 1980s from centralized and hierarchical organizations that were highly efficient but extremely inflexible; moving quickly to networked and geographically distributed organizations functioning in real-time due to sophisticated communications technologies that offered greater flexibility. However, head offices have remained central to organizational functions. Sassen explains, "The more dispersed a firm's operations across different countries, the more complex and strategic are its central functions - that is, the work of managing, co-ordinating, servicing, financing a firm's network of operations" (2000: 111).

This dissertation projects the theory of the space of flows into the corporate office where it is embodied. Knowledge workers are increasingly mobile and unfettered by routines. They

\footnotetext{
${ }^{9}$ Canadian adults of Filipino origin are much more likely than the rest of the population to have a university degree. In 2001, 31\% of Canadians of Filipino origin aged 15 and over had either a Bachelor's or post-graduate degree. This is more than double the figure for the overall adult population, only $15 \%$ of which had a degree (Statistics Canada, The Filipino Community in Canada http://www.statcan.gc.ca/pub/89-621-x/89-621-x2007005-eng.htm\#5).

10 Canadians of Filipino origin with post-secondary qualifications are more likely to hold degrees in highly technical fields. In 2001, people of Filipino origin made up about $2 \%$ of all university graduates in Canada, but represented $3 \%$ of those with degrees in engineering or applied science, and 3\% of those with degrees in health-related professions and technologies (Statistics Canada, The Filipino Community in Canada http://www.statcan.gc.ca/pub/89-621-x/89621-x2007005-eng.htm\#5).
} 
imitate the mobility of the professional elite who travels between centres of finance, shifting their place of work to suit the task, and taking advantage of opportunities as they arise. The routine clerical workers are the underclass in the contemporary organization, performing jobs that are usually contracted out and occupied by women, who are often immigrants. They are captive in a hegemonic system that keeps them doing routine work with little prospect of promotion. ${ }^{11}$ They are not beneficiaries of the new democratic ways of managing organizations because "at the lowest levels of the organization, where fairly large numbers of women do routine computer aided work, there seem to be few possibilities of worker participation in decision-making because few decisions are made at that level" (Acker 1992: 57).

Castells argues there is a crisis of conflicting demands between the spaces of flow and the space of places in cities, with a resulting "fragmentation in the framing of social life". He describes cities as communication systems that link the local and the global, where the global is often much more powerful than the local, and increasingly the individual is forced to co-exist and negotiate individual and collective identities. Castells believes space expresses society, as "it is a fundamental dimension of society, inseparable from the overall process of formation" of a networked society (2004: 441).

The ways we can see this in the office is in the fragmentation of traditional human management systems to deal with very different ways of working. Knowledge workers require different management techniques; they are increasingly seen as self-managing and supported by technology, whereas routine office workers can be closely monitored and their productivity measured by keystrokes. The creation of teams is often performed virtually for knowledge workers, whereas routine clerical workers rely on teams to do higher-level tasks requiring experience and face-to-face support.

\footnotetext{
11 In 2001, 33\% of women of Filipino origin had a university degree, compared to $27 \%$ of their male counterparts. In comparison, in the overall (Canadian) population $16 \%$ of men and $15 \%$ of women had a university degree. People who reported Filipino origin made up about $1 \%$ of all workers, but represented $2 \%$ of people employed in health occupations and manufacturing. In contrast, their representation was disproportionately low among those holding management positions, as well as among those employed in education, government and the social sciences (Statistics Canada, The Filipino Community in Canada http://www.statcan.gc.ca/pub/89-621-x/89-621-x2007005-eng.htm\#5).
} 
The space that expresses these two classes or levels of work have received very different attention from employers and designers. Space for the knowledge elites is carefully considered, well-funded and considered an investment, whereas the design of space for routine clerical workers is often subcontracted to furniture companies, considered to be less relevant to the businesses' bottom line and slow to be upgraded.

The space occupied by the women who are the subjects of the case studies has not changed substantively since 1987 . The one advantage of working in space designed in the 1980s is the size of the desks and corridors is generous in comparison with space standards of today. Clerical workers were not the focus of design intentions for the creation of the new headquarters in the 1980s, with the planning of their spaces being assigned to the furniture suppliers, and they remain an undervalued resource in 2015. "Typically the sectors and occupations filled by women tend to have lower income ceilings, poorer benefits and less career mobility" (Hansen and Pratt 1995: 3).

Data from 20 global markets shows women comprise nearly 60 percent of employees in the financial services industry, but only 19 percent progress through the leadership ranks to senior level roles. Board and CEO representation is more telling; women hold only 14 percent of board seats and two percent of CEO positions. ${ }^{12}$

The unmooring associated with the movement of immigrants or transnational identities generates a need for the creation of a space of identity (Sassen 1999), and in the office the desk represents such a place for those workers to recreate identities.

This chapter will establish the context of the Investors Group financial services company being studied. It looks at Winnipeg, its history and urban development, and discusses the Core Area Initiative that led to the decision in the 1980s to construct the new headquarters for IG at One Canada Centre on Portage Avenue in the downtown area. The context of Investors Group's history and its relationship to the city is addressed, as is the narrative of the building and its designer's aspirations and the critics' evaluation. The chapter will introduce the interior designers' role and the shift in organizational culture represented by One Canada Centre. It will

\footnotetext{
12 World Economic Forum, The Corporate Gender Gap Report 2010. Financial services data includes financial institutions and insurance companies.
} 
provide a context for the idea of a building designed for the financial services industry in the 1980s with its largely female clerical workforce and look at the rapid evolution of technology.

\section{Winnipeg}

Winnipeg's geography and location has been the source of much of the city's growth and identity. Situated at the confluence of the Red and Assiniboine rivers, the city grew up around the ancient site of meetings and trade for aboriginal peoples travelling on traditional canoe routes. ${ }^{13}$ The name Winnipeg is derived from the Cree word for muddy waters - "winipe-k". As the Europeans settled North America, Winnipeg's central location in the continent made it a logical hub for the distribution of people, produce, and goods moving around Canada and from Canada into the United States. The French trappers married into the aboriginal population, creating a distinct new culture and people called the Metis. There is a strong French and Metis culture in evidence in Winnipeg that is celebrated in the winter at the Festival du Voyager, in Frenchspeaking communities such as St. Boniface, and in a vibrant and diverse artistic community.

Winnipeg grew with the mass immigration that occurred when the Canadian Pacific Railway link to Eastern Canada was completed in 1881. Sir Clifford Sefton, Minister of the Interior (1896-1905), promoted immigration by Ukrainians, Mennonites and Hungarians whose forbearers had been farmers in harsh climates similar to the Canadian Prairies. These groups settled the Prairies rather than congregating in the cities and were followed by Icelandic, Chinese and Jewish immigrants. ${ }^{14}$ By 1887 the Canadian National Railway provided a lucrative transport route crossing Canada, from east to west. ${ }^{15}$ "The boom period of immigration between 1867 and 1914 had a major impact on the development of the Prairies, and has permanently shaped Canada's society, economy, and culture" (Gagnon n.d.).

\footnotetext{
13 The rivers provided an extensive transportation network linking many indigenous peoples, including the Anishinaabe, Assiniboine, Ojibway, Sioux and Cree. Flynn, Catherine and E. Leigh Syms, "Manitoba's First Farmers," Manitoba History (31), Spring 1996.

14 Gagnon, Erika, http://www.pier21.ca/research/immigration-history/settling-the-west-immigration-to-the-prairiesfrom-1867-to-1914.

15 This route served until the establishment of the Panama Canal in 1914. The canal allowed for shipping and trade to move directly from the Atlantic to the Pacific oceans.
} 
Economic drivers in the prairie province of Manitoba have been grain and pulse growing, with Winnipeg becoming the location of the Canadian Wheat Board in 1935, and attracting representation from major banking institutions. Winnipeg is also home to major insurance and investment corporations such as Great West Life Insurance and Investors Group, who followed the money to the city once known as the Chicago of the North.

The essential components of a rich cultural life were established early in Winnipeg. The first university in Western Canada was established only seven years after the province was founded in 1870. The University of Manitoba was established in 1877 to confer degrees on students of all backgrounds, graduating from the three founding colleges: St. Boniface College, St. John's College and Manitoba College. In 1912 Canada's first civic gallery was established by a group of Winnipeg businessmen wanting to bring the civilizing effects of art and culture to the city. This gallery became the Winnipeg Art Gallery, famous for its early collection of Inuit carvings. Winnipeg became the capital of Manitoba and the seat of the provincial legislature.

\section{Development of The Downtown}

The development of Portage Avenue as a premier retail location began with the construction of the Eaton's building in 1905. It was so successful that an additional floor was added within a year of the store opening. ${ }^{16}$ The Hudson's Bay Company (HBC) was delayed in building its planned department store on Portage Avenue by the recession and World War I. By the time the store was opened in 1926 the south side of Portage Avenue was well established as the dominant retail strip. The HBC store marked the western edge of the business district and helped to raise property values. "Indeed by the end of the 1915-45 period, both sides of Portage Avenue were lined by variety, specialty and department stores, many of them in separate buildings, but others occupying the ground floor of office structures" (Lyon and Fenton 1984: 96).

The downtown of Winnipeg had developed along the bullock tracks and carriageways of the original township without any kind of planning or design consideration. Businesses would

\footnotetext{
16 Lyon and Fenton, 1984:93.
} 
close or relocate, leaving vacancies and perpetuating the spread of retail activity over long stretches of the downtown. ${ }^{17}$

The effects of decentralization were most evident after the establishment of suburban developments in 1948 and compounded by a policy to build six regional suburban shopping malls, five of which were completed by $1969 .^{18}$ The opening of the Polo Park Shopping Mall on Portage Avenue in 1959, three kilometres outside the central business district, in combination with growing suburban retail strip malls, had a deleterious effect on downtown retail business which was estimated to represent only approximately 21 percent of Winnipeg's retail sales in 1982. Winnipeg suffered the fate of many North American cities where the centre declined as the suburbs boomed."The decade 1950 - 1960 was one of the most vigorous growth periods in the history of Greater Winnipeg. During that decade the metropolitan area grew by an average of 3.4\% per year" It then declined - in the 60's it averaged $1.35 \%$ per year, 70 's averaged $0.8 \%$ per year, first half of 80’s 0.5\% per year" (Levin 1984: 23).

In Canada the 1980s were a time of rapid development of the suburbs established after World War II. By the 1970s growth in Winnipeg was almost at a standstill. As retailers moved to the suburbs, empty shopfronts became a plague in the North Portage area, sapping the vitality of the city and decreasing the public perception of safety in the downtown area. In response to this perception of a dying and dangerous downtown, a number of prominent business people came together to discuss the issue and proposed possible solutions. Federal and provincial governments supported major revitalization and planning solutions in Winnipeg. The result was one of the nation's largest and most notable regeneration efforts, the Core Area Initiative (CAI) launched in 1981. "Spanning a decade and reflecting unprecedented tri-level governmental cooperation, the CAI was considered to be a unique and notable experiment in public policy and drew considerable attention throughout North America and Europe" (Layne 2000: 249-50).

The CAI took an integrated approach to community development with a focus on employment and economic development, physical renewal, training and education.

\footnotetext{
17 Ibid., p. 98.

18 Ibid., p. 100.
} 
It represented a unique opportunity to create a development funded over the longer term. The CAI had representation from three levels of government: the city, the province and the federal government. The committee was struck to strategically invest $\$ 196$ million dollars in focused urban development over a period of eight years. The CAI investment acted as seed funds for over $\$ 300$ million dollars from the private sector for retail, commercial and residential urban development. $^{19}$

The North Portage Development Corporation (NPDC) was incorporated in 1983 with a specific mandate to provide a mechanism for implementing the redevelopment of the North Portage area, seen to be the most in need of redevelopment, through a combination of investments by the corporation, private sector, institutions and government. Lyon and Fenton summarize the significant components of the desired redevelopment. The official Metro Development Plan (1968) identified a number of issues such as need to have residential development in close proximity to retail, office and open space in the downtown.

\section{Investors Group Limited}

The Investors Group today is IGM Financial Incorporated, a Canadian financial services company with $\$ 120.7$ billion in total assets under management as of December 31,2012 . It is a publicly traded subsidiary of the Power Corporation of Canada, a major financial services provider and one of the country's leading mutual fund firms. The company has grown exponentially since its establishment by appealing to the growing middle class as an unpretentious, egalitarian organization with a sense of civic responsibility. Investors Group has an established reputation as a good employer; offering employees low interest mortgages and stock purchase incentives and instituting exemplary employee recognition programs. They also have a strong record of civic responsibility, and community support and development: an example would be the construction of the Investors Group Field at the University of Manitoba as the home of the Winnipeg Blue Bombers football team.

The research associated with this project has been carried out with the co-operation of Investors Group. This Winnipeg-based investment firm specializes in mutual funds, retirement investments, mortgages and other long-term investment products. Its operational model is

\footnotetext{
${ }^{19}$ Levin,1984.
} 
founded on regionally based investment advisors who deal with clients face-to-face. The head office is the operational and administrative centre of the business and presents the face of the corporation to employees, consumers and the media.

IG has its origins in Investors Syndicate of Canada Ltd., which was incorporated through legislation in Winnipeg in $1940 .^{20}$ The company had operated as Investors Syndicate Inc., an offshoot from an American company of the same name, since 1926. Based in Minnesota, the company had been set up by John Tappan in 1884 to meet the needs of the salaried working class. He recognized the average person's mistrust of banks, and developed a weekly personal saving scheme with financial counselling, sold in the same way as insurance. The system was eminently successful and was transplanted to Canada in 1926. By 1940 there were 13 sales offices located in seven of the nine provinces of Canada (Jones 1993: 3).

Investors Syndicate of Canada Ltd. launched its first in-house financial product in 1941 and Canada's first mutual fund in 1950. The firm continued to market financial products and advice to ordinary Canadians."Building long-term relationships with clients is the best way to help individuals reach their financial goals at each stage of their lives" (IG website, September 5, 2012).

Investors Syndicate of Canada Ltd. completed the company's first purpose-designed head office on 280 Broadway Avenue in 1956. Designed by Winnipeg Architects Moody and Moore, the building incorporated a staff lounge and cafeteria. It was a four-storey modernist pavilion, with a floor plate of 17,000 square feet per floor to house a staff of approximately 187 employees. In 1963 the building was extended by three floors, to accommodate personnel growth and expanded financial services. This building is described in greater detail in Chapter Four.

By the 1980s the company recognized it had outgrown the expanded building and needed to find new accommodation that would allow a consolidation of functions and departments that had expanded beyond the Broadway address and provide for their continued strong growth. The Investors Group became a member of the Montreal-based Power Financial Corporation group of companies in 1986.

\footnotetext{
${ }^{20}$ Building Futures: A history of Investors Group by R.H. Jones explains the confusion about the exact year of registration.
} 
In 1987 IG employed 1,850 financial planners in 73 planning centres throughout Canada. ${ }^{21}$ In Winnipeg IG employed 822 staff at the end of 1986, located mostly in their head office but also housed in outlying office buildings. Chief Executive Officer (CEO) Art Mauro determined that their issue of lack of space would be best addressed with a new building on a prominent site representing the western boundary of the proposed new North Portage development site. Instead of expanding their existing premises on Broadway Avenue where they had accumulated adjacent land, Mauro, who was a board member of the NPDC and a booster for Winnipeg, saw an opportunity in the Core Area Initiative and the development of Portage Avenue to reposition Investors Group.

The potential site was located on Portage Avenue between Vaughan and Colony, across from the Hudson Bay retail store, and facing south towards the Legislative buildings. Mauro described the location as forming the apex of "a triangle of power" that included the big banks at Portage and Main and politicians in the Legislative building. ${ }^{22}$ The site would give the organization a significant visual connection to both. The CEO's office was to be located so it had a clear view to the Legislature. Investors Group negotiated a 100-year lease for the site, with North Portage Development Corporation retaining ownership of the site. Investors Group would fund the cost of developing the building designed to meet its requirements. The site was key in the North Portage Development Corporation plans to develop the north side of Portage Avenue; IG would act as the "western anchor" ${ }^{23}$ for the development, and as such would be the beneficiary of new housing, retail and services that were planned as intrinsic components of the larger North Portage development. In return Investors Group would bring a salaried population of 800 employees to the site, ensuring urban vitality.

The retail component, Portage Place Mall, was planned as a foil to the suburban retail malls that were springing up outside the city. The city mall would give downtown shoppers an undercover retail environment with free on-site parking and access to the major retailers, such as the Bay and Eaton's on Portage Avenue, via a network of raised walkways.

\footnotetext{
${ }^{21}$ Harry Mardon, "Year End Review," The Investor, in-house magazine, December 1987.

${ }^{22}$ Art Mauro, personal communication, August 2012.

${ }^{23}$ Ibid.
} 
Investors Group's commitment to playing a key role in the promotion and growth of the downtown was expressed through the process of designing, building and outfitting the 18-storey building. The building today remains largely as it was designed and completed 25 years ago. It was conceived of primarily as an investment property, with five floors to be sublet to a number of complimentary businesses such as the Royal Bank, a legal firm, stockbroker and travel agent. The provision of floor space beyond the foreseeable needs of the organization allowed the firm to continue to grow in good times, and the leasable space was quickly absorbed by the natural growth of the company.

\section{Globalization}

Very high interest rates and volatile deregulated financial markets marked the ' $80 \mathrm{~s}$ in Canada. The stock market crashed in 1982 and again in 1987, destabilizing real estate prices and mortgage rates and frightening investors. Remarkably Investors Group continued to grow through the 1980s, offering its clients a secure environment for their savings, experiencing very few layoffs, and by 1986 posting sales figures of more than $\$ 1.4$ billion, a 34 per cent increase over the previous year's sales. Investors Group had been slowly growing its global reach. It started with an IG International Mutual Fund in 1962 and developing its first offshore fund in 1971 with investors Japanese Growth Fund. Investors Group Investment Management Ltd. opened offices in Dublin in 1993 and Hong Kong in 2000. Globalization and the opening up of financial markets had a huge impact in the 1980s.

Globalization' seems first to have acquired its prominence as American Express advertised the global reach of its credit card in the mid-1970s... The term then spread like wildfire in the financial and business press, mainly as legitimation for the deregulation of financial markets... And by the mid-1980s it helped create a heady atmosphere of entrepreneurial optimism around the theme of the liberation of markets from state control. It became a central concept, in short, associated with the brave new world of globalizing neoliberalism.

(Harvey 2000: 13)

Entrepreneurial optimism was in evidence in North American corporate office design. The post-modern '80s were remarkable for lavish and extravagant corporate headquarters. Reception areas, executive offices and boardrooms of this period were distinguished by custom furniture and rugs and wall panelling made from rare exotic timbers, imported marble floors and walls, 
mirror and glass used in furniture, and chrome and brass finishes and inlays. The effect was often ostentatious, theatrical and extravagant, reflecting a post-modern aesthetic of luxury and sensory extremes that symbolized the new optimism evident in companies competing in the open market environment established under Neoliberalism. Companies used design to differentiate themselves in the market; corporate identity was established with graphic logos and a corporate vision, which became essential components of a competitive organization. The appearance of the building and its interiors created an impression for clients and employees. The reception area, executive offices and boardrooms were considered a measure of the substance and success of the business itself.

\section{Mauro's "Act of Faith"}

In comparison to many corporate executive spaces built at this time, the new Investors Group head offices were restrained and conservative, reflecting the values of both the enterprise and the Board of Directors. They did, however, recreate the new logo that represented Investors Group and carved it into the Texas red granite that clad the structural columns.

The Financial Post reported, “Winnipeggers call the 19-storey tower Arthur Mauro's act of faith" (Wells 1987). Investors Group had chosen to establish its head offices in Winnipeg, Manitoba, conveniently located centrally in Canada, and with a contemporary architectural tradition of modernist restraint. Its decision to be remote from the Bay Street stock markets in Toronto was made at a time when communications between cities were being opened up by improved telecommunications systems and early data networks. IG saw an advantage in being in a time zone one hour removed from the heat of the financial markets in Toronto and the pressures of financial decisions made with the herd. Winnipeg had a lower cost of living and a steady supply of employees, bolstered by strong migrant communities such as the Filipinos.

Mauro suggests the form of the iconic prairie grain elevator inspired the architecture of One Canada Centre. ${ }^{24}$ The design uses a controversial post-modernist architectural language that speaks to both the architect and the general public by referencing familiar, vernacular and historical building elements (Jencks 1977: 8). The building acts to advertise the strength and

\footnotetext{
24 Art Mauro, personal communication. 2012
} 
success of the company to its dispersed regional field agents, financial advisors and the public at large. One Canada Centre was designed to inspire confidence and trust in employees and investors alike, with consolidated training facilities and a large cafeteria to bring groups of people together for education seminars and events. "Our $\$ 37$ million headquarters building is a handsome symbol of the strength and stability of the company." ${ }^{25}$

Published in the Winnipeg Free Press in October 1987, Jonas Lehrman, Associate Dean in the Faculty of Architecture at the University of Manitoba, wrote a critique of the newly opened building, which headlined Out Of Place - One Canada Centre Presents A Pompous Image. Lehrman comments on the generally understated and monochromatic aesthetic of the modernist buildings that had previously formed the skyline of Winnipeg, buildings that did not call attention to themselves. One Canada Centre differs. "Most noticeable about the exterior is its Texas granite facing that has a warm, light red colour; this contrasts strongly with the green tint of the window glass and stronger green of the window frame itself and metal panel below "(Lehrman 1987).

Lehrman is offended by the post-modern move that brings colour to the façade and creates a termination of the building at a roofline that echoes pitched roofs. He suggests such novelty, although human nature, is unnecessary and superficial. This was not an unusual criticism of post-modern architecture. Lehrman finds there is a conflict between the state-of-art technology and building services, and the static floor plan and structurally simple architectural design.

Here we find little structural innovation, in noticeable contrast to the advanced heating, ventilation and air-conditioning systems that control the interior environment, and particularly in contrast to the extensive use of sophisticated computer technology upon which Investors Group depends. Many patrons like their building to stand out from its neighbours. Yet the static, symmetrical, almost pompous appearance of One Canada Centre seems at variance with the image expected of a flexible and dynamic company (1987).

Investors Group made no apologies, describing the building to employees in their in-house magazine The Cornerstone as follows: "The Investors building will present a solid front, stable, yet

${ }^{25}$ Harry Mardon, "Year-end Review," The Investor, December 1987. 
progressive. The most impressive feature of the new building is the grand...colonnade, a curved front three stories high. As the tower rises gracefully above, it will create a striking frontal effect, a fitting tribute to investors. ${ }^{26}$ The populist nature of post-modern design served Investors Group well, and the simplicity of the floor plate has allowed for necessary replanning of departments to be carried out with relative ease.

At the time the offices were planned, technology was advancing into the workplace with unanticipated speed. At the beginning of the planning process the company imagined one microcomputer would service four employees. By the time the building was completed some 18 months later, two employees shared a desktop computer. ${ }^{27}$ An employee interviewed for the inhouse magazine, The Cornerstone, noted somewhat prophetically, "No one can be sure how technology will affect us," says Sophie Melnychuk, assistant manager, New Building Project. "People won't just change jobs, their jobs will change too" (The Cornerstone, 7: 2 (February) 1986).

26 The Cornerstone, Vol 6, no. 9, November 1985.

27 Tyshynski, personal communication, 2012. 


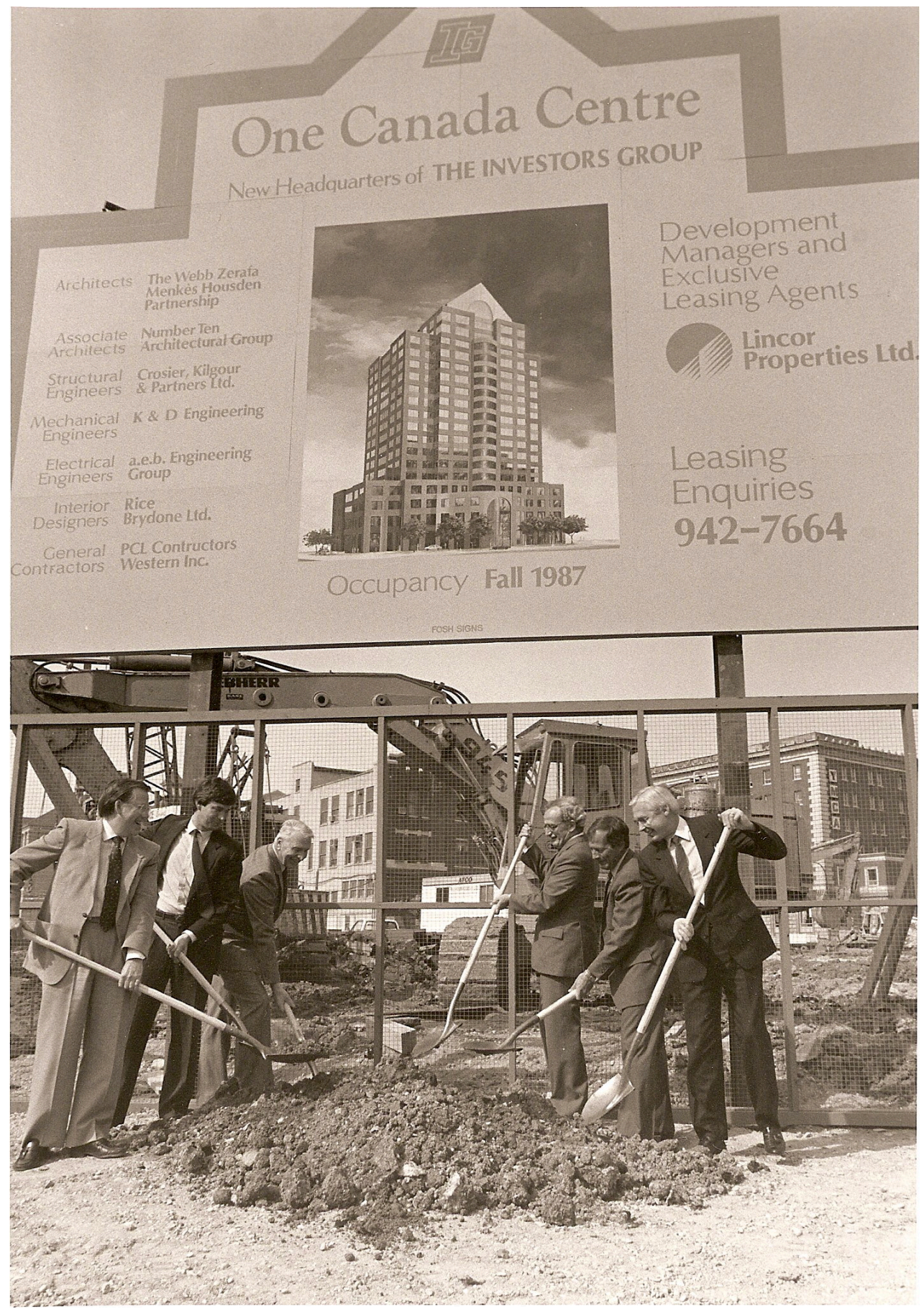

Figure 1. Sod Turning Ceremony for One Canada Centre (Investors Group Archives) 
One Canada Centre was designed to provide unprecedented access to the space of flows through the provision of oversize ducts and raceways that distributed the power and computer cabling through the core and around the perimeter of the building. This feature has enabled easy changes in the configuration of floors and the arrangement of offices and workstations. The computer system at the time the building was completed required the entire fourth floor of the building. It was provided with raised access floor and its own air-conditioning system. The elevators were staggered to give rapid access to all levels of the building with a separate elevator having access to basement parking.

Conceived of as a development project, Investors Group chose to work with the development firm Lincorp and Sam Linhart, with whom it had carried out another property development in Phoenix. The Phoenix project acted as a model for One Canada Centre. The developer brought a team together to allow for the most efficient design and construction process. The architects for the design of the building were a Toronto-based firm known for their successful commercial office projects, the Webb Zerafa Menkes Housden (WZMH) Partnership. Number Ten Architectural Group managed the construction project in Winnipeg. Rice Brydone, the Toronto interior design firm, was brought into the project from the beginning, having established a close working relationship with WZMH Partnership on previous projects of this scale. Insite Design were also engaged from the beginning of the project, as its parent company Business Furnishings Limited were long-time suppliers of Steelcase furniture to Investors Group and other office specialists. The collaborative team that developed from this unusual but productive arrangement enabled the project to move forward quickly, with close attention to budget and careful co-ordination of design elements. ${ }^{28}$

The floor plate for the building moved away from the deep office space more typical of North American office buildings designed in the 1950s and 1960s (Duffy 1976). The plan is at its largest at the base where floors two and three wrap around the large public atrium that is the primary entrance into the building. The atrium is three stories high, creating a curved drum at the Portage Street façade housing Warren Carther's soaring glass sculpture, "A Prairie Boy,"

\footnotetext{
28 Tyshynski, personal communication, 2012.
} 
installed in 1994. Floors four to 17 assume a rectangular floor plate with elevators, stairs and services located centrally, and the maximum distance from the core being approximately 40 feet. On executive floors 18 and 19 the floor plate is reduced considerably to provide a smaller footprint well suited to the executive functions of the organization. A staircase designed to be a focal point of the executive areas allows easy movement between the two floors.

\section{Technology}

Computers launched in the 1950s were vast lumbering machines, evolved from Turing's code encryption machine. They performed simple repetitive tasks faster than ever before, and instructions for each aspect of the task were punched on cards or tape in numerically based computer code. Word processors were first introduced in the 1960s as intelligent typewriters that allowed for the correction of errors and standard letter formats. The Visual Display Unit soon followed as the representation of the page on a screen with the printer trailing on behind, giving very rough draft quality to this leading edge technology.

Investors Group installed its first computer in 1961; an IBM 1401 with 8K (kilobytes) of memory. It cost approximately half a million dollars and was replaced only two years later by an IBM 7010 with $100 \mathrm{~K}$ of memory that was used to run Funds Shareholders Accounting and Investors Certificates. It continued in operation late into the '70s. A central network support centre was established at 288 Broadway to service Investors' new "nationwide communications network" dealing with installation, operation and software problems, as "regionals are now using the terminals for client and product information and fund statement inquiries". ${ }^{29}$ Storage of information was on five-inch floppy disks. The computer was still understood as an essentially clerical tool that was used by "processors", or as an adjunct to a printer.

Flextime, an innovative system of computerized time banking, was introduced to the head office in 1974, allowing employees to choose and track their own working hours. In 1982 the Legal Department at IG implemented computerized contracts. By 1984 the Client Relations and Corporate Communications departments were producing the Investors Group Annual Report and letters and notices to clients on new word processing equipment and a large laser printer. Fifty

\footnotetext{
${ }^{29}$ Focus: Network Support Services Group, The Cornerstone, Vol 6, no. 4, April 1985.
} 
regional offices were equipped with one terminal and a printer each for the production of product and client information in $1985 .^{30}$

In the 1970s and ' 80 s a dedicated computer room was still a fixture in the modern office at Investors Group, and was located on the fourth floor. The room was required to maintain a constant temperature and humidity for the computing equipment and was very often located on a raised floor to allow for the distribution of cabling from the central processing unit (CPU), and peripherals and the power supply to every piece of equipment. The floor needed to be able to support quite high loads, including mobile carts to move supplies and remove equipment for servicing and repair. The floor was also able to serve as a plenum for the distribution of cooled air. Walls were fire rated to safeguard the computer from an external fire on the floor.

Equipment such as paper-tape readers, card punches and line printers were quite noisy, and ceilings were usually dropped acoustic ceilings with gridded fluorescent fittings to maintain a constant lighting level. Computer rooms were fitted with smoke suppression devices rather than sprinklers to avoid the potential combination of water and electricity. It was also usual to have backup power and emergency lighting to deal with power and equipment failure. Computer rooms were the source of a great deal of sensitive information, so security systems were required to secure entrances and exits from the space and waste was shredded (Hutton 1976: 183-87).

The new head offices at One Canada Centre were designed to provide secretarial support for managers and senior executives as no one envisaged the possibility of computers becoming the preferred means of communication in all arenas of office work in the near future. Since the '80s the finance industry has become "the most digitized, dematerialized and globalized of all activities" in the economic sector (Sassen 1999: 116).

By the time the One Canada Centre building was completed in 1987, there was a dedicated computer complex on the fourth floor and half of the clerical workers in the building had a desktop computer. Two mainframe computers were used to run everything from clients' records to mutual fund histories. "One of these computers - an IBM 4381 - is moving directly to One Canada Centre. The other- an IBM 3090 - is being replaced by a brand new IBM unit that is larger and has more processing power" (Cornerstone August 1987). The computers were moved

\footnotetext{
${ }^{30}$ Progress in “The Cornerstone" Vol 6, no.1, January 1985.
} 
over a long weekend in October, two weeks ahead of the employees. The system had to be functioning by Tuesday morning at 8:00 a.m. to allow operations to continue at 280 Broadway. The 1980s were a time of rapid technological change, and desktop computing became a business reality when IBM released its first personal computer, the 5150 . The IBM reputation as a supplier of mainframe computers opened the door to major corporations. It had a DOS operating system that was clumsy to use, but within the decade it spawned a software revolution with business programs, spread sheets and word processing programs. When other computer companies entered the market, prices of desktop and laptop units came down and the pace of innovation increased. The floppy disk made storage easier and in 1984 Mac delivered its graphical user interface which lead to easily readable screens, Mac/PC compatible software development, and a much more accessible interface for all users. The computer continued down

the path already established by the typewriter a century earlier, and it allowed for the integration of functions such as writing and publishing and "the creation of much private independence" (McLuhan 1964: 259). As women took up typewriting, they also inherited the role as computer operators. The production of text had become a female domain.

\section{Conclusion}

George Nelson, product and furniture designer and teacher, gave a guest lecture in Toronto in 1977 on "The Office Revolution". He suggested that from his own broad experience there were three ingredients that could be described as the source of a coming revolution in the office: electronic developments, furniture and equipment as sophisticated industrial systems and products, and "the growing interest in what we might call humane working environments" (Nelson 1979: 153-59).

Discussing electronic developments, Nelson referred to the fantastic capabilities of new chip technology to reduce the size of future workplace technologies and lower prices to make them affordable. His firm had completed research for a telephone company about the form of the future office, which predicted technology could lead us into the electronic office as early as the 1980s. He spoke about the exponential acceleration of technological developments being tempered by a desire to improve the office to create more humane environments; environments 
"that are, amongst other things less monotonous" (1979: 156), where designers begin to ask questions about the ways people and work environments work together for the efficiency and satisfaction of all. "With human motivation and behaviour still a dark and mysterious area, anything we discover here is bound to have an effect on furniture and interior architecture, not to mention planning patterns. It looks as if a new breed of psychologist may presently be in demand" (1979: 159).

Nelson spoke about the scale of the office furniture industry and the need to move to industrial production for all scales of competitive furniture production. This shift called for the reinvention of office furniture as a system of parts. He pointed to Robert Propst's radical Action Office System as a leader in the field that had yet to be taken up by industry. Action Office was first designed in 1967 with the Quickborner's Office Landscape planning methodology as its inspiration.

In the 1960s traditional ways of operating had been challenged by counter-culture movements (feminism being one of them) such as the drug culture, the production of food, and healthy lifestyles that had moved society and caused businesses to reconsider their employees' well being, along with their increasing community and environmental responsibility. Nelson suggests the most significant responsibility for designers in the future would be the humanization of technology (1979: 159).

As Nelson reflected on the coming wave of change he captured the significant issues that were informing the design of offices into the 1980s, however like many commentators and critics he missed the significant demographic shift that had occurred in the 50s, 60s and 70s. There was a changing approach to organizational management structure that had become increasingly influential in the 1980s. It was premised on the management philosophy that had successfully rebuilt Japanese industry after World War II and involved working in teams with a flatter hierarchical structure. The philosophy was informed by a text written in 1941, by Mary Parker Follett, called Dynamic Administration. Follett was an early member of the Human Relations Movement who continued her career in Britain, after being largely ignored as a woman working in organizational behaviour. 


\section{CHAPTER FOUR}

\section{INSIDE THE OFFICE}

\section{Introduction}

In the 1980s North America saw a strong shift towards the commodification of office buildings. Real Estate investment moved the development of office space from custom or purpose designed buildings towards generic office towers that were built speculatively and tenanted by diverse organizations. "Custom designed buildings have given way to ready-to-use building shells which can be fitted out with off-the-peg components to meet specific tenant needs" (Worthington and Allan 1988: 2). Buildings conformed to an economic rationalism that determined a "shell, scenery and settings approach (Duffy 1976). The shell was designed to last 50 years and could see many changes of activity and occupant; the building services "have a life expectancy of probably 15 years, and possibly even less as the pace of technological change increases...The shell is adapted to a specific firm's requirements by [interior] scenery finishes, ceilings, light fixtures, furniture etc. [Scenery] typically has a life span of $5-7$ years depending on its specification, reflecting the style and function of the organisation" (Worthington and Allan 1988:3) .

Settings are the spatial and furniture configurations that represent the workspaces and public spaces for the human occupation of the building. Worthington explains this shift as the logical outcome of the need to accommodate rapid change brought by new technologies. "The result has been a shift from custom design buildings with tailored interior design layouts to loosely fitting, predesigned, ready to use shells with a flexible set of interior components" (Worthington and Allan 1988: 4).

The growth of services and administrative functions in the 1970s in North America saw significant change in the percentage of the population who were employed in offices. The growth of white-collar employees, including women, meant there was a 
need for design specialists who would closely assess organizational functions and future needs and design to allow for change.

\section{Interior Design Services}

Interior designers sought a close understanding of the whole organization, rather than the often limited perspective of the senior executives, and were able to provide design responsive to their clients' organizations. The interior design industry developed and grew in response to the need for knowledge of, and sensitivity to, the connectedness of disparate elements within a corporation; and the willingness to spend time in the client organization interviewing employees and valuing their experience.

Florence Knoll (1917), who was educated as an architect, brought a rigorous and systematic programming approach to the design of corporate offices that was significant in the movement towards the professionalization of interior design. The Knoll Planning Unit (1943-71), led by Florence Knoll until 1965, were responsible for some of the most iconic post-war corporate office projects, grounded in "painstaking analysis and organization of functions as a basis for interior design" (Rae 1999).

The Knoll Planning Unit's scope of services, defined in the early 1950s, is still used in current practice, representing a radical departure from interior decoration services then in vogue. Client operations were studied and analysed in graphic and written form. Personnel and equipment were surveyed. Interdepartmental relations, work and traffic flow were studied through the process of interviews with executives and department supervisors. A preliminary space plan was developed, and the character of the interiors was established in consultation with the client, and the building architect. Study models were constructed and materials were studied, interior and exterior materials were coordinated with the architect. Mechanical and communications elements were evaluated and integrated into the plan. Engineering and shop drawings were checked. All finishings and furniture were selected, and recommendations made for the functional and unobtrusive placement and design of all special 
equipment. Construction observation services were provided as was the installation of all furniture and furnishings. Maintenance manuals were also provided. (Wilkes 1989:109-10)

Professionalism and attention to detail became the hallmark of good practice in contemporary interior design services around the 1980s. It gave designers a rigorous method with which to develop detailed knowledge and understanding of the specific enterprise being researched, and to influence and work with clients in all sectors of business. This method underpins the work of Rice Brydone, the interior design consultant for the Investors Group interiors, and is celebrated in their office publication The Corporate and Professional Office: Organization and Design, the Double Discipline (Rice Brydone 1983). The book is a glossy coffee table book, illustrated with projects prior to 1983; it sets out the role of the interior designer in a commercial project as a symbiotic union of two disciplines, creativity and organization. The text explains, "A designer is directly concerned with facilitating useful and logical work relationships, beginning with people and translating their requirements into spatial ones for performing daily office functions, receiving and meeting business associates and housing technical operations" (13-14) and "responding to human needs involves more human solutions for living with high technology, a softening of the hard edges of the office experience, the balancing of high tech... with high touch" (27).

Architects, for the most part, scorned this aspect of design for the workplace and distanced themselves from the messy human face of office design. In fact, as office buildings became more generic the architects' role in the design process was greatly diminished. Worthington makes a plea to architects to pay close attention to the details of workplace design but many architects in the UK and USA felt workplace was not sufficiently challenging or creative to be worthy of their attention.

Architects may expect to find themselves competing with 'design and build' services, and product suppliers who provide an advice and installation service. If architects wish to continue to work in this field they may need to adapt their skills and services to compete. (Worthington 1988: 2) 
The gap was filled quickly by interior designers, furniture suppliers and office planners many of whom morphed into facilities managers in the 1990s.

The architects' role was to design the building shell and co-ordinate the services with the building engineers, while the finishing of the building was turned over to interior specialists.

\section{Feminist Standpoint Theory}

The interior design profession has operated as a handmaiden to architecture, with architecture as the traditional "masculine" profession of the built environment, and interior design as the "superficial" feminine newcomer. The $20^{\text {th }}$ century saw the commercialization and professionalization of interior design, much of it due to the increasing complexity of commercial interiors. However "the duality that places architecture as the dominant term in a binary opposition with interior design remains largely deconstructed" (Havenhand 2004:33).

Lucinda Havenhand, an interior design academic and theorist, discusses the problem of interior design as a profession dominated by women and gay men. She asserts that interior design has yet to examine its marginal, feminine and "other" position, and calls for a reconsideration of the feminine through second wave "feminist standpoint theory". Standpoint theory recognizes the gendered construction of knowledge and reverses the negative connotations associated with the feminine.

"Feminine knowledge and characteristics are valorized, not as mere inversion of the binary opposition, but as a starting point for a new understanding of knowledge" (Havenhand 2004:36). Havenhand cites Donna Haraway as an advocate for subjugated standpoints which "are preferred because they seem to promise more adequate, sustained, objective, transforming accounts of the world" (Haraway 1988: 583).

Most useful for the subject of this dissertation, Havenhand introduces the work of feminist architect Karen Franck. In her essay "A Feminist Approach to Architecture: Acknowledging Women's Ways of Knowing," Franck establishes specific "feminine" characteristics that will provide a critical framework for this research project and its 
analysis. The framework is not without flaws as it suggests a set of gendered universal values associated with women's ways of knowing that might be seen as an instrumental or essentialist view (Allcoff 1988). However, it provides a subjective and embodied entry point to the re-examination of office space from the perspective of gender.

The qualities Franck develops as characteristic of "women's ways of knowing" are the following:

The underlying understanding of the connectedness to others, to knowledge and sensitivity to the connectedness of categories. Franck asserts women's self-identity is formed through connection to and identification with everyday experience. As a consequence women tend to look for connections rather than dichotomies; "boundaries between categories such as public/private, work/home, and male/female tend to be broken down in women's ways of knowing" (Havenhand 2004:39).

Desire for inclusiveness. Franck explains that this characteristic is reflected in a feminist design approach that blurs distinctions between client and designer, designer and user, and programmatic distinctions such as spatial typologies and subjective and objective knowledge. We can recognize Florence Knoll as using this strategy in developing her approach to the programming of corporate projects.

Ethics of care and responsibility to the needs of others. Franck also proposes that the ethics of care is more likely to inform decisions made by women, with men tending to make decisions informed by the ethics of justice. "Women and girls draw upon a reflective understanding of care requiring that no one be hurt and that one respond to the need of others, whereas men and boys are concerned that everyone be treated fairly" (Gilligan, cited in Havenhand 2004: 296). Designing that acknowledges the ethics of care would tend to consider the individual and the subjective needs of the user before applying universal design standards.

Acknowledgement of life and experience and the value of everyday life. The focus of women's contribution to design reforms has consistently been motivated by everyday life, examples would be social and urban reformers such as Clare Cooper Marcus and 
Jane Jacobs, and designers such as Eileen Gray and Florence Knoll who brought design attention to the mundane details of living through their design projects.

Acceptance of subjectivity and feelings as a strategy this attribute would manifest itself in the design process as an acknowledgement of personal feelings and subjective knowledge as valuable in contrast to rational and scientific ways of understanding the world.

Acceptance of and desire for complexity. This could potentially undermine hierarchical control and suggests participation from the users is characteristic of women's ways of knowing.

Acceptance of change and desire for flexibility. This might manifest itself as valuing multiple voices in the design process, embracing the need for change and design for robust and flexible spaces and needs.

I use these qualities of women's ways of knowing as established by Franck in relation to designers, to develop a frame of reference to inform a discussion and evaluation of the design of office environments with consideration of women workers. Havenhand makes the connection between second wave feminist ways of knowing and the interior designer's role in the creation of close space. "Interior designers focus on the intimate movements, needs, and emotional concerns of the users of interior space, as individuals and in connection with others. Good interior design creates a kind of 'second skin' or prosthetic that facilitates or reflects not only the functional needs of its 'wearer' but their emotional, personal and spiritual needs as well" (Havenhand 2004:40). The framework that Franck develops becomes a useful way to analyze and discuss office interiors and plans, furniture configurations and organizational structures in response to women's practices and values.

I begin by looking at the masculine modernist office that served as Investors Group's (IG) first headquarters in Winnipeg. 


\section{Broadway Ave Head Office}

In February 1957 Life Magazine published Walter Sanders' photographic essay "The Many Different Lives of an Office Building". The essay was organized chronologically and spatially to capture a life in the day of the occupants of 260 Madison Avenue. As a visual and textural source it is useful for understanding the gendered culture of the office of the 1950s and 1960s. Discussing the images Williams, a professor of Visual Culture at Edinburgh University affirms "Men are the doers in all of this, making decisions, holding the meetings, getting the girls. Women feed, decorate, entertain and support" (Williams 2013:99). One image is of the boardroom of Mathes Advertising Agency where the men make serious decisions, whereas women's work is represented by "conviviality and a shower", an image of "groups of women secretaries in lighter moments of socialization (coffee with friends, a surprise shower of gifts for one of the group)"; and another image of a secretary trying to escape her boss at the end of the day is titled "thwarted escape".

The sexual politics of this Life feature are always explicit. This is a world in which men are active, and women passive, in which men do things and women support them. Men wear suits and hats, stand upright, smoke and make decisions; women are the figurative and literal bustle around them. If [the] Seagram [building] was the ideal built representation of normative sexual politics of the era, an upright male figure, surrounded by attentive females, then here is the mundane reality of that representation. Men are always bigger, taller, harder, more assertive and visually bolder. Women are the rococo detailing, pretty but not structural. (Williams 2013:99).

Williams provides a context for understanding the admittedly less glamorous, but equally hard line modernism of IG's first headquarters in Winnipeg.

Moody and Moore were the architects for the original headquarters on Broadway constructed in 1956. It was a four storey modernist pavilion, with a floor plate of 17,000 square feet per floor to house a staff of approximately 187 employees. Moody and Moore also designed an extension to the building in 1963; three floors to accommodate personnel growth, and expanded financial services. The furnishing was carried out by the department store Robert Simpson Company. The executive floor was 
relocated to the new seventh floor with extensive views across the city through full height glazing around the entire perimeter.

Interiors of most individual offices are in American black walnut and vinyl wall covering. Storage walls between offices are designed as a series of oiled walnut panels, some of which are hung on concealed hinges, providing a continuous panelled wall without visible hardware. All interior panelling is premium quality veneered plywood, quarter cut or flat cut, centre matched and sequence matched with Danish oil finish and solid trim and edges. (Western Construction and Building.1963:7)

The building on Broadway reflected modernist principles and featured interiors with typically spare spaces, restrained modernist detailing and contemporary furniture all locally sourced. Only the president and the vice president's offices were furnished more traditionally. The reception and executive areas featured timber-panelled walls, terrazzo floors and minimal decoration. Departments were individual fiefdoms with oversized suites for management. They were compartmentalized, competitive, and quite separate spatially and operationally (Archer 2012: pers.comm.; Tyshynski 2012: pers.comm.). Clerical spaces, occupied mainly by women, were characterized by the open 'bullpen' or secretarial pool, with bulky metal desks in formation, and secretaries located outside management offices that ranged around the perimeter window walls consuming the views and the natural light (Tyshynski 2012: pers.comm.).

The seventh floor - which is the top floor of the extension - was designed to accommodate the executive offices of the company. These are all partitioned offices with room in the centre for the stenographic pool. The sixth floor includes 17 private offices on the perimeter with again, central stenographic and clerical areas. The fifth floor is largely clerical and general office space with a limited number of individual offices (Derksen 1963). 


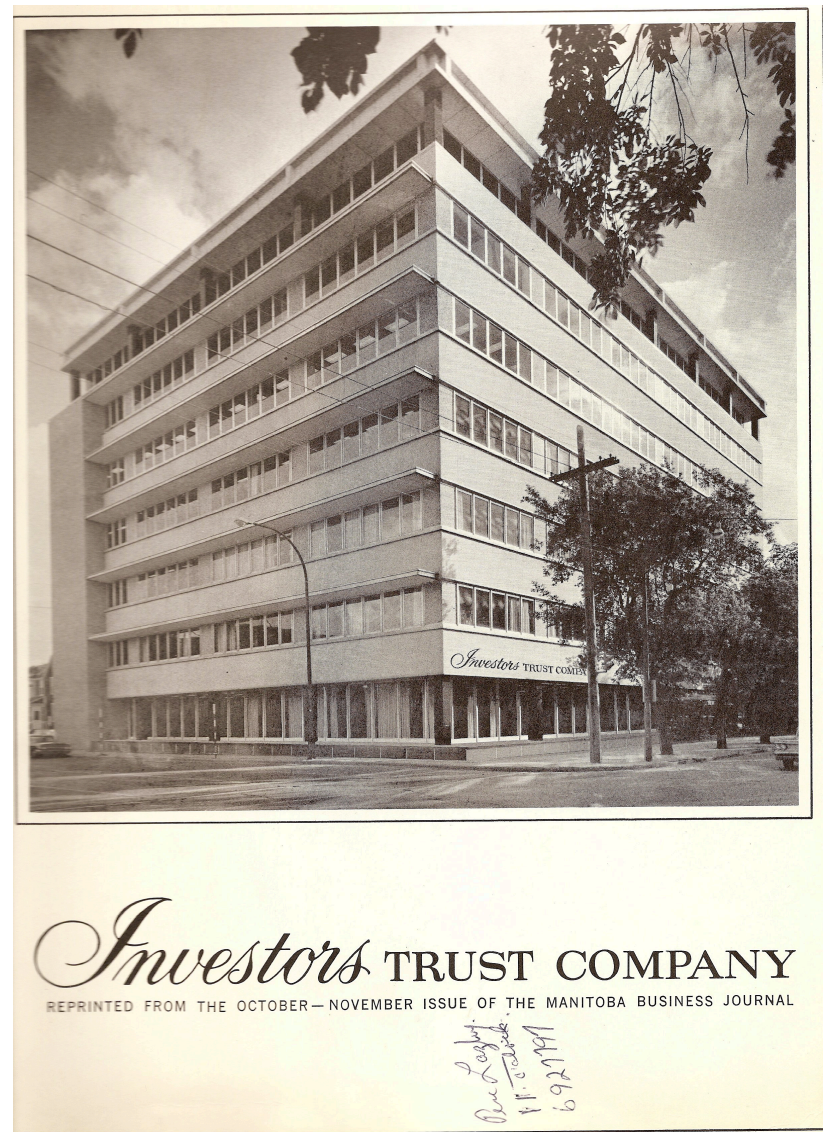

Figure 2. Investors Group head offices in 1963 after the addition of three floors (Investors Group Archives)

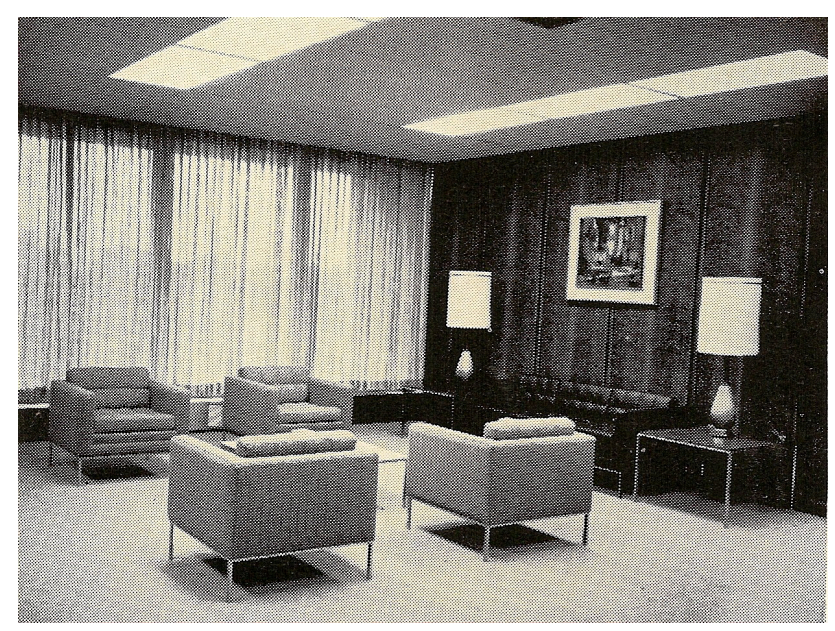

Figure 3. Executive office area in 280 Broadway Avenue (Investors Group Archives) 


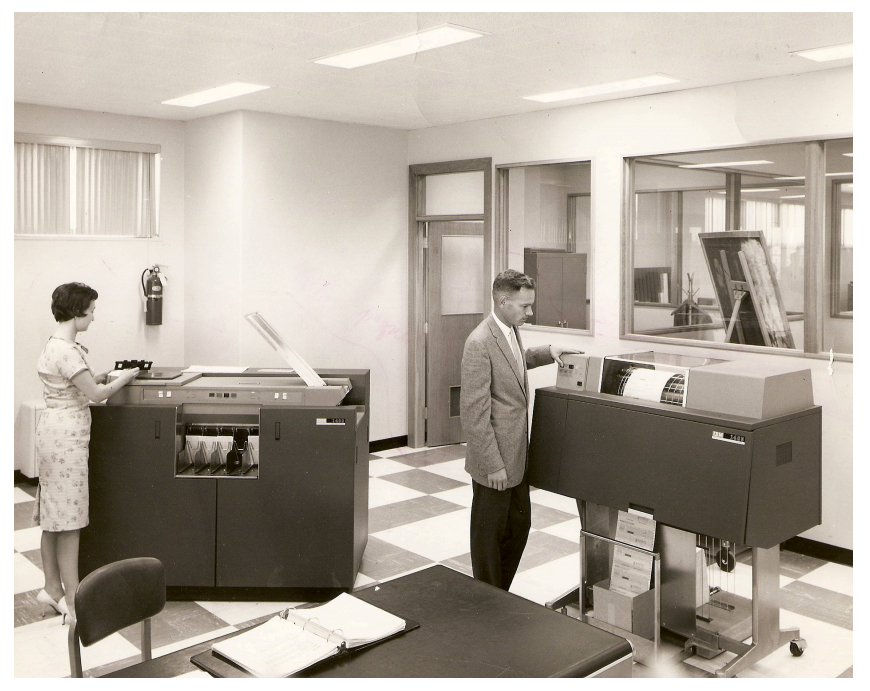

Figure 4. Investors Group first computer in 1959 was an IBM 1401 (Investors Group Archives)

The fourth floor became the data processing department and housed IG's first computer.

Prior to One Canada Centre, the work culture of Investors Group had developed as independent and autonomous departments located in segregated and spatially separated regions in the Broadway office. The new location One Canada Centre was planned to represent a new culture with better communication and transparency between work units, with consistent space and furniture standards for similar job titles, common to all business units. The company moved from a feudal system to a republic.

\section{Organizational Culture}

By the 1980s organizational management philosophies had shifted towards less hierarchical office structures due to the need for better internal communications and the introduction of desktop computing which gave employees greater access to information. The global economy was faster and competitive; it required better communications within the company and with the outside business community. This shift represents the beginning of the flows of communications, capital and people that Castells (2000) captures in his theorization of the space of flows. Significantly the new office planning for One Canada Centre moved strongly away from the masculine hierarchical environment that had represented its Broadway facilities, to an 
organizational model developed in consultation with the interior designers and architects for the new building (Archer 2012: pers.comm.).

\section{New Strategic Plan}

In the 1980s amid the turmoil in global money markets, Investors Group's board and management were experiencing a renewal. With key retirements and a restructuring of its relationship with the Power Corporation, IG began its five-year restructuring process by developing a new focus. The three core values for the organization were quality in product design and delivery; responsiveness to needs of clients, the field force, employees and shareholders; and integrity in all their dealings. IG shifted the focus of its operations away from product towards service, and gave new importance to the efficiency of the operations division. The plan included reorganization of management roles and responsibilities, expanded training for employees and a new emphasis on data processing and information distribution systems. Arthur Mauro, the new Chief Executive Officer in 1984, saw the opportunity to design a new building to reflect the revitalized organizational structure. The move was promoted amongst employees as an opportunity for Investors Group to participate in and commit to the redevelopment of downtown Winnipeg, and the building moved quickly from an idea to a reality. It was announced in 1985 and occupied in late 1987.

Eleanor Brydone explained, "Art [Mauro] led the project, his strategic plan for the organization drove the design. The new building was to inspire financial confidence. It was to reference Winnipeg history and look to the future." Brydone spoke of the clients' desire to move away from traditional timber panelling and benefit from Rice Brydone's experience as the designers for the Toronto and New York Stock Exchanges, Canada Permanent and various brokerage houses (Brydone 2013: pers.comm.).

Investors Group employed a team of consultants which included the architects, engineers, building contractors, interior designers and furniture suppliers; an unusual and highly efficient team who used an integrated design process to move the project 
forward. ${ }^{31}$ Rice Brydone was responsible for the co-ordination of the interiors in the building and established the space requirements and protocols for office size and allocation after carrying out an extensive survey of each employee's workspace and equipment. The survey of $575 \mathrm{IG}$ employees formed the basis for establishing norms for workspaces that were generous and exceeded the ergonomic requirements considered standard at the time. " 32 It was the third largest survey ever undertaken by organizers Steelcase Ltd and Business Furnishings" (n.a. 1986: 7:2).

Anita Jones, the site manager for Rice Brydone, remembers that the consistency of office sizes was unusual for the time. Attention to the users' needs lead to the development of small private offices with a "work wall" dividing them, and assistant managers were allowed to determine the layout of their own offices. The work wall was also employed in the manager's offices where the power and telephone cabling and storage elements such as a coat cupboard and filing storage were located. The desk could then be chosen to suit the occupant, and some managers' offices had tables rather than a more formal desk. This was a significantly different approach for the time (Jones 2010: pers. comm.). Managers were encouraged to participate in the selection of furniture and the configuration of their offices, reflecting an acceptance of the everyday experience of the employees at Investors Group and a desire for flexibility and the capacity to accommodate change, all qualities that the design team brought to the project of the new headquarters building. These new ways of thinking about the design of office spaces, can be traced back to the early process work of the Knoll Planning Unit, where all employees were considered important in the satisfactory resolution of a planning problem.

Inconsistencies in position, rank and spatial allocations inherited from 280 Broadway were adjusted to provide more equitable working conditions for all staff. Rice Brydone suggested moving away from a typical floor with offices lined up around the perimeter and a bullpen for the clerical employees; offices were grouped together

\footnotetext{
31 "The Cornerstone", October 1990 Vol 12, no 9.

32 Art Mauro personal communication.
} 
with smaller clerical workstation clusters located around them. ${ }^{33}$ The main objective for the project was to achieve a better quality of air and light for the employees, so much of the floor plate at each level was open at the windows, housing workstations. Typically the South side of each floor is planned with a meeting room or two and the offices of managers for the units located on the floor.

Many employees were relocated from offices to workstations in the open area.

To ease concerns about privacy higher screens and wider circulation routes were provided to create more acoustic separation for these employees.

A five-foot-wide corridor encircles all floors with private offices located on the outside perimeters. Common work areas are located near windows, to allow the flow of natural light. Two large meeting rooms and a large reception area give each floor spacious comfort. The carpet in the main lobbies are a blend of colours, with each floor picking up one of the five colours in its granite, chairs, carpet and possibly even table-tops. Workstations are standardized, according to job function. A manager's office takes up 200 square feet, but it doesn't necessarily incorporate standard office furniture. For maximum flexibility some offices are built of drywall, others of easily moveable, functional and private, acoustic [work walls]. Opening or closing one or both panels lets you be completely open or unavailable to visitors. Built into the [work walls] are bookshelves, filing units or coat racks. The goal is to use space effectively. The floor plans are designed to accommodate changes and growth.

(The Cornerstone 1986: 3)

Worthington (1988) advocates for wide corridors as an alternative to private offices

allowing for occupants of cubicles to hold private conversations without being overheard. Today a more typical solution would be artificial sound (white or pink noise) used to conceal conversations in open office areas.

\section{Clerical Workstations}

The design of the open office space was typical of the office typology of the 1980s. It had suspended acoustic ceiling tiles with flush mounted fluorescent light fittings and fitted carpets, the perimeter windows that provided daylight into the space were large fixed windows with venetian blinds for light control.

\footnotetext{
${ }^{33}$ Dick Archer personal communication.
} 
The layout of the clerical workstations on each floor of IG was developed by Insite, the furniture contractor for the project and approved by Rice Brydone. The amount of consideration given to individual needs would have been based on the employee survey and the development of standard workstation configurations, but clerical employees would not have had a say in the type of furniture selected or their preferred working configuration. In the financial services industry clerical workers are often contract employees and considered replaceable. Their workspaces are subject to higher levels of churn, as teams are assembled and broken up as seasonal work flows through the offices. Workstations for routine clerical workers at IG are Steelcase Lshaped desks where the computer screen is most often accommodated in the crook of the $L$, acoustic panels modules are generally 42 " high by 30 "to 45 "wide giving some definition to the boundaries of the individual's workspace. This height allows very little visual privacy and is used in areas where team working is encouraged or required. The workstations of the women clerical workers are larger on the sixth floor than the second floor. All desks are 70 " by 30 " and spatial allocations are a total area of 46.8 square feet on the sixth floor, on the second floor 39 square feet is typical. The most desirable locations in workstation configurations are usually at the ends of a row, where a window wall creates a more private space or a corridor provides more social interaction.

Higher screens and banks of filing storage are often used to define the boundaries of team areas. Access to client and project files became more functionally distributed at this time, in alignment with greater availability of information critical to the operation of units. The management of paper was a big issue at Investors Group, as it was in many other organizations before the advent of floppy disks and CDs. Banks of filing had to be located on the structural grid or extra reinforcement was required to be included into the floor slab. Filing cabinets and storage furniture is beige, carpets are neutral, and the environment is flooded with natural light that has to be managed with venetian blinds on the east, south and west facades. This means the view is often obscured or completely shut out, defeating the best intentions of the organization to provide natural light for employees. 
The clerical spaces are drab and cluttered, lacking focal variation, colour or interest. The service areas such as meeting rooms and lunchrooms that were provided when the building was designed are now too small or have outlived their original purpose. Meeting rooms are too formally located on the plan to encourage impromptu meetings and the lunchroom is a small space that would only accommodate a few employees at one time. The provision of these ancillary spaces was quite innovative at the time the building was designed and their purpose was to encourage team working and regular meetings that would improve internal communications. Placing a lunchroom on each floor allowed employees to take a break when it was convenient rather than a scheduled time. There is a telephone room that is rarely used now. It is a windowless room the size of a closet where a phone was provided for personal calls. This was necessary because many clerical employees have desks without access to a phone and taking personal calls during working hours is not encouraged

\section{Criticism of the Interiors}

In his article in the Winnipeg Free Press, at the time the building was opened, architecture critic Jonas Lehrman dismisses the Investors Group building as pompous and out of place in Winnipeg, but he saves his sharpest critique for the interiors of the building. "The decor of the executive areas, selected by a firm of interior designers largely independent of the architects, seems to revert to a nouveau riche eclecticism that by comparison makes the exterior of the building seem positively risky" (Lehman 1987).

Lehrman's concern is two-fold; he perceives the interiors were not the work of the building architects, breaking with the established tradition in modernist architecture. He also asserts that the architectural aesthetic is not carried into the interiors; which would have been reflected with more contemporary furniture and finishes. He was, no doubt, surprised to find traditional furniture, juxtaposed with contemporary art and a pastel colour scheme on the executive floors (see Appendix 2). He didn't comment at all on the configuration of the open office areas. 
In my opinion, the two executive floors strongly reflect 1980 s post-modernity, with references to classical form and detailing in elements such as the oversized dentil mouldings at the cornice, proportions of the door openings and the symmetrical planning of floor layouts. These classical references are contrasted with a palette of pastel hues in wall colours, details, and textiles with contemporary painting and sculpture that evoke a lighter and less masculine environment that is also a feature of the postmodern office design of the period. Leone Glenat, a young designer working for Insite Design at the time, remembers:

A year or so after the Investors project was completed Eleanor Brydone told me that their inspiration [for the colour palette] for the interior design was based on Manitoba sunsets. Eleanor said that when she and her design team came to Winnipeg, they were amazed at the colors of the sunset skies and incorporated these colors into their concept for the interior. This explains the original finishes on the $18^{\text {th }}$ and $19^{\text {th }}$ executive floors, which had an abundance of lilacs, as well as reds and light and dark greens. The remaining floors had white wood desktops and tables but the wood pedestals, chair fabrics and carpet inlays were different colours on each floor. There was a green floor, red floor, purple floor, yellow floor and an orange floor. As there were originally ten non-executive floors that Investors occupied, Rice Brydone repeated these floor colors on the remaining five floors. In the open office, the Insite team continued with this concept and selected white furniture systems with tackboards and chairs in the color theme of the floor. (Glenat 2012)

\section{The Executive Floors}

The executives occupy the $19^{\text {th }}$ floor with the CEO and the chairman's offices. The boardroom and the dining room were located on the $18^{\text {th }}$ floor. These spaces were designed to provide a "quiet elegance" ${ }^{34}$ with traditional furniture in a contemporary environment accented by exotic timber furniture and doors and specially commissioned rugs from Israel. Today the Investors Group art collection, representing many significant contemporary Canadian artists, is displayed through out the building, including the newly renovated cafeteria.

The executive offices, designed by Rice Brydone, assumed a warmer, less formal aesthetic than their previous timber panelled space, providing more colour and comfort,

\footnotetext{
${ }^{34}$ Anita Jones, senior designer Rice Brydone, personal communication.
} 
luxury and softness than was typical of the workplace during the modernist period. The public interiors on the $19^{\text {th }}$ floor provide elegant and quite spare spaces that reference the conservative traditions of the banking industry but with a less gendered frame of reference. Executive offices were furnished to suit the taste of the individuals concerned and most often contained traditional dark wood desks and bookshelves with wing back chairs for lounge seating, which may have been reused from the Broadway offices. Seating in the public spaces of the executive floors are contemporary club chairs with button tufting, upholstered in lilac grey leather. They are juxtaposed with drum tables of dark walnut timber with white marble tops (see Appendix 2 for images of the executive floors).

The proportions of the space emphasize the horizontal, with artwork placed quite low on the walls and door openings framed by the strong horizontal dentil banding at the ceiling. A suggestion of columns is created to frame larger openings by the placement of vertical moulding and emphasis with a darker paint colour. Lighting is generally recessed spot lights. Key transition zones are framed at the ceiling to create an atrium effect with a wash of concealed light, giving the space atmospheric variations of lighting levels. A similar ceiling detail is created in each lift lobby and on the walnut floors beautiful custom designed rugs announce the two executive levels.

The secretarial units located outside the senior executive offices were custom designed workstations that included built-in filing storage, desks and low-height partitions all finished in pastel colours reflecting the wall colours. They were topped with pyramidal forms that that created quite heavy design elements, and stopped the accumulation of files or plants. It is interesting to muse about their design of these units and who it was thought to serve. Was this a request from the senior executives or a designer's idea of a method for controlling the accumulation of visual clutter in these prominent workspaces? The workstations were designed for the women whose jobs were to support and attend to the needs of the male executives. As their roles and their numbers diminished with the onset of technology some of the workstations were 
removed. It seemed that they were the least successful aspects of the interior designers' concept and they were replaced with very traditional dark timber furniture.

A recurring square grid detail references the external façade of the building. It is found in the pattern of squares in the lobby rugs, the dentil moulding at the ceiling, the coffering in the boardroom ceiling and above the open stair connecting the executive floors. The square motif reinforces the postmodern design language of simple geometric forms that are used consistently in the building.

\section{Typical Floors}

The floors 17 and below also reference a postmodern architectural language by using materials and detailing compatible with the simple geometry of the building. The elevator lobbies are designed to present a consistent image to the visitor with only the principle accent colour varying. The plan is repeated from floor to floor. The reception area is located on the south side of the building and has built-in bench seating, a reception counter and noticeboard. The focal point of the Lobby space is daylight filtered through the glass screen wall of the meeting room positioned to enjoy views to the south of the Winnipeg Art Gallery and the Legislature. The consistency of the planning creates legibility for users and visitors to the building, and conceals staff facilities such as a telephone room, a small kitchen and a small meeting room. The reception areas are largely unused now due to the changes in security systems in the building. When the building was opened they would have served as gateways to the business of each floor, a job that has been subsumed by technology in the form of the security cards issued to employees and visitors that determine their access to each floor via the building elevators. 


\section{Typical Floor Plan}

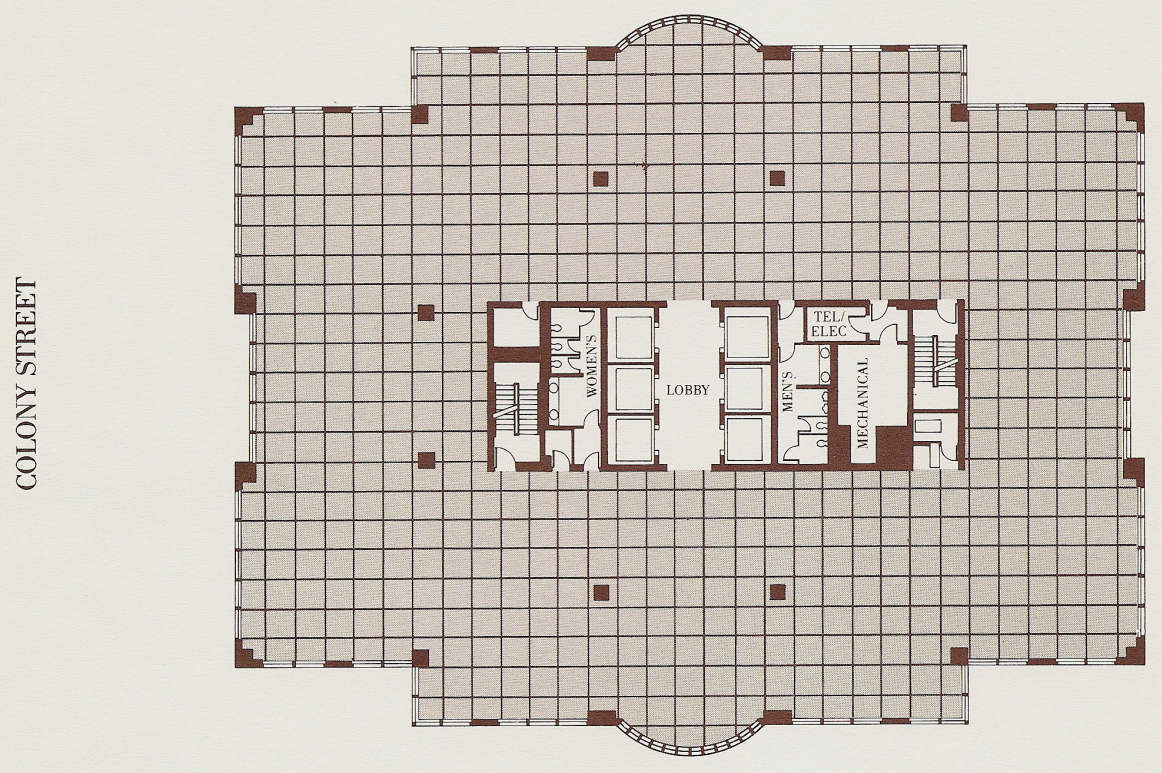

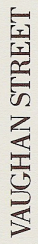

PORTAGE AVENUE

Exclusive Leasing Agent:

Lincor

Properties Ltd.

1500 - 444 St. Mary Avenue

Winnipeg, Manitoba

R3C $3 \mathrm{~T} 1$

(204) $942-7664$

\section{One. Canada Centre}

Figure 5. Typical Floor Plan, 1988 Brochure to celebrate the opening of One Canada Centre (Investors Group Archives) 


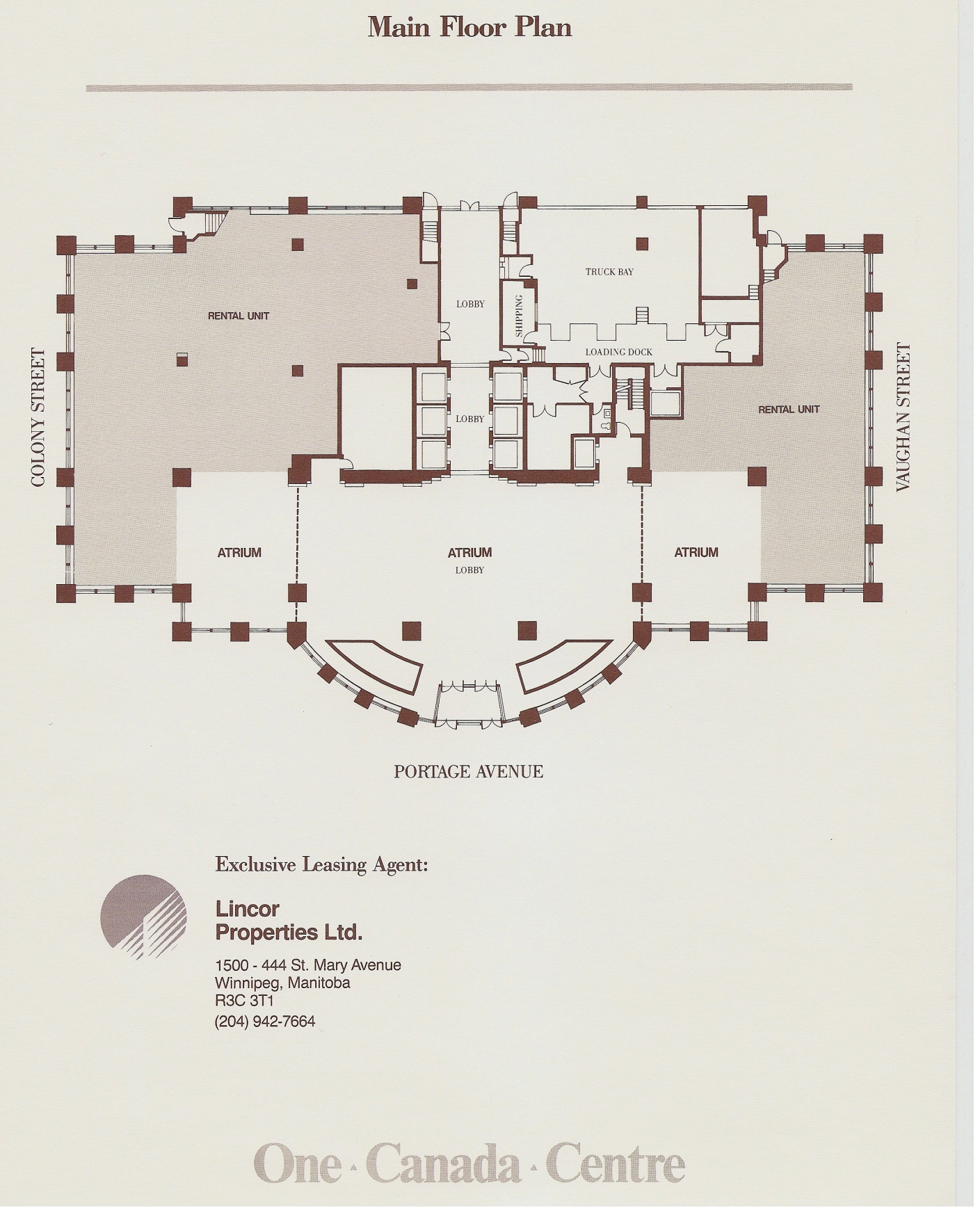

Figure 6. Main Floor Plan, 1988 Brochure to celebrate the opening of One Canada Centre (Investors Group Archives) 
A walkway link on the third floor provides access to the Portage Place Mall to enable employees to shop, bank, or go to the YMCA in their lunch hour. This was a shift in culture. In the previous building on Broadway, the tradition had been for a common morning and afternoon break with almost all employees gathering in the cafeteria, creating an unusually cohesive bond amongst staff and a particularly familiar culture. David Archer, former Executive Vice-President of Investments and Trusts, was pleased to see this feature of Investors Group culture give way to a more flexible schedule where employees could take time for appointments and parental responsibilities and breaks were staggered to give coverage in each department for the whole day. (Archer 2012: pers.comm.)

\section{State of Art for the Investment Industry}

Design changed the culture of Investors bringing the company head offices into line with the state of the art for the investment industry.

(Tyshynski 2012: pers.comm)

Broadgate London, a 30-acre development site owned by the British Land Corporation, was under construction at the same time as IG's new building (1985-90). It was commissioned by the City of London and designed by Arup and Associates and Skidmore Owings and Merrill. It houses London's financial services industries. Duffy (1997) asserts that its distinguishing features were extensive market and user research that informed the design, and a particular focus on office technology and its impact on the demand for office space. The design was arranged around a series of urban squares, creating a significant impact on the urban environment. The buildings were configured as clusters of groundscrapers giving the occupants unprecedented access to natural light, open plaza space and facilities such as shopping, restaurants and entertainment. Duffy suggests this project set "the highest international standards for accommodating the emerging needs of the financial services industry"(1997). It provides an early example of the convergence of new urban planning theories, neoliberal public/private funding models, and ways of working that are dependant on new communication 
technologies. It most certainly reflected the "space of flows" Castells (2000) was writing about at the time. In many significant ways the issues that preoccupied the designers of the huge Broadgate complex were also of concern to the architects and designers who designed One Canada Centre. The project was initially conceived of as an urban intervention, part of a larger plan to renew the vitality of the downtown. The project ensured connections to the larger urban environment providing facilities for employees such as walkways to the Portage Place Mall, with links to the Bay and the Eaton's Centre, underground car parking, and convenient access to transportation through the provision of a bus shelter in front of the building, on Portage Ave. The building has a small footprint, breaking with the traditional deep space planning of North America, and offers occupants maximum access to natural light with continuous windows on all faces of the building.

One Canada Centre provided exceptional environmental conditions for the time with a computer-monitored heating, ventilating and air conditioning system with 25 zones per floor. The old building on Broadway had only two zones per floor, leading to cold spots. Oversized perimeter cable raceways allowed for inevitable changes to occur for growth and restructuring, and the communications technology provided to the building was the state of the art.

Training facilities were located on the third floor along with the cafeteria. The facilities incorporated two training rooms for 30 persons that were sound isolated and equipped with 14 computers each, in addition to a "data processing education complex" for training head office processors "and anyone else in Head Office that uses a terminal"35. In 1987 the company could not foresee the reach of the revolution in workstyles that would be instigated by desktop computing, but they recognized the needs to develop the skills in their workforce to support the new technologies.

Extensive user consultation was a hallmark of the One Canada Centre project, allowing for the development of more equitable allocation of workspaces. The plan determining the co-location of departments (called the stacking plan) was developed by

35 "The Investor" September 1987 
Rice Brydone in conjunction with the heads of each department. New Steelcase systems furniture replaced the "metal tanks" that had served as desks in the Broadway location and the offices were planned to provide air quality and good levels of daylight and views for workers and to provide the ambience of a "head office".

The air conditioning system was designed to allow optimal comfort levels for offices and the open work area. Managers' offices were provided with built-in storage and a choice of desk type; their spaces were designed to be open to employees most of the time. A lunch room was located on each floor equipped with a fridge and sink that allowed employees to take a break at any time during the day. Meeting room facilities were introduced at each floor and were located to provide places for employees and clients to meet within the reception zone on each floor. The CEO recognized the importance of the new building as a tool for self-promotion and pride for head office staff, but also for training visiting regional sales staff and advisors. Investors Group wanted employees to have pride in the new offices and modern amenities and by association the company. ${ }^{36} \mathrm{~A}$ brochure was produced to promote the building to all employees.

\section{Organizational change}

Organizational theory at the time (Drucker 1985) predicted a transition to greater numbers of managers and professionals (knowledge workers), and less clerical staff, with an attendant need for more meeting spaces to allow for greater information sharing and informal conversations. Worthington suggests the new class of knowledge worker spends more time in meetings, so the size of the office cubicle is less important (Klein 1982:234).

But the clerical workers' jobs didn't decrease substantially in number, and in many organizations in the 1980s male middle managers lost their jobs instead. The office was subjected to increased change and churn, as small responsive teams were assembled to carry out a project or task, and dispersed when the task was completed. 
Greater numbers of women were employed as clerical staff. The skills they brought in terms of their capacity for collaboration and their ability to adapt to change, and accommodate flexible ways of operating have benefitted the office, facilitating the new ways of operating required by globalization and technology.

As clerical jobs grew in number and were filled by more women, the status of the work was devalued. More opportunities were created for educated immigrant women to occupy routine clerical jobs at an even smaller pay scale. The shift from male to female clerical workers in evidence in the 1980s facilitated a new organizational culture that focussed on the skills and ways of working that were in alignment with women's values. Women's capacity for collaboration and teamwork was often employed at the expense of personal privacy, women's acceptance of change and flexibility was often at the expense of secure employment and regular hours of work. The case studies represented in Chapters Six will study the close environments of women clerical workers at IG and explore how they represent their values in the "feminized" office space.

The 1980s were the time when the interior design profession was consolidating its role and the numbers of graduates from interiors programs were growing. As a result more women were involved in the design of offices as planners, facilities designers and as employees of the burgeoning office furniture industry. They brought with them an acknowledgement of life and experience and the value of everyday life, which enabled the design of new office space to potentially be recast, to implicitly reflect the greater valuing of the feminine. This was a moment of optimism about the potential of design. Organizations such as IG did not provide the employees with day care for their children or telephones at every desk to allow employees to be in contact with their families. But there was recognition of the need to make the work environment appear to welcome women and express a sincere desire to create a contemporary workplace that functioned in a more communicative and collaborative manner in line with organizational theory of the time. 



\section{CHAPTER FIVE}

\section{NARRATIVES AND VISUAL COMPOSITES}

\section{Introduction}

Entering the lobby of One Canada Centre, the sun streams into the three volume space through the curved glass façade. The building is a modest 19 floors, scaled to the needs of the organization and the skyline of Winnipeg. The vestibule that creates an airlock at the entrance is human scaled in contrast to the height of this space, modelled on the vertical banking chambers typical of larger office towers. The height of the space is emphasized by Warren Carther's soaring glass sculpture "Prairie Boy's Dream"(1994), installed so it contains the view through the space to the elevators. On the right framed by a wall of imposing red Texan granite is a large desk and the concierge who greets everyone and seems to know the names of every IG employee. He has a security badge waiting for me and directs me to the seating area to wait for my appointed contact. Obviously waiting is not something Investors Group expects of their visitors - there are only four club chairs and as I sit and look up into the volume, I realize the upper level offices and cafeteria have views down into the lobby. The curved wall terminates against the vertical wall of the façade at the third floor, with a glazed atrium bringing even more light into this south facing lobby. It is a generous volume that creates the impression of the importance of Investors Group. I am drawn to Carther's glass installation with its glowing honed and textured surface representing the topography of the prairies in blues and muted greens. Roberta has arrived to take me to her office and I wait with her for the first elevator to take us up into the building.

The lift lobby walls and floor are polished red granite, and the curved ceiling is lit from sconces built into the granite walls. The lift is obviously not from the time the building was first designed; it is sleek and stainless steel and a voice welcomes us to Investors Group. Each floor has a similar plan form, bringing visitors to the south side 
of the building where meeting rooms and managers' offices are located. They have been designed to transfer as much light as possible from the perimeter to the core with opaque glazing to the meeting rooms and large openings into the managers' offices. The style references post-modern detailing, but the integrity of the design has been maintained with the original colour schemes from the late 1980s intact. Roberta's office is large enough to comfortably accommodate a small meeting table for three placed away from her desk. It is a thoughtfully designed space and still seems to serve its function well.

I sit so I have a view out to Memorial Drive, the Winnipeg Art Gallery and the Bay. Pondering the vista, I remember Art Mauro's comments about the siting of the building so the chairman's office would face the centre of power in the province, the Legislative building. Roberta and I discuss the research and how it will unfold. IG does not want the interviews to take place at the women's desks as this might cause interruptions to the other workers, so I will set up appointments to meet with each participant.

I ask to see the office space where the women work and she arranges for a tour of the sixth floor. It has the typical plan with the 1980 s reception and meeting spaces on the south elevation. There are a number of smaller managers' offices and the space opens into a large open office area with beige regimented workstations. The space has an abundance of natural light that the occupants screen out with venetian blinds, and some are closed completely against the sun. The space is busy, desks are full and the occupants, mostly women, are engrossed in their work. A few look up curiously. At first appearance there is little personalization at the desks, but as I look more closely at the tidy desks the personalia becomes more obvious. 


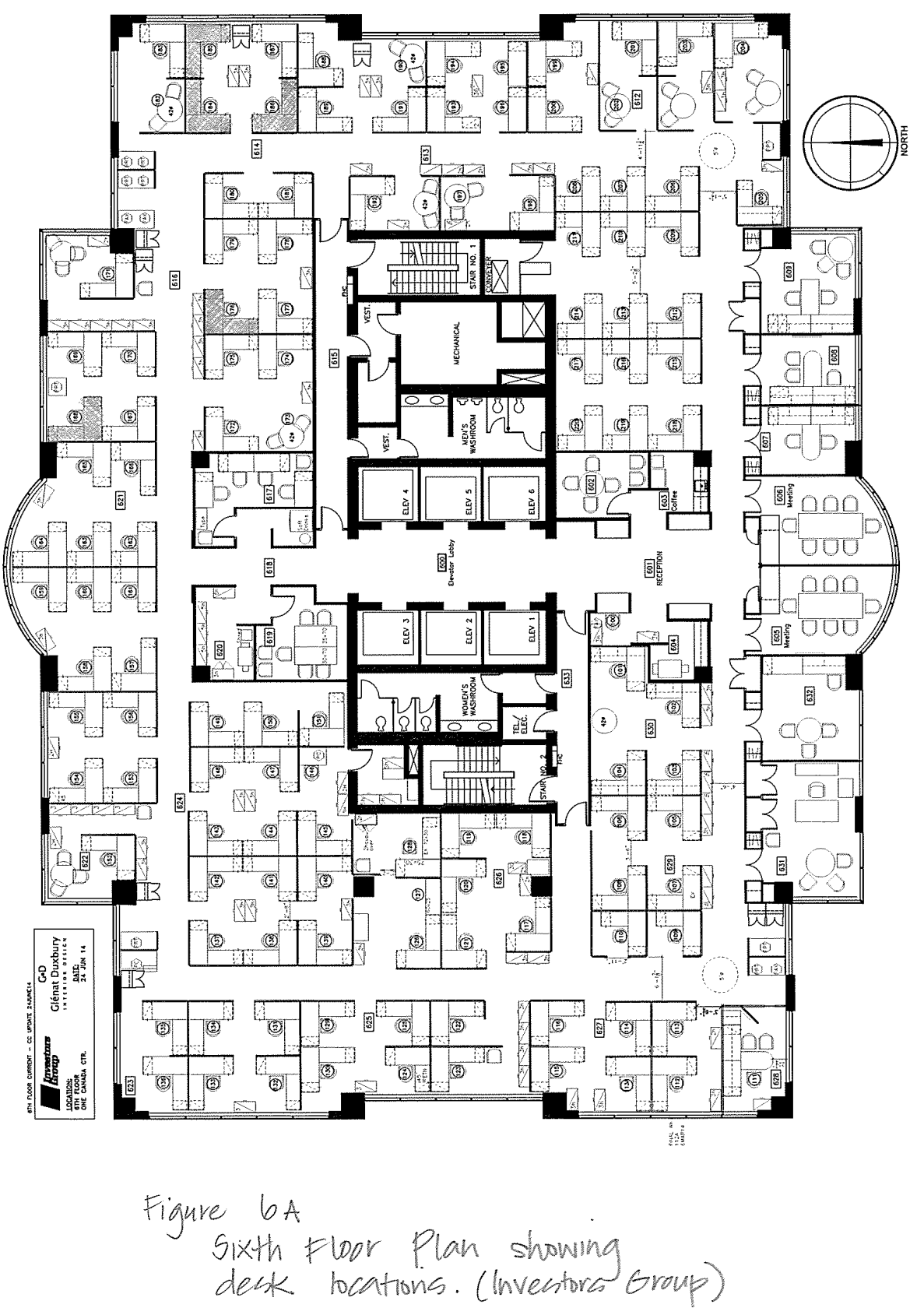




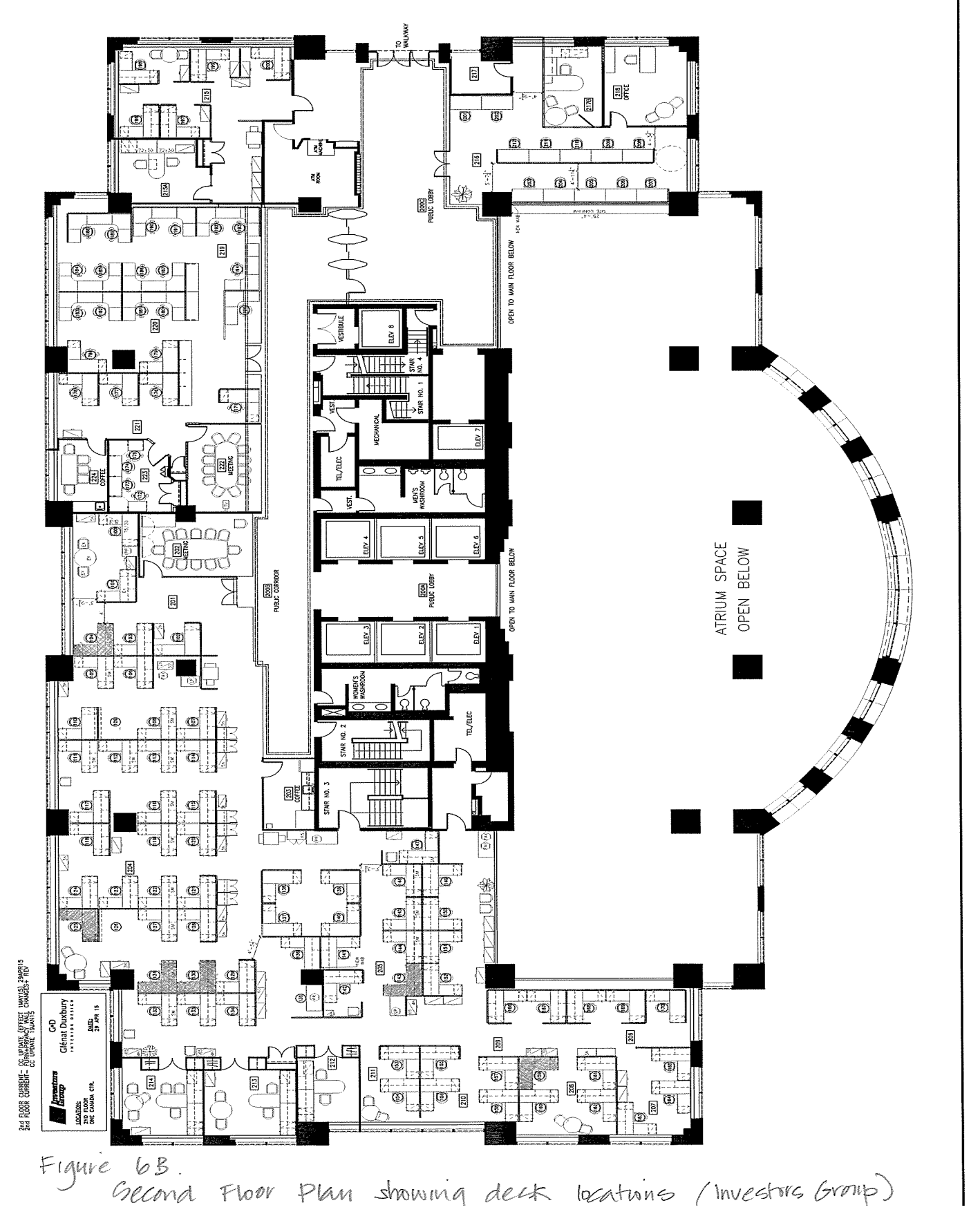




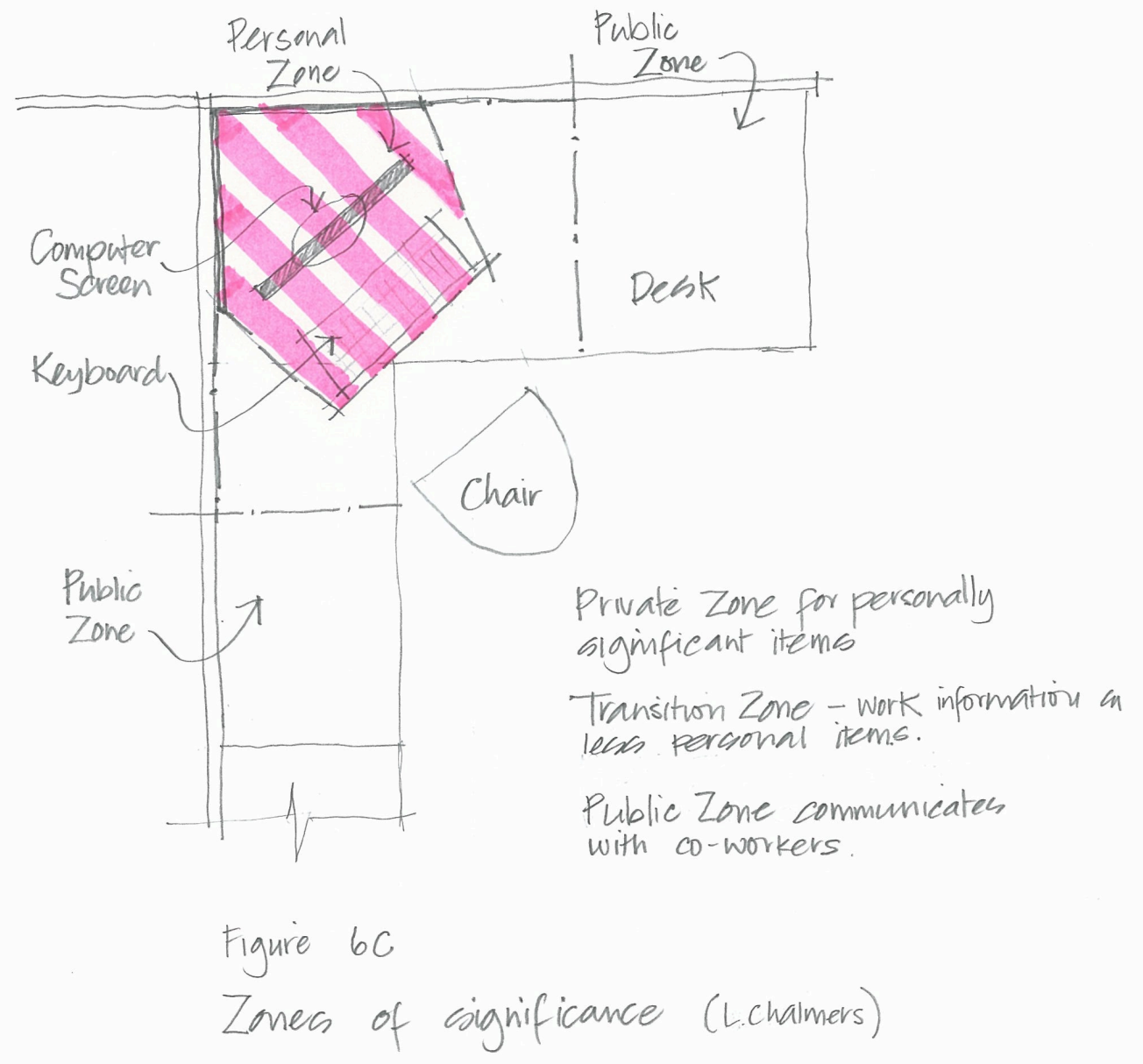




\section{Context for the research}

The two groups that were approached to volunteer participants are part of Client Services at Investors Group. This department provides services to the IG sales representatives and individual investors.

The Registered Educational Savings Plan (RESP) processors and account administrators on level two prepare the required paperwork for clients and perform financial adjustments during the RESP season and for annual assessments.

The Mutual Group on level six prepare the documentation for IG's Mutual investment products and deal with the required paperwork for clients Registered Retirement Savings Plan investments.

Verdonck -Milne suggests the work requires business knowledge and skills and is not the work for an entry-level position (Verdonck 2015: pers.comm.). The work is performed by mainly by salaried clerical workers at IG but contract staff is employed in the peak tax season. She estimates the proportion of women employed in Client Services to be $74 \%$ of the total staff numbers.

The subjects of the research are women who perform routine clerical work at dedicated desks in office cubicles for seven to ten hours a day. Their roles as processors do not involve direct contact with the public. Five women work on the sixth floor in the RESP department and are responsible for RESP processing and account administration. The other six women work on the second floor in accounts processing and mutual funds administration. Six of the study participants are Canadians, four are immigrants from the Philippines, and one is from Indonesia. (relocated)

The research process and selection of subjects, along with the questions that form the framework for the interviews, were developed early in the process as part of the information provided for Ethics approval. The subjects were approached by IG from routine clerical workers in the Client Services department; group leaders called for volunteers after an information sheet describing the research had been circulated. 
Twelve volunteers names were provided to me, only one volunteer was male. The volunteers had agreed to allow their desks to be photographed and to participate in an interview about the nature of their personalia. The process I used was to make an appointment to visit each desk when it was unoccupied to take photographs. The photographs were taken mainly from the perspective of a seated person, ranging around the desk, then close-up shots to examine detail and arrangement, approximately 15 - 20 images of each desk, depending on the number of artefacts present. The gendered structure of the financial services industry was very apparent in the sample of subjects I was able to work with, I determined to use this as focus of the research and removed the male subject from the sample.

The interviews were scheduled two weeks later, in meeting rooms on the second and sixth floors. Each interview used the questionnaire format as a loose framework for the discussion of the desk and its personalia. Follow up questions allowed me to pursue areas of interest that developed as the interview proceeded. Interviews were approximately 45 minutes to one hour in duration. The photographs provided the background for the interviews and I observed that the subjects were moved to make extended observations about their personalia prompted by the images on my laptop.

The photographs acted as authentication of the personal artefacts at the desk, the subjects took the interviews quite seriously and as our conversations progressed stories of the social significance of the personalia at the desk unfolded.

The following narratives were written as a reflection on the interview conversation and to capture the women's voices. Accordingly, the narratives do not reflect the complete content of my field notes or photographic records, but rather attempt to capture the essence of the women at their desks, their operations and practices, values and identities. 


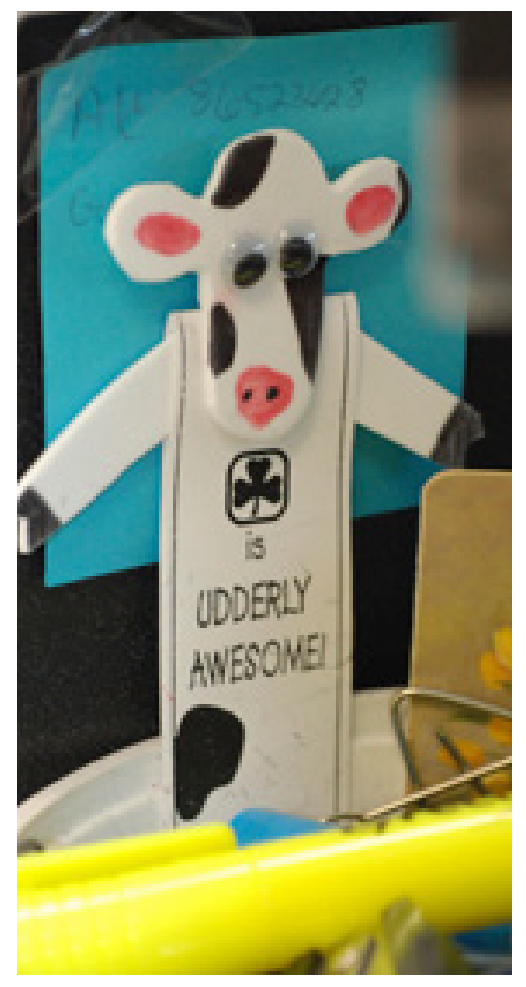

Gloria is in her early 60s and has been employed at IG for ten years. She has spent six years at this location and desk which she describes as her "home away from home". She is looking forward to retiring in a few years and expresses her frustration with her desk chair as it is not comfortable to sit in all day. Her arthritis means she needs to get up and move around periodically to stretch. Gloria is also having hearing problems that allow her to more easily tune out the office environment. She works with her back to the team as her desk is positioned against the windows with the venetian blinds closed. She is in a loosely defined team that shares peer support for the individual projects that require particular expertise.

Gloria says she has personalized the space on her desk for her own benefit. She defines her work as routine and likes it that way. When I ask if she is looking forward to her retirement, she replies, "Yes, I don't want to learn anymore; no new systems or new programs."

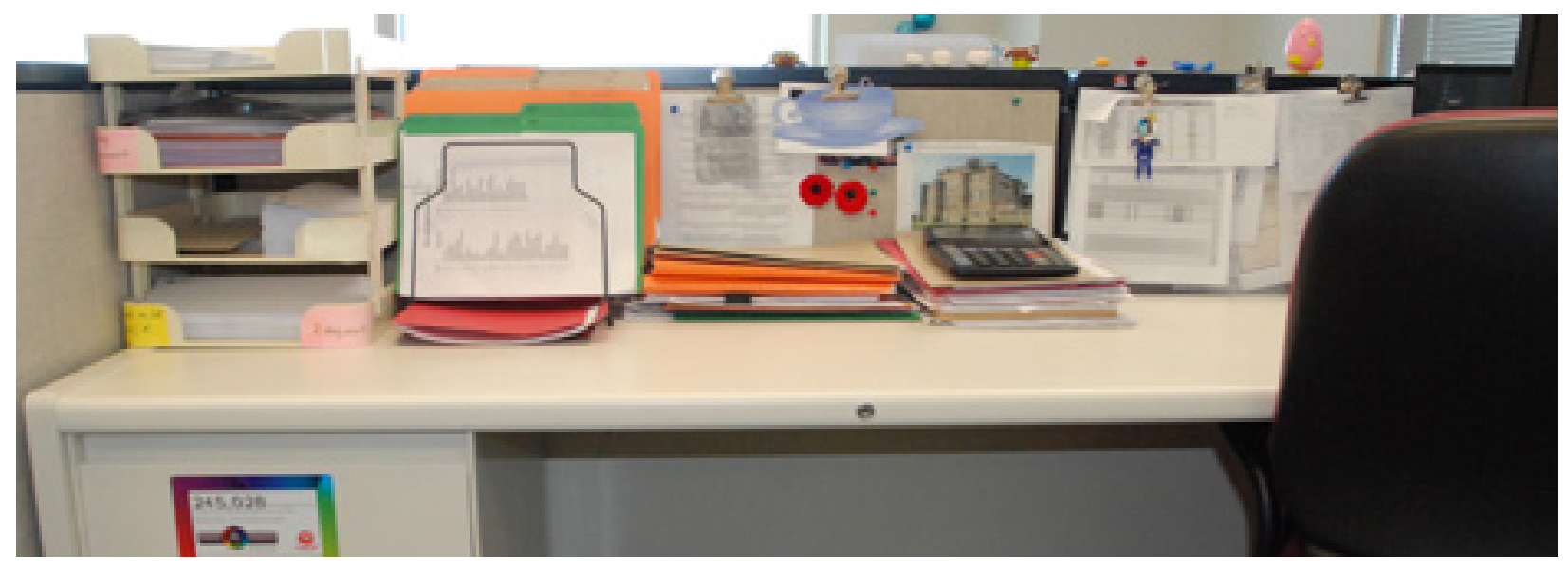

\section{Gloria}


The personal items on her desk are important to her. "[They] make it my station, those who have nothing on their desks ... it seems so sterile." She tells me the days are long and she needs to make the space feel personal. The display is also a good conversation starter when co-workers first join the unit, and she doesn't mind anyone looking at the things on her desk. Gloria often gets asked about a set of eyeballs on the top edge of the panels that enclose her workstation. These "extra eyes" were made by her granddaughter at daycare, giving her "eyeballs in the back of my head". They seem to say "I know what you are doing, if you are watching me, I am watching you too".

Gloria sees the things at her desk as providing "stories to tell others in the workplace". She has a picture with a story in a prominent location on her pin board. It is a castle in Scotland that her mother's family surrendered in the 1940s for unpaid estate taxes. She brought it in to show a work colleague and left it pinned up to dream about. There are a number of hand-crafted tchotchkas made by one of her granddaughters at Girl Guides. One is a felt cutout cow that says "Girl guides is udderly awesome", as well as a robot man hanging ornament made from beads. Her grandson has given her a number of small toys he made from Kinder Surprise because he knew she had things made by her granddaughters at her desk. They are displayed alongside the play dough critters on the top edge of her workstation.
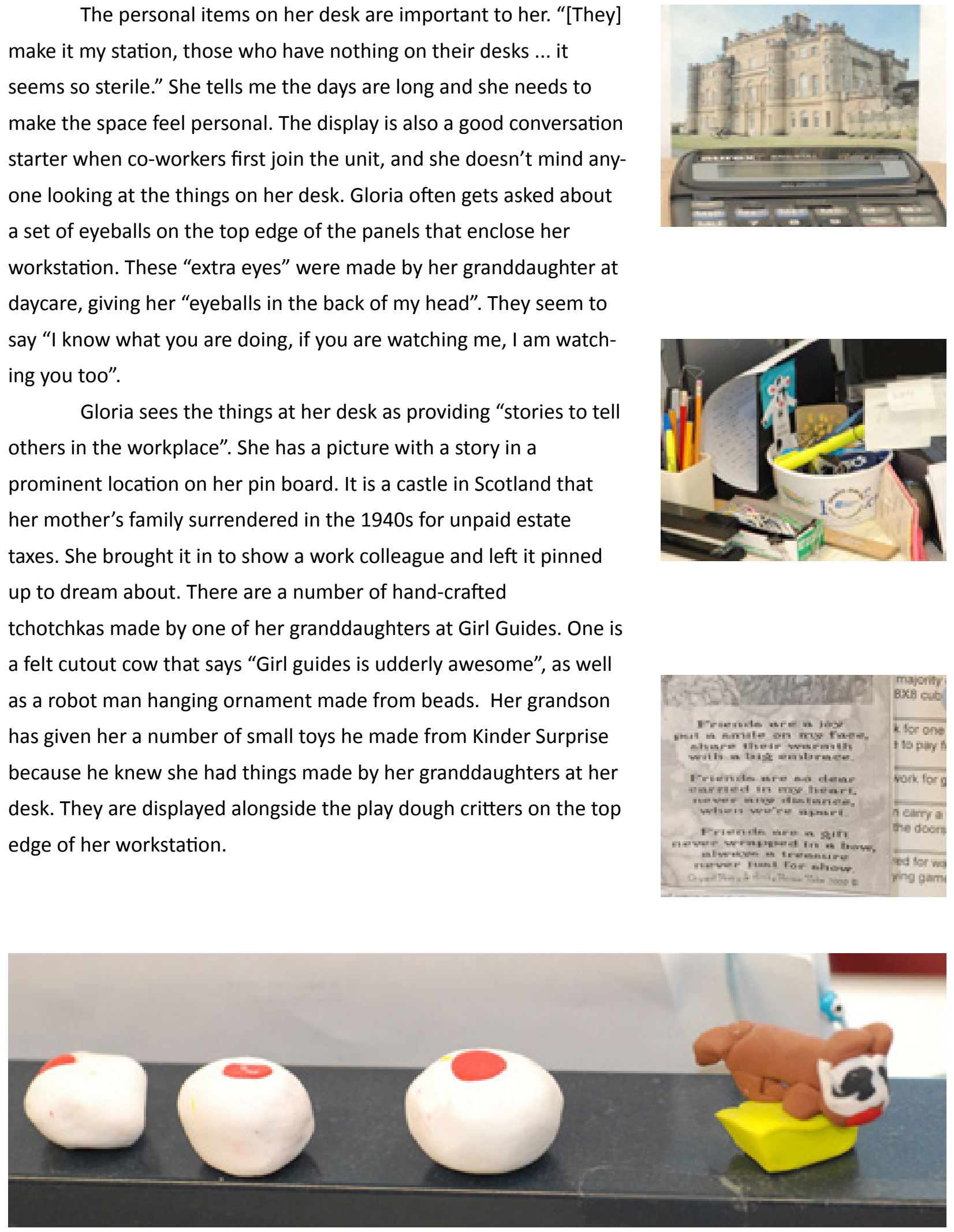

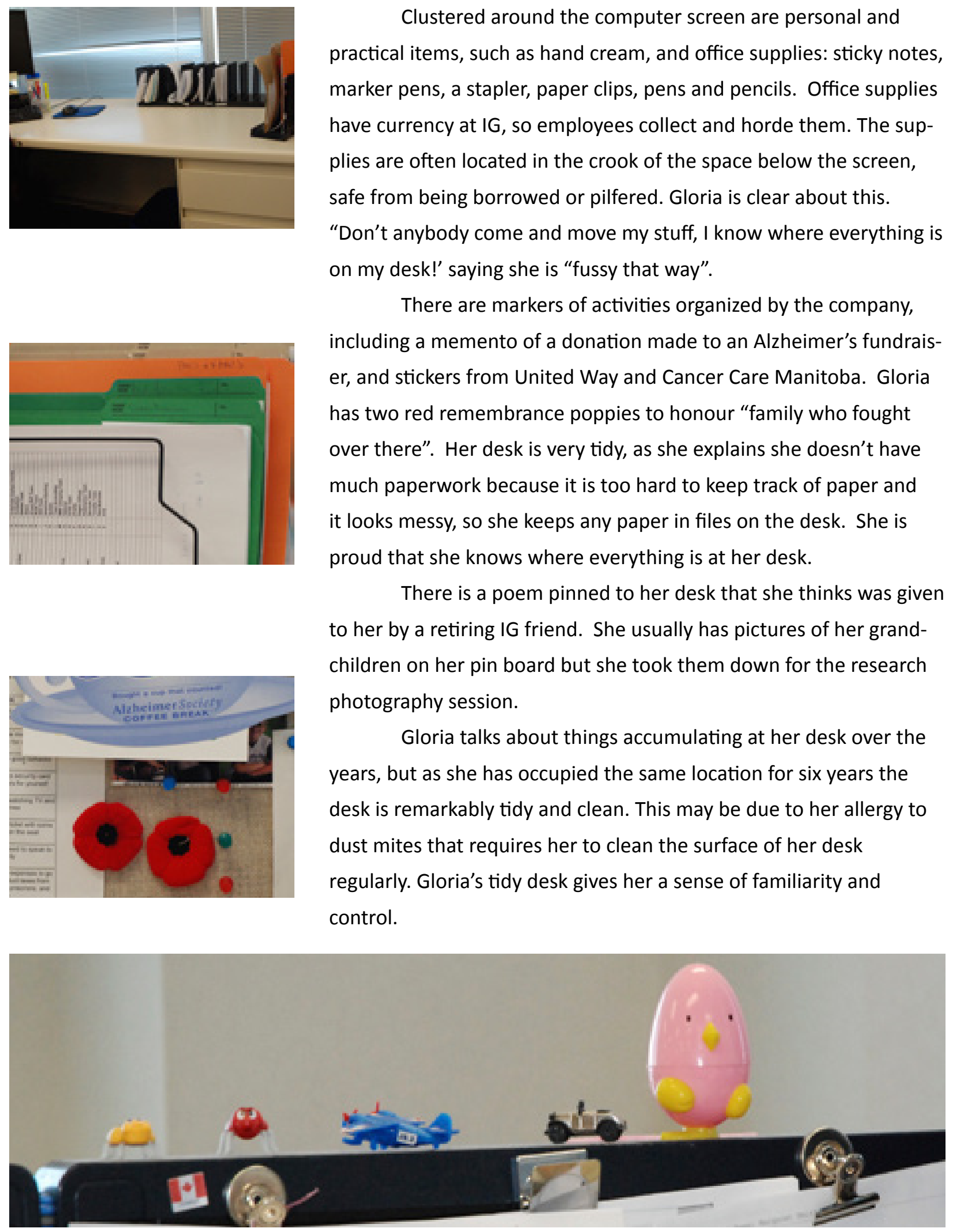
desk is remarkably tidy and clean. This may be due to her allergy to dust mites that requires her to clean the surface of her desk regularly. Gloria's tidy desk gives her a sense of familiarity and control.

There are markers of activities organized by the company, including a memento of a donation made to an Alzheimer's fundraiser, and stickers from United Way and Cancer Care Manitoba. Gloria has two red remembrance poppies to honour "family who fought over there". Her desk is very tidy, as she explains she doesn't have much paperwork because it is too hard to keep track of paper and it looks messy, so she keeps any paper in files on the desk. She is proud that she knows where everything is at her desk.

There is a poem pinned to her desk that she thinks was given to her by a retiring IG friend. She usually has pictures of her grandchildren on her pin board but she took them down for the research photography session.

Gloria talks about things accumulating at her desk over the years, but as she has occupied the same location for six years the 
Sharon has worked for IG for 18 years. She has four more years to retirement and has had triple bypass surgery. She has been in this department for four years and has been sitting at this desk for all that time. The desk opens onto an aisle but has higher panels separating it from the next row of desks.

When I raise the issue of privacy, Sharon says she doesn't use earphones but "just blocks it out". If she has work that requires greater concentration, she "works on it early in the day or last thing at night when it is quiet". She takes her cell phone to the cafeteria if she needs to make a private call because she doesn't have a phone at her desk. Sharon emphasizes the collaborative aspects of her job, saying she collaborates "every hour of every day". Her work is routine but she performs a variety of functions that require a backup person or team leader, as "you can't possibly know all of the answers for the situation".

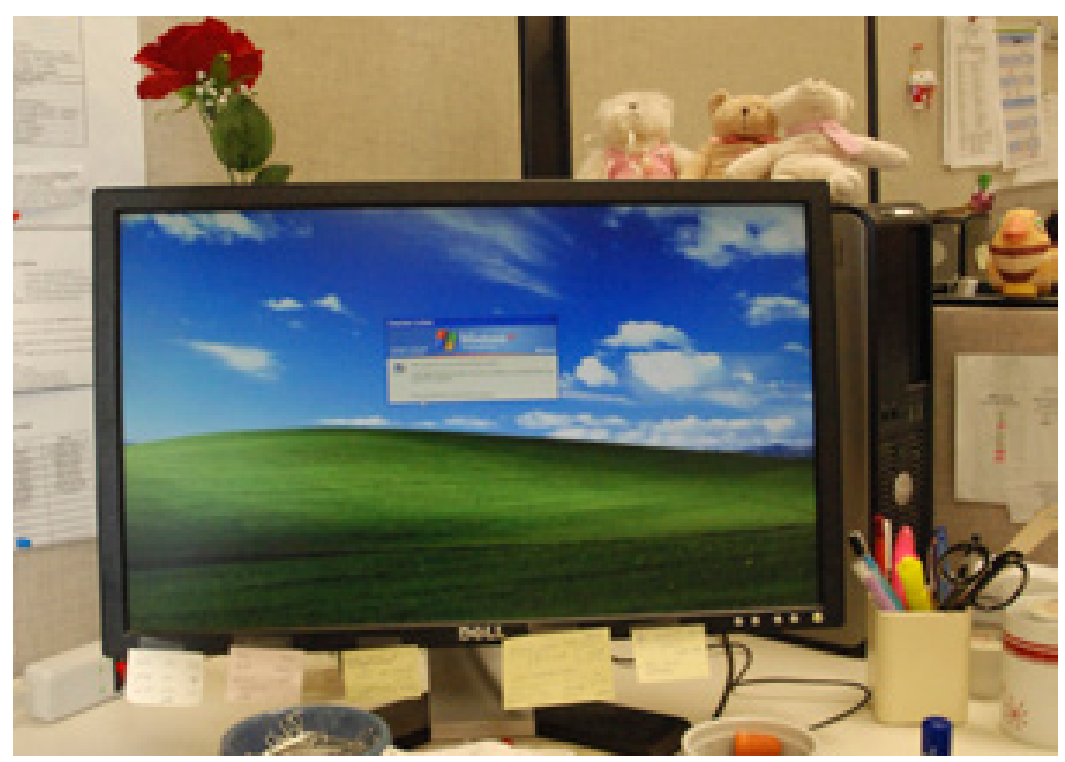

\section{Sharon}
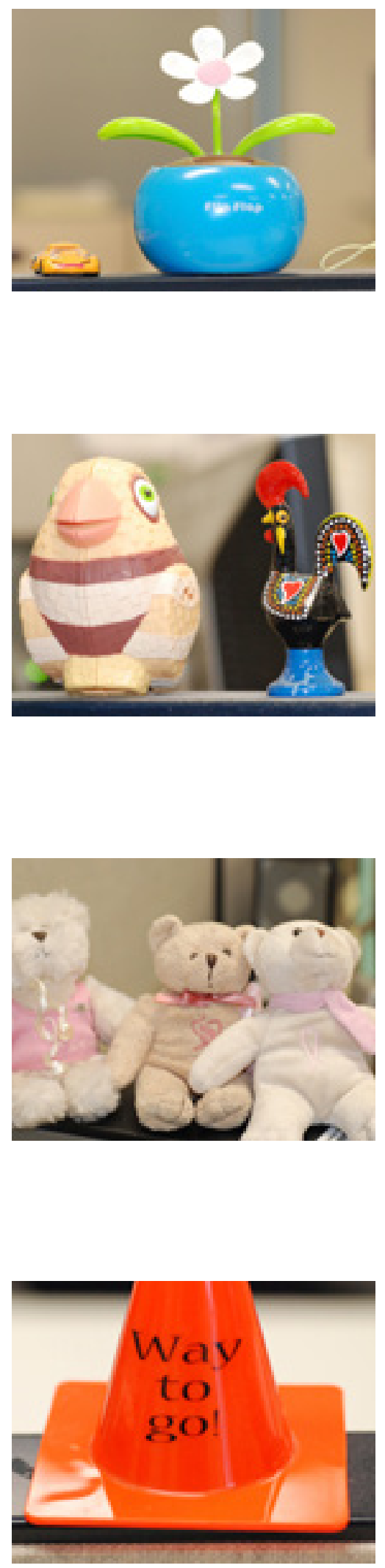

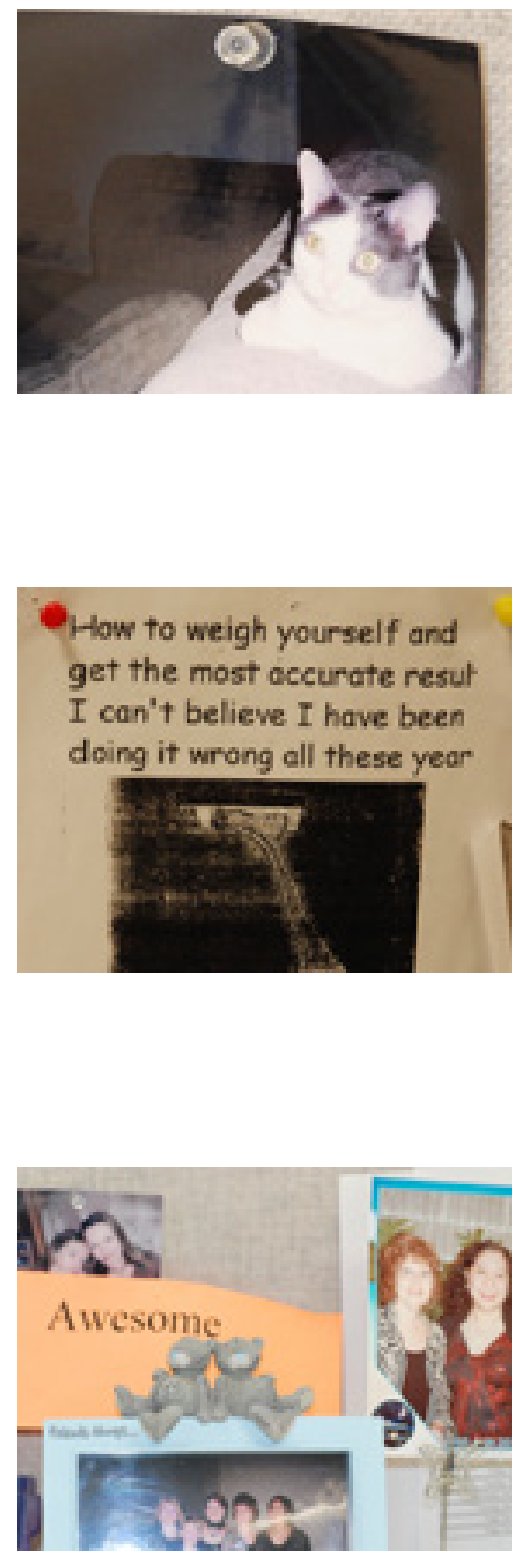

The personalia at her desk is important to Sharon because “it gives you a nice feeling when you're stressed, to look at it and think of that person". She speaks of the kindness of co-workers when she was in cardiac rehabilitation. Yan gave her a pedometer and Ying came to visit her. Sharon has tchochkas arranged at the top of the low panels on the right side of her desk and gives me accounts of some of her favourite items. The flower ornament in a bright shiny blue vase is solar powered and moves toward the light. It was given to her by a special co-worker and friend who now works for Liberty Tax. The black rooster from Portugal "is supposed to bring good luck", and the stuffed bears on her hard drive are from Avon. One of her co-workers sells Avon cosmetics, and for the last three years she has received them as gifts with a purchase. Sharon has a number of photos at her desk; one of herself with Santa at an IG Christmas breakfast event, and pictures of her grandchildren who don't live in the city. "I like to have them at my desk." The grandchildren's picture are on the left side of her desk located near the screen.

Sharon lives on her own with her cat, a handsome tabby who also features in the photographs. Work events are obviously an important part of Sharon's life and the event calendar is located close to her screen on the right. A display on the panel on the right-hand side includes mementos of work events; a postcard with the Jets logo on it, the Christmas photo, and an orange plastic work cone that says "way to go!" Sharon belongs to Team Awesome and the work cone is a reward from her team leader. She displays it at her desk "to show I appreciate it". The display stretches the length of the desk and return panel. Tucked behind the screen at Sharon's desk is a red rose. She explains her friends at IG gave it to her when she turned 60.

Sharon has worked overtime every evening in January, February and March. Her favourite place at IG is the newly renovated cafeteria, as it is very clean and modern looking. She takes a walk most lunchtimes through the mall next door across the skywalk to the Bay, around the second floor and back. 
Perl was born in Indonesia in the 1960s. She has worked for IG for 11 years and has been in this department for three years, spent at this desk. Her desk is located behind Molly's desk, and it is adjacent to the external window wall with low panels on her right. She explains she doesn't have a problem doing private work. "I just focus." She tells others she is working and "must not be disturbed". She is a straight-forward person who "says what I think". Perl phones her husband once each day and doesn't have a problem with private calls. She is at her desk for most of the day, taking a walk at lunchtime.

Perl's desk is clean and very tidy. She explains she doesn't like knick-knacks, has no luck with indoor plants, and “doesn't like photographs of myself". She didn't think the display of personal items was very important, and reflected on the pressure to conform. "I was pushed to have my picture taken with Santa; it reminds me of a Canadian idea of Christmas." Another photograph is tucked between the panel and her hard drive on the right side of the desk. It is a picture of her in Vietnam with her boss and a friend, and she tells me the story that accompanies this photograph. Perl worked as a systems analyst in Indonesia, taking an IBM course after high school, and was asked by her boss to go to Vietnam to set up a system with a colleague. She didn't want to go and insisted on taking a female work friend with her. This picture celebrates their time in Vietnam.
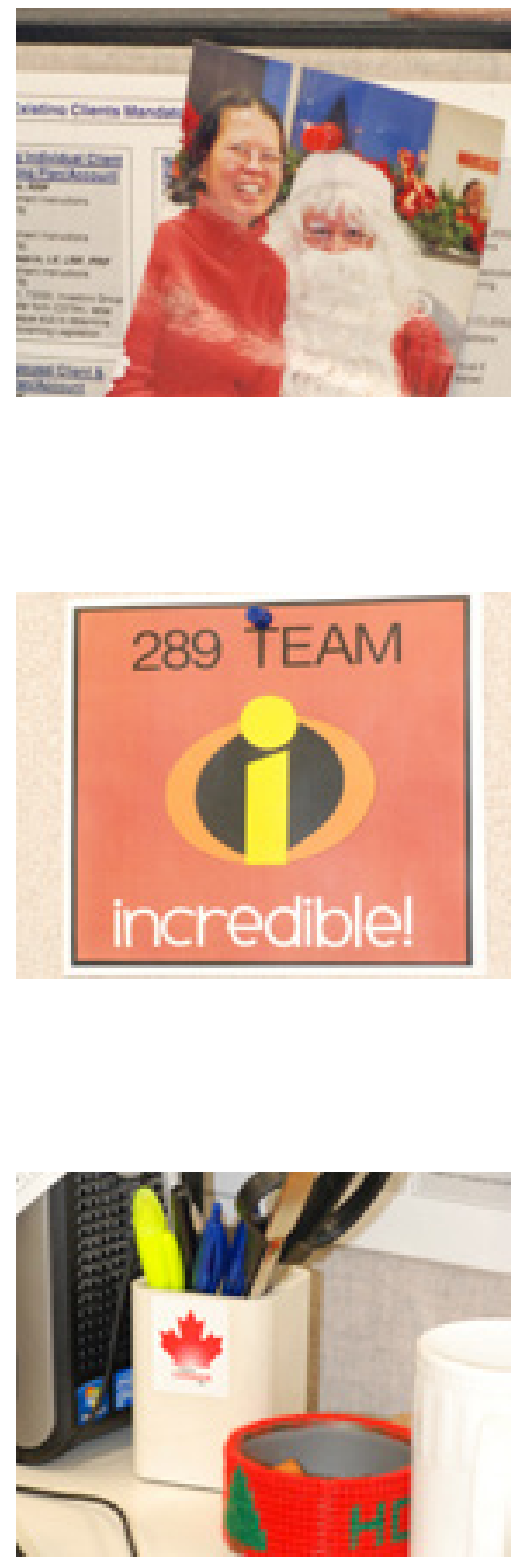

\section{Perl}




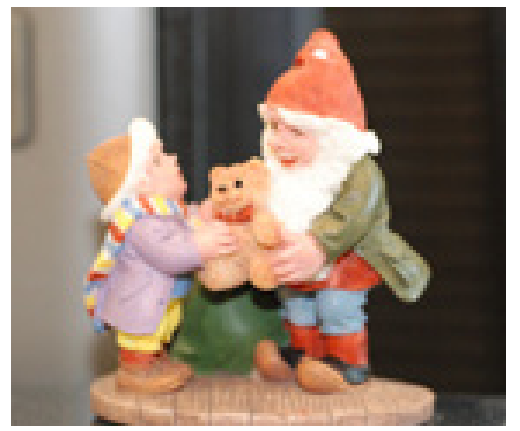

The flag mug also has a story, as it celebrates her taking Canadian citizenship in $\mathbf{2 0 0 4}$. She is "very proud to be a Canadian citizen" and it allows her to return home for a holiday every four years. She points out there are no old-age pensions in the Third World.

Another item at her desk is a red and green beaded dish made from a recycled tuna can. It says "HO HO HO" and was made by a co-worker. This is accompanied by a figurine of a Christmas gnome, and Perl says they are a reminder that Christmas is a good thing since coming to Canada.

Perl is very open about her desk and regards it as public, with "nothing secret". Her desk mostly celebrates the work she does there with shortcuts, phone contact numbers and codes taking prominence. The small number of personal items are grouped on the left side of her screen, and the right side, which is open to Molly's work area, is used for laying out files and work in progress. We talk about the food on her desk: two pickles and an avocado. Perl explains she likes to share her food. This seems to be a family tradition "coming from a family where food is not always available". Her boss from Toronto "brought fruit to my desk knowing I will share it with the others".

Perl doesn't have a favourite place at IG but her least favourite place are the washrooms at the end of the day. She has complained many times about their condition.

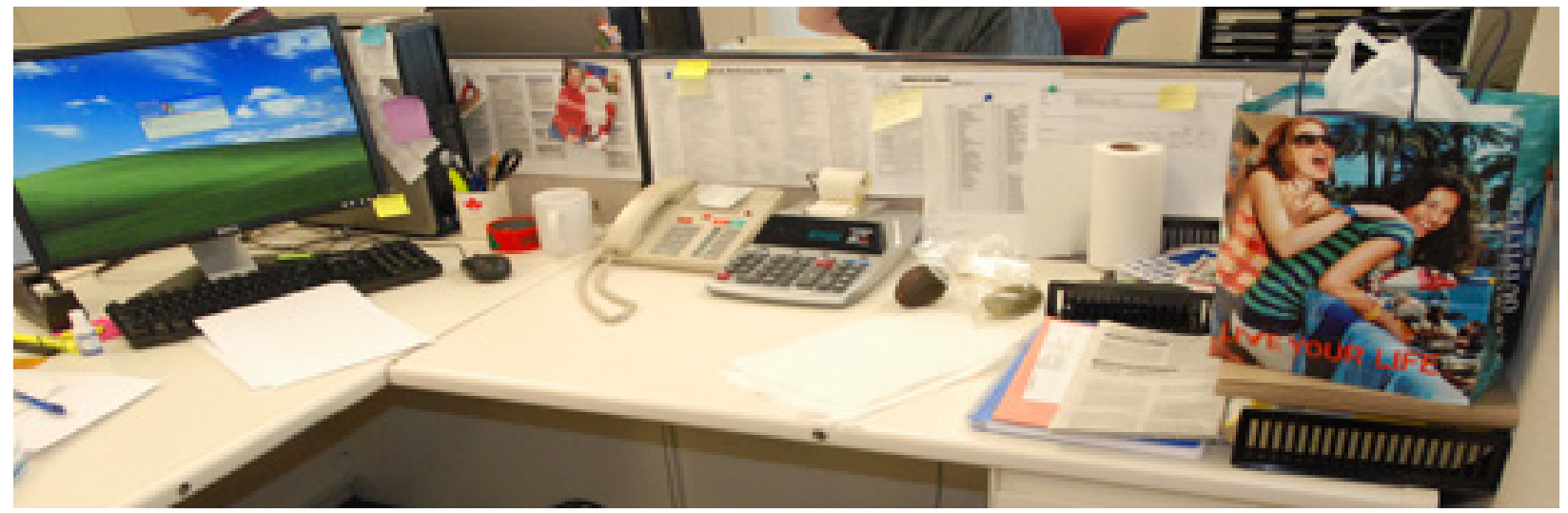


Molly has worked at IG for six years, five spent in this department. She has been sitting in this location for 12 months. She was born in the Philippines in the 1960s. In the same way as her co-workers Molly dismisses the idea that it might be hard to focus working in the open space, saying "you don't let it distract you". She also has issues about the lack of privacy for personal calls, suggesting that if the hallway is busy "you might need to leave the building" to find a quiet spot for conversations. Molly's desk is clean and tidy, and while she had just taken down personal photographs, she does keep some of her children and grandchildren on her screen saver. She says the items at her desk "make my identity - make it my workstation" and proceeds to tell me about "the treasure" (personalia) she has collected at her desk from her friends.

Her desk is connected on three sides to other workstations, giving Molly only a small area of pin board. The front of her desk is lined with file storage, two plants, a plaque with a message celebrating friends, her coffee mug, and a collection of pens and markers neatly stored next to her stapler.
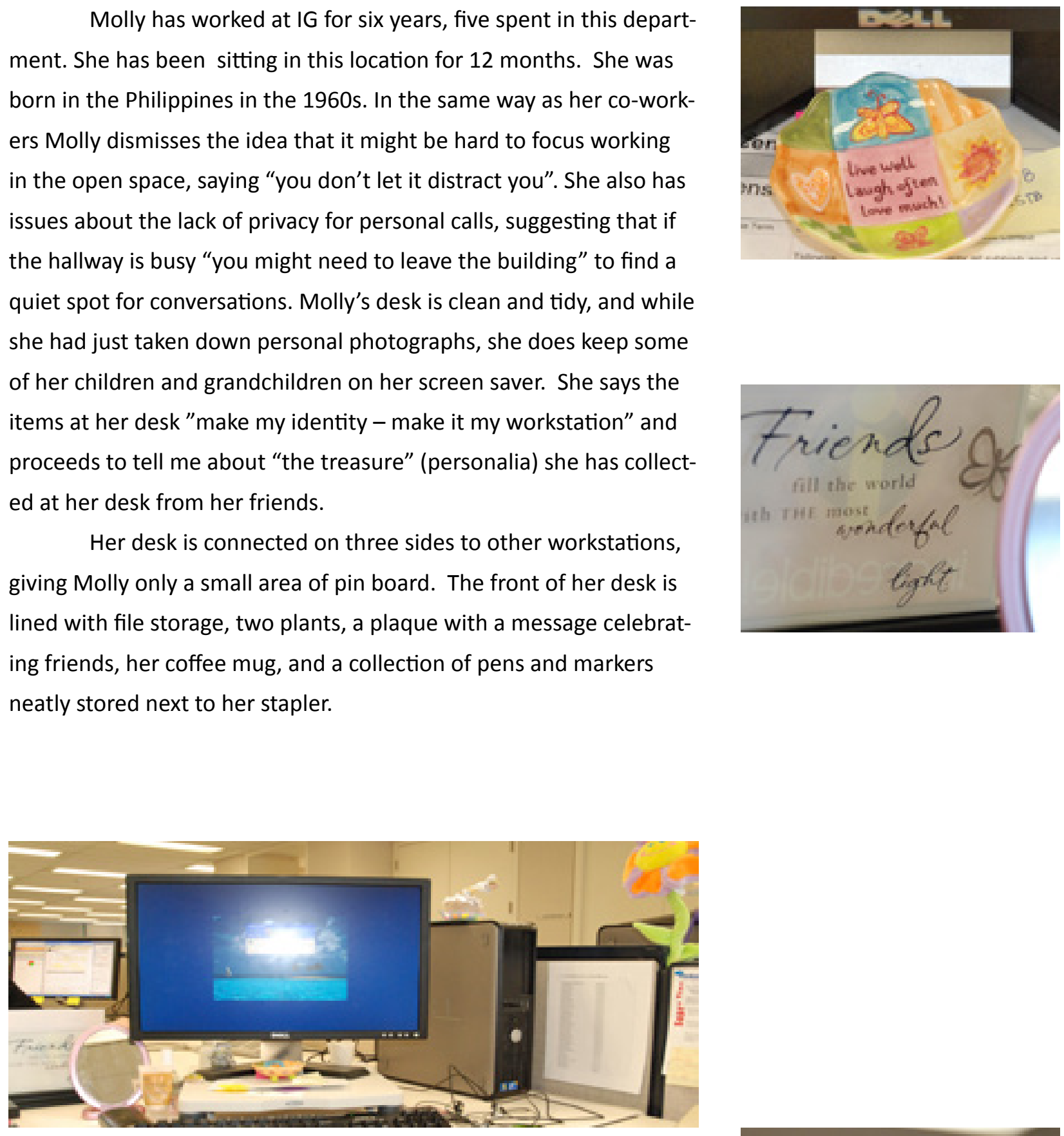

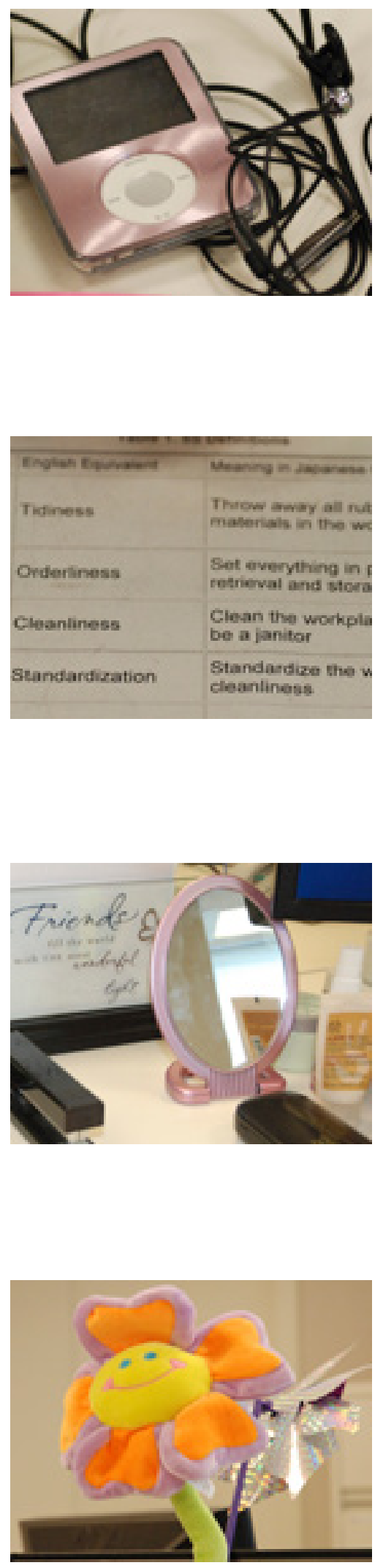

These possessions create a barrier between her and her neighbour on the unscreened front edge of her desk. Molly has her keyboard and screen located in the corner of the L-shaped configuration of her desk.

Closest to the screen on the left-hand side is a mirror. I am curious and ask her about it. She tells me that "Filipinos always have a mirror to check their personal hygene". Next to the mirror is hand lotion and hand cleaner. Below the screen is a traveller's memento, a carved-out shell with a starfish from a friend in the Philippines, and a colourful ceramic dish with butterflies with the words "live well, laugh often and love much". There is a christening ornament sitting on the hard drive on the right side of Molly's desk with a stork and baby. It has been carefully arranged on a mirrored tile. Molly explains this is a traditional christening gift. Hovering over her workspace is a fabric sunflower with a big smiley face. This was given to her during an IG event held during the months when they are really busy; "to relieve stress", she explained.

Molly has a photocopied sheet under her keyboard explaining the $5 S^{\prime}$ s, a Japanese organizational method. The $5 S^{\prime} s$ advocate tidiness, orderliness, cleanliness, standardization and discipline, and were introduced to industry as part of restructuring in the 1990s. Molly brought this with her from the Philippines: "I was really inspired by that, I read it once in a while and it reminds me to take control." Molly likes to clean her desk and keep things tidy, she mentions "I get teased about it by others".

She uses the headset at her desk to listen to music "when I get bored or sleepy to wake me up". When I ask her who the display on her desk celebrates, she says work friends and family, but she is clear that she displays these artifacts and personalia for her own benefit. She has two coffee mugs at her desk because they were both gifts; one from her daughter and one from a friend for her birthday. 
Amanda was born in Canada. She is in her early 40s and has worked at IG for 11 years in total, returning to work after a four-year absence. She has worked one and a half years in her current department and location and is a team leader. Her desk is located against the windows and she sits facing her team with her back to the view. She doesn't find the work environment noisy, saying "my team is quite quiet". Amanda works later in the day on projects that require her focused attention, between 4:00 and 5:00 when the staff has gone for the day. She describes her work as "not 100 percent routine, things change from day to day". Asked about corporate policy on personalia at the desk, she reflects that "nothing deemed offensive, sexually explicit or overtly religious" would be appropriate, but doesn't recall any policing of that.

For Amanda her desk represents "my happy spot on the days that are not so good", with images of her kids' smiley faces in homemade frames. She decorates her desk for her own benefit. She is a crafter and brings projects from home with "special words, pictures of my husband and the kids". She speaks about her co-workers' enjoyment of the things she has made at her desk and "other people love to comment ".

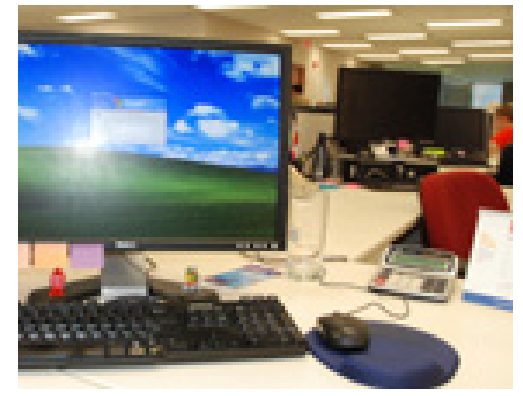

\section{Amanda}



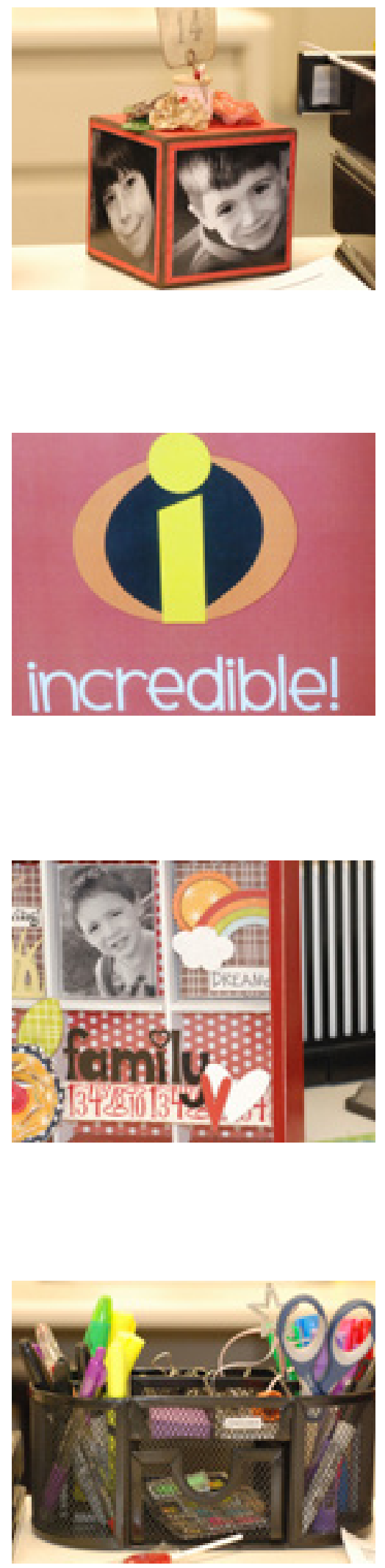

Relationships at work are very important to Amanda and these are expressed when she discusses those items at her desk that have been given to her by co-workers. A button given to her by a former team when she was having a bad day says "a million pats". She speaks about the "good feelings that it evokes". She also has a large red shoe that dispenses tape and a notepad in the shape of a purse, which were also gifts from team members and co-workers. Amanda talks about "enjoying the people that I work with and that plays into my enjoyment of work". Amanda confides that she was shy at school but has grown past that.

Her desk also celebrates peers at IG and she posts a card near her screen with the photograph of another team leader's baby son, explaining that the annual dinner dance was an opportunity to get to know her peers better. The Team Incredible logo is prominently displayed at her desk; the team is an amalgamation of five former teams. Amanda had wanted to increase moral and team spirit and their competitiveness, so she used the logo from The Incredibles movie to rebrand and unite the group. She remarks with some pride, "They were a quiet team before."

At the base of Amanda's screen is a little red smurf, a devil. She describes it as "a troublemaker" that "befits my personality". It was part of a larger collection that occupied her desk until some went missing. She took the rest home but the devil returned with her. It has a special meaning but she didn't discuss the details with me.

When we evaluate the personalia at the desk, it is clear the devil and the pictures of family and friends are for her benefit, but many other items are a celebration of relationships at work, including anniversary cards from IG. It is a source of pleasure and pride to Amanda that the eight and a half years she worked at IG before resigning to have a family were recognized on her return. She displays her ten-year anniversary card and speaks about the significance of years of service in terms of benefits to employees, such as increased paid vacation time. 
Larger milestones at IG are celebrated by teams with cake and a presentation.

The desk represents Amanda's favourite place at IG. She wants to be approachable to others and understands the significance of personal items at the desk as a conversation starter. She has a pad of pink sticky notes with her name printed on them, a gift of recognition from IG. As she relates the story of the pink stickies, she explains their importance to her co-workers who love this particular item of stationery. When it is time to reorder stationery, she makes sure there are plenty of pretty sticky pads and that each team member gets some.

Amanda would like a larger desk so she could spread out her work, and suggests her desk could do with a clean. She describes her work as "gravitating from the centre to the edge of my desk, it can then be tossed or filed". Amanda is very clear about the significance of celebration and relationships in her work life. She notes

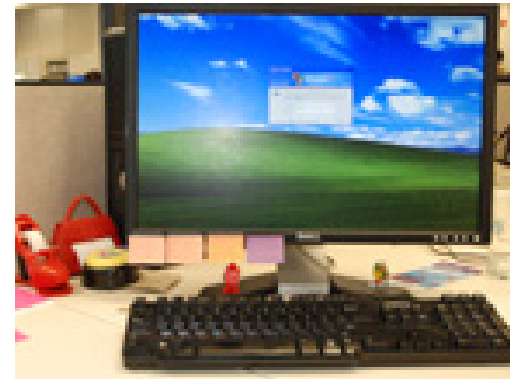
that she "spends more time at work than at home" and talks about her husband's support in managing their children. Because she is a team leader she is able to use the meeting rooms if she needs to make a personal phone call, although she says "my husband does most of the running around, he has a cell phone".

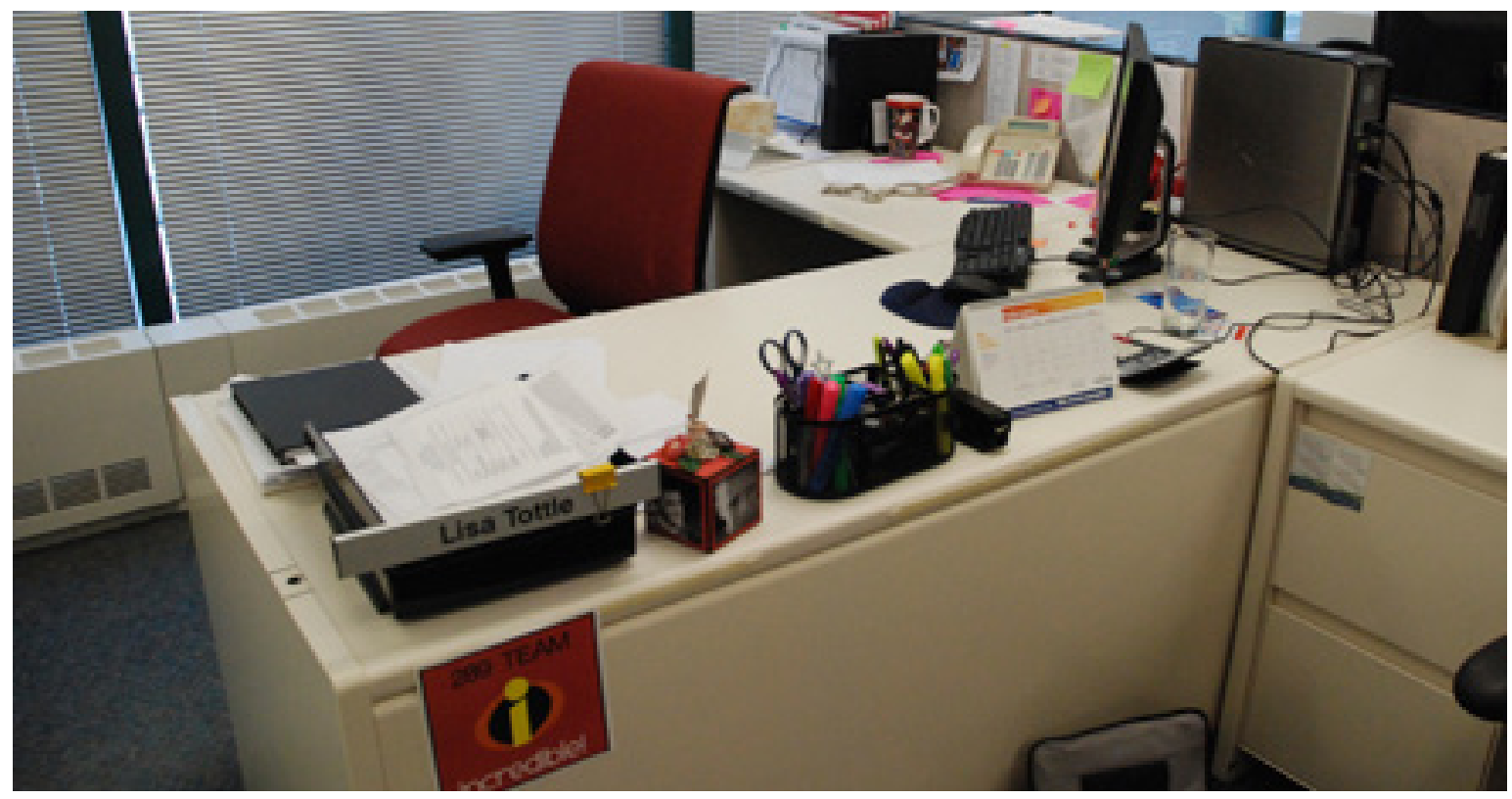


Camila is in her mid-30s and has worked at IG for seven years. She is Canadian, describes herself as someone who loves people and enjoys helping her co-workers who she describes as "friends". She has a young daughter whose handprints decorate her workstation. She has worked in this department for five years and has occupied this desk location for two weeks. Camila explains she likes to take time to set up her desk, and talks about her office supplies. "I love my tape dispenser, it's green and brightens up my desk." Office paraphernalia is supplied by IG but Camila likes to buy her own so she can have something different at her desk. The personal items on her desk have taken years to accumulate, as even highlighters and office supplies are passed on from retiring employees. "It is sad to see them go" but the supplies serve as reminders. They obviously have a trade value and are redistributed as gifts. They seem to become a colourful part of the décor of her desk. Camila notes that most of the things at her desk are personal but she doesn't mind sharing them.

She describes her work as "very very routine," "especially for the processors who ask the same questions of different clients". Her job keeps her sitting at her desk "90 percent of the day". The personalia she chooses to describe are her daughter's handprints. She made these at home with her daughter "when she discovered her hands" at two and a half years old. She made a set for her husband too, so they could both take them to work to display. Camila has photographs of her child at various ages, from a baby to a toddler and sitting on Father Christmas's lap at the IG Christmas party. Her colleagues at work "like to see the children growing up" and appreciate current pictures. She says, "Pictures of my daughter help me get through the day. On a bad day they help me to cope."
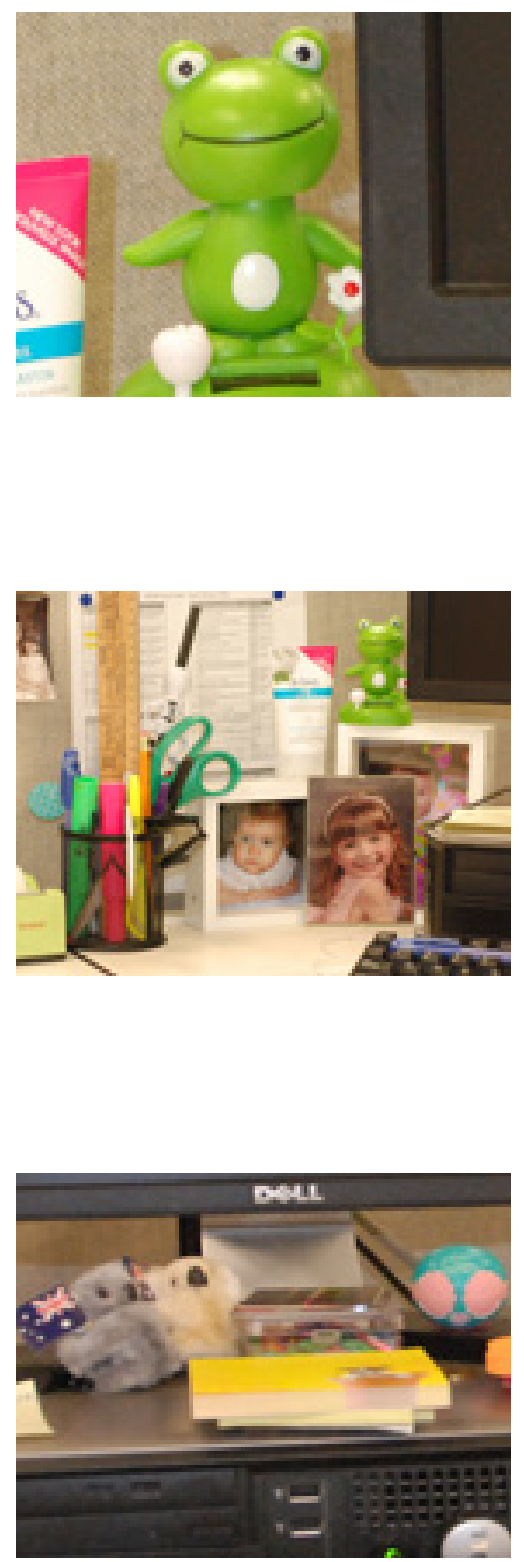

\section{Camila}


There is a cheeky green frog that dances sitting on top of her baby photos close to the base of the screen on the left-hand side. A tiny car holds decorative bulldog clips by the calendar on the right side of her screen, and on her hard drive below the screen is a collection of colourful post-it notes, a fish in the shape of a ball that opens its fins to expose its eyes (a McDonalds happy meal toy), and two koalas with Australian flags. She explains the koalas were brought back by her cousin from a trip to Australia. She tells me "the toys remind me of my daughter, I miss her during the day". She shares a nice story about the toys. Her little girl plays with the toys in the car and then slips them into her mother's handbag so Camila finds them when she gets to work. Camila says they are "great icebreakers for someone new" in the department, and create a place to start a conversation. She tells me about a co-worker who has a collection of hundreds of happy toys around her workstation. Each time she moves she packs them into a shoebox and carefully rearranges them when she settles into a new location.

Like her co-workers, Camila has a number of IG-related magnets that celebrate United Way campaign donations and anniversary cards that mark the years worked at IG. She wonders if displaying them is "obsessive". But she answers her own question with the assertion that "I feel proud, I worked hard for it". There is a photo-strip from a photo booth of a masked man and woman exchanging a kiss. Camila explains these images were taken at an IG formal masquerade ball from Christmas 2011 that she attended with
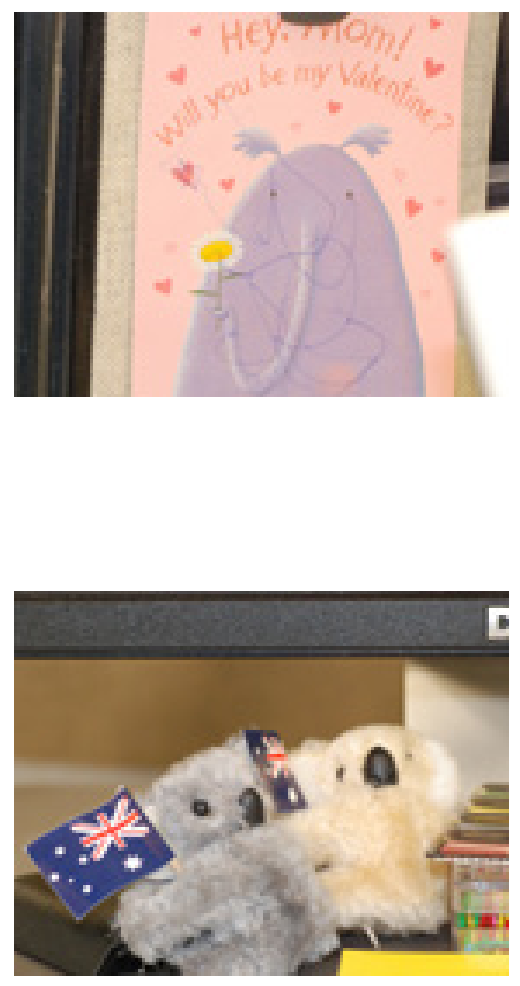
her husband. The teams also exchange secret Santa gifts at Christmas and these things often find their way onto the desktop; her white picture frame is an example. She notes that about half of the personalia on her desk are planned and the others arrive spontaneously. The magnetic letter $D$ at her desk was the last remnant of a set of letters from home and for some reason she brought it to work. Co-workers will "notice anything new on the desk". 


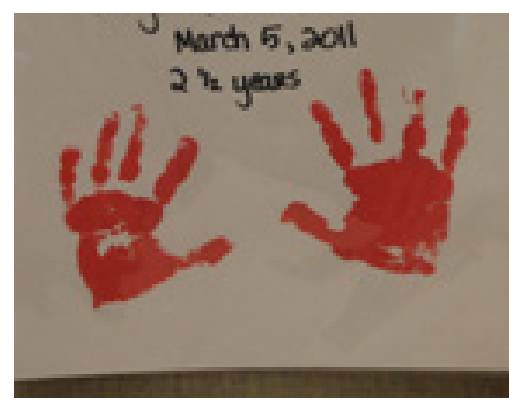

Her desk is her favourite place in the office with its reminders of her daughter and the closeness of her other co-workers. She suggests her co-workers would be able to identify her from the things on her desk; "someone in my department would know it's my desk."

We talk about privacy at her desk. She says, "It isn't too bad, but I have to tune out noisy people. I turn up the music, we are allowed to listen to our own IPODs or CDs. They don't mind what we you do, if you do your work." Personal telephone conversations are a problem because employees are discouraged from having them at their desks. "I go out into the hallway - it's the only place for private conversations." This makes arranging dental or doctor appointments or talking with the bank difficult. Camila reflects "it would be nice to have a spot to go to make personal calls". If she has to have a personal conversation at the desk, she faces the wall or sits lower to the desk, but this isn't a comfortable or convenient solution.

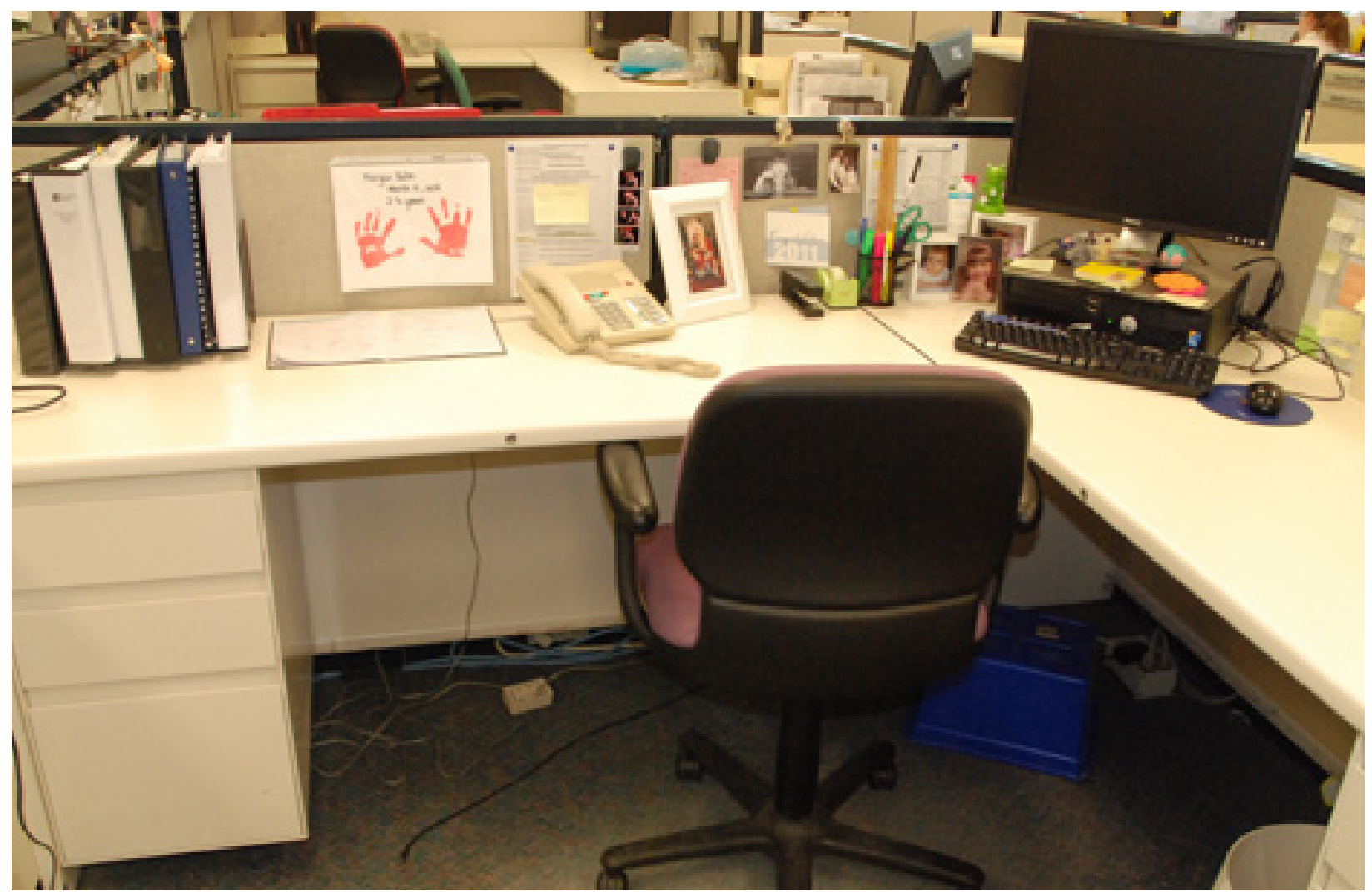


Laura has worked at IG for nine and a half years in the same department and has been sitting at this desk for two years. Her desk is next to the windows and is screened on two sides with panels; she takes an occasional break to enjoy the view. Her work is not routine and changes everyday. Laura's desk has very little personalia on it and she doesn't like to have her work space cluttered. She says a cluttered desk in the morning would mean she couldn't concentrate

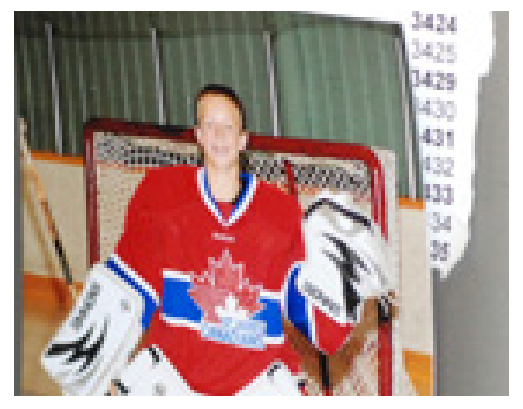
all day. There is a picture of her son, who has just turned 14 , in his goalie gear. He plays AA hockey for St James and won a championship this year. He is living away from home with his grandparents because of his hockey commitments in the city. Laura lives in the country and obviously misses him. This photograph is displayed on the hard drive on the right side of her screen, and I am told later by a co-worker that sometimes this photo gets put away too.

Laura uses earphones to listen to music when she needs to concentrate but she says co-workers "can interrupt at any time".

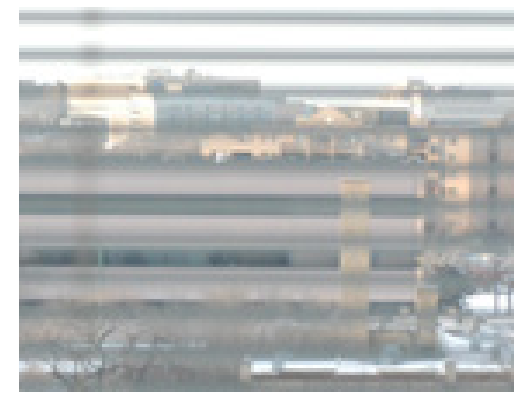
She takes her personal calls in the hallway when necessary but she doesn't make a lot of private calls. Teamwork for Laura may involve visiting another desk or more formal meetings but she says "getting up is good".

Laura has a system to identify a document when she first looks at it. She uses a different coloured marker for each day of the week. She keeps her markers in a Tim Hortons papercup that is on her desk next to a stapler and a yellow star made of soft material. This was given to her by her son and "I play with it to relieve stress".
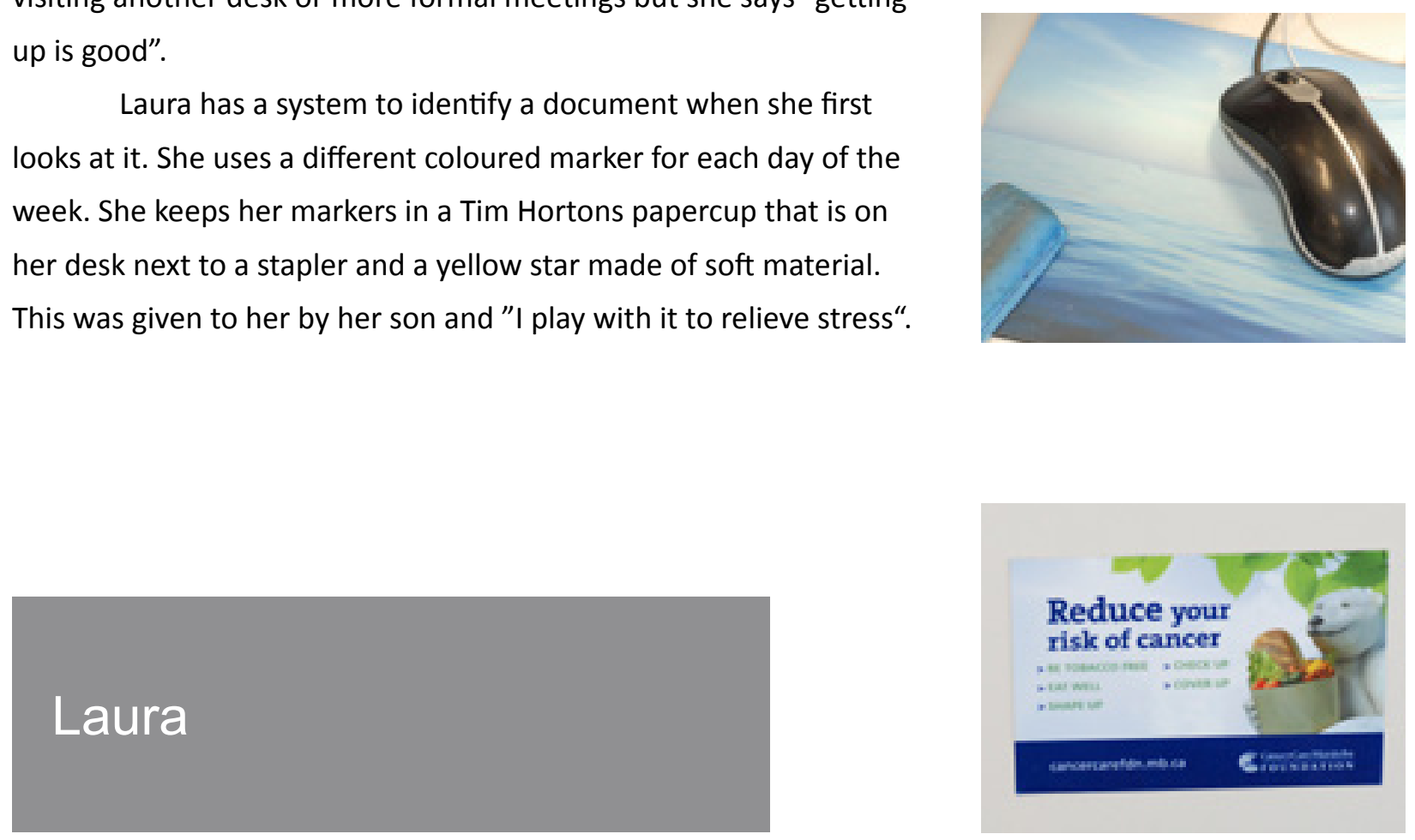


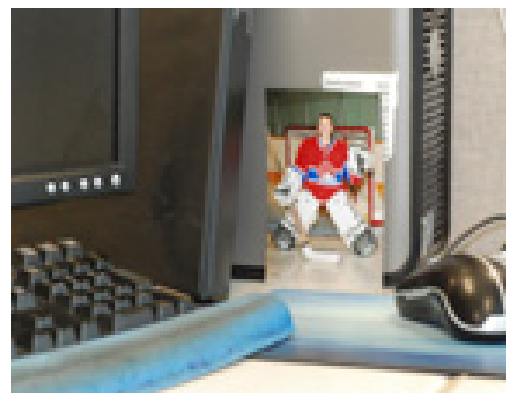

Laura has the IG social event calendar pinned up and explains, "IG organizes social events mainly over the RSP season to try to recognize the extra work and long hours worked." She shows me the mouse pad that was a gift from management; she chose the blue one. A magnet on her desk drawer from Cancer Care was given to her for participating in a wear-jeans-to-work day. When I ask if this display is for her benefit only, she says, "You betcha!" She says her desk doesn't invite co-workers' comments unless she changes something.

Laura likes to look outside during the working day for

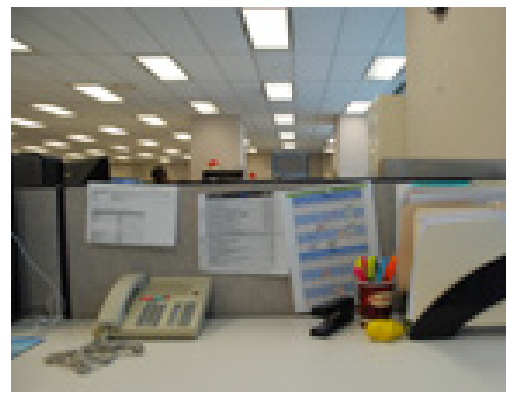
relief from her intense screen-based work. She complains the boss's desk is too close to hers and suggests it should be moved so she wouldn't feel so scrutinized. Laura tidies her desk before leaving each evening, making sure everything is put away. She doesn't dust or clean down her desk as some of her co-workers do.

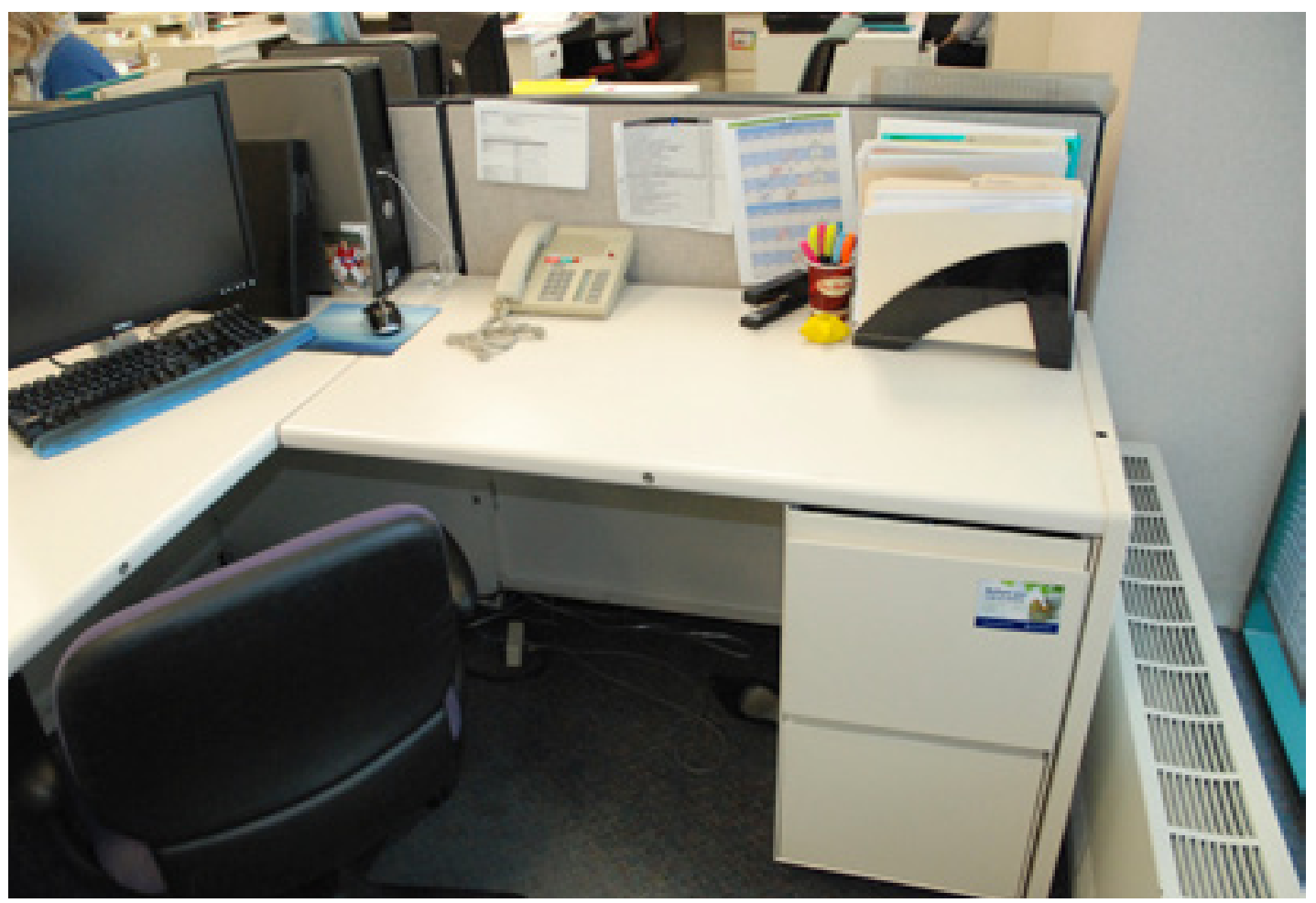


Reyna was born in the '70s. She comes from the Philippines and has worked for Investors Group for eight months, with six of those months spent in this department at this location.

When things get busy, she uses her headset to shut out external distractions and is able to concentrate by focusing on her monitor. Her desk is only screened on one side and is open to her neighbour on the other. This gives Reyna a very small area that she can personalize. She is a processor working with repetitive transactions. She has placed her computer screen to face the dividing panel so her back is to her nearest neighbour. There are very few personal items at her desk as she says she prefers to focus on her work. She is a private person who "likes to separate work and home". Later in our conversation she tells me she doesn't want personal things on her desk "that might generate conversation about my personal life". She mentions the problem of having to take personal calls in the hallway at lunchtime, as IG policy prevents the women in this department from taking calls at their desks during working hours.

Tucked into the corner of her desk is a red tinsel Christmas tree (it is now February), obviously a remnant from Christmas celebrations in the office "It was given to me by a co-worker," Reyna explained, and has "forgotten to put it away". On the left side of her screen is a drink flask that she fills twice a day along with the paper towel she uses to clean her desk every morning. The Satsuma plum stickers on the file drawers are a remnant of the previous occupant of the space.
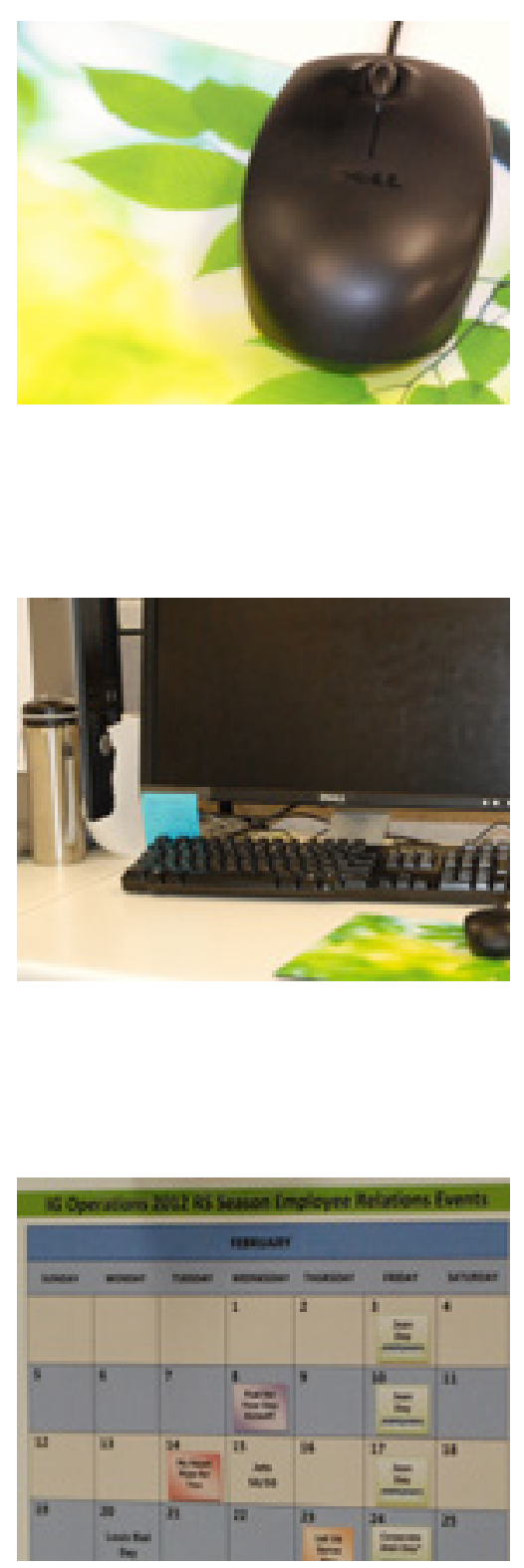

Reyna

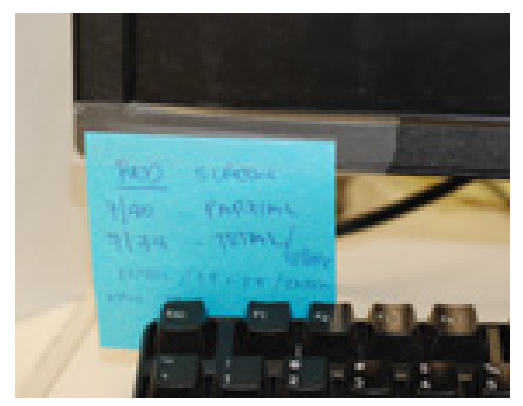


Reyna has the social event calender posted on her hard drive, and talks about these events as significant to relieving the monotony of the week. There is "an event for everybody" that occurs during the working day; some are games and workers take 15 minutes off to participate, and "sometimes they bring us food". Reyna explains the social events are how IG shows its appreciation for their hard work. I ask about the fresh green mouse pad on her desk and she tells me "green is very good for the eyes". It has its own narrative, having been

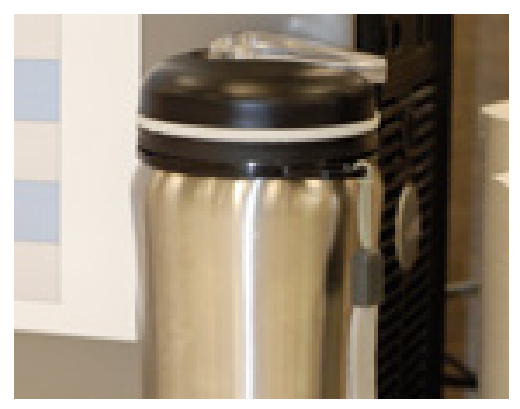
brought from the Philippines by a co-worker at a previous employer, and given to Reyna. She tells me "it brightens every single moment of the day". She describes her desk as her favourite place at IG because it is "comfortable". She has the codes she needs for her work pinned up on the right-hand side of her screen to remind herself to check them. At night she removes the day's files from her desk and tidies up so she is "organized for the next day". Reyna likes to feel in control.
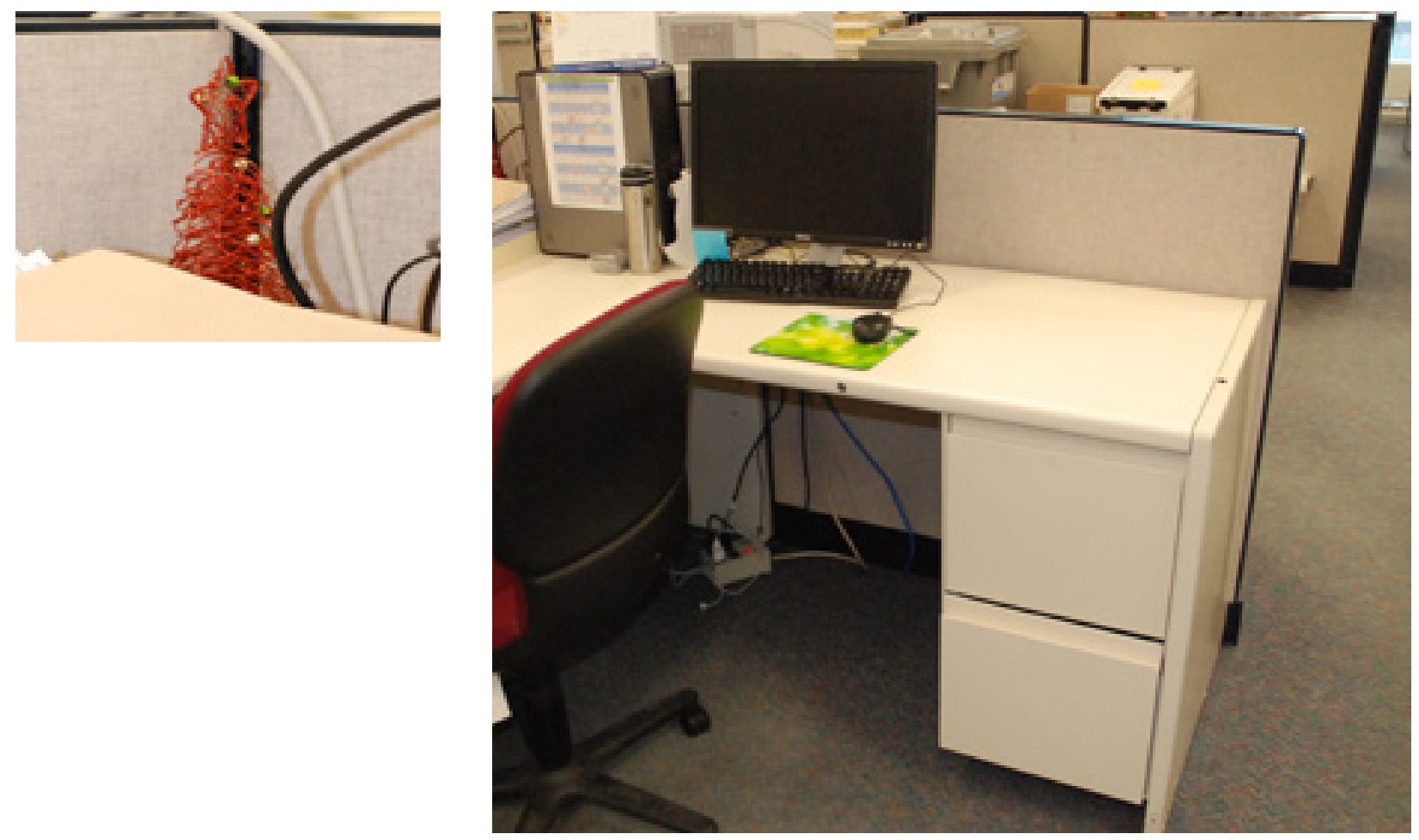
Felicity is in her mid-30s. She is a Canadian with ten years at IG; six years at her current department and one year at her current workstation location. Her desk is spare and clean. Felicity has either cleaned her desk in anticipation of the interview or she is a very tidy person. There is a headset at her desk but Felicity uses it for phone conversations rather than to listen to music, and she is able to control the volume without disturbing other colleagues. She talks about adjusting her working day depending on what she needs to accomplish. If the project needs particular focus she will work on it in the morning and tune out other activities around her. Felicity doesn't see her work as routine, although it used to be. "Over the last year I don't know what I will be doing when I come in" to work, and there is "a good variety".

She sits facing out into the office "so I can see anyone approaching me" and likes to work with the screen lower so she can see over it. Her hard drive sits next to the screen and is covered with

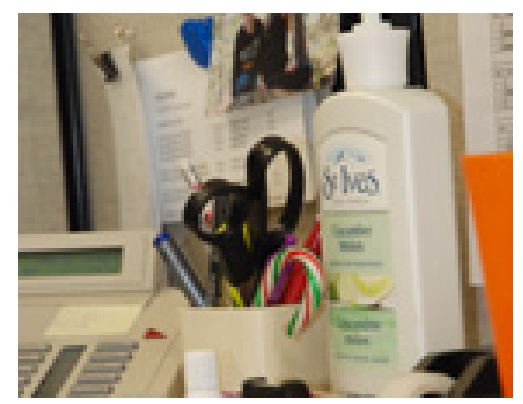
images of family members, kids and summer snapshots at the lake. She explains they are her nephew and niece and she likes to be able to see them as she works. They "lighten up a difficult day" and represent "something to look at when you are frustrated". The location on her hard drive makes the photos "easy to look at".

There is no company policy she is aware of about what she can display at her desk. However, she thinks she would have been told if anything was considered "inappropriate". I ask about the hooded figure (looks a bit like a Star Wars character) that sits on the top of her workstation panels and she shared the story of its origin with me. It is a mascot of the department and has travelled around the department, spending time on a number of desks.

\section{Felicity}

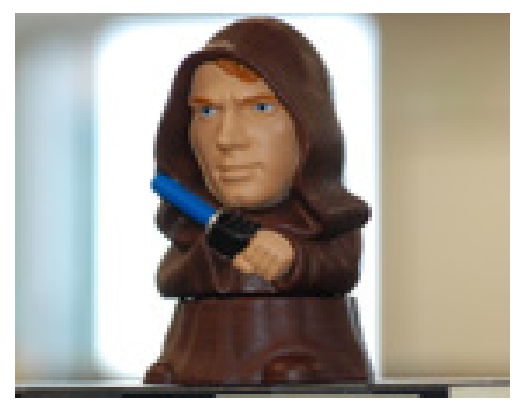



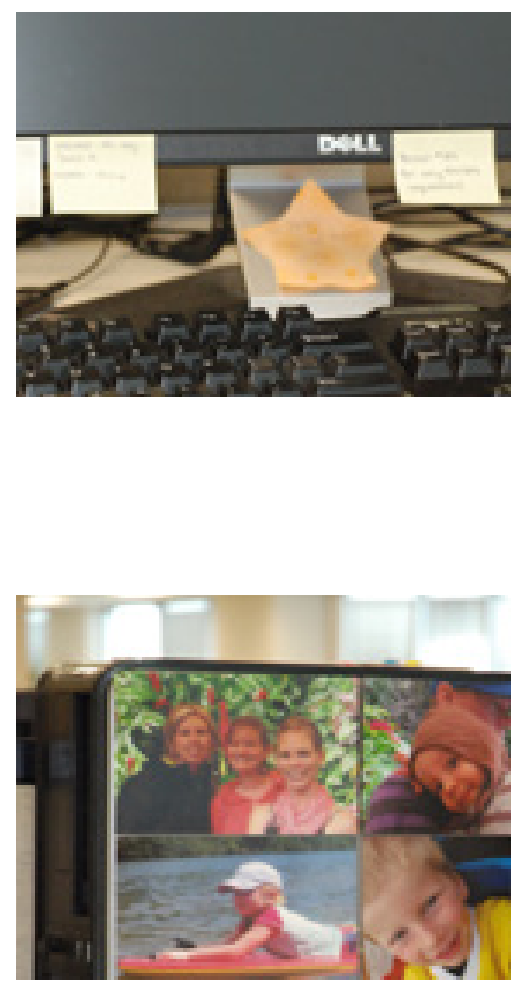

Felicity recalls that it came into the department with a co-worker's visiting child and stayed on even after the co-worker left.

The small silver cup that sits next to the hard drive is from a Christmas party with work colleagues on a winning bowling team, although "none of those people are in the department anymore, the last person to leave passed off the trophy". A red shoe ornament hanging to the right of her screen was a gift from the team leader Kelly-Jo. Two work anniversary cards for 2012 and 2013 from IG are prominently displayed. When I asked her why she displayed them she was unsure. "I don't even know why," but after further consideration she offered "they relate to our employee benefits, we earn an extra week of holidays" after a certain number of years in IG's employment. Felicity's desk also displays a number of stickers received for donations to causes supported by IG employees, such as the Christmas Cheer Board and the Rainbow Society. She suggested, "People like to feel they are contributing to something else."

Felicity sees the personalization of her desk as a balance between her work and home life, and while she puts the personalia there for her own benefit she seems to enjoy her co-workers asking about the pictures. She would like to have more pinable surfaces at her workstation. When asked about her favourite space in the workplace, she identifies her desk, with her least favourite space being a desk she worked at in "the closet", a small room with four co-workers and much less personal space and desk space.

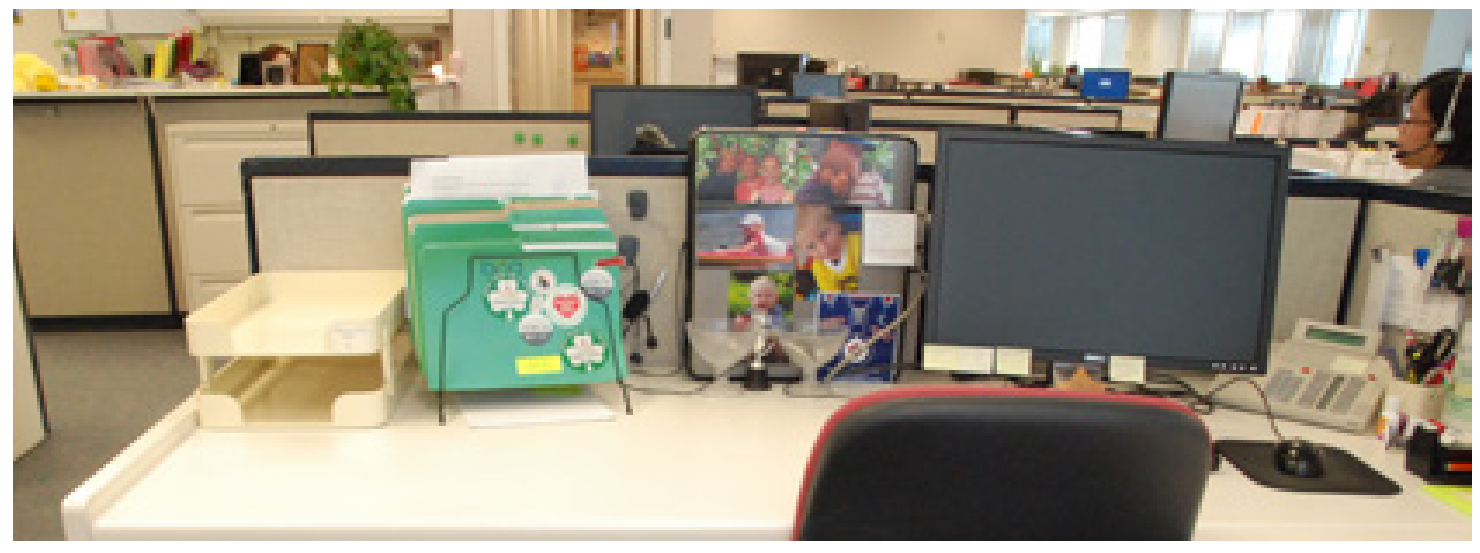


Leigh was born in the Philippines and is in her early 40s. IG has employed her for nine years and she has worked in this department for four years. She has only been at this workstation location for a month. She is teamed up so she can consult with her neighbours on similar work. She works facing the aisle and looks across at other workstations in the centre of the floor space. Her work requires her to sit for long periods of time working on the computer and phone. It is routine work, she says, but the details of each file are different. She doesn't like to work facing the window so she has her phone and headset on her right-hand side and her monitor facing the aisle. She says she has no problem concentrating but uses the headset to "let others know she is working". Team meetings usually happen at the leader's desk. She likes to work with her manuals on her desk for easy reference, but strives to "keep paper under control". She has a few marker pens and a nail file in a container on the right side next to her screen, but personal items are limited to a thermos, hand cleaner and hand cream further away from the screen on her right. The objects she has chosen to display in her new workstation are fairly small in number, mostly photographs of her two daughters who are now seven and two years old. She has the two girls photographed at the same age contained in one frame located on the right side of her screen and notes how much they look alike. She has more current images of them framed on the left side of her screen. She explains that it "feels relaxing when I look at them, especially when work is stressful".
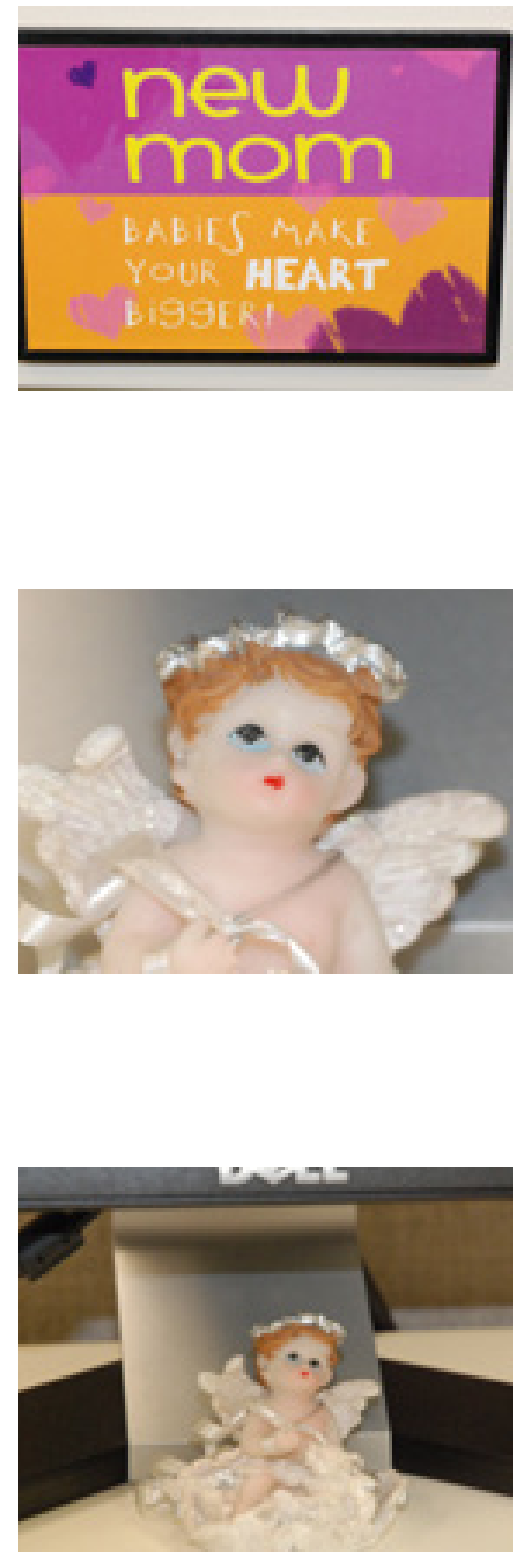

Leigh

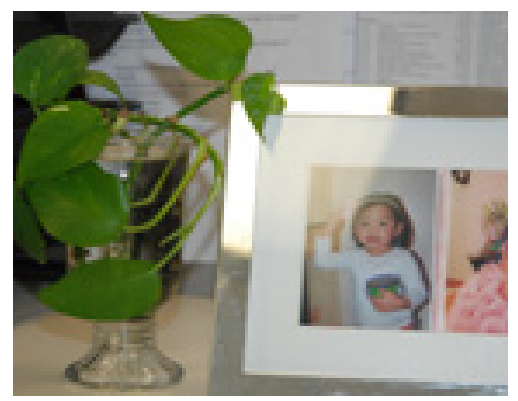


Leigh is obviously a proud mother and she talks about the special significance of the MOM magnetic sign on her file cabinet. Her co-workers gave it to her when she returned to work after baby number two. It says "New Mom, babies make your heart grow bigger." She also has a ceramic angel, given to her by friends at work; it is her "guardian angel at work". She has taken a piece of a colleague's plant and is waiting for roots to sprout. It sits in a glass by the framed family photograph and provides "something green at my desk, a real plant, not something artificial".

Leigh tells me that everything has its place on her desk, and

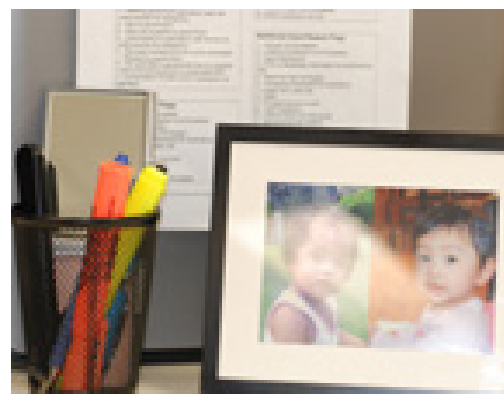
she cleans it regularly to ensure good hygiene. "This helps me to think, before I start another task I tidy my desk." Leigh talks about her desk as her favourite place at IG, and describes it as having "a serene feel, my daughters are there". They effectively surround her while she is working.

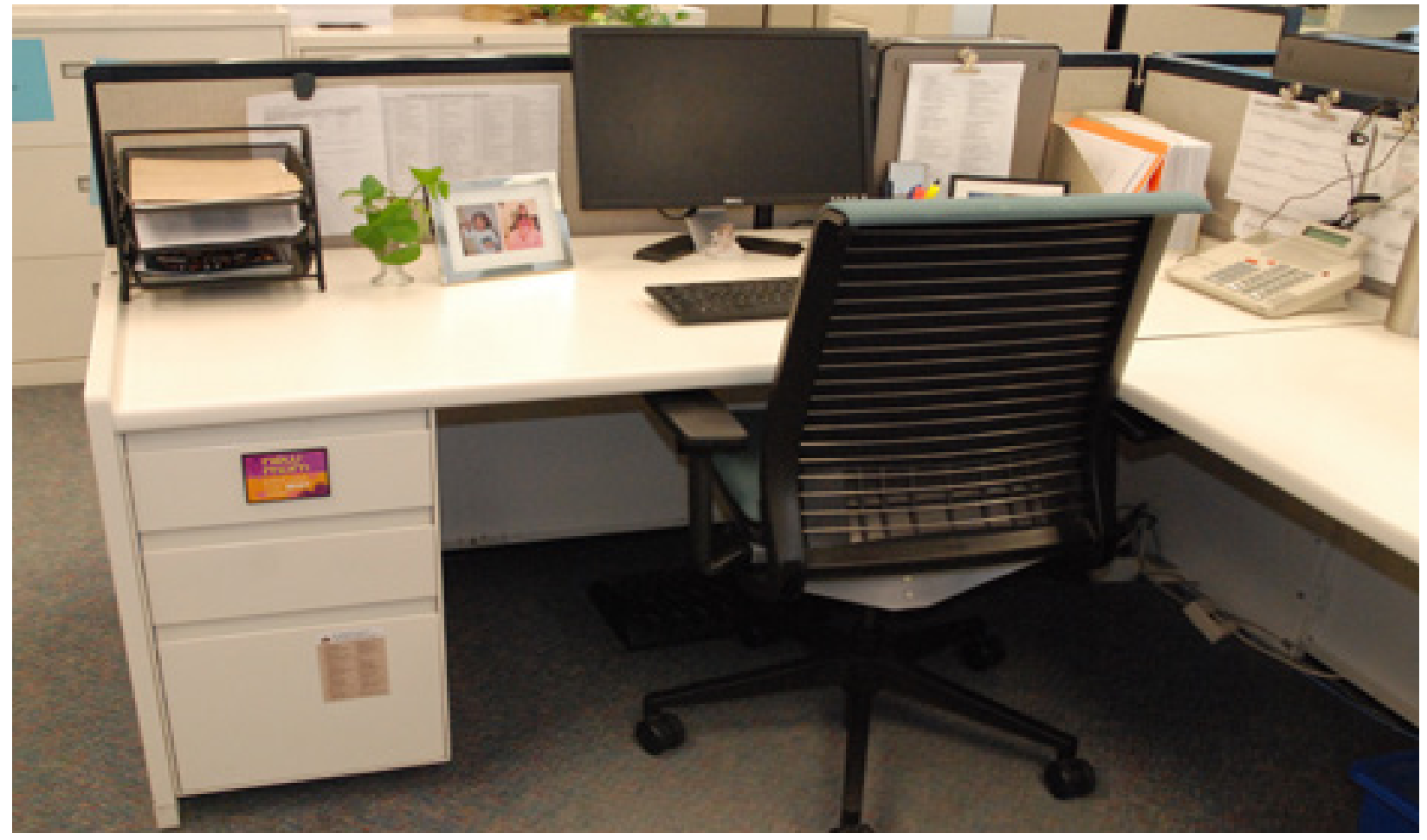


Rose comes from the Philippines originally. She is in her mid-30s and doesn't have any children. She has worked for IG in this department for three years and has been sitting at this location for about a year, her first year as a full-time employee. She listens to music on her headphones or just focuses to get work done, and "because I am small I can hide behind my monitor".

She decribes her work as routine "with some special cases that require new skills". Her desk is located next to a large window but she chooses to "face the neighbourhood" of adjoining cubicles. She loves being located close to the windows although it gets cold sometimes. She is still in training and is able to ask advice from her team for complex problems. She meets with her team leader one-on-one, once a month, but the team has projects or fundraiser meetings once a week. There is a busy social program at IG. The last Friday of each month has events like paying a donation to wear jeans to work. She proudly shows me her first anniversary card from IG and explains she received two employee recognition awards in the form of vouchers to select a gift from the IG employee website. She chose a headset and a purse. She notes they "keep my spirits up" and "help to motivate me', but they are also a source of curiosity for her workmates who want to know how she earned them.

Rose doesn't have any photos on her pin board, and says she can't keep up with photos of her nephews. She is more likely to display personal cards, but she does have a rather extraordinary ornament on her desk. It is a small paperweight in the form of an underwater scene, with blue dolphins leaping over a water-filled globe with a swimming dolphin inside.

Rose
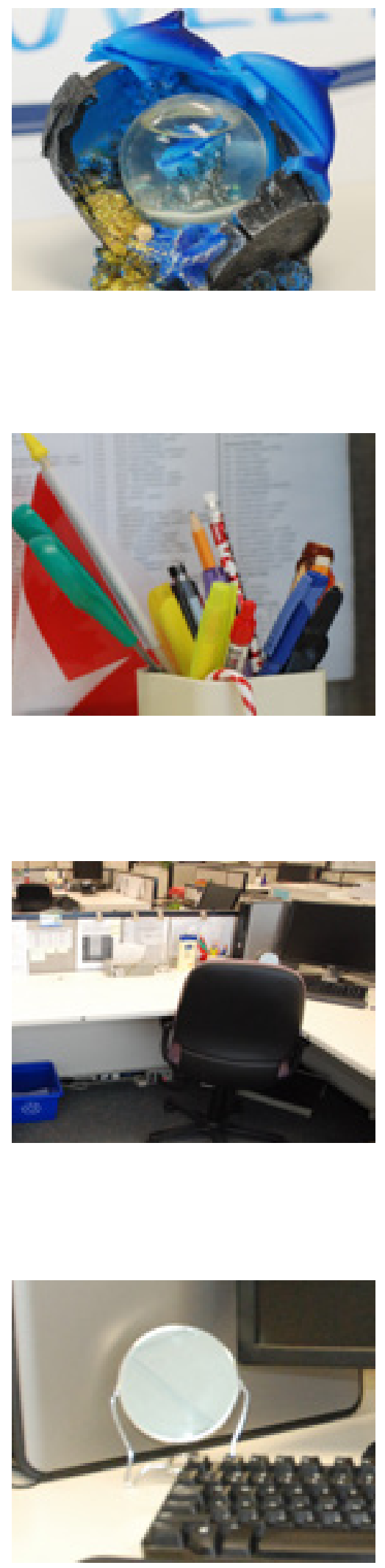

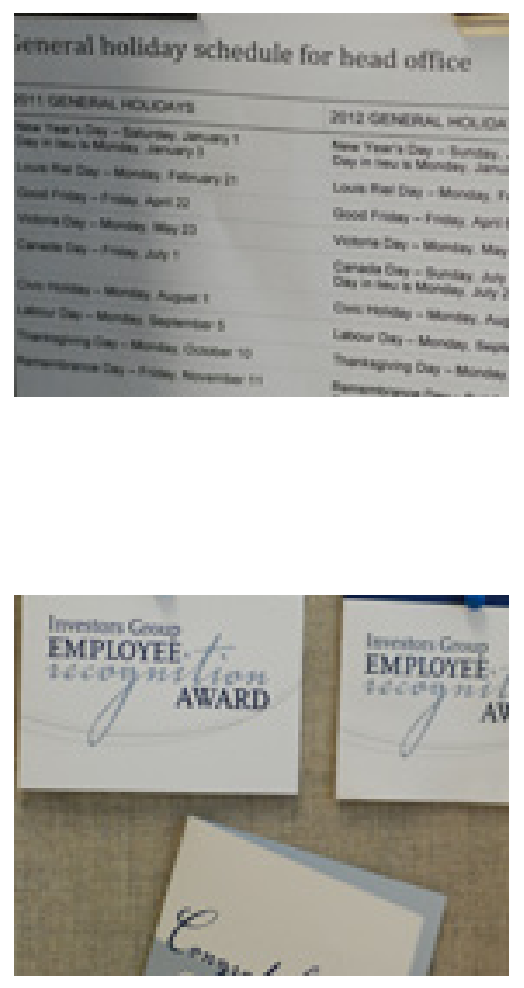

She brought it from home and it functions as a conversation starter with her co-workers who comment "this is so nice".

Rose values having personal space and wants it "to reflect what I am" because she spends so much time at work. She is very efficient and likes to keep folders aligned and paperwork to a minimum. She also likes to be able to see the desk surface clean and clear. She cleans her desk surface once a week and takes pride in how her work area looks.

She has a memento from the Philippines that was given to her by a co-worker who visited home. A Canada Day pencil was given to her by the social committee, and they also gave her a flag when she took her citizenship exam. These items are located in her pencil container at the left side of her computer along with the headset that was provided by the company for training. She uses it to listen to music on her computer.

There is a mirror tucked into the space below the screen. When I ask her about it she shows me her braces and explains that "after eating I check my teeth." She also has a water bottle at the desk, as she is not a coffee drinker. We agree that the focus on her desk is mainly work items, and things that motivate and inspire her. The desk is carefully laid out to provide the information she needs in an efficient and tidy way. She uses online manuals so she doesn't need to store them at her desk. She says "I have everything I need" and "I enjoy being here". At lunchtime she likes to have lunch with office mates and go to the mall for a walk, and so she consolidates her breaks to have one hour of free time.

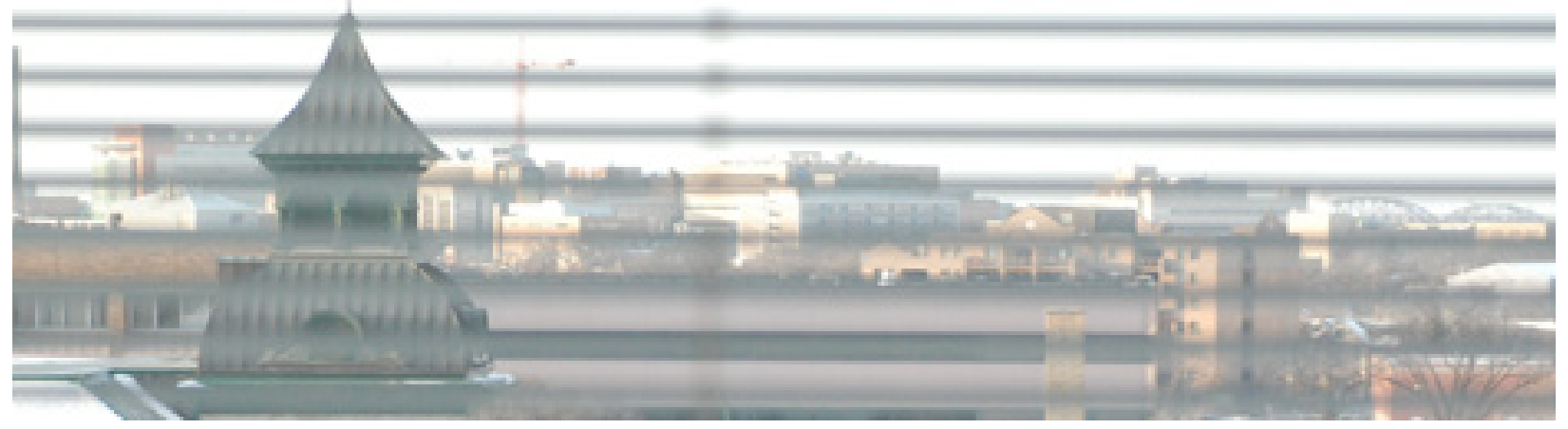




\section{CASE STUDY ANALYSIS}

'Je suis l'espace ou je suis' - 'I am the space where I am'.

(Arnaud quoted in Bachelard 1994: 137)

\section{Introduction}

Camila has a turquoise fish in the shape of a ball that opens its fins to expose its eyes (a McDonald's Happy Meal toy) and two koalas with Australian flags positioned just under the logo on her computer screen. Camila's little girl plays with the small toys while travelling in the car to daycare and then slips them into her mother's handbag so Camila discovers them when she gets to work. Camila explains, "The toys remind me of my daughter, I miss her during the day."

The space of the women's desks is lived, personal space. For some the area occupied with personalia is very small, closely focused around the computer screen at the nexus of the two work surfaces. This space is occupied by their most valued personal items - photographs, personal messages, hand lotion, a small mirror for checking teeth or lips or noses, and often a collection of neon markers and pens, as well as codes, shortcuts and other important work-related information. The area is in their peripheral vision while they are working and they find these chosen objects and images relaxing, colourful, comforting reminders of life outside of work, and the reason for their stressful and routine office lives. The personalia connect them to their other lives as mothers, wives and friends.

Some of the women who have occupied their desks longer have extended their collections of personalia along the top edge of the cubical panels and pin board to the end of the area that defines their desk. As the objects radiate outwards, they become more public and less personal, having more to do with the importance of co-worker 


\section{CHAPTER SIX}

\section{CASE STUDY ANALYSIS}

'Je suis l'espace ou je suis' - 'I am the space where I am'.

(Arnaud quoted in Bachelard 1994: 137)

\section{Introduction}

Camila has a turquoise fish in the shape of a ball that opens its fins to expose its eyes (a McDonald's Happy Meal toy) and two koalas with Australian flags positioned just under the logo on her computer screen. Camila's little girl plays with the small toys while travelling in the car to daycare and then slips them into her mother's handbag so Camila discovers them when she gets to work. Camila explains, "The toys remind me of my daughter, I miss her during the day."

The space of the women's desks is lived, personal space. For some the area occupied with personalia is very small, closely focused around the computer screen at the nexus of the two work surfaces. This space is occupied by their most valued personal items - photographs, personal messages, hand lotion, a small mirror for checking teeth or lips or noses, and often a collection of neon markers and pens, as well as codes, shortcuts and other important work-related information. The area is in their peripheral vision while they are working and they find these chosen objects and images relaxing, colourful, comforting reminders of life outside of work, and the reason for their stressful and routine office lives. The personalia connect them to their other lives as mothers, wives and friends.

Some of the women who have occupied their desks longer have extended their collections of personalia along the top edge of the cubical panels and pin board to the end of the area that defines their desk. As the objects radiate outwards, they become more public and less personal, having more to do with the importance of co-worker 
relationships, worker recognition and the corporate team, and the mythology of the happy office worker through mementos of social events and fundraisers.

The office environment in the Investors Group headquarters is a space of representation where each workstation cubicle imposes the order of the hegemony on the bodies of the women workers. The conceived space of the office is systematized and standardized, with each workstation looking exactly like its neighbour. The environment speaks of anonymity with uniform furniture imprinted with corporate values and team identities. Positions next to the windows are coveted, like window seats on an aircraft, because they present the illusion of having more space. The space outside the window presents the opportunity to remove oneself for a few minutes to daydream. The quality of natural light varies through the day, with large windows providing maximum access to views and connection to the outside weather conditions. Venetian blinds attempt to filter strong sunlight on the southern orientation.

De Certeau celebrated the notion that the everyday person retains some vestige of control over their environment. De Certeau patiently develops a research methodology, derived from sociology, anthropology and narrative research, to uncover these slippages and subtle practices. In "The Practice of Everyday Life Volume 2", De Certeau and his circle of young graduates study the city and its inhabitants to understand the cultural practices of the everyday; practices such as cooking, reading and walking around the city. They move beyond the usual depiction of the mindless masses to closely analyze the everyday practices of personal consumption (1998:xx). De Certeau is most interested in the purposes to which the consumed objects are put, looking for small practices of resistance. In the street it might be the path taken home that delights in small diversions; in everyday life it might be the role of a café or bar in the satisfaction of an individual's need for community or an escape from family expectations.

This chapter of the dissertation looks at the close environment of 11 routine office workers in the financial services industry to observe and study embodied space and the tactics the women clerical workers employ to claim space as their own. As my 
methods were informed by De Certeau's approaches, I began by writing a narrative for each woman based on my interview field notes (Chapter 5). Interviews were typically 60 minutes long with a semi structured interview format (Appendix 1). At the request of IG, employees were interviewed in a meeting room and not at their desks; my photographs of their desk space served as empirical evidence that brought a new perspective and implied value to their personal space. The photographs have been edited into a visual composite for each woman's desk (Chapter 5). Using the narratives, field notes and photographs, I developed an analytical model for the analysis in this chapter that springs directly from the values and priorities identified by the women at their desks. It starts from the organizational culture and addresses social networks and habitus, identities and values, tidiness and control, time and space, and private space. The analysis situates the photo-elicitation research within the framework of the organizational culture of Investors Group gleaned from company literature, interviews with senior management, and the former CEO and Chairman of the Board, as well as Robert Jones' book, Building Futures: A History of Investors Group (1993). I also talked to middle managers and the concierge, a long-term employee.

Investors Group was established in 1926 in Canada to meet the financial needs of the salaried working class with a weekly personal savings scheme. IG introduced the first Canadian mutual fund in 1950. By the 1980s the firm was restructured to improve internal and external communications. The company has grown exponentially since its establishment by appealing to the growing middle class as an unpretentious, egalitarian organization with a sense of civic responsibility. IG has an established reputation as a good employer; offering employees low interest mortgages and stock purchase incentives as well as instituting exemplary employee recognition programs. The company also has a strong record of civic responsibility and community support and development. An example would be the recent construction of the Investors Group Field at the University of Manitoba as the home of the Winnipeg Blue Bombers football team. IG partnered with the province to fund the project. The family culture of IG, with its strong social committee, may be viewed positively in terms of it being caring and 
supportive, or it may be seen negatively in terms of being controlling and motivated by corporate needs.

Investors Group is a hierarchical organization where the power resides with the managerial elites, the majority of whom are men. The relationship between the organizational culture and women's values is one of imbalance due to the normative structure of hegemonic power. This relationship generates a differential space, a space of tension and potential. It is here that we see the women's operations and tactics as a technique to take ownership of their desk spaces. The co-dependency of the women's values and office team culture are clearly seen in the symbolic value of IG awards and team leaders' gifts of recognition. The women use practices of tidiness and cleaning routines to establish their professionalism and gain control over the steady stream of work that crosses their desks. These operations may also be seen as tactics of resistance in response to specific environmental conditions over which they have little control. "The place of a tactic belongs to the other. A tactic insinuates itself into the other's place, fragmentarily, without taking over its entirety, without being able to keep it at a distance" (De Certeau 1984: xix).

The women highly value their social networks and create an identity at their desks that reflects their work relationships, past and present. Personalia at their desk were most often described as gifts from co-workers and friends; they take the form of birthday and thank-you cards and poems, coffee mugs and office supplies, tchotchkes and travel mementos. These objects were described in terms of the event and person they celebrate. Sharon received a rose from her co-workers for her $60^{\text {th }}$ birthday; it was still in a special place at her desk a few years later. Pictures of family are sometimes shared for personal reasons, but the photographs generally provide motivation and stress relief to the women. The personalia become a talking point for others, as it invites connectedness and spontaneous conversations. It has an important role in the representation of these individuals as team players. Desks become home places, and heterotopias or ideal worlds where the women can exercise a sense of control and 
indulge in daydreams that provide relief from the stress of the continuous flow of work at their desks.

The research found that all of the women used their desk space to represent individual and multiple identities. Those who chose not to share personal information at their desks were quite open about not conforming to the expected norms of the office, and articulated a desire to keep their personal lives separate from their work lives. A few women commented on the "empty desks" of co-workers as not being welcoming, thus reinforcing the habitus of personal display as an invitation to coworkers to know each other better. Bourdieu defines "habitus" as socializing norms that guide behaviour. Habitus is socially constructed and constantly relegitimized by an interplay between structure and agency (Bourdieu 1984).

\section{The Locus of Personal Space}

Investors Group has no formal policy that prescribes the nature of personalia that can be displayed at the desk. None of the women seemed constrained by overt organizational censorship and all viewed their desk space as their own space, often describing it as their favourite place at work.

Levels of privacy for the personalia at their desks became clearer as the research proceeded. The internal corner of the desk where the screen was most often located became the most private space. Tchotchkes and photos located in this area were the most personal, and often positioned so they couldn't be easily seen by co-workers. The narrative associated with these objects are often more emotional and personal. Perl reflected on a half-hidden snapshot of a group of people that was taken in Vietnam. She explained that before coming to Canada, she had been co-opted to set up a new operating system in Vietnam for a former employer. She had not wanted to go but insisted on taking a female work friend with her. The photo records a happy time, but it is not one she shares with her current co-workers. Further away from her screen is an image of her taken with Father Christmas. "I was pushed (by co-workers) to have my picture taken with Santa, it reminds me of a Canadian idea of Christmas." The more 
public display of this image demonstrates Perl's commitment to her co-workers and their implicit expectations, and her concession to the operations of social networks and the office habitus.

As objects are distanced from the screen and become more readily visible to others, they also became more related to organizational, team and social values. Tchotchkes often had narratives that involved co-workers who were no longer in the same department, or there were family items for social networking purposes, positioned to become the subjects of "icebreaking" conversations with new co-workers. They became symbols that identify the women as moms or aunties, cat-lovers and friends. These items encouraged others to linger and engage in conversation.

For some women the need to keep their personal lives distant from their work lives is clearly reflected in the personalia or lack of it at their desks. Laura's desk has very little personalia and she doesn't like to have her workspace cluttered. She says, "A cluttered desk in the morning would mean I couldn't concentrate all day."

Reyna is also a private person who says she "likes to separate work and home". Later in our conversation she tells me she doesn't want personal things on her desk "that might generate conversation about my personal life". These examples demonstrate the complexity of the relationships individuals have with the habitus of the office and their expectations of others. Both Reyna and Laura understand the significance of being team players. They participate in IG events, display the IG event calendar and speak about welcoming others to their desks, but for them the private/public divide is much more difficult.

\section{Identities and Values}

De Certeau describes tactics in relation to the everyday of living, as the creative intelligence we employ to ensure our environment works for our needs. Tactics allow ordinary people the capacity to subvert the all-pervasive pressures of consumerism, economics, and politics to assert their individuality and autonomy. Amanda is a team leader. Her desk is at the end of a line of cubicles against a window. 
Under her screen is a red smurf, a little plastic devil. She describes it as representing her true personality as a "troublemaker". She has reappropriated this object to create new meaning that is very personal to her, and that becomes obvious by its placement at her desk. The red devil acknowledges aspects of Amanda's identity that don't fit seamlessly with her image as team leader. She subverts the smurf character to remind her of this aspect of herself, and as such knits together a more complex and authentic representation of her own identity, one that speaks of autonomy. De Certeau looks at such practices of consumption to uncover the ways in which the consumer appropriates and reappropriates the objects of their consumption to create new meaning (1984: xiii).

Through the research I found many examples of poaching (the reappropriation of objects to serve another purpose). The women use their hard drives as pin boards when pin-up space is insufficient, and organize personal items across the front of an unscreened desk to create a territorial boundary between co-workers. The reappropriation of office supplies that become gifts from departing co-workers speaks of poaching, as does using the computer screen to hide behind when making illicit personal calls from the desk. Routines for cleaning the desk give the women the opportunity to pause before starting a new project. These IG offices offer very little freedom to the women who occupy them. They are highly supervised and constrained by the quantity of work they need to address in a day.

The women complained about very few aspects of their work lives; however, they consistently mentioned their concerns with the cleanliness and hygiene of the washrooms on their floor. Most of the women had rituals around the cleaning of their desk surface as a daily or weekly exercise. I interpreted this tactic of cleaning as a partial response to the condition of the washrooms, which they cannot control. But the cleaning ritual also brought closure to the endless stream of routine work to be done. This ritual marked the end of the day or week, and exerts a habitus where moral virtues are expressed through bodily actions, emotional states, thoughts and social performance (Mahmood 2001). The virtues of cleanliness and order are particularly apparent at the desks of the Southeast Asian women. 
Filipino women are the most visible group of foreign workers in Canada today (Bonifacio 2013). Bonifacio argues that due to a number of historical factors they have become "ideal" migrants. They are well educated and assimilate quickly into Canadian society. "They are also the most highly socially integrated group of women from Asia due to intermarriage and a western colonial legacy" (2013: 2). Despite their capacity for integration, identity for immigrant women is complex. "Transnational border crossings between 'home' (country of origin) and 'other home' (host community) for permanent residents and citizens make the notions of identity, citizenship, and community appear fluid and unbounded by a specified territory. Filipinos in diaspora, especially women, create and recreate semblances of what it is to be 'at home'"' (2013: 19).

Reyna, Perl, Molly, Leigh and Rose are all from Southeast Asia. Perl comes from Indonesia and the other women are from the Philippines. They all have some small item at their desks that evokes home. I ask Reyna about the fresh green mouse pad on her desk and she tells me a co-worker brought it from the Philippines for her. She tells me "it brightens every single moment of the day" and its connection to her home makes it a special part of her otherwise impersonal and very tidy desk. As a new employee she has not accumulated much at her desk apart from a small red tinsel Christmas tree tucked behind her hard drive. This is obviously a remnant from Christmas celebrations in the office. "It was given to me by a co-worker" and she has "forgotten to put it away". On the left side of her screen are a drink flask that she fills twice a day and the paper towel she uses to clean her desk every morning. The tree seems accidental in its placement at her desk but it establishes Reyna's connectedness to her adopted North American culture, where excessive consumerism at Christmas can be shocking to those raised in the developing nations of Southeast Asia.

This theme is also seen at Perl's desk where she has a Christmas gnome ornament and a red and green beaded tray that says $\mathrm{HO} \mathrm{HO}$, made by a co-worker. She explains to me that the Canadian idea of Christmas seems very foreign to her and she has these items at her desk to remind her "Christmas is a good thing (in Canada)". 
Molly has a small carved shell at her desk, a traveller's memento from a friend in the Philippines. But she also prizes a small ornament of a stork and baby that is carefully displayed on a square of mirror on the top edge of her desk. She explained this is a traditional Filipino christening or baptism gift. Leigh also has a christening gift that sits at the base of her screen. It is a fat pink cherub that she describes as her "guardian angel at work". These praying angels are often given as favours to family celebrating a Catholic christening. Not too overtly religious, these small favours are reminders of family celebrations and religious and cultural traditions for the women, and perhaps provide a place where the women recognize and share similar cultural traditions.

Symbols of the women's adoption of Canadian culture are evidenced by the display of small gifts of recognition from IG's social committee. They are proudly displayed on Perl and Rose's desks and are part of the objects they choose to talk about. Perl explains the flag mug celebrates her taking Canadian citizenship in 2004. She is "very proud to be a Canadian citizen" and reminds me that having citizenship allows her to return home for a holiday every four years. She points out "there are no old age pensions in the Third World".

These ornaments not only create identities for the women who display them, they also allow peers to recognize that a different culture is present and alive. They demonstrate the complexity of making a home away from home that honours and is respectful of conflicting and diverse loyalties.

\section{Social Networks}

Daniel Miller $(2008,2009)$ asserts that human relations are fundamental to human life in contemporary society and material possessions provide the underpinning to them, an assertion that was borne out by this research. Drawing initially from Bourdieu, Miller suggests objects socialize people to "particular cultures". The particular cultures at IG are backgrounded by the organizational culture, but in closer proximity is the team culture of the departments. Team leaders reward team members with tokens of appreciation for their hard work. My research was undertaken in January 2013, 
which is RSP season, when a lot of overtime hours are necessary to manage the workload. Felicity showed me a red shoe ornament, Laura had a coloured mouse pad, and Molly displayed a cheery fabric sunflower, all gifts from team leaders. A number of the women have notes of appreciation from team leaders, and when questioned about them explained they displayed them to show their appreciation for the recognition. If Miller's (2008) assertion that objects influence the behaviours and beliefs of people is true, these gifts of thanks are significant supports that encourage the women to continue those very behaviours that have been rewarded. The relationships within the team culture are complex and demonstrate the underlying understanding of the connectedness to others, to knowledge and sensitivity to the connectedness of categories that are part of women's ways of knowing. The women's self-identity is formed through connection to and identification with everyday experiences; as a consequence women tend to look for connections rather than dichotomies. The IG social committee recognizes and celebrates the occasions when employees obtain citizenship status with small gifts of a Canadian flag, a mug with a Canadian flag and a pencil. These object act to solidify the women's sense of belonging.

There are other sub-cultures at work, such as the lunchtime walkers. A loosely defined group of women walk together at lunchtime. It is not clear if this group participates less in organized social events but they use their lunch hour to exercise, walking the raised walkway that connects IG with Portage Place and other downtown buildings and loops around the city core.

As previously discussed, the personalia at the women's desks were often quite consciously placed to provoke and invite conversations. New employee Rose discusses her reasons for bringing a dolphin ornament to work as a substitute for photos of children, because she doesn't have any children. It is a paperweight in the form of an underwater scene; blue dolphins leaping over a water-filled globe with a swimming dolphin inside. It functions as a conversation starter with her new co-workers who comment, "This is so nice". 
Aids to conversation are important to most of the women. They are expected to welcome others at their desks to facilitate the collaboration that is required for their work, but they also wish to appear approachable and friendly. Co-workers notice when there is any change in the personalia at the desk and always want to see recent photographs of children, grandchildren, nephews and nieces. These photographs give glimpses into the women's lives away from work and allow friendships to develop. However, this is not always a welcome outcome. Laura has a picture of her son, who has just turned 14, in his goalie gear. He plays AA hockey at St. James and won a championship this year. He is living away from home with his grandparents because of his hockey commitments in the city. Laura lives outside the city and obviously misses him. This photograph is displayed on the hard drive on the right side of her screen, and another employee tells me later that sometimes this photo gets put away. Laura has no desire to share this relationship with others.

A complex network of social relationships is evident on most of the desks of the women. Familial groups, friends and co-workers are most frequently the givers of the personal objects that reside on the desks. The culture of the organization is also strongly represented through certificates of work anniversaries, mementos of work events and the IG social event calendar that most women have at their desks.

Sharon describes the collaboration required to perform her job and understands this informs the layout of the office cubicles that give so little private space to each woman. The personalia at her desk are charged with social relations, implicating her coworkers as friends and supporters. The number of objects at her desk attests to time accumulated in this department at this desk. Sharon speaks about the importance of demonstrating her affiliation with "Team Awesome" and proudly displays rewards she has collected alongside photographs of her cat. This is the busy period in the department and Sharon has worked overtime consistently for the last three months. She uses the gifts and photos at her desk as reminders of the world outside her work to relieve stress. 
Molly describes her personalia as "treasure", including a traveller's memento from the Philippines and a carefully placed christening tchotchke that have specific cultural meaning for her.

Even in the office environment that has its own explicit culture, Laura seeks her own ways to express her identity. She chooses to keep her desk empty of personalia, resisting the expectation of normative ways of operating by withholding her personal stories and private life, resisting peer pressure to share. She does, however, value the IG social events and takes advantage of opportunities to get up from her desk. Perl also reflects on the pressure to have photos at her desk. Laura and Perl demonstrate there are flexible ways of operating that women can adopt without excluding themselves from the social networks of activity in the organization. Perl enjoys opportunities to share food with her co-workers, building relationships through personal generosity. Perl was the only participant who had food at her desk. She spoke about "coming from a family where food was not always available" and the importance of sharing. Her boss from Toronto "brought fruit to my desk knowing I will share it with the others". This recognition was a source of pride for her.

The objects at many of the women's desks show their participation in corporate fundraising activities that demonstrate their "ethic of care". From the personalia at the desks, it is evident that individual subjects choose to support the organizational culture through participation in IG events. Camila suggests, "People like to feel they are contributing to something else".

\section{Material Culture}

The objects at the desks generally have little monetary value, but they bring colour and detail to the desks and create home places for the women. They are playful and often whimsical. Some women have accumulated many objects and like the busyness they create, and they take great care in arranging the objects on their desks. Others have very little on their desks and are judged by some co-workers for not providing a work identity for others' consumption and comment. There are tactics for 
dealing with the culture of personal display. Rose's dolphin ornament is a distraction that replaces photographs of loved ones, allowing her to engage with her co-workers who like to comment. The relevance of material culture research to the project of studying the everyday is significant, as evidenced in the work of Daniel Miller $(2008,2009)$. His work seeks to understand our relationship to objects in contemporary society and the complex role that consumption plays in human emotions such as separation and loss, and expressions of love. At Leigh's desk we see her devotion to her children with images of them taken when they were both two years old. She proudly displays the New Mom magnetic sign and the ceramic cherub, both gifts from coworkers. They are reminders of her other important role as mother.

\section{Time and Space}

Relationships between co-workers span a temporal spectrum with new friendships formed as people move into the department. Team and co-worker relationships are established while they work together, and as they depart, retire and move on, past co-workers are remembered by gifted tokens and office supplies. The objects hold oneiric value for the women and honor co-workers' contributions and past friendships. A habitus has developed among the women that relates to the redistribution and gifting of office supplies, with highlighter pens and sticky notes being of particular value. The tradition was explained to me as those who retire or leave distribute their office supplies amongst their co-workers. Talking about the personal items on her desk, Camila says they have taken years to accumulate; "Even highlighters and office supplies are passed on from retiring employees. It is sad to see them go but the supplies serve as reminders." These utilitarian items become a colourful focal point in the beige environment of the desk. Harmless collections of office necessities mark time passed, with the length of time worked celebrated by accumulation.

The women often reflect on the personalia at their desks as narratives of departed co-workers. Among the stories that offer a temporal narrative is the story of the Jawa. I ask about the hooded figure that sits on top of Felicity's workstation panels 
and she shares the story of its origin with me. It has become a mascot of the department, travelling around the department and spending time on a number of desks. She recalls that it came into the department when a co-worker's child was visiting and it remained even after the co-worker left. Felicity also remarks on the small silver cup that sits next to the hard drive. It is from a Christmas party with work colleagues who were the winning bowling team. "None of those people are in the department anymore, the last person to leave passed off the trophy." These objects symbolize friendships and memories that have meaning to Felicity. She has become the keeper of these everyday stories that value personal experience, and demonstrates an ethic of care in line with women's ways of knowing.

The women's relationships to their close work environment speak of spatial tactics; with the use of the very few tools they have at hand, they manipulate their environments to better serve their complex individual needs. They craft the displays at their desks to comply with the implicit requirement for collaboration and co-operation while keeping their most private stories hidden in proximity to their computer screens. They create work-arounds to accommodate personal needs. Camila hides behind her computer screen to take an occasional private call and Felicity keeps her screen low so she can see people approaching her desk. A number of the women work with their backs to their nearest neighbours, while others welcome and enjoy the movement of others around their desks as a distraction from the routine work of the day. Low height panel-based furniture provides no opportunity for privacy, acoustic or visual, and most of the women have learned to shut out outside distractions, and with the use of headphones can disregard activity around them. Sharon spoke of adjusting her schedule to work on projects requiring concentration either early in the morning or late in the day when the office was quieter. The IG policy of no personal calls contains the opportunity to connect with life outside of their space. For a minimum of seven hours a day, the workers are focused and refocused on the priorities and needs of the organization. 
The quality of natural light varies through the day with large windows providing the potential for maximum access to views and connection to the outside weather conditions. Reyna and Rose have chosen to orient themselves to their co-workers in very different ways. Reyna maximizes her privacy by sitting facing away from her coworkers, emphasizing her need to be private. Rose sits facing the neighbourhood of coworkers, emphasizing her dependency as a newer employee and developing social networks of support.

The women interviewed all complained about their office chairs, saying they are not comfortable for extended sitting. The problem of doing such focused work in a seated position all day has consequences for their health. An example is Gloria, an older worker, who suffers from arthritis. She talked about the need to get exercise in her lunch hour and shift her focus from the screen to a middle distance to provide relief for her eyes.

Embodied spaces are the locations where "human experience and consciousness takes on material and spatial form" according to Setha Low. Low looks at the contemporary origins of the body as an intrinsic component of spatial analysis (2003:9). Starting with the work of Michel Foucault $(1975,1986)$ regarding the relationship of space, bodies and power, and considering Pierre Bourdieu's (1977) notion of the intersection of culture, space and bodies as habitus, Low also notes the work of Edward Hall (1968) concerning proxemics - the study of human behaviour in response to space and culture. Low argues for an integrated embodied spatial theory that "addresses the metaphorical and material aspects of the body in space as well as the body/space to communicate, transform, and contest existing social structures" as a solution to the problem of research that crosses micro/macro boundaries from the individual body to the social and political forces.

\section{Tidiness and Control}

Attention to the mundane activities of the everyday can be recognized at the women's desks where cleanliness and efficiency are important, with most women 
cleaning the surface of their desks regularly or maintaining a strong emphasis on keeping paper under control. Molly has almost erased time from her desk with her careful cleaning at the beginning and end of each day, allowing her to start fresh each morning. Others talk about cleaning their desks before starting a new task, or having a routine of cleaning the desk at the beginning of the week.

Hygiene and efficiency were quite significant and often synonymous for the Southeast Asian women. Leigh says, "This helps me think, before I start another task I tidy my desk." Molly suggests that she likes to clean her desk but "I get teased about it by others". She has a photocopied sheet under her keyboard explaining the 5S's, a Japanese organizational method. The $5 S^{\prime}$ 's advocate tidiness, orderliness, cleanliness, standardization and discipline (according to Molly's sheet). These values were introduced to industry as part of restructuring in the 1990s. Molly brought this with her from the Philippines and remembers, "I was really inspired by that, I read it once in a while and it reminds me to take control." Perl doesn't mention her desk cleaning routine but notes the paper towel at her desk is for cleaning her desk and sharing food. The value of professionalism is represented by tidiness at the desks for most of the women, and paper is managed with a variety of individual practices. Laura uses markers for different days of the week so she can easily track how long a document has been in her hands, while Rose talks about aligning the folders to help her efficiency. I observed objects and operations working to influence the behaviours and beliefs of the women. Amanda's work starts in the centre of her desk and works its way to the edges of the desk when completed; then it is filed or thrown out. Some women's desks have procedural files in hard copy, while others choose to refer to manuals online and keep the desk surfaces clear. 


\section{Oneiric Spaces: dreams and angels}

Topo-analysis is a poetic exploration of intimate space that seeks to uncover "how we inhabit our vital space, in accord with all the dialectics of life, how we take root, day after day, in a 'corner of the world'" (Bachelard 1994: 4). The concept of topoanalysis $^{37}$ considers the emotional, poetic and non-rational ways of operating that are evident in the spaces of the women workers at Investors Group. The workstation configurations used by the clerical workers recreate corners. The space of the women's desks is personal space. The objects and images at their desks have no significant material value and therefore have been kept due to an emotional connection or important memory. They may be transient objects chosen for their colour or quirky form. The women with children talk about the images of their families as reminders of the reason for their often-stressful routine office lives.

Leigh is a younger and newer employee who has opened herself up to making new friendships and working collaboratively. She signals this with her location at the edge of a corridor and her position at the desk. Leigh's workspace radiates calm and order; she talks about her desk as her favourite space at IG. Leigh is from the Philippines and is watched over by "a guardian angel", a chubby ceramic cherub given to her by her friends at work. This takes a special place at the base of her computer screen but the space around her screen is also occupied with photographs of her two daughters. The desks themselves form miniature worlds where time and space collide in unexpected ways. Captured in a picture frame are images of Leigh's two girls taken at the same age. These images delight her because the girls look so much alike. The photographs hold them captive in time when they were smaller and more vulnerable. Living in a miniature world, "one relaxes in a small space. This is one of the daydreams that take us out of this world and into another" (Bachelard 1994: 162).

\footnotetext{
37 Gaston Bachelard's phenomenological study of oneiric (remembered) spaces, The Poetics of Space, develops his theory of topo-analysis.
} 
Gloria has a postcard of a castle in Scotland that once belonged to her mother's family. She brought it in to show a work colleague and it has stayed in a special place near her computer screen.

Vibrant colour is often a significant aspect of the collections of personalia, as they offer visual contrast and colourful intrusions into the neutral environment of the desks. Camila talks with enthusiasm about her bright green tape dispenser, as the colour provides her with great pleasure. "I love my tape dispenser, it is green and brightens up my desk." The work surface and pinup spaces of the desks define the limited terrain of the women workers, as it is here they exercise their unselfconscious desires to create heterotopias $^{38}$.

\section{Habitus}

When I questioned the women about their comfort with the lack of visual privacy afforded by low screen heights, none of them considered this to be a problem. In fact, they seemed to enjoy being in closer proximity to their team. Instead they use a series of devices to accomplish acoustic privacy. Headphones can help isolate the worker in their own sound bubble (Bull 2004), or can by their symbolic presence indicate to others that the wearer is concentrating and shouldn't be interrupted. This adaption creates a social convention that informs behaviour in the group, creating a habitus (Bordieu, 1984). The headphones become a symbol that communicates do not interrupt me.

Habitus is also observable in the social behaviours of the women working in teams. They welcome opportunities to consult or provide advice to other co-workers and use it as a chance to get up from their desks and stretch. They expressed concerned about the comfort of their desk chairs, as they are seated for long stretches of time. Their need to move around was reinforced by the focus on Investors Group's weekly activities that are designed to provide a short break in the routine and engage employees in social activity.

\footnotetext{
38 Heterotopia (Foucault )-spaces of otherness that are simultaneous physical and mental, utopian projects of real and unreal.
} 
The women generally enjoy their desk as their home place at work and express few issues with the lack of privacy. They understand this way of working is required by IG for the tasks they perform daily. However, tactical behaviours and spatial practices suggest other factors are at work.

There are many ways in which routine office workers are held in stasis in the workplace. Tactics are most visible when the women talk about the difficulty of making personal calls. They employ a number of methods, from hiding behind their screens to take calls, using the lift lobby or one of the meeting rooms, taking time at lunch to go to the mall next door, or flaunting the rules completely.

The need for space to make private calls was also raised in most of the interviews. Taking private calls at an individual's desk is not encouraged at Investors Group and many of the clerical desks don't have a phone. The women talk about making a trip to the mall at lunchtime to use their cell phones in private. This issue becomes more problematic as cell phones become ubiquitous and constant communication is the norm. Camila described the difficulty she had when she was buying a house and trying to maintain contact with her lawyer and the bank to enact a confidential transaction. However, everyday communications such as co-ordinating children's drop-offs and pickups and dental and medical appointments become much more difficult when personal organization is limited to the lunch hour. This negation of an employee's connection to her family seems anachronistic. It reinforces the women's sense of isolation from the outside world and explains some of the women's behaviour.

Laura sits next to the window and close to her supervisor. She likes to take a few moments in her day to see what is happening outside and rest her eyes. She enjoys connecting to the outside world as an escape from the space of consumption and the clutter of the working world, but is also conscious of her supervisor watching her. The prevalent sense of disconnection amongst the clerical workers heightens the importance of the everyday. Images of kids and pets, humorous green frogs and cartoons, and coffee mugs offer a brief escape from the work on her desk or the opportunity to engage in a conversation with a friend. The personal items that most 
women have at their desks, such as hand lotion, nail files and tissues, remind the women they are women and they celebrate the shared desire to look and feel good.

\section{Co-worker, Team Player}

IG has an active social committee that creates a social network by scheduling events in the building. The events allow for the routines of the office to be briefly interrupted for games, team events, casual dress days and celebration meals. This schedule breaks the monotony of the week and is, for many of the women, a chance to move away from their desks, renew and maintain social relationships, and relieve the stress of extended working hours and intense screen-based work. Half of the women display the IG social events calendar, and its location in relation to their computer screen indicates how important these events are. Events include jeans day, where employees donate to support a cause and in return they are allowed to wear jeans to work. The employees also participate in fundraisers for cancer, diabetes, Rainbow Society, Christmas Cheer Board and Fire-fighters Burn Fund. The stickers given to participants are usually displayed at the more public perimeter of the desks where they provide markers of participation in the organizational culture.

The women's self-identity is formed through connection to, and identification with, everyday experience. As a consequence women tend to look for connections rather than dichotomies; where "boundaries between categories such as public/private, work/home, and male/female tend to be broken down" (Havenhand 2004: 39).

Mementoes of IG sponsored events are prominently displayed to reinforce team membership and collegial and co-operative values that are a part of women's ways of knowing. The organization relies on the women's desire to work collaboratively to accomplish the complex tasks they have to complete. Although there is a lot of repetition in the work, individuals become experts in different aspects of the task and provide support and information for newer colleagues. The successful completion of the routine tasks that comprise their day involves collaboration. Each employee belongs to a team and team-building events are held regularly to encourage good 
communications and rapport. The women signal their commitment to the team by displaying stickers, magnetized logos and slogans at the perimeter of their desks where they are more visible to others and management. Symbols of their close connections to and relationships with other workers are usually displayed closer to the centre of the desks where they create a different meaning, one with more emotional content. There are often narratives that go with these mementos; narratives of friends, former employees, colleagues working in other units at IG, those who have retired, or colleagues who have moved onto new jobs.

There are a few occasions where photographs of IG events or certificates to celebrate "work anniversaries" (years working fulltime for IG) shift closer to the screen. The women who occupy those desks value these symbols of recognition relative to their goals, ambitions and sense of identity, and often are the ones are earlier in their careers with IG. The routine clerical workers at Investors Group begin their careers as contract employees and work toward securing a permanent position with benefits and vacations.

\section{Family Space and Private Space}

The acceptance of subjectivity and feelings as a strategy is one of the attributes of women's ways of knowing. The desktop images of family acknowledge the importance of familial connections as a strategy for negotiating negative emotions and stress in the workplace. Byron and Laurence's recent study of desktop personalization (2015) would support this by referring to this behaviour as self-regulating. Selfregulating behaviour uses desktop personalia to modify and regulate office behaviour. Photographs of children were most often identified as relievers of stress and as motivators.

The objects on the desk become symbols that are imbued with emotions ranging from love and pleasure, to gratitude and friendship. Symbols can become a representation of kindness and warmth. Camila says, "Pictures of my daughter help me get through the day, on a bad day they help me cope." Amanda talks about her desk with its many photographs of her "kids' smiley faces" and husband as "a happy spot on 
days that are not so good". She is a crafter and has made a number of the things at her desk that incorporate her own creativity with special words and favourite photos of family to give special interest and meaning. For Amanda these handmade objects and family images make her desk a home place because, as she notes wistfully, "I spend more time at work than at home."

Sharon, an older worker recovering from bypass surgery, has photos at her desk that she is happy to talk about. One is of herself with Santa at an IG Christmas breakfast event, and others are pictures of her grandchildren who don't live in the city. "I like to have them at my desk." The grandchildren's pictures are on the left side of the desk located near the screen. However, it is the gifts from co-workers returning from vacations, Kinder Surprise toys, and humorous cartoons that she identifies as stress relievers. "I just look at them and they make me feel less stressed." Having developed close friendships over her 18 years at IG, Sharon remembers the particular kindness of two co-workers who visited her in cardiac rehab and brought her a pedometer. She says she likes to look at the personalia at her desk and be reminded of the givers. The women talk about their children as the reason they do this job; for Rose who has no children, employee recognition awards and a card celebrating her first anniversary with IG motivates her.

Camila has a young daughter whose handprints decorate her workspace in a bold and graphic orange. She made a copy of the prints for her husband too so they could both display them in their workspace, creating a connection that serves to link them all when they are apart. Photographs of her husband and daughter at various ages are to the right side of her screen. Family is obviously important and when I ask her about the images, she tells me co-workers "like to see the children growing up" and appreciate current pictures. She keeps some toys at her desk, such as a bright green frog and koala bears with Australian flags. "The toys remind me of my daughter, I miss her during the day."

Gloria, an older worker, describes her desk as her "home away from home". Preferring to work with her back to the busyness of the office, she has created her own 
private corner. “Don't anybody come and move my stuff, I know where everything is on my desk!" She is protective of her cache of markers and sticky notes and offers a warning to those who might borrow things from her desk. She resolutely claims her desk space as her own; "the things I have here are for me." She is close to retirement and is distancing herself from the camaraderie and new friendships required to actively participate in the office environment.

Rose thinks it is important to have personal space at her desk and "want(s) it to reflect who I am". She is young, tidy and organized. She "likes to keep folders neatly aligned" and tends to her appearance in a small mirror tucked behind her monitor.

\section{Conclusion}

"The making of space draws attention to bodily performance and experience. Workplaces and spaces are not just made by meaning or what people think but also by what they do and how this is experienced bodily" (Halford 2008: 939).

The analysis of the case studies demonstrates the integrated ways in which the women interviewed bring their ways of knowing and their operations to bear on the small personal spaces of the desktop.

Tactics for subverting office supplies to create a currency, imbued with memory and place, are made evident, as are the ways they operate to recognize, support and appreciate their co-workers. A web of relationships implicates family, friends, employers and co-workers in a miniature world where an ethic of care connects them all. This chapter demonstrates that the creation of a "home place" at the women's desks draws upon women's ways of knowing in the workplace. The case study research into these intimate spaces suggests they reflect individual attempts to construct, modify and contest the cultural field of the office. The workspaces communicate the individual women's values, identities and priorities through the personalia at their desks, their arrangement, and the social networks and relations they represent. 
To access ideas of agency this dissertation draws on Michel de Certeau's theories and ethnography to understand the everyday experience of workers. It looks at the tactics and techniques they employ to creatively manipulate the conceived space of the neoliberal organization. 


\section{CONCLUSION}

The research underscores the significance of micro-spatial practices in relation to the study of the everyday. The case study research into desktops and pin boards demonstrates individual attempts to construct, modify and contest the organizational culture of the office. The arrangement of personalia in the women's personal space is expressive of their values, identities and priorities. This research provides a source of rich phenomenological information that could inform the design and management of spaces that better accommodate women, and could be used to evaluate office environments. Designers and managers of work environments need to understand differential space as a space of tension and potential and women's operations that "reappropriate spaces organized by techniques of sociocultural production" (de Certeau 1988: xiv).

The routine clerical workers do not currently have the choice and control available to knowledge workers with mobile technologies; they work in offices isolated by the space of flows. I support Halford's recommendation that "we should pay far more attention to the agency of individuals and groups in responding to organisational space" (2008: 932).

This dissertation addresses the questions that were framed in the introduction.

- How does the physical environment of the workplace, the desk and its personalia reflect the creation of identities and the women's values in response to the hegemony of the financial services industry?

- How does the workplace reflect women's values, and how have women's values influenced the design of the workplace?

The head offices of Investors Group at One Canada Place, Winnipeg, are an environment that functions essentially as it was designed and occupied in 1987. But it is not unusual; the work environment designed for routine clerical workers often speaks of 
colourless conformity. Jacqueline Vischer has observed "ever growing numbers of office workers now sit at terminals for most of their working day and are often the least comfortable group in the building" (1999: 34). There is a need for greater focus on clerical positions and data processors in offices. These employees are often hired on a contract basis and usually have no voice in the design process. The design process that produces conceived space needs to carefully consider the needs of employees who are spending a minimum of 40 hours a week at a desk with limited control over their work

environment. Ellis points out in Vischer's Environment as a Tool for Work that good space planning solutions lie more in good planning process than in seeking out the "best fit" physical layout. Vischer advocates for a negotiation process that "allows managers to respond to intrinsic as well as to extrinsic pressures for change" (1999: 40).

\section{Personalia}

The research uncovers the significance of the location of personalia at the desk. This is a unique research finding. The space immediately around the screen is where items identified by the women as being more personally significant were located. They are less visible to co-workers and are in the peripheral vision of the women as they work. It is also the location for regularly used codes, phone contacts and work-related shortcuts. As personalia moves away from the screen location it is described more often in terms of co-workers' responses, but may still represent family members, children, holiday snapshots, and cute and odd items brought to work that provoke comments and reactions from co-workers (see figure $6 \mathrm{C}$ ). The need to protect personal identity may be seen as a way of operating, where desk space is appropriated for the expression of emotions, private memories or deeply felt connections to others.

In recent research into desk personalization across 11 countries, Uta Brandes and Michael Erlhoff (2011) found that women had a significantly higher preference for collecting objects than their male counterparts. They counted 5,885 objects on 351 desks belonging to female workers and 3,361 objects on 335 desks belonging to male workers. However you might interpret these numbers it is obvious that the desire to express 
individuality and values in the limited space of the work desk is a human need that should be recognized and accommodated.

\section{Space for Social Networks}

The offices that were the focus of the research at Investors Group have the benefit of lots of natural light and generous spatial allocations typical of the 1980s, but the clerical space is laid out with rows of low height partitions that create cubicles, clustered to reflect the priority for teamwork and easy consultation at the desk. Women's preferred ways of operating value social networks and connectedness to others. This was reinforced by the research, which found that the women understand IG's priority for collaboration and find ways to make this work, including the creation of a habitus around the wearing of headphones. Collaborative practices are a fundamental part of contemporary management theory that aligns well with women's values.

There is an obvious need for the women to be able to enjoy a place at work that has meaning for them. A place that honours the formal and informal social networks so evident in the personalia on their desktops. They need a communal space, close to the open office, a comfortable lounge for social networking that allows employees to relax and unwind during their breaks. It should be provided with facilities for making coffee and sharing food. The newly completed canteen at IG was only mentioned by one employee as a favourite space. It is located on the second floor and has nice views of the city but it has been designed to accommodate large groups and it feels impersonal and institutional.

There are many strategies that designers can employ. Management can also work with employees to create a more positive energy at their workspaces that would be of great benefit for women working long hours in stasis at their desks. In 1985 sociologists looking at workplace suggested that "energetic diversity in offices excites innovation, communication, and healthy cooperation" (Williams, Armstrong and Clark 1985: 68). Strategies that allow for the greater use of colour, greater diversity in the design of furniture, and the capacity to personalize and modify the configuration of desks and chairs could be implemented. This would greatly improve working conditions. 


\section{Social Networks, Friends and Co-workers}

The friendships that develop at IG are of significant importance to the women. Co-workers become friends, and intrarelationships become interrelationships as workers move in and out of the department and around the organization. Work friendships present and past are recognized and honoured at the desk.

Belonging to a work team and participating in IG social events are identified and owned at the desk as valued aspects of the women's work identity. Gifts and recognition for long hours and special effort, as well as work anniversaries, are often displayed with pride to demonstrate and acknowledge their value to the women. I was not expecting to find so much of the desk dedicated to social networks associated with work, and was fascinated to uncover the rituals associated with departing workers poaching office supplies to be gifted to co-workers. The narratives of the Jawa and the bowling cup mark out individuals as keepers of the symbols of office friendships and continuity.

\section{Choice and Control}

Choice and control are consistently identified in environmental research as significant to productivity and satisfaction. So it was no surprise to find this was also evident in the women's spaces, from the rituals for cleaning the work surface to the general frustration about the lack of consideration of privacy when making personal calls. Social expectations of being in constant contact have changed dramatically from 1987 but the space has not accommodated this change.

The organization needs to consider many more ways to give employees control, from managing excess daylight in their workspaces, to having places to stretch and rest their eyes after hours spent in focused work at the desk. These employees may have very little in the way of status in the company, but their work is critical to the IG's success and they will value the investment in their comfort. Desk spaces should be provided with adequate pinup space that encourages employees to participate in growing the social networks of organizations in unstructured and organic ways. 
Better maintenance of washrooms and providing a greater number of washroom stalls per floor would considerably improve the women's perceptions of the working environment. Facilities such as an in-house gym, yoga studio and emergency daycare facilities should be offered to support clerical employees in managing their health and family responsibilities. A supervised home workroom for the children of employees working overtime would allow families to share child-minding responsibilities more equitably.

Office furniture that allows the worker to change position would provide greater control and choice for the women. Carefully considering the selection of alternative working positions and chairs with better ergonomics are especially important for older workers. Adjustable work surfaces at the computer would allow the worker to move easily from sitting to standing over the course of a day. Recent research in the United Kingdom (Buckley, Hedge and Yates 2015) suggests that the sedentary office has become a health issue that increases the risk of cardio-metabolic diseases and premature mortality. The UK has launched a program called "Get Britain Standing" as a response.

\section{Family}

Family photos and friendships are primary sources of motivation and relieve stress, helping the women to cope with the pressures of the constant work. They imbue the women with status as aunts and mothers, grandmothers and friends. They connect the women to their loved ones, to happy memories and life away from the office. The personalia at the desk generally have little monetary value, but are instead valued for bringing colour and detail to the desk and creating home places for the women. They demonstrate the individual's values but they also show a playful and less serious side. Some women have accumulated many objects at their desk and like the busyness of them; they take great care in arranging the objects on their desks. Others have very little on their desks and are judged by some co-workers for not providing a work identity for 
others' consumption and comment. There are tactics for dealing with the culture of display, as the dolphin ornament seems to be a substitute for photographs of loved ones.

\section{Identity}

Identities are multiple. They are demonstrations of the individual as a person who values friendship, has a sense of humour, loves nature, likes the colour green, appreciates recognition from their boss or IG, does their job professionally, cares about others and likes to have fun. The collections of personalia at the desk are representations of complex identities and narratives. Identity includes places of origin, oneiric symbols of home such as the christening ornaments, an ancestor's English castle or an Asian fruit. All are significant markers of familiarity and comfort, reminders of places where our birth identity is secured. The Canadian flag is a symbol of IG's recognition of citizenship and is a source of pride for the women. It speaks of formal acceptance into Canadian society and attests to the meaning of belonging in the women's lives.

\section{Home places and Heterotopias}

Desks become home places and ideal worlds or heterotopias, where the women can exercise a sense of control and indulge in daydreams that provide relief from the stress of the continuous flow of work at their desks. Personalia that cluster around the screen are often symbols of life away from the office, crossing boundaries between work life and home life. They come with stories of how they were acquired, perhaps as gifts from children, co-workers or team leaders. Other objects at the desk are randomly acquired, left behind or part of a collection now dispersed. They also have ebb and flow as mobile symbols of continuity. Cleanliness and tidiness become a performance of moral virtues for some of the women; for one individual it relates to allergies, and for others the ritual brings closure to the work of the day. 


\section{Research Methods}

The research emphasizes the importance of inclusive design considerations that inform programming and reinforces the significance of the messages that are imparted to the women working in these spaces. Rich phenomenological data established by engaged research helps to build a more complex picture of values and operations.

Photo-elicitation research provides a productive and powerful point of access for research at the micro-scale. I was able to access and uncover spatial, social, and personal practices and ways of operating that are not evident in other studies of the workplace, proving Halford's assertion that "spatial discourse shapes the production of working selves - who we are at work and how we understand our working identities" (2008: 932). Much of the research that addresses the workplace looks at the imposition of behaviours and subjectivities through organizational space. My research approach is purposefully looking for agency in the claiming and occupation of space by women with little power and status. This research represents point of entry into the ways women create identities and social networks in the contemporary workplace.

The prospect that routine clerical work would be taken over by computers has not been realized and the routine tasks that require human decision-making and critical oversight remain the work of routine clerical workers. "Many lower-level women's jobs that cannot be automated still require high skill and responsibility, but are devalued in our society and vastly under rewarded." (Aker 1992:62)

At IG women represent 74\% of the clerical workforce (Verdonck 2015: pers.comm.). The work is referred to as "on-boarding", as opposed to "outsourcing", and IG suggests it will be a part of the financial services industry for the foreseeable future. This research seeks to add to the critical literature on the workplace by studying the creation of identity and meaning at the desks of these clerical workers who are left in the wake of a mobile society.

I am interested in the influence of women on the essentially "masculine" nature of the office and its design. I argue that the outcome of the shift in gender and management philosophies, supported by the influence of the newly-professionalized 
interior designer, resulted in the emergence of an office environment in the 1980s and 90s that became more closely aligned with women's preferred ways of working.

But it becomes clear that the innovation in office design since that time has largely effected the design of knowledge workers spaces. The working lives of routine office employees have received much less attention from designers. As lower paid and often contracted employees, these women are less visible to management and are perceived to be less critical to the company's bottom line.

In conclusion, women and women's culture has been widely studied in relation to domestic environments (Sparke 1995, Lupton 1996, Colomina 1996) my research shifts the focus to the understudied area of personalia in the office environment in an attempt to generate attention and interest in its potential as the site for feminist cultural studies research. 


\section{REFERENCES}

Acker, Joan. 1992. "The Future of Women and Work: Ending in the Twentieth Century." In Sociological Perspectives 35:1.

Albrecht, Donald, and Chrysanthe B. Broikos. 2000. On the Job: Design and the American Office. New York: Princeton Architectural Press.

Allcoff, Linda. 1988. "Cultural Feminism Versus Post-structuralism: The Identity Crisis in Feminist Theory." In Signs: Journal of Women in Culture and Society 13:3.

Anteby, Michel, and Rakesh Khurana. n.d. A New Vision: Part Six: Women in the Relay Assembly Division. Harvard Business School, Baker Library Historical Collections .www.library.hbs.edu/hc/hawthorne/06.html\#six

Archives of American Art. 1999 compilation.

Florence Knoll Bassett Papers. Box 1, folder 2. Portfolio Selected Publications, 1946-1990. http://www.aaa.si.edu/collections/container/viewer/PortfolioSelected-Publications-from- 1946-until-1990-compiled--224304

Ardener, Shirley. 1981. Women and Space. London: Croom Helm.

Aronowitz, Stanley. 1991. "The ignored philosopher and social theorist: The work of Henri Lefebvre" In Situations 21:133-55

Attfield, Judy, and Kirkham, Pat. 1989. A View from the Interior: Feminism, Women and Design. London: The Women's Press.

Bachelard, Gaston. 1994. The Poetics of Space. Boston: Beacon Press.

Baran, Barbara, and Suzanne Teegarden. 1987. "Women's Labor in the Office of the Future: A Case Study of the Insurance Industry." In Women Households and the Economy, edited by L. Beneria and C. Stimpson, 201-24. New Brunswick, NJ: Rutgers University Press.

Becker, Franklin, and Fritz Steele. 1995. Workplace by Design: Mapping the HighPerformance Workscape. San Francisco: Jossey Bass.

Belenky, Mary Field, Blythe Mcvicker Clinchy, Nancy Rule Goldberger, and Jill Mattuck Tarule. 1986. Ways of Knowing: The Development of Self, Voice and Mind. New York: Basic Books. 
Benjamin, Walter. 1968. Illuminations: Essays and Reflections. New York: Schoken Books.

1999. The Arcades Project. Cambridge, MA.: The Belknap Press of Harvard University Press.

Bianchi, Suzanne and Nancy Rytina. 1986. "The Decline of Occupational Sex Segregation during the 1970's: Census and CPS Comparisons." Demography 23 (February) : 79-86.

Blaxall, M., and B. Reagan. 1976. Women and the Workplace: The Implications of Occupational Segregation. Chicago: University of Chicago Press.

Bonifacio, Glenda Tibe. 2013. Pinay on the Prairies: Filipino Women and Transnational Identities. Vancouver: University of British Columbia Press.

Bourdieu, Pierre. 1977. Outline of Theory and Practice. Cambridge, MA.: Cambridge University Press.

1984. Distinction: A Social Critique of the Judgement of Taste, translated by Richard Nice. Cambridge, MA.: Harvard University Press.

Brill, M.,Weiderman, S., Margulis, S. and Konar, E. 1985. Using Office Design to Increase Productivity (2 vols). Buffalo, NY.: Buffalo Organization for Social and Technological Innovation (BOSTI).

Brown, C., and Pechman, J. 1987. Gender in the Workplace. Washington: Brookings Institute.

Buckley, J. P., A. Hedge, T.Yates, R.J. Copeland, M.Loosemore, M. Hamer, G. Bradley, D. W. Dunstan. 2015. "The Sedentary Office: a growing case for change towards better health and productivity." Expert statement commissioned by Public Health England and the Active Working Community Interest Company. Br J Sports Med published online doi:10.1136/bjsports-2015-094618

Bull, Michael. 2004. "To Each Their Own Bubble." In Media Space, edited by N. Couldry and A. McCarthy. London: Routledge. 
Castells, Manuel. 1989 The Informational City: Economic Restructuring and Urban Development. Oxford: Blackwell Publishers.

. 2000. "The Space of Flows." In The Rise of the Network Society, The Information Age : Economy, Society, Culture. Volume 1. Oxford: Blackwell.

2010 Second edition, Volume 1, new preface. Oxford, UK: Wiley-Blackwell.

Chaney, D. 1983. "The Department Store as Cultural Form." In Theory, Culture and Society 1 (3): 22- 31.

Colomina, Beatriz. 1996. Privacy and Publicity: Modern Architecture as Mass Media Cambridge, MA. : MIT Press.

Creswell, Tim. 2007. "Introduction: Theorizing Place." in Mobilizing Place and Placing Mobility. Amsterdam: Editions Rodopi B.V.

de Certeau, Michel. 1984. The Practice of Everyday Life. Berkeley: University of California Press.

1998. The Practice of Everyday Life, Volume 2: Living and Cooking. Minneapolis, MN.: University of Minnesota Press.

Derksen, George. 1963. T.O Peterson President and Chairman of Investors Syndicate of Canada Ltd. In Western Construction and Building (August).

Drucker, Peter. 1957. Landmarks of Tomorrow. New York: Harper and Row. 1968. The Age of Discontinuity. London: William Heinemann.

. 1985. "The Practice of Innovation." Innovation and Entrepreneurship Practice and Principles. 19-33. New York: Harper and Row.

1993. Post Capitalist Society. London: Butterworth Heinemann.

Duffy, Francis. 1976. Planning Office Space. London: Architectural Press. . 1997. The New Office. London: Conran Octopus.

Ellis, Peter. 1991. "Toward the Organic Office." Facilities 9:4 (October):8-12.

Emmison, Michael and Philip Smith. 2000. Researching the Visual: Images, Objects, Contexts and Interactions in Social and Cultural Inquiry. London : Sage Publications. 
Follett, Mary Parker. 1941. Dynamic Administration. London: Pitman.

Foucault, Michel. [1977]1995 Discipline and Punish: The Birth of the Prison, $2^{\text {nd }}$ edition. New York: Vintage.

Frampton, K. 1986. Introduction to Frank Lloyd Wright and the Johnson Wax Buildings, edited by Jonathan Lipman. New York: Rizzoli.

Franck, Karen, A. 1989."A Feminist Approach to Architecture: Acknowledging Women's Ways of Knowing." In Architecture: A Place for Women, edited by Ellen Perry Berkeley. Washington and London: Smithsonian Institute Press.

2000. "A Feminist Approach to Architecture: Acknowledging Women's Ways of Knowing."In Gender Space Architecture: An Interdisciplinary Introduction, edited by lain Borden, Jane Rendell Jane and Barbara Penner. London: Routledge.

Friedberg, Alice.1993. Window Shopping: Cinema and the Postmodern. London: University of California Press

Gagnon, Erika. n.d. Settling the West: Immigration to the Prairies from 1867-1914. http://www.pier21.ca/research/immigration-history/settling-the- westimmigration-to-the-prairies-from-1867-to-1914

Gilbreth, Frank and Lillian. 1921. Time and Motion Study As Fundamental Factors in Planning and Control, New Jersey: The Mountainside Press. [booklet].

Geertz, Clifford. 1973. The Interpretation of Cultures: Selected Essays. New York, NY: Basic Books.

Gilligan, Carol. 1982. In a Different Voice: Psychological Theory and Women's Development. London: Harvard University Press.

Gordon, Beverly. 1997. "Intimacy and Objects: A Proxemic Analysis of Gender-Based Response to the Material World." In The Gender of Power and the Power of Gender, edited by Katharine Martinez and Kenneth Ames. London: University Press of New England.

Granath, Jan Ake. 1991. Architecture, Technology and Human Factors: Design in a SocioTechnical Context. Goteberg, Sweden: Chalmers University of Technology, School of Architecture and Planning.

Guillen, Mauro F. 2006. The Taylorized Beauty of the Mechanical: Scientific Management and the Rise of Modernist Architecture. Princeton: Princeton University Press. 
Halford, Susan. 2008. "Sociologies of Space, Work and Organisation: From Fragments to Spatial Theory." Sociology Compass 2 (3): 925-43.

Hall, Edward T. 1966. The Hidden Dimension. New York: Doubleday.

. 1968. Proxemics. Current Anthropology 9 (2): 83-95.

Handy, Charles. 1989. The Age of Unreason. London: Business Books.

Hanson, Susan, and Geraldine Pratt. 1995. Gender, Work and Space. London: Routledge.

Haraway, Donna. 1988. "Situated Knowledges: The Science Question in Feminism and the Privilege of Partial Perspective."In Feminist Studies 14:3 (Fall):583.

Harvey, David. 2000. Spaces of Hope. Berkeley: University of California Press.

.2001. Spaces of Capital. Edinburgh: Edinburgh University Press.

Hayden, Dolores. 1984. Redesigning the American Dream: The Future of Housing, Work and Family. New York: W.W. Norton.

Havenhand, Lucinda. 2004. "A View from the Margin." Design Issues 20:4 (Autumn) Cambridge, MA.: MIT Press.

Hedge, Alan. 1987 "Privacy Behaviour in Open-plan Office Design" in The Importance of Office Design to Organizational Effectiveness and Productivity: The Behavioural Basis of Office Design, edited by Jean Wineman. New York : Van Nostrand Reinhold.

Hutton, Geoffrey. 1976 "Automatic Data Processing”. In Planning Office Space, edited by Francis Duffy, Colin Cave and John Worthington. 183-187. London: Architectural Press.

Investors Group. 1990. The Cornerstone, 12:9 (October). Winnipeg.

. 1987. The Investor. (September). Winnipeg.

Iorio, Mary E. 1994. "Pieces of the Dream." In Cranbrook at 90: Celebrating the Spirit Cranbrook Journal (Fall). Archives of American Art, Florence Knoll Bassett Papers, box 3, folder 1. Accessed March 1, 2015.

http://www.aaa.si.edu/collections/container/viewer/Kingwood-CranbrookAcademy-of-Art--224309 
Jones, Robert H. 1993. Building Futures: A History of Investors Group. Winnipeg: Investors Group.

Kalstad, E. 2010. "Women's Ways of Knowing." Exploring College Student Development Theory, October 10. Accessed May 16, 2014. http://collegestudentdeveltheory.blogspot.ca/2010/10/womens-ways-ofknowing-synopsis-by-e.html

Kanter, Rosabeth Moss. 1977. Men and Women of the Corporation. New York: Basic Books.

Kessler-Harris, Alice. 1982. Out of Work: A History of Wage Earning Women in the United States. New York: Oxford University Press.

Kittler, Friedrich A. 1999. Gramophone, Film, Typewriter. Stanford : Stanford University Press.

Klein, Graf Judy. 1982. The Office Book: Ideas and Designs for Contemporary Work Spaces. New York: Facts on File Inc.

Lefebvre, Henri. 1991. The Production of Space, translator D.Nicholson-Smith. London: Blackwell.

Lehrman, Jonas. 1987. "Out of Place - One Canada Centre presents a Pompous Image". Citiscape. In the Winnipeg Free Press, October $16^{\text {th }}$,Winnipeg, Manitoba.

Lerner, G. 1971. The Women in American History. Menlo Park, CA: Addison-Wesley.

Lipman, Jonathon. 1986. Frank Lloyd Wright and the Johnson Wax buildings New York: Rizzoli.

Low, Setha M. 2003. "Embodied Space(s): Anthropological Theories of Body Space and Culture." In Space and Culture 6:1 (February): 9-18.

Lupton, Ellen. 1996. Mechanical Brides: Women and Machines from Home to Office, New York: Cooper Hewitt, National Design Museum, Smithsonian Institution.

Malpas, J.E. 1999. Place and Experience: A Philosophical Topography. Cambridge: Cambridge University Press.

Massey, Doreen. 1984. Spatial Divisions of Labor: Social Structures and the Geography of Production. New York: Methuen. 
Mayo, Elton. 1933. The Human Problems of an Industrial Civilization. New York: Macmillan.

McLeod, Mary. 1997. "Henri Lefebvre's Critique of Everyday Life: An Introduction." In Architecture of the Everyday, edited by Steven Harris and Deborah Berke, 9-29. New York: Princeton Architectural Press.

McLuhan, Marshall. 1964. Understanding Media: The Extensions of Man. 258-64. Toronto: McGraw-Hill Book Company.

Merleau-Ponty, Maurice. 1962. Phenomenology of Perception. Translated by Colin Smith. New York: Humanities Press (originally published 1945).

Miller, Daniel. 2008. The Comfort of Things. Cambridge: Polity.

Mills, C. Wright. 1951, reprinted 1976. White Collar: The American Middle Classes. New York: Oxford University Press.

Moore, Wilbert. 1962. The Conduct of the Corporation. New York: Vintage Books, Random House.

Mugerauer, Robert. 1994. Interpretations on Behalf of Place: Environmental Displacements and Alternative Responses. Albany: State University of New York Press.

Myerson, J. and G. Turner. 1998. New Workspace New Culture: Office design as a catalyst for change. Aldershot, UK: Gower.

n.a. 1963. Notes from the Architects Notebook, in Western Construction and Building, (August): 7

n.a. 1986. The Cornerstone 7:2 (February)

Nelson, George. 1979. George Nelson Design. New York: Whitney Library of Design.

O'Neill, M. 2008. Open Plan and Enclosed Private Offices: Review and Recommendations. White Paper, New York: Knoll, Inc.

2009 Wymer, T. Design for Integrated Work. White Paper, White Paper, New York, NY.: Knoll, Inc.

. 2010. Research Case Study: Design Features that Reduce Costs and "Brain Drain" in Mobile Organizations. White Paper, New York: Knoll, Inc. 
Perry, William. 1970. Forms of intellectual and ethical development in the college years. New York: Holt, Rinehart and Winston.

Rae, Christine. 1999 compilation. "First Lady of the Modern Office." Archives of American Art. Florence Knoll Bassett Papers, box 2, folder 2, item 57. Accessed February 25, 2015. http://www.aaa.si.edu/collections/container/viewer/portfolio-photographsflorence-knoll-and-others-andarticles-newspapers-and-magazines-224307

Reich, Robert. 1992. The Work of Nations. New York: Alfred A. Knopf.

Rice Brydone. 1983. The Corporate and Professional Office Organization and Design The Double Discipline. Toronto: McLelland and Stewart Publishers.

Richardson, Miles. 1982."Being-in-the-Plaza versus Being-in-the-Market: Material Culture and the Construction of Social Reality In Spanish America." American Ethnologist 9:421-36.

Said, Edward. 1994. Culture and Imperialism. London: Vintage.

Sassen, Saskia. 1997. "Hong Kong: Strategic Site / New Frontier." In Anyhow, edited by Cynthia C. Davidson, 130-137. Cambridge: MIT Press.

.2000. "Geographies and Counter Geographies." In Anymore, edited by Cynthia C. Davidson, 110-19. Cambridge: MIT Press.

. 1999. "Juxtaposed Temporalities: Producing a New Zone." In Anytime, edited by Cynthia C. Davidson, 114-21. Cambridge: MIT Press.

Schlereth, Thomas J., editor 1985. Material Culture: A research guide. Lawrence: University of Kansas Press.

Seamon, David, and Anne Buttimer. 1980. The Human Experience of Space and Place. London: Croom Helm.

.n.d. "Phenomenology, Place and Architecture: a review." editor David Seamon Environmental and Architectural Phenomenology Newsletter. Accessed February 14, 2014. http:/www.arch.ksu.edu/seamon/Seamon_reviewEAP.htm

Sheth, Shital. N. 2003. Interior Components of a Patient Care Unit: Impact on experiences of children undergoing treatment for eating disorders. Unpublished Masters of Interior Design Thesis. Faculty of Graduate Studies, University of Manitoba Mspace http://hdl.handle.net/1993/19972 
Slavin, Maeve. 1989. Wilkes Encyclopedia of Architecture: Design, Engineering and Construction, Volume 3. New York: John Wiley and Sons. Accessed March 4, 2015. http://www.aaa.si.edu/collections/container/viewer/Portfolio-SelectedPublications-from-1946-until-1990-compiled--224304

Soja, E. 1996. Third Space: journeys to Los Angeles and other real-and-imagined places. Cambridge, MA.: Blackwell Publishers.

Spain, Daphne, and Suzanne Bianchi. 1986. American Women in Transition. New York: Russell Sage Foundation.

.1992. Gendered Spaces. Chapel Hill : University of North Carolina Press.

Sparke, Penny. 1995. As Long As It's Pink: The Sexual Politics Of Taste. London : Pandora. 2008. The Modern Interior. Bodmin, Cornwall : MPG Books.

Stalder, Felix. 2001. "The Space of Flows: Notes on emergence, characteristics and possible impact on physical space." Paper presented at $5^{\text {th }}$ International PlaNet Congress, Paris. http://felix.openflows.com/html/space_of_flows.html

Steele, Fritz, and Stephen Jenks. 1977. The Feel of the Work Place, Reading, MA: Addison-Wesley Publishing Co.

Statistics Canada. The Filipino Community in Canada. Accessed March 20, 2015. http://www.statcan.gc.ca/pub/89-621-x/89-621-x2007005-eng.htm\#5

Statz, C. 1979. "The Early History of Visual Sociology", in J.Wagner editor Images of Information: Still Photography in the Social Sciences. Beverly Hills: Sage.

Stern, Dorothy. 2010. "With a Past View from Winnipeg: Thoughts on the Evolution of Canadian Interior Design Education." Unpublished essay, Magill University, Montreal.

Stewart, D., and A. Mukunas. 1990. Exploring Phenomenology. 2nd edition. Chicago: American Library Association.

Sundstrom, Eric. 1986. Work Places: The Psychology of the Physical Environment in Offices and Factories. New York: Cambridge University Press. 
Swartz, David L. 2002. "The Sociology of Habit: The Perspective of Pierre Bourdieu." Occupational Therapy Journal of Research 22 (Winter):61S-69S.

Taylor, Frederick W. 1911. The Principles of Scientific Management. New York : Harper and Brothers

Tian, Kelly, and Russell Belk. 2005. "Extended Self and Possessions in the Workplace." Journal of Consumer Research 32:2 (September):297-310. Chicago: University of Chicago Press.

Tigerman, Bobbye. 2007. "'I Am Not a Decorator': Florence Knoll, the Knoll Planning Unit and the Making of the Modern Office." Journal of Design History 20 (1). London: Oxford University Press.

Vischer, Jacqueline. 2005. Space Meets Status: Designing Workplace Performance. London: Routledge.

.1996. Workplace Strategies: Environment as a Tool for Work. New York : Chapman and Hall.

Wells, Jennifer. 1987. "Grays' strategy equals black bottom line" The Financial Post, October $26^{\text {th }}$.

Wilkes, Slaven Maeve. 1989. in Encyclopedia of Architecture, Design, Engineering and Construction 3:109 -10. New York: Joseph Wiley \& Sons.

Wilson, Elizabeth. 2000. "Into the Labyrinth" in Gender Space Architecture: An Interdisciplinary Introduction. Edited by Jane Rendell, Barbara Penner, and lain Borden. London: Architext, Routledge.

Williams, Cecil, David Armstrong, and Clark Malcolm. 1985. The Negotiable Environment: People, White Collar Work and the Office. Zeeland, Michigan: Herman Miller.

Williams, Richard J. 2013. Sex and Buildings: Modern Architecture and the Sexual Revolution. London: Reaktion Books.

Worthington, John, and Allan Konya. 1988. Fitting Out the Workplace. London: Architectural Press.

Wright, Frank Lloyd. 1943. FLW, An Autobiography. New York: Duell, Sloan and Pearce. 
Zahidi, Saadia, and Herminia Ibarra. 2010. The Corporate Gender Gap Report 2010. Geneva, Switzerland: World Economic Forum. Accessed March 15, 2015. http://www3.weforum.org/docs/WEF_GenderGap_CorporateReport_2010.pdf.

Zeisel, John. 2007. Inquiry by Design: Tools for Environment Behaviour Research. (First edition published 1981) Monterey, California: Brooks/Cole Pub. Co. 


\section{APPENDIX ONE}

\section{Research Proposal}

\section{WORKPLACE RESEARCH PROJECT :}

The proposed research project, with Insurance company employees, will form the basis of Associate Professor Lynn Chalmers' PhD dissertation "Everyday Spaces of Routine Work: a critical study". Her thesis advisor is Dr Janine Marchessault, from York University Ontario (contact information below).

Research Ethics Approval has been given by Ryerson University Ethics Committee for the the following project which seeks to answer the questions below:

- What is the significance of identity and personalization in routine workers environments?

- How is individual identity accommodated in the contemporary workplace?

- How does the individual make meaning in the workplace environment?

The beneficiaries of the research will be designers of workplace environments and the routine workers for whom they design. The research project will provide a better understanding of an increasingly diverse workforce and their needs for identity and personalization. A detailed study of the individual in their work setting should provide the knowledge to create a more responsive workplace, for a wider range of routine workers, who often have limited flexibility in work tasks and locations.

The study will involve four departments and ten subjects in each department, 40 subjects in all. The researcher, Lynn Chalmers is from the University of Manitoba, Faculty of Architecture, and will carry out the research in late October and early November. The project will involve observation of four departments, for a period of 2 hours each. Floor plans of each department studied will be required. A number of research subjects will be identified and offered the opportunity to discuss their personal workspace in detail. The subjects will be selected to represent a diverse range of workers particularly in consideration of age, ethnicity, gender, and ways of responding to the environment that they occupy.

An outline of the questions forming the basis of the discussion (see below ) will be supplied to the selected subjects so that they will understand the nature of the discussion, if they choose to participate. They will have the opportunity to withdraw at any time from the research, or they can refuse to answer any of the questions without consequence if they decide to participate. Interview/discussions will take place at the subjects' workspace, at a time negotiated with the department leadership and the individual concerned.

The discussion will take 30 minutes for each subject. The researcher will request the participants' permission to photograph the space, as the visual configuration of the 
space is a significant component of the research. Subjects will not be identified in the research.

Contact information:

Lynn Chalmers, Associate Professor, Rm 412 Architecture 2 Building

Department of Interior Design,

Faculty of Architecture,

University of Manitoba. office phone: 4746435 summer no: 7749560

PhD Advisor:

Dr. Janine Marchessault,

Professor in Media \& Culture

York and Ryerson Universities Joint Graduate Program in Communications and Culture

(416)736-2100, ext. 33485

\section{DRAFT Questionnaire:}

In what decade were you born?

Were you born in Canada?

How many years have you been employed by the company?

How long have you worked in this department?

How long have you been located at this workstation?

What do you do when you want to work on a project that requires greater

concentration?

What do you do to make your workstation more private?

Are you required to collaborate to do aspects of your work?

How and where do you do team work?

Would you describe the work you do as routine?

Are there rules about what you can display at your work station?

What sorts of personal items can you have at your desk?

Are the display of personal items important to you ? why?

Which personal items are important to you? why are they important?

Could you describe 5 items on display at your desk?

Do the items mostly celebrate work events ? or family and friends from outside work? Is the display for your benefit only, or does the display say something important about you to your co-workers?

What is your favorite place at work - why ?

If you could make change in your immediate work environment what would it be? 


\section{RYERSONUNIVERSITY}

RESEARCH ETHICS BOARD

To: Lynn Chalmers

Communications \& Culture

Re: REB 2011-231: Spaces of Everyday Work: a critical reading. The research studies the personal space of routine office workers to understand the construction of identity and meaning through the physical environment of the workplace.

Date: August 9, 2011

Dear Lynn Chalmers,

The review of your protocol REB File REB 2011-231 is now complete. The project has been approved for a one year period. Please note that before proceeding with your project, compliance with other required University approvals/certifications, institutional requirements, or governmental authorizations may be required.

This approval may be extended after one year upon request. Please be advised that if the project is not renewed, approval will expire and no more research involving humans may take place. If this is a funded project, access to research funds may also be affected.

Please note that REB approval policies require that you adhere strictly to the protocol as last reviewed by the REB and that any modifications must be approved by the Board before they can be implemented. Adverse or unexpected events must be reported to the REB as soon as possible with an indication from the Principal Investigator as to how, in the view of the Principal Investigator, these events affect the continuation of the protocol.

Finally, if research subjects are in the care of a health facility, at a school, or other institution or community organization, it is the responsibility of the Principal Investigator to ensure that the ethical guidelines and approvals of those facilities or institutions are obtained and filed with the REB prior to the initiation of any research.

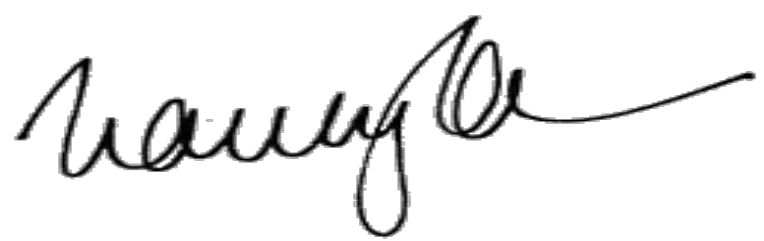

Please quote your REB file number (REB 2011-231) on 
future correspondence. Congratulations and best of luck in conducting your research.

Nancy Walton, Ph.D.

Chair, Research Ethics Board 
Appendix Two Executive Floors 


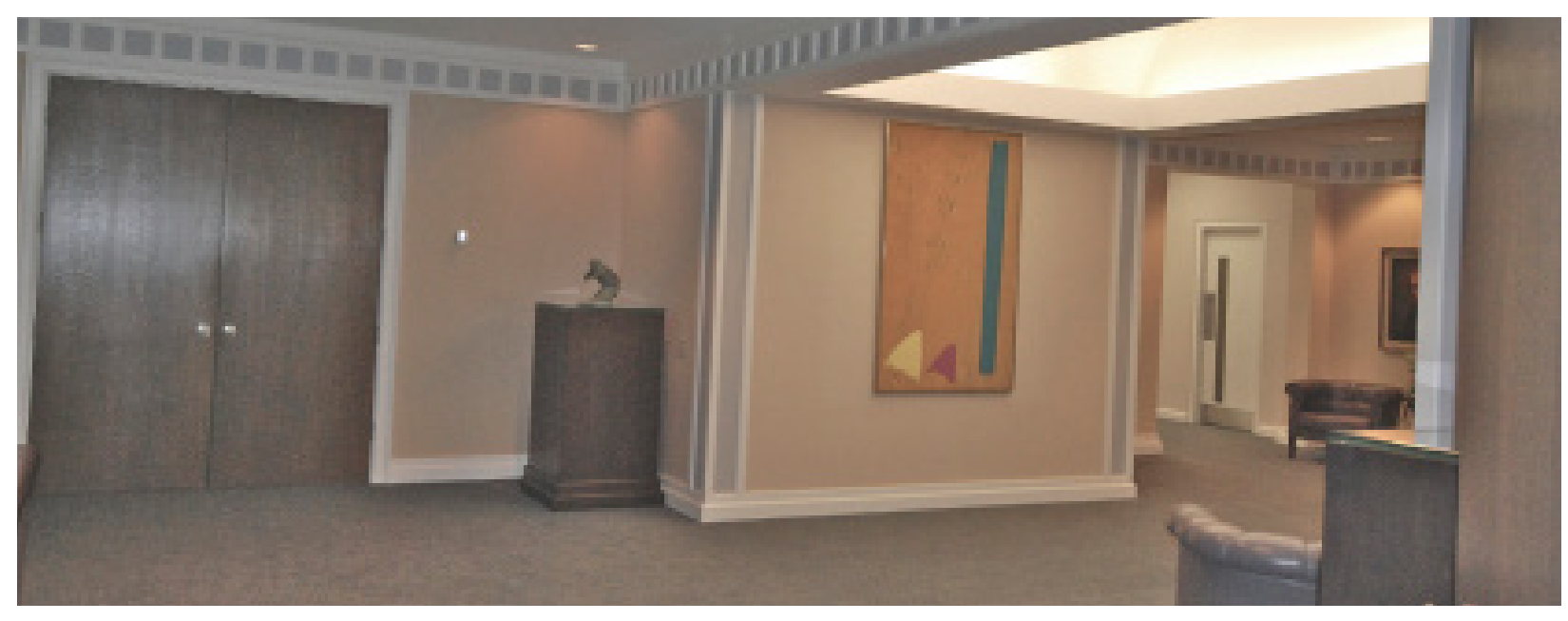

Floor 18

Boardroom Anteroom

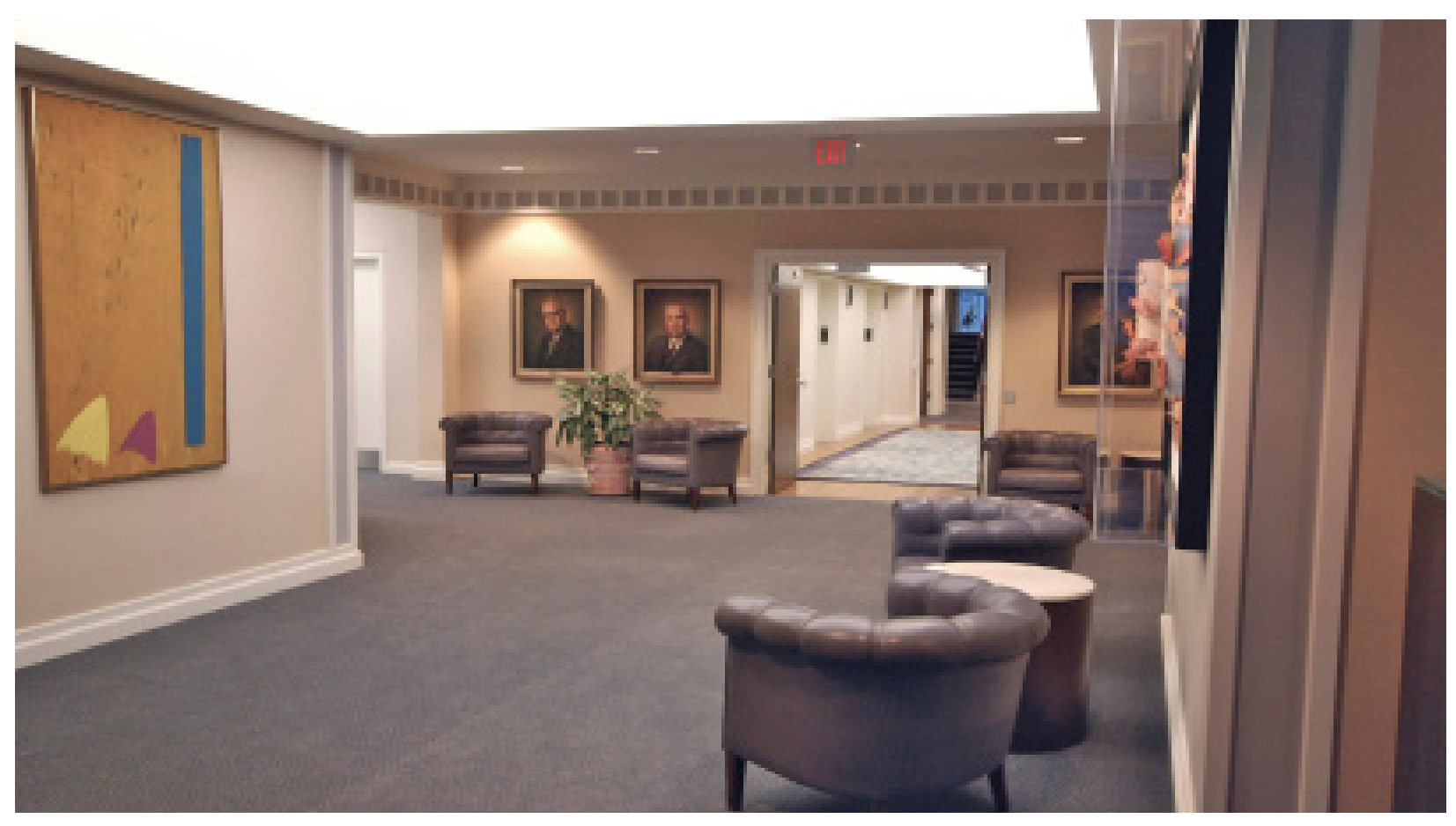



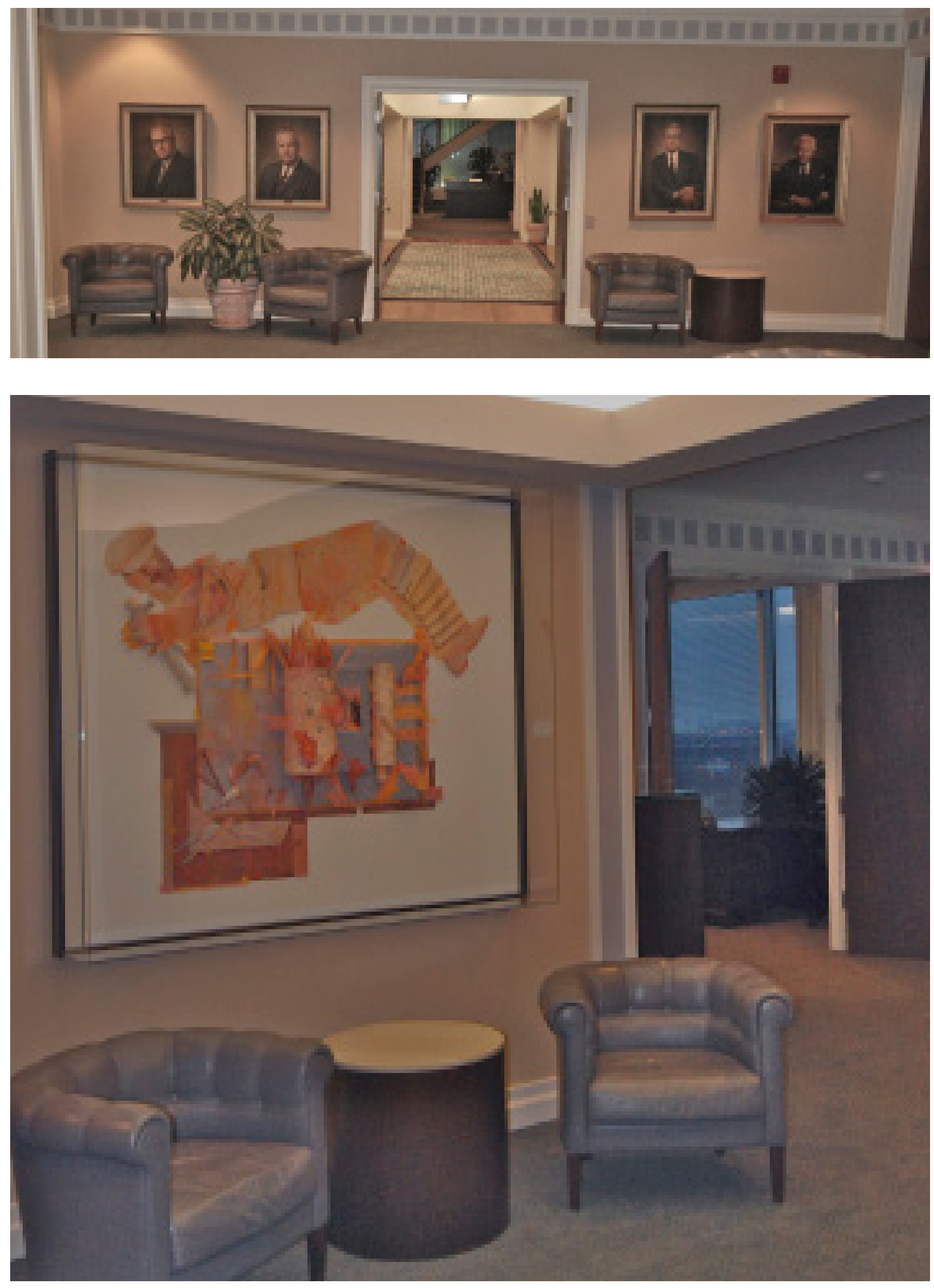


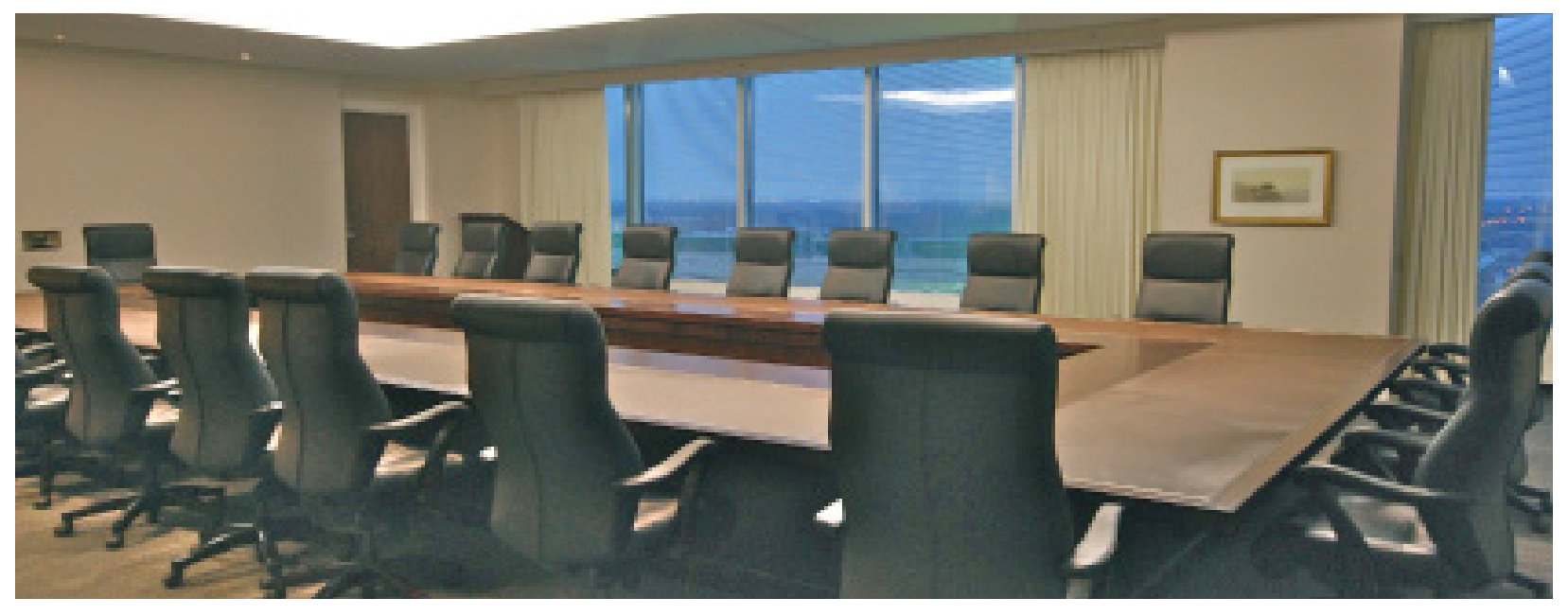

Floor 18

Boardroom

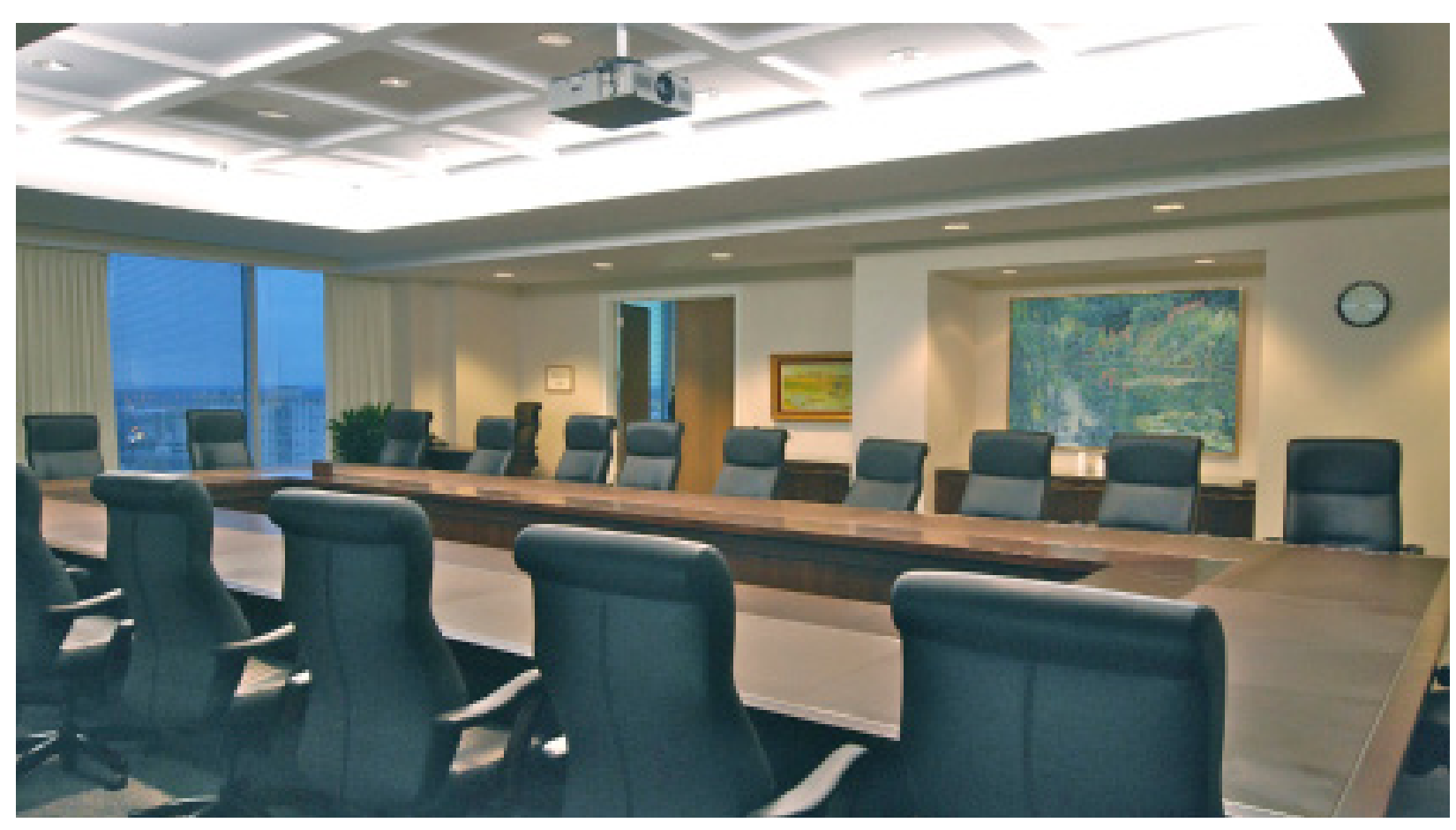




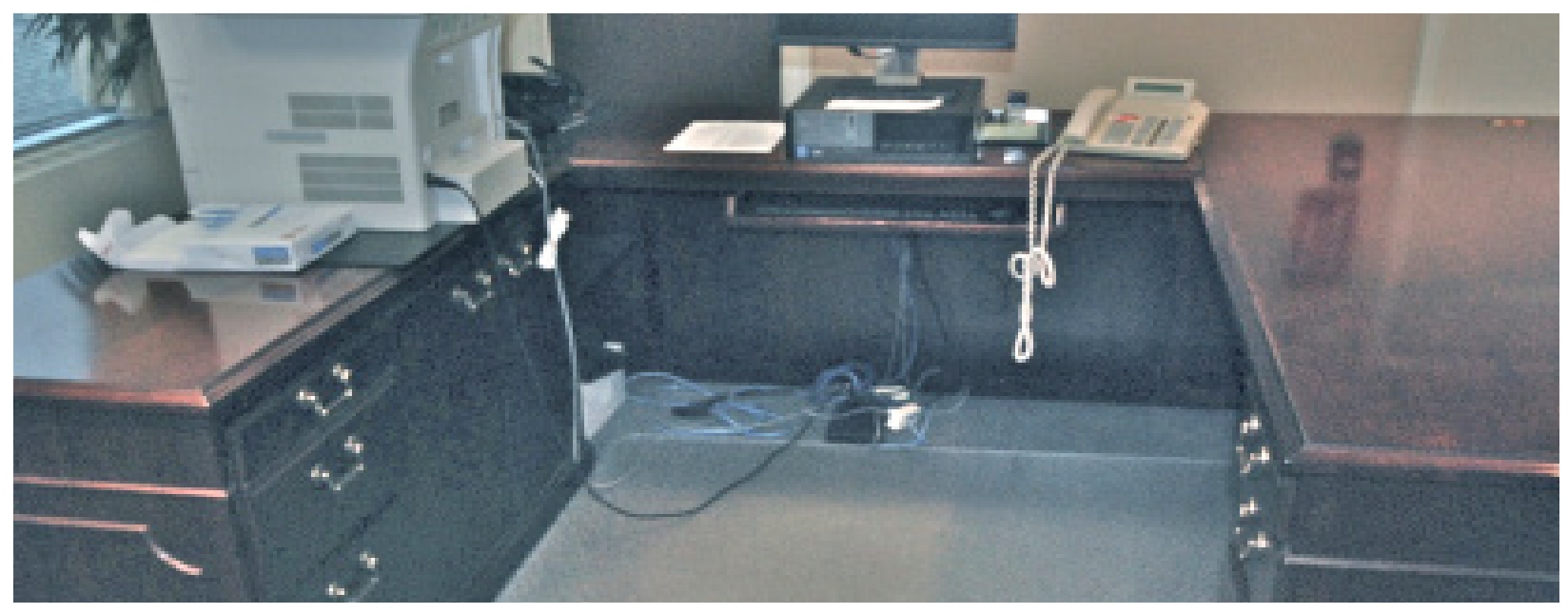

Floor 18

Chairman's Secretarial Desk
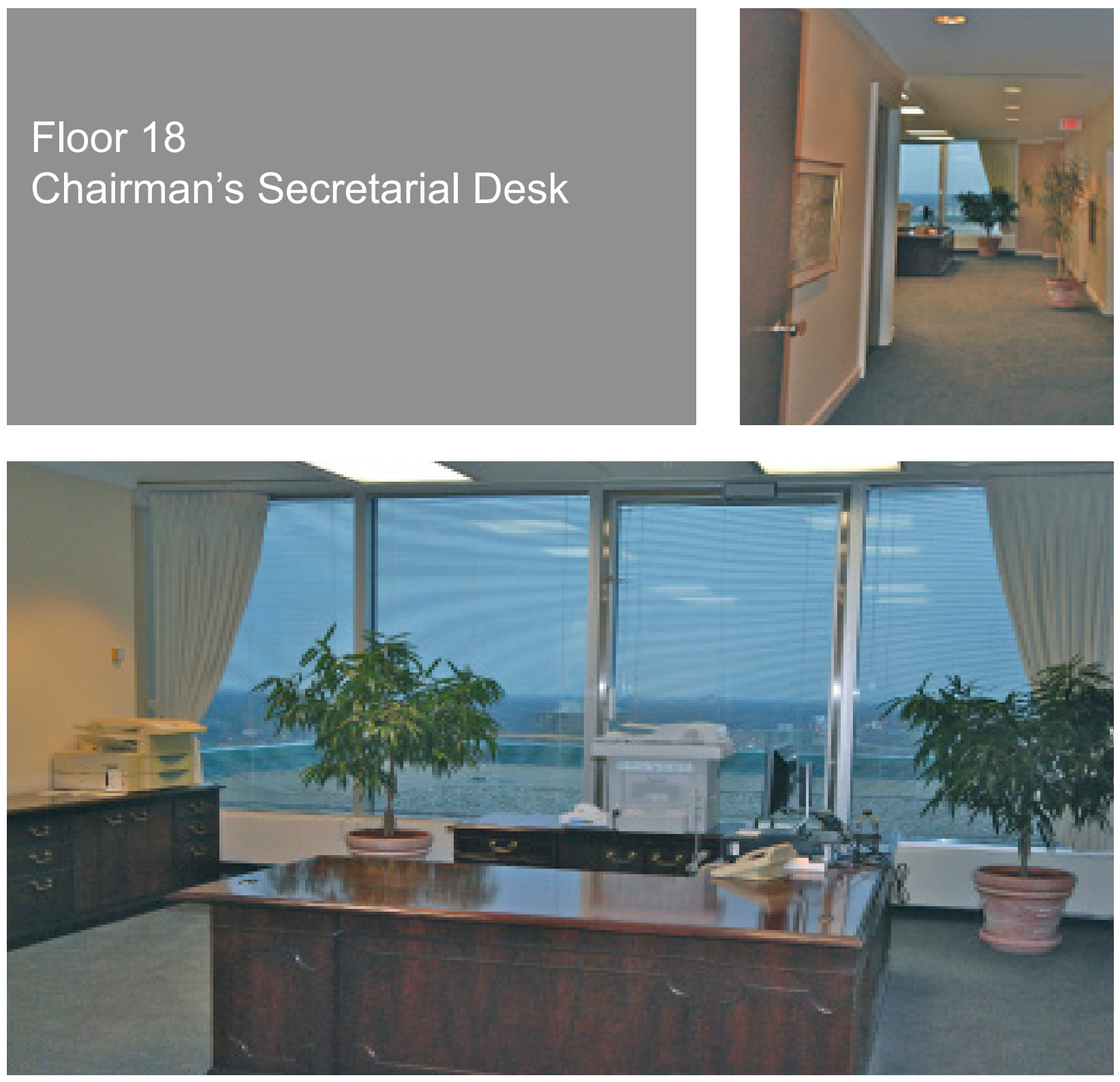


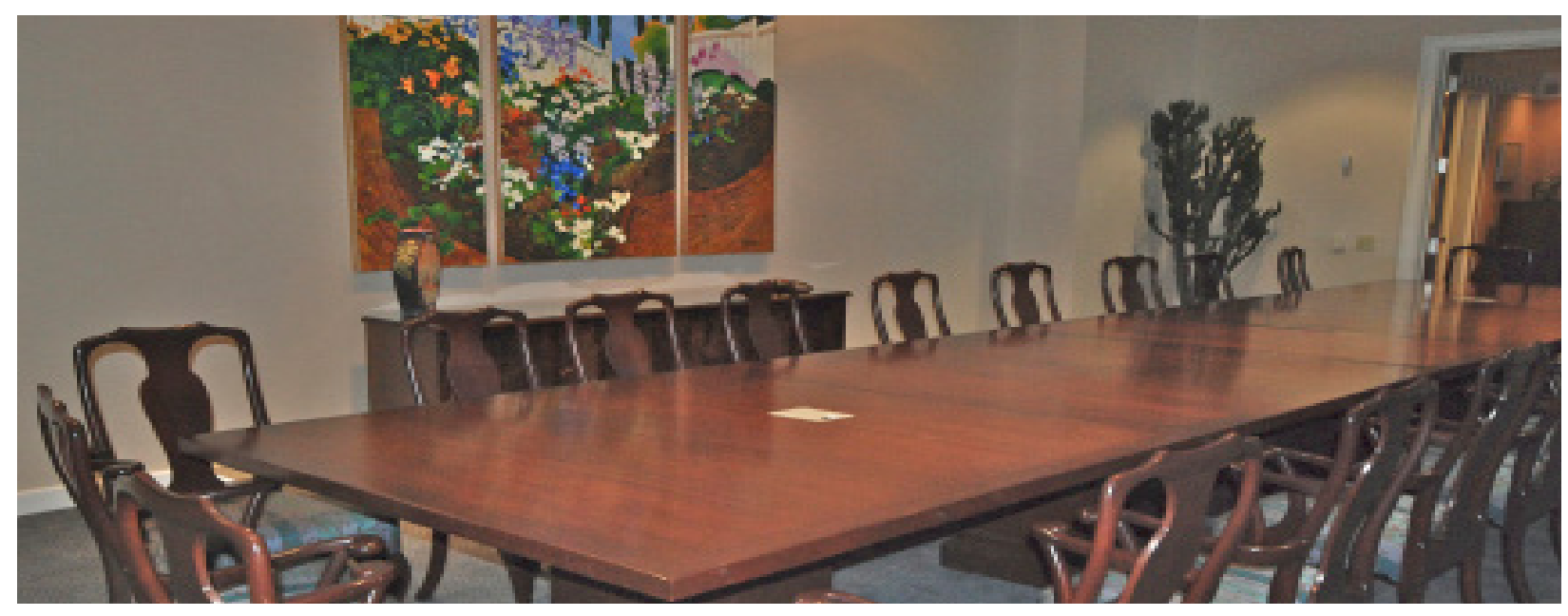

Floor 18

Dining Room

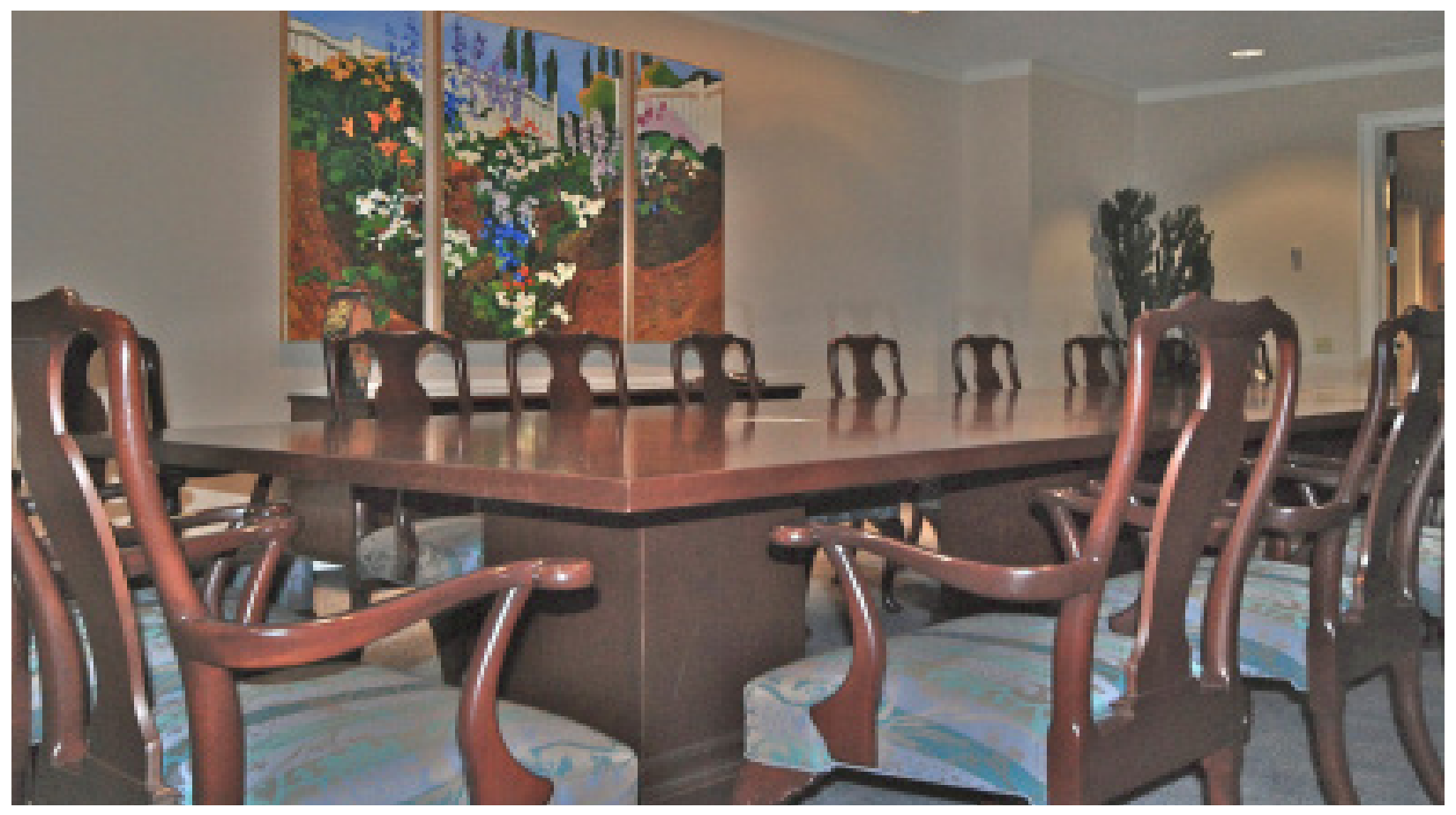




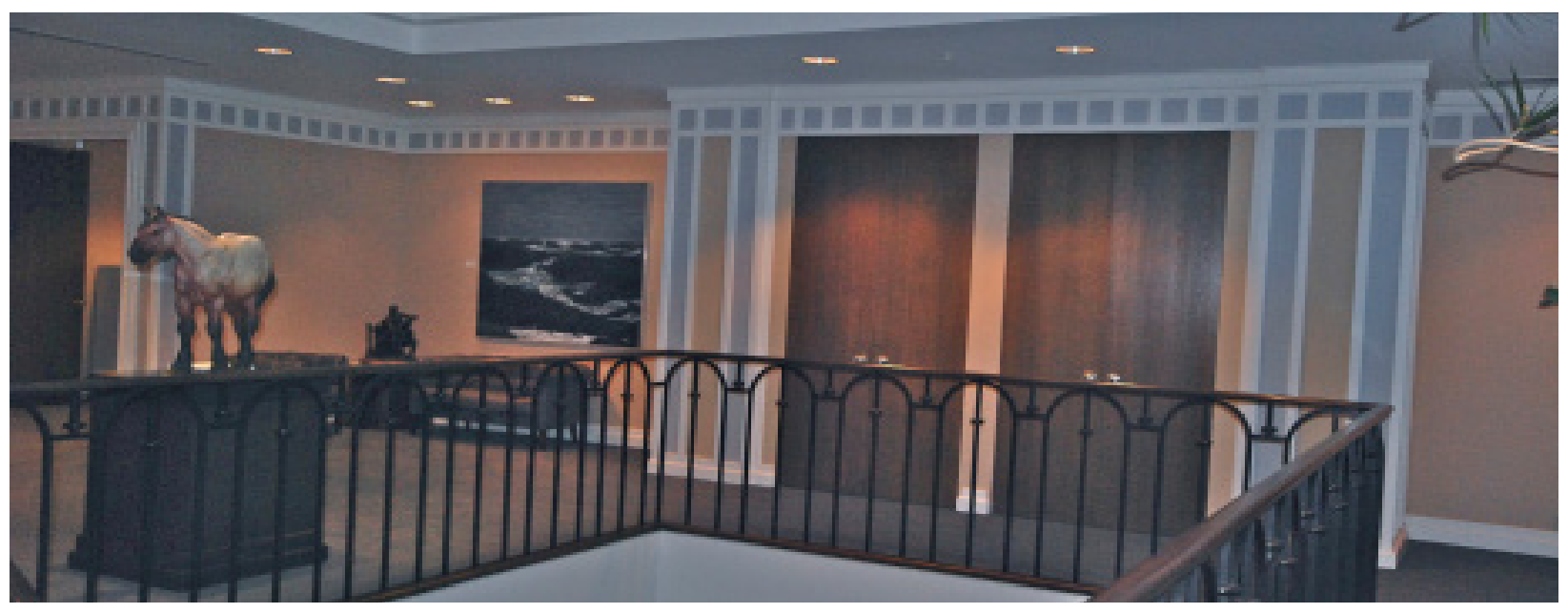

Floor 19

Reception Area
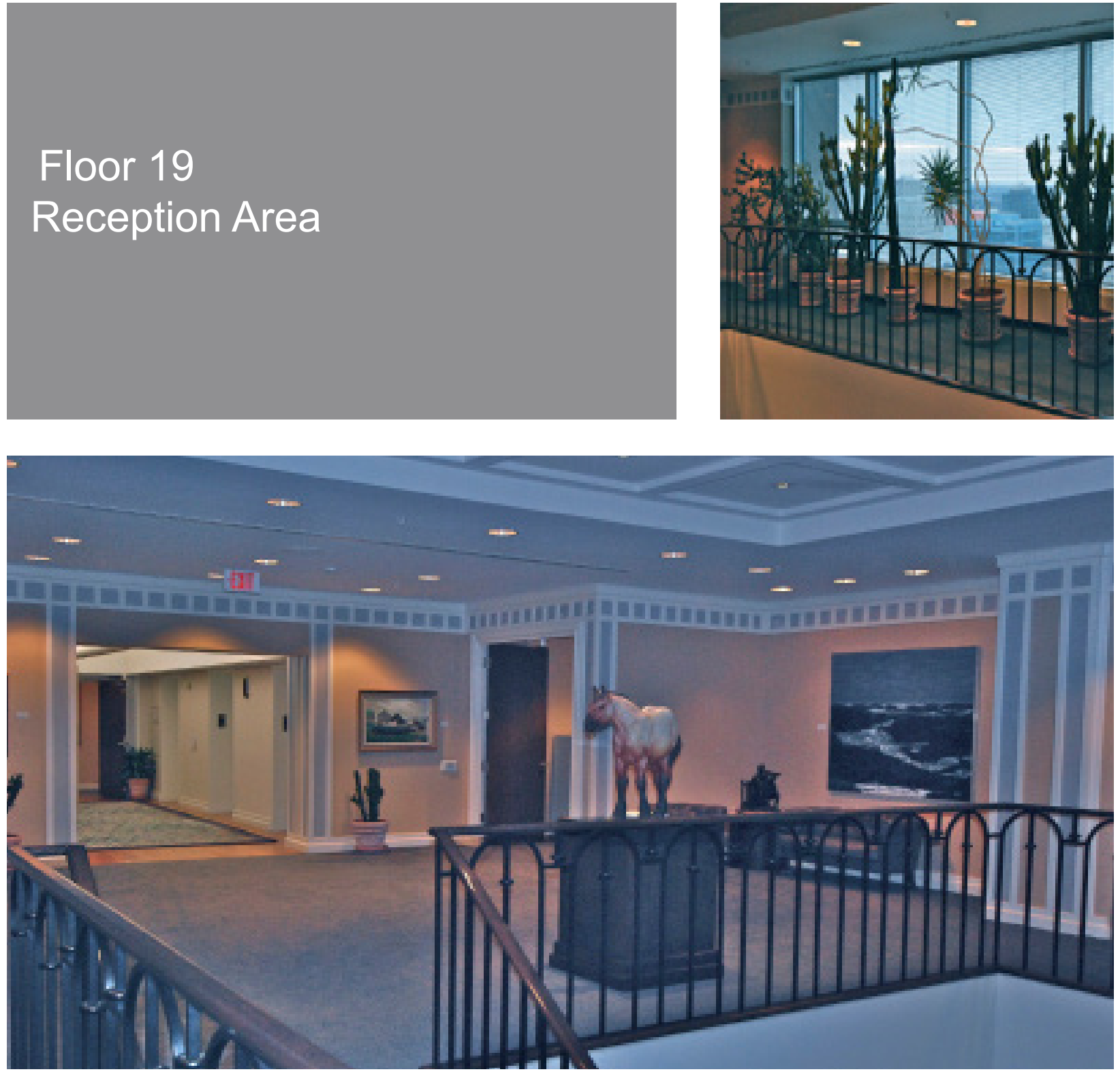


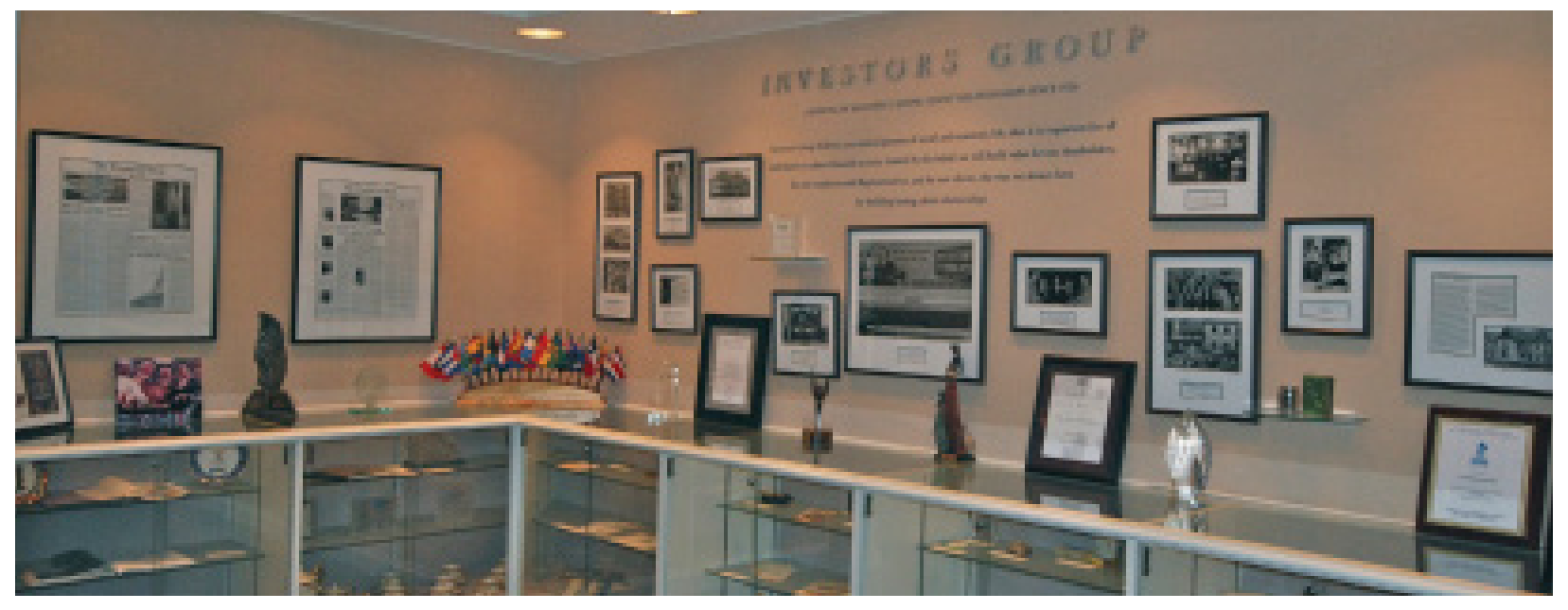

Floor 18

Historical Display \&

Director's Lounge
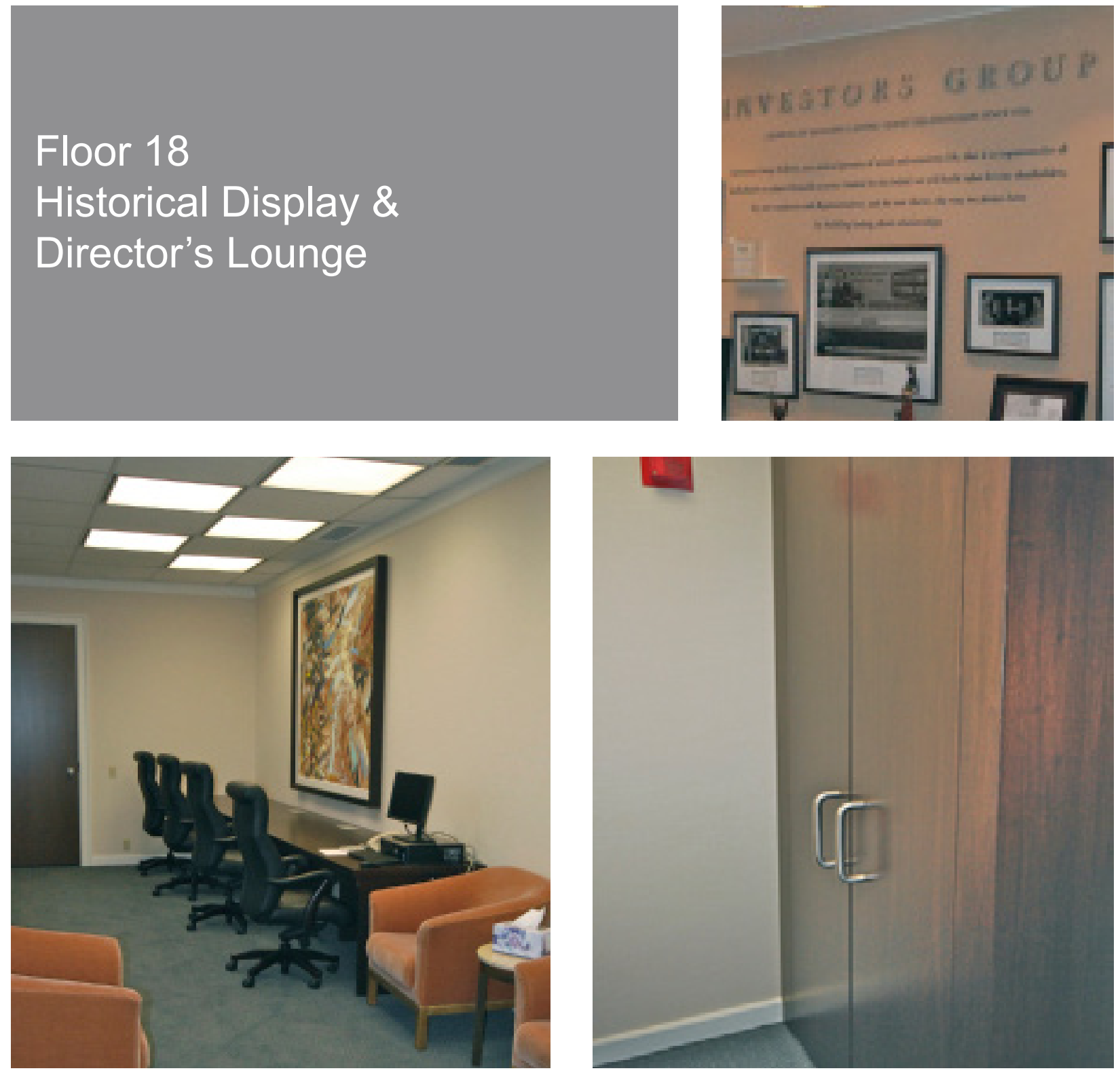


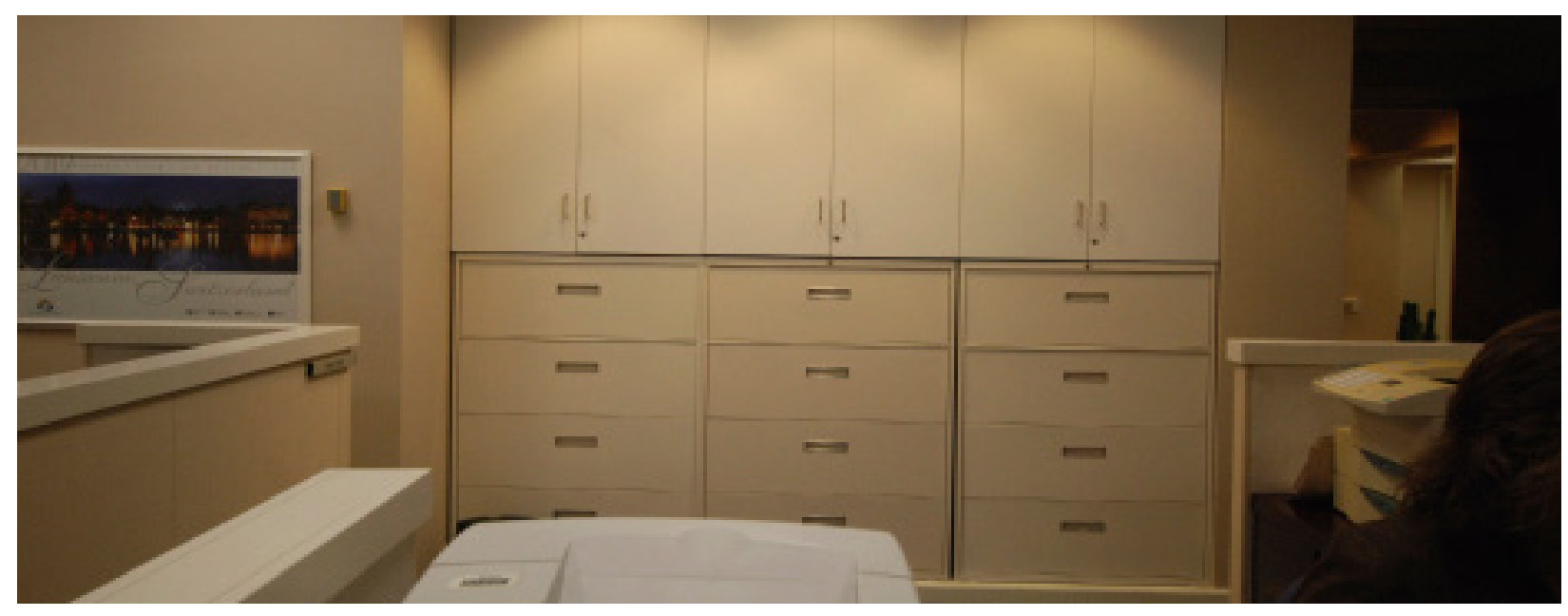

Floor 18

Executive Assistant Storage \& Desk
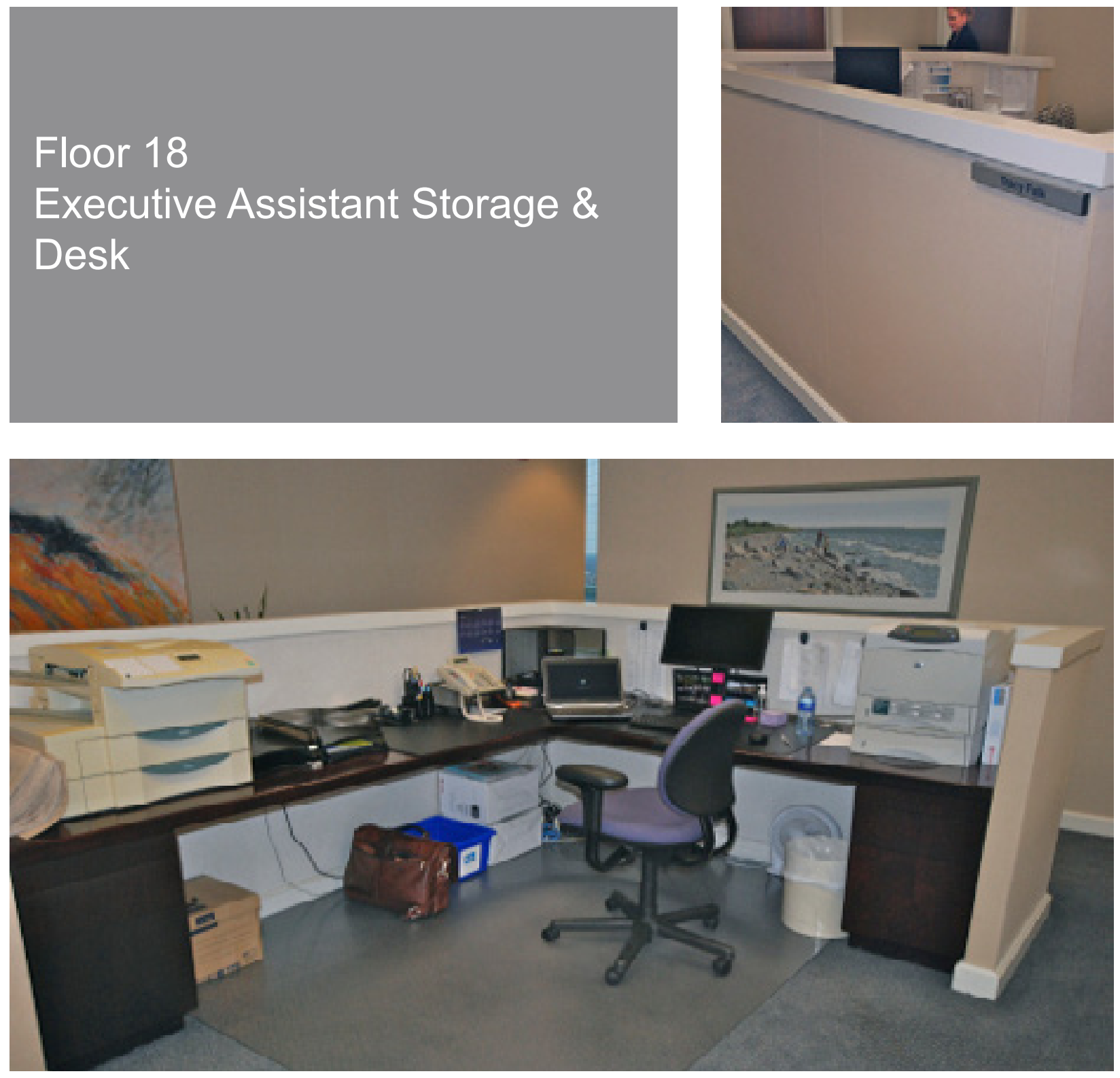

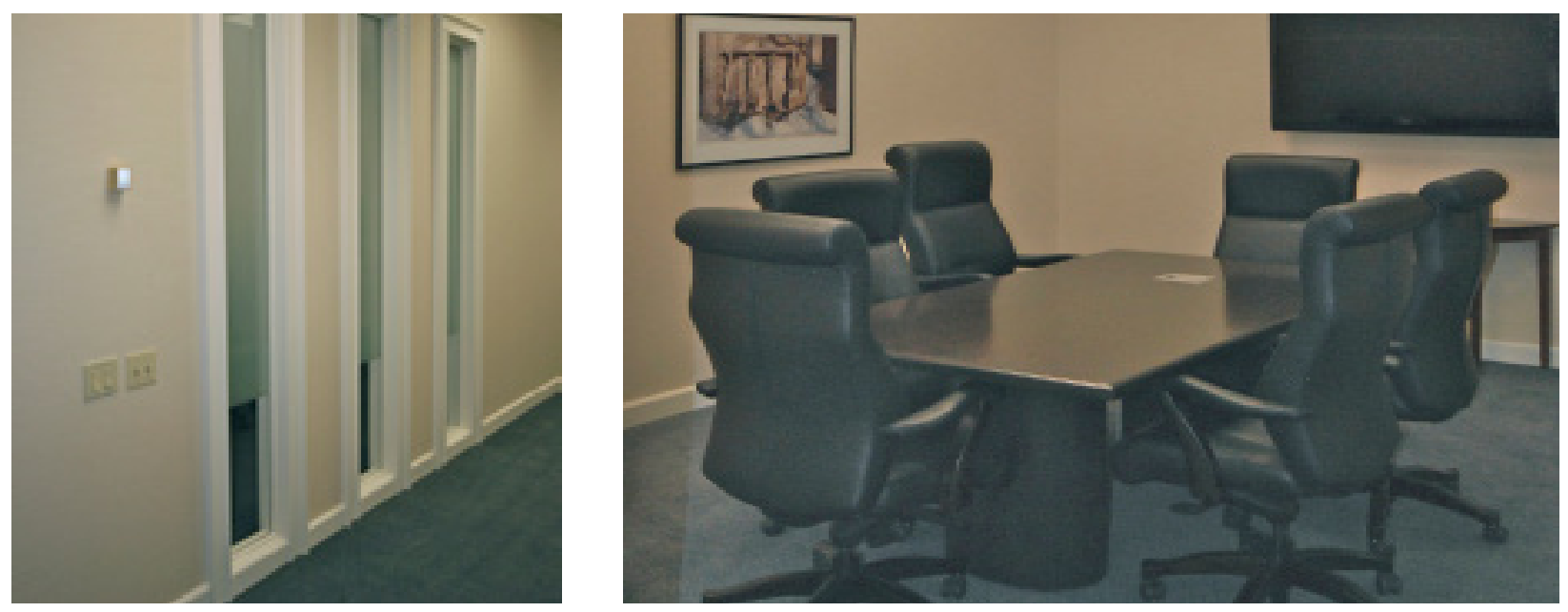

Floor 18

New Meeting Room,

Telephone Room, Lift Lobby

\& New Cloak Room
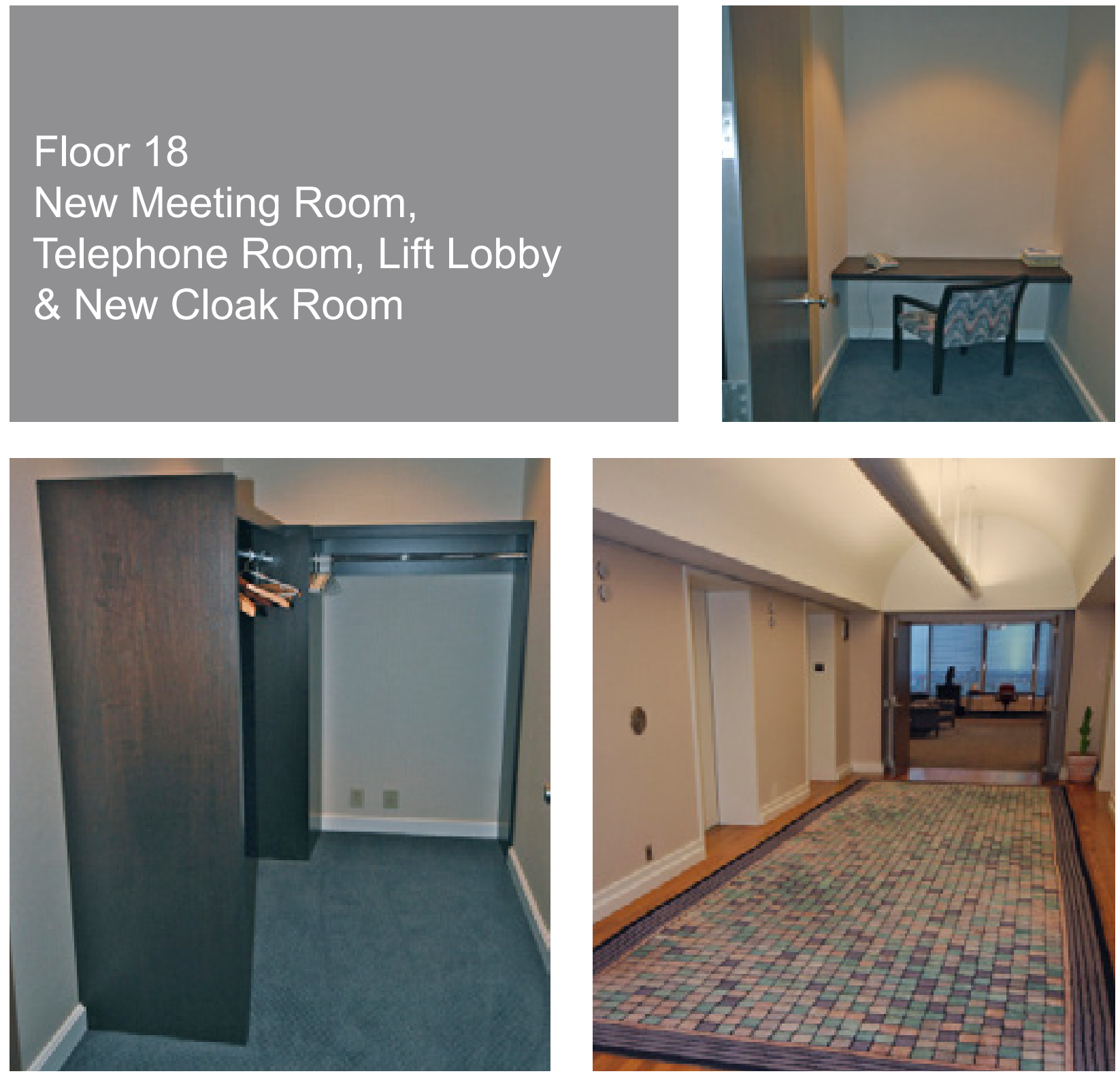

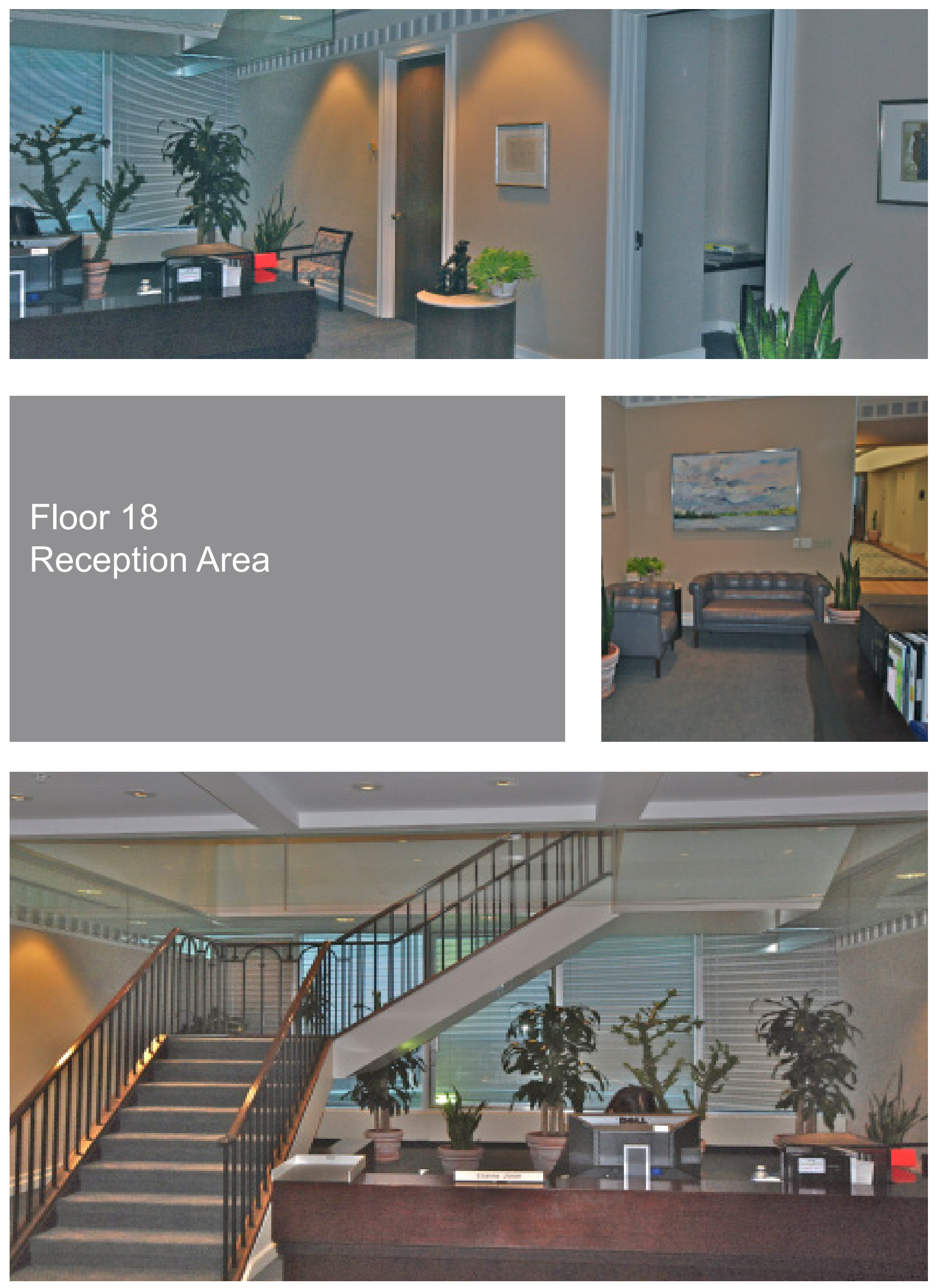


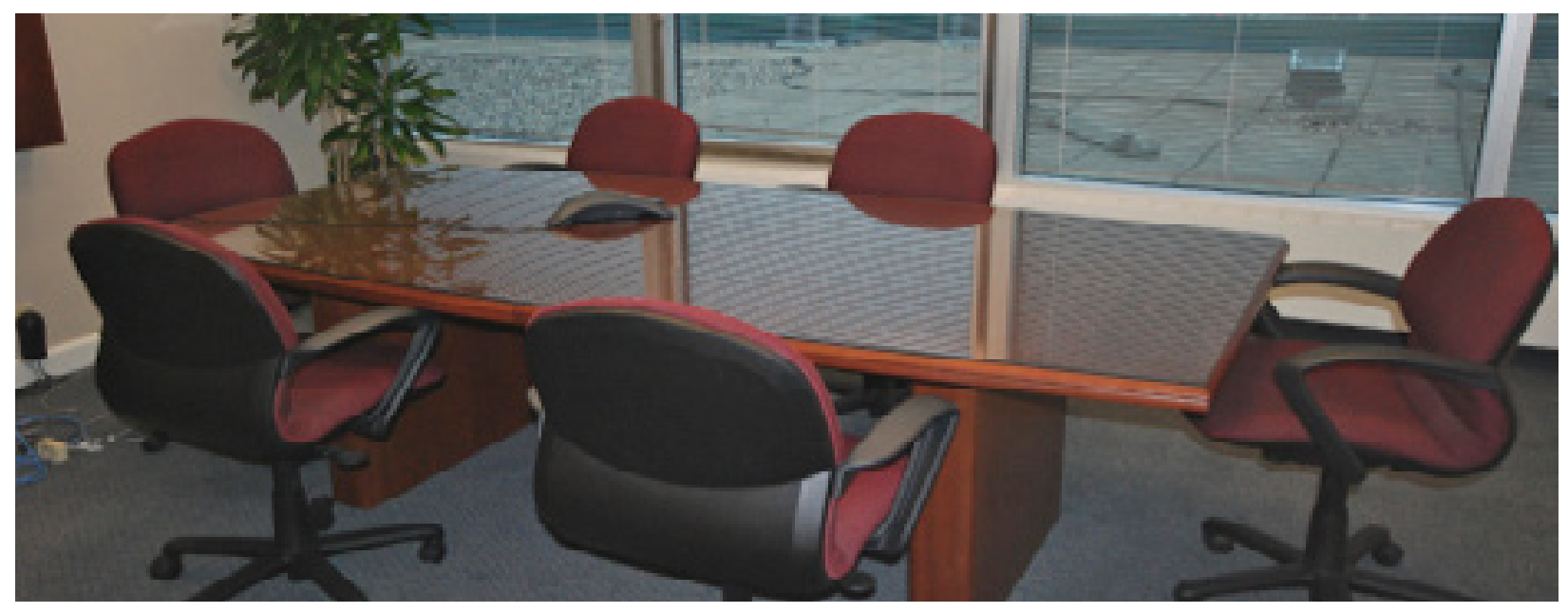

Floor 18

VP's Office \& Meeting Room
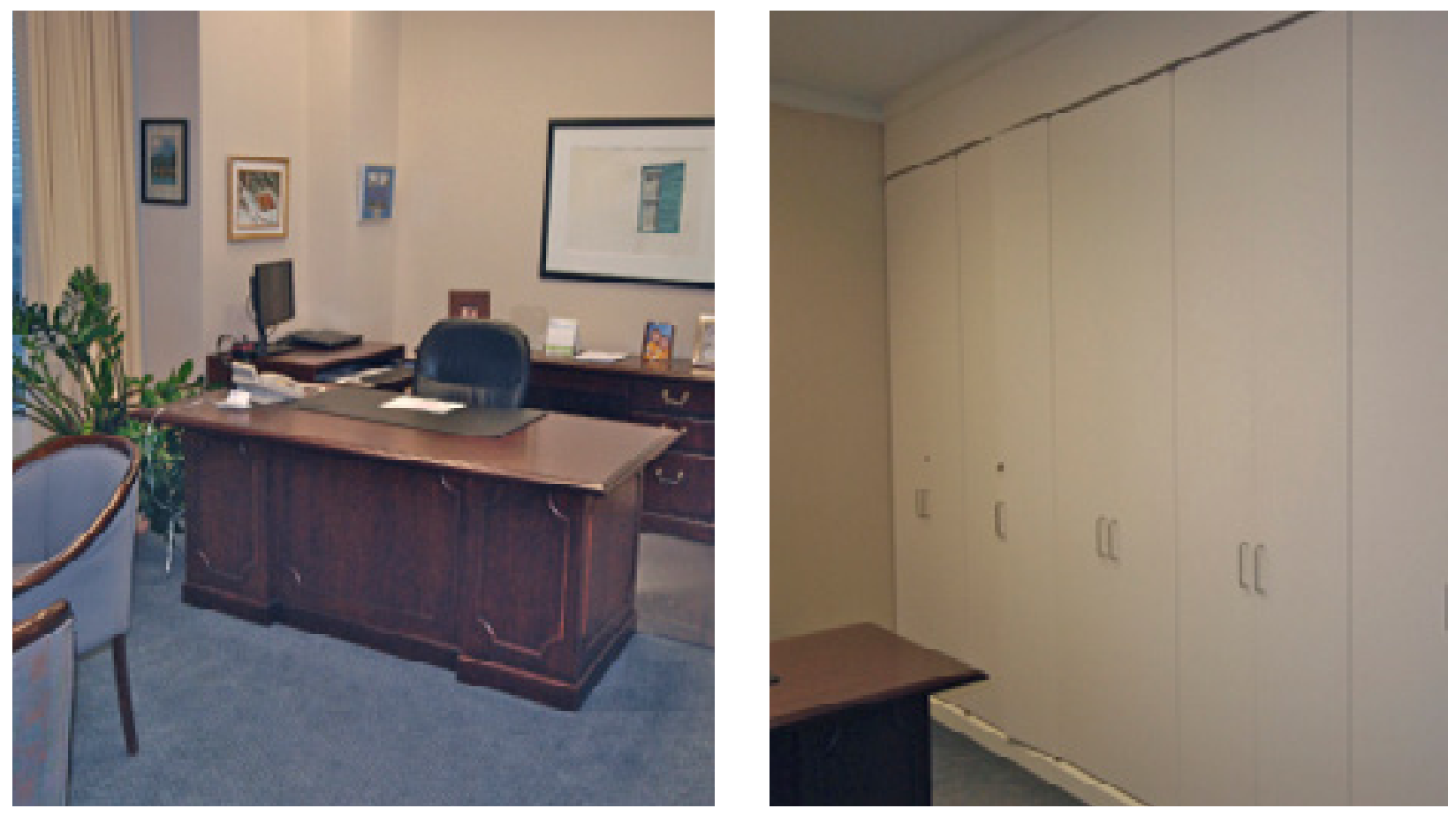